\title{
GEORg StAuth
}

\section{Islamische Kultur}

\section{und moderne Gesellschaft}

Gesammelte Aufsätze

zur Soziologie des Islams 
Georg Stauth

Islamische Kultur und moderne Gesellschaft

Gesammelte Aufsätze zur Soziologie des Islams 
Meiner lieben Mutter

Margarete Fornoff, verbeiratete Stauth, zum Neunzigsten 


\section{Georg Stauth \\ ISLAMISCHE KULTUR \\ UND MODERNE GESELLSCHAFT \\ Gesammelte Aufsätze zur Soziologie des Islams}

$$
\text { [transcript }]
$$


(c) $(1) \bigcirc$ This work is licensed under a Creative Commons
Attribution-NonCommercial-NoDerivatives 3.0 License.

Die Deutsche Bibliothek - CIP-Einheitsaufnahme Stauth, Georg

Islamische Kultur und moderne Gesellschaft :

gesammelte Aufsätze zur Soziologie des Islams /

Georg Stauth. - Bielefeld : transcript, 2000

(Globaler, lokaler Islam)

ISBN 3-933127-47-5

(C) 2000 transcript Verlag, Bielefeld

Satz: digitron $\mathrm{GmbH}$, Bielefeld

Druck: Digital Print, Witten

ISBN 3-933127-47-5 


\section{Inhalt}

\section{Einführung}

Konfigurationen von Ideen und Kulturtechniken

\section{Teil I: Der Islam und die »fundamentals« der Moderne}

Moderne Essentialisierungen des Islams

Kultur und Lebenswelt. Der kulturelle Konflikt in

peripheren Gesellschaften

Foucaults Abenteuer im Iran

\section{Teil II: Modernität, Globalisierung, Islam}

Globalisierung, Modernität, nicht-westliche Zivilisation

Islam als Selbstbegriff nicht-westlicher Modernität

Religiöser Fundamentalismus zwischen Orient und Okzident: Religiöse Identitätspolitik und ihr Verhältnis zur Demokratie

\section{Teil III: Islamisierung und materielle Kultur}

Materielle Not, kulturelle Globalisierung und sozialer Konflikt. Reflexionen zur Hermeneutik symbolischer Idealisierung 
Stadt und Land in Ägypten:

Folgen der Modernisierung

Arbeitsmigration und Restrukturierung ländlicher

Gesellschaften: Fallbeispiel Ägypten

\section{Teil IV: Islam und Soziologie}

Frühe Ansätze zu einer Soziologie des Islams:

Ignaz Goldziher und Max Weber

Anmerkungen zur Soziologie des Islams

Der »entgrenzte « Islam als soziologischer

Forschungsgegenstand

\section{Literatur}

Gesamtliteratur

Zitierte und nicht zitierte Arbeiten Georg Stauths

im breiten thematischen Bezug

Quellenverzeichnis 


\section{Einführung}

\section{Konfigurationen von Ideen und Kulturtechniken}

Noch vor wenigen Jahren wäre mir der Gedanke, manche meiner auf Deutsch verfaßten und an den unterschiedlichsten Orten erschienenen Arbeiten einmal zu einem Buch zusammenzufassen, absurd erschienen. Es überwog der Glaube an den organischen Zusammenhang von Text und Öffentlichkeit und an die latente Wirkungskraft von Texten auch aus dem relativ Verborgenen heraus. Diesen Glauben habe ich nicht ganz aufgegeben. Als nun aber kürzlich anläßlich der Eröffnung einer islamsoziologischen Reihe von Roswitha Gost, Sigrid Nökel und Karin Werner, die die Reihe beim transcript-Verlag betreuen, gerade dieser Vorschlag gemacht wurde, habe ich kaum gezögert, ihn aufzugreifen. Neben der Idee, meine verstreuten Aufsätze zu einem Buch zusammenzufügen, reizte mich die gestellte Aufgabe: Über die biographische und chronologische Abfolge der Arbeitsphasen hinweg sollte der Schwerpunkt auf meine Arbeiten zur Soziologie des Islams gelegt werden. Die Grundlagen für diese thematische Stoßrichtung selbst hatte ich im Wintersemester 1980/81 in einem Seminar in Bielefeld gelegt, mehr als fünf Jahre nach meiner ersten sozialanthropologischen Feldarbeit bei den »Fellachen « im Nil-Delta und viele Jahre, bevor die damaligen Teilnehmerinnen mich jetzt zu diesem Buch anregten.

Ein biographisches Verfahren, nämlich das Wichtigste, was ich in einzelnen Lebensphasen geschrieben habe, in der Reihe des Erscheinungsdatums zu ordnen und hier zu versammeln, hätte aus mehreren Gründen scheitern müssen. Zunächst ist festzuhalten, daß die thematische Kontinuität meiner Arbeiten mit der zeitlichen nicht in Übereinstimmung zu bringen ist. Zwar beschäftigten mich unzweifelhaft schon bei meiner von Fuad Sezgin (Frankfurt) angeregten und von Ewald Wagner (Gießen) betreuten Dissertation von 1969 soziologische Fragen. Eine große Anziehungskraft übte das der Goldziherschen Islamwissenschaft zugrunde liegende »Ideenwerk « auf mich aus. Aber es fehlte die Kenntnis seiner frühen Arbeiten und seiner Biographie. So blieb mir damals der »Modernist« und »Wissenschaftsprophet«, in einem Wort, der »Soziologe« Goldziher noch verschlossen. Und erst mit der Entdeckung dieses Goldzihers (der den »Mythos bei den Hebräern« schrieb, der klandestine al-Azhar-Gelehrte seiner frühen Zeit 
in Kairo, der Entdecker des Wissenschafts-Islams) wurde mir bewußt, welche kulturproduktive Sprengkraft auch ein streng philologisch gesetzter Arbeitsrahmen haben kann. Zum Zeitpunkt dieser Entdeckung war der Zug zum rein philologischen Arbeiten abgefahren. Unzweifelhaft aber waren es die aus der arabischen Philologie unbewußt, gewissermaßen politisch weitersprießenden Fragen, die mich später auch in »reine« Theoriebereiche führten: Kulturkritik, Wissenschaftskritik, Theoriekritik. Ich muß darauf hinweisen, daß sich mein späteres Interesse an den "politischen Philologen « erst aus der allmählichen Reflexion des Ideenerbes der Islamwissenschaft und Orientalistik erschloß: Kein anderer als Goldziher stand so sehr wie Friedrich Nietzsche im Bann des abendländischen Wissenschaftspropheten Ernest Renan. Goldziher folgte Renan in der Bestimmung der Wissenschaft als modernem Emanzipationsinstrument der Religion, Nietzsche sah in dieser Verbindung nur die Fortführung des christlichen Nihilismus und wollte insgesamt eine andere Wissenschaft. Man erlaube mir den Hinwies, daß die Gegensätze und Drehungen, die das Spannungsfeld zwischen Religion und Wissenschaft seit der Aufklärung kennzeichnen, fast alles betreffen, was die »Idee" des modernen Islams hervorgebracht hat. Die vorliegenden Aufsätze können hierfür nur den Blick zu öffnen versuchen.

Mit der Stoßrichtung auf die soziologische Bedeutung des modernen Islams und der Islamwissenschaft zugleich waren die TheorieAufsätze, die sich thematisch nicht auf den Islam beziehen, von vornherein auszuschließen. Eine Ausnahme stellt der in Kapitel I enthaltene Aufsatz zu »Kultur und Lebenswelt« dar, den ich zusammen mit Hans-Günther Semsek verfaßt habe. In Anlehnung an systemtheoretische Denkfiguren und im Versuch einer Kritik wurde hier skizziert, wie man die (etwa zwischen Marxismus und Islam) ideologisch überfrachteten »small territories « lokaler Gruppen in Dörfern und Stadtvierteln zu untersuchen hätte. Die konflikttheoretische Brisanz dieses Themas hat sich in den späten 1990er Jahren durch den lokalistischen Terror solcher Gruppen überall auf der Welt, besonders aber auch in muslimischen Ländern, aktualisiert. Das Kapitel zum »entgrenzten Islam « am Ende des Bandes markiert eine entsprechende Weiterentwicklung der Forschungsperspektive.

Mehr als ein Jahrzehnt lang wurde das meiste, was ich geschrieben habe, in englischer Sprache verfaßt. Einige der Aufsätze dieser Zeit 
waren schon ins Deutsche übersetzt oder auf Deutsch publiziert. Soweit sie sich thematisch einfügten, wurden sie hier aufgenommen. Da notwendigerweise Bücher und Forschungsberichte ebenso auszuschließen waren wie die kleineren Schriften, Buchbesprechungen und Vorträge, blieb die thematische Beschränkung auf die Soziologie des Islams eine wichtige Limitierung. Andererseits entspricht es der Anregung des Verlags, hier empirische Skizzen zur materiellen Kultur lokaler Gemeinschaften in Ägypten aufzunehmen, auch wenn sie die soziale Wirkungsweise der Idee des Islams nicht in besonderer Weise reflektieren.

Sämtliche der in diesen Band versammelten Arbeiten wurden weitestgehend so übernommen, wie sie erstmals veröffentlicht waren. Dies hat zur Folge, daß Überschneidungen und Wiederholungen nicht auszuschließen sind. Es liegt in der Natur der hier verhandelten Sache, daß Ideen und Begriffe, ja auch Sachbeschreibungen, eine generalisierende Bedeutung gerade erst in unterschiedlichen Umfeldern, Lagerungen und differenten Konnotationen erfahren. Eine in dieser Hinsicht durchaus überpointierte Wiederholung der Beschreibung des Dorfstrukturwandels von Abu Girg (Provinz Minya) schien mir durchaus vertretbar: In der Studie über »Materielle Not, kulturelle Globalisierung und sozialer Konflikt. Reflexionen zur Hermeneutik symbolischer Idealisierung " (Seite 155ff.) steht Abu Girg im Kontext des Zusammenspiels von Ideen und Strukturen, in der folgenden Arbeit über »Arbeitsmigration und Restrukturierung ländlicher Gesellschaften: Fallbeispiel Ägypten« (Seite 197ff.) wird das Beispiel Abu Girg in den Zusammenhang von Strukturwandel und Migration gestellt.

Eine Ausnahme hinsichtlich der Vorveröffentlichung bildet der Text über »Foucaults Abenteuer im Iran«, dessen deutsche, leicht verkürzte und veränderte Fassung - ich nehme dazu noch weiter unten Stellung - hier zum ersten Mal veröffentlicht wird. Die Texte müssen für sich selbst sprechen und es wurde aus diesem Grunde auch keine »tour de force« der themenbezogenen Überarbeitung unternommen. Vom Verlag wurde freundlicherweise eine einheitliche Zitierweise und Form der textlichen Gestaltung durchgesetzt. In der unter manchen Orientalisten gewissermaßen zum professionellen Ethos verkommenen Frage der Transliteration konnte ich mich den Forderungen des Verlags nicht immer fügen. Das ist einmal darauf zurückzuführen, daß 
in den einzelnen Aufsätzen ursprünglich eine Strategie verfolgt wurde, Umschriftformen zu wählen, die die Eigenart und den Kontext der einzelnen Wörter reflektieren. Aus dieser Wahl der Dinge gibt es hier drei Sprachebenen des Arabischen und dementsprechend auch drei Umschriftformen: das Nieder-Ägyptische, das Hocharabische und das längst Eingedeutschte. Auf diakritische Zeichen wurde grundsätzlich verzichtet.

Einige biographische Hinweise auf die Lebens- und Arbeitsphasen, auf die sich diese Texte beziehen, scheinen mir wichtig. Nicht zu vergessen ist, daß ich in Reaktion auf ein Unbehagen an der mir lebensund sprachpraktisch in vielfältiger Weise sinnlos erscheinenden Akribie der orientalischen Philologie, dem »Text « als Forschungsgegenstand schon früh den Rücken zugekehrt habe. Das Erlebnis Alexandria und der Umgang mit den Menschen während meiner Zeit als DAAD-Lektor dort (1969-1971) hat mein weiteres Forschungsinteresse bestimmt. Ich habe mich danach ganz dem Projekt gewidmet, die ägyptische Volkskultur, vor allem aber die Wirtschafts- und Handlungsmuster der Fellachen im Nil-Delta und dort, wo Fellachen zu "Städtern« geworden waren, in Kairo, zu untersuchen. Über mehr als zehn Jahre hinweg schlug ich mich in den Dörfern des Nil-Tals und in den Volksvierteln von Kairo herum, immer dem Rätsel auf der Spur, warum solche, ganz den natürlichen Überlebensbedingungen anheimgegebenen Verhältnisse nicht oder nur für so wenige zu überwinden waren. Es ist nicht zu leugnen, daß die Anregungen, aber auch die Zwänge, zu einer streng empirischen Bemessung dieses Rätsels von den Kollegen der Bielefelder Entwicklungssoziologie inspiriert, man könnte fast sagen, beherrscht waren. Die hier im Teil III präsentierten Endprodukte dieser Phase nehmen bereits die Islam-Frage auf.

Anfang der 1980er Jahre begann ich nach intensiven Nietzsche-Studien, die parallel zur islam- und entwicklungssoziologischen Forschung und Lehre liefen, mich mit kulturtheoretischen Fragen zu beschäftigen. Entscheidend waren dabei Erkenntnisse über die Wirkungen von Nietzsches Kulturkritik: Manches was bei Nietzsche noch als kritische Idee herrschte und das »Sinnganze« des Abendlandes wie ein Blitz treffen sollte, tauchte bei modernen Soziologen wie Max Weber oder Theodor W. Adorno und Max Horkheimer wieder als ein affirmativ gewendetes Prinzip der Analyse des modernen Selbstverständnisses auf. Ein ähnlich spannungsgeladenes Verhältnis von Kritik und 
Affirmation schien mir der islamische Diskurs mit dem Westen aufzuweisen. Unter anderen Bedingungen und durch den Kulturkontakt in unterschiedliche Lagerungen hineinverschoben ist hier in den Wechselwirkungen von Islam und Moderne eine ähnliche Mischung von Kritik und Affirmation wirksam. Von dieser Einsicht getragen nahm ich Arbeiten in Angriff, die darauf zielen sollten, die Vereinfachungen - wie mir schien - der Thesen des Amerikaners Edward Said vom europäischen »Sinnganzen", das mit dem »Orientalismus « nur sich selber gemeint habe, zu überwinden. Zusammengefaßt sind diese Arbeiten in meiner 1987 in Bielefeld eingereichten und mit Veränderungen 1993 als »Islam und westlicher Rationalismus « erschienenen Habilitationsschrift enthalten. Mit diesem Unterfangen wollte ich den immer als zu früh und zu abrupt empfundenen Bruch mit der konventionellen Islamwissenschaft mit den Mitteln soziologischer Reflexion lösen. Durchaus im Sinne Saids und der lange vor ihm wirkenden Phalanx der »Orientalismus «-Kritiker war die Frage nach dem abendländischen Sinnganzen »kritisch « und das heißt aus der Sicht des Orients, des Islams, zu stellen. Dies schien unter dem Gesichtspunkt des damals langsam wiederaufkommenden Verständnisses für die Gleichzeitigkeit und Einheit der menschlichen Interaktionen im Weltganzen wichtig. Es mußte also auch die Suche nach einem »orientalischen «, einem islamischen Sinnganzen unterstellt werden. Zunächst galten hier über die Orientalismus-Kritik hinaus Max Webers Fragen nach der vergleichenden Bedeutung und ordnenden Gewichtung unterschiedlicher Rationalisierungen des Weltbildes als orientierungsweisend. Doch in der Frage nach den »letzten Dingen « mußte sich schließlich zeigen, daß Weber bereits die Nietzsche-Fragen nach der möglichen interaktiven Auflösung solcher Rationalisierungen aufgenommen und modernistisch affirmativ gewendet hatte. In vielen Verästelungen spitzen die in den Teilen I und II zusammengebrachten Aufsätze solche Fragen der »inneren « Modernität auf Fragen der gegenseitigen Beziehung von »Modernisierung des Orients « und »Islamisierung der Moderne« zu. Ohne Zweifel war es Bryan Turner, der mir schon früh den Blickwinkel dafür geöffnet hatte, Orient und Islam als eine Art abwesendes Zentrum der modernen Gesellschaftstheorie zu betrachten. Es folgten die Jahre am St. Antony's College in Oxford (1988-1990), in Singapur (1990-1992) und in Australien (1994/95), die den Abstand brachten, den Reflexion und Theorie-Arbeit braucht. Aus unterschiedlichen 
Gründen mußten Theorieprojekte immer wieder zugunsten empirischer Feldarbeit, zuletzt in Malaysia und Indonesien, aufgegeben werden.

Das Problem, dem sich dieser Band widmet, ist die moderne Präsenz des Islams. Die hier angesprochenen Wissenschaften, die Islamwissenschaft, die Sozialanthropologie, die Soziologie, haben kaum erst begonnen, sich den Herausforderungen dieses Problems zu stellen. Allmählich beginnt man zu erkennen, daß wie kaum ein anderes Phänomen, die moderne Wirkungsgeschichte dieser Präsenz die überkommenen Grundlagen der westlichen Geistes- und Sozialwissenschaften in Frage gestellt hat. Den Hintergrund für meine Überlegungen bildet die Annahme, daß in der Tat die moderne Präsenz des Islams alles betrifft, was heute über die strategischen Bedingungen der »Weltgesellschaft « gesagt werden kann. Mit Hilfe der bemerkenswerten Toleranz des Verlags habe ich in diesem Band die thematische Spannweite dieses Phänomens, das man auch mit dem Begriff der »Modernität des Islams« belegen könnte, auf vier Komponenten hin ausgelegt: Teil I fokussiert in der Rückfrage an die »eigenen «, die abendländischen »fundamentals«, die noch jede kulturübergreifend ausgelegte Forschung zumindest implizit zur Grundlage hat. Teil II widmet sich der Frage nach den Dynamiken und Richtungen der Globalisierung, die das Phänomen der modernen Präsenz des Islams aufwirft. Teil III enthält einige Untersuchungen in den gesellschaftlichen Spannungsfeldern, die durch das Aufeinandertreffen von ideologisch politisiertem Islam mit überkommener lokaler Alltagspraxis entstehen. Teil IV führt unter fachgeschichtlichem Blickwinkel wieder auf Teil I zurück und stellt die Frage, ob es eine auf Islamwissenschaft aufbauende Soziologie des Islams geben kann.

Eine Schlüsselfrage, die in diesem Buch aufgeworfen wird, betrifft nur indirekt die Grundvisionen und Prinzipien des Islams. Ob man sie nun als statisch bestehende Textgebäude von Koran und Sunna und der schon nach drei Jahrhunderten im wesentlichen festgeschriebenen Dogmenlehre begreift oder nicht, sie bestehen und bilden den Hintergrund für islamische Modernitätsdiskurse. Dabei werden sie als spezifische, sich manchmal gar widersprechende »Ideen « ausformuliert und zugleich auch in spezifische Kulturtechniken transformiert. Die Frage, was vom Westen übernommen wird und wie es kommt, tritt dabei in den Hintergrund. Entscheidend wird dagegen die Frage, wie sich 
»Ideen« in »Techniken « transformieren, wann das Beharren auf Wesensformen zu einem Instrument der simulativen Kulturproduktion wird und vice versa. Es wäre sicher falsch, die Ideengebäude des Islams und ihre stabilisierenden Kräfte nur aus dem Wechselspiel mit Europa heraus zu erklären. Aber seit Fanon und Sartre, die Manifeste des algerischen Befreiungskrieges universalisierend, den Begriff der »Freiheit « mit dem Begriff der Kultur neu verknüpften, wissen wir, mit welcher Sprengkraft Europas Ideen unter den Intellektuellen der Kolonialländer wirkten. Der Islam ist mit diesen Ideen fortgeschrieben worden und kommt im Gewand dieser Fortschreibungen zu einer eigenständigen modernen Selbstauffassung; als solcher wirkt er sicher auch nach Europa zurück. Auch aus dieser Perspektive sind die Wechselwirkungen der modernen Präsenz des Islams zu bestimmen. Es handelt sich nicht nur um den Austausch von, gewissermaßen unberührten, statischen Grundvisionen und Prinzipien, sondern oft um in einem technischen Sinne weiterentwickelte, mutierte Ideen, deren »Herkunft « ganz unabhängig von ihrem äußeren symbolischen oder begrifflichen Gewand, mit dem sie sich auf etwas »Authentisches «, »Historisches « berufen, völlig ungewiß ist. Die hier an mancher Stelle getroffene Entscheidung, das entwertende Wort der »Kulturtechnik « dem produktiven Potential von »Wert « und »Idee " gegenüberzustellen, mag aus dem verstaubten Begriffsarsenal der modernen Kulturkritik herrühren. Doch sind Techniken wie etwa »Affirmation « oder »Askese « immer auch kulturproduktiv und wert- und ideenbildend, unabhängig davon, wie stark die operativen Potentiale dieser Techniken selbst im begrifflichen oder sozialen Umfeld etwa des Islams oder der modernen Wissenschaftskultur auseinanderklaffen. Es gibt in diesem Buch - der Leser sei hier vorweg gewarnt - kein »System«, aber ein durchaus fragendes Spiel mit analytisch unterschiedenen Kategorien, wie »Idee«, »Technik « und »Kontext «. »Fragend « und »Spiel« bleibt der Bezug auf diese Kategorien deshalb, weil das stabilisierende Ordnungspotential, das der systemtheoretische Bezug dieser Kategorien unterstellt, selbst eher als verstaubt betrachtet werden kann.

Die in diesem Buch skizzierten Fragen betreffen die kritische Soziologie mehr als den affirmativen Methodenapparat moderner Sozialforschung. Während letzterer immer noch die Hybridität der Dummen und Armen konstatieren kann, während er für sich Kohärenz und »Identität« unterstellt, hat die kritische Soziologie immerhin den Fin- 
ger auf die hybriden Dispositionen der modernen Gesellschaft gelegt. Deren eingedenk wird man heute fragen müssen, welchen Islam die orientalisierten »fundamentals « der Moderne zu schaffen im Begriffe sind und wie dieser in den Westen zurückwirkt: zuerst in die Gesellschaft und von dort weiter in die bestehende Wissenschaftskultur. Wenn die strategischen Dispositionen der Macht sich aus dem Rationalismus allein nicht speisen lassen, dann werden auch Programme der nachholenden Rationalisierung obsolet. Den Muslimen wird dennoch immer wieder vorgeworfen, daß sie sich den für äußere technische Evolutionen notwendigen technischen Revolutionen des Inneren verweigerten. Die soziologischen Arbeiten, die ihnen vorschlagen, diese inneren Entwicklungen etwa der Selbst-Rationalisierung nachzuholen, sprechen Bände. Auf islamische Machtmodelle wird in diesem Buch nur am Rande eingegangen. Aber muß man unbedingt so dumm sein, wenn man die christlichen ablehnt? Es ist wahr: die Globalisierung stellt immer wieder neue Anerkennungszwänge an die Einzelkulturen. Das gilt auch für alle soteriologischen Ideen und Prinzipien der Weltreligionen. Aber auch ein Muslim - wenn ich das hier so sagen darf ist nicht so dumm, daß er sich den äußeren Bedingungen globaler Machtzwänge entzieht, indem er etwa nur gekaufte, nur simulierte, nur instrumentalisierte Technologien, »soft « oder »hard «, innere oder äußere, zurückwiese. Und täte er es, so wäre er sich des Preises und des Gewinns durchaus bewußt.

In diesem Kontext sind selbstverständlich Überlegungen, die die soteriologischen Bedingungen des Islams, also die hier gebotenen, gewissermaßen modern potentialisierten Lösungs- und Erlösungswege miteinbeziehen, nicht von der Hand zu weisen. Wie überhaupt die Frage nach den Welthaltungen des Islams und die Tatsache, daß er sich gerade mit ihnen unter weltgesellschaftlichen Bedingungen so überzeugend stabilisieren konnte, eine der großen Fragen unserer Zeit bleiben wird.

Dennoch wird der Leser eine anatomische Beschreibung der Ideen des modernen Islams vermissen. Noch einmal: Es geht in diesen Arbeiten nicht um das »System « Islam, sondern um die Bedingungen und Formen der Zirkulation der modernen Idee des Islams. Die ideellen, machtstrategischen und technischen Aspekte stehen im Vordergrund. Ideen ereignen sich und wandern. Sie nur unter dem Gesichtspunkt der Ökologie zu betrachten, ist eine unangemessene Einschränkung, 
denn Ideen nehmen oft auf die Ökologie keine Rücksicht, am wenigsten noch bei den Wechselspielen des Kulturkontaktes. Die subtilen, kulturproduktiv wirkenden Mutationen und Umkehrungen, etwa der Übergang von Wert in Ordnungstechnik, von Heil in Methode, von Leben in Charisma etc. könnten unter Hervorhebung des ökologischen Gesichtspunktes nicht begriffen werden. Es sind eben nicht nur die Gegensätze der sich kontrastierenden Kulturen, die die »qualitativen Sprünge«, nach »oben« wie nach »unten«, bewirken. Es ist in diesem Zusammenhang viel über die Macht der Selbstkreation und die Irrealität der Differenzbildung gesprochen worden. Ideen kennen Qualitäten wie »Wert « und »Leben«, aber auch »Transzendenz«, oder geben vor, sie zu erkennen; das impliziert, wenn man sie untersuchen will, eine Kombination von ganz unterschiedlichen Erfahrungsebenen.

Wie unausweichlich jene Qualitäten, die »Ursprung « und »Mythos « vermitteln, im Wechselspiel des Kulturkontaktes sind, und sicher nicht so einfach mit der List der interessierten, dialektischen Vernunft zu übertölpeln, zeigt sich hin und wieder im Leben selbst, jedenfalls gerade dann, wenn »Ideen « wieder zum Leben gebracht werden. Das große, das moderne Ereignis dieser Art, war das Ereignis der islamischen Revolution im Iran des Winters 1978/79. Ausgehend von dem dort gewonnenen weltgesellschaftlichen Format ereignete sich die Idee des Islams dann auch in den anderen muslimischen Ländern, vor allem aber in Ägypten. Früh hatte Michel Foucault das Weltpolitische, das die weltgesellschaftliche Ganzheit Fassende dieses Ereignisses im Iran erkannt und es zum Gegenstand einer philosophischjournalistischen Analyse gemacht. Foucault sah im islamischen Aufstand im Iran das Hervorquellen einer jahrtausendelang unterdrückten Idee, nämlich die im Namen des Heils und der Gerechtigkeit gegen das fremd-versteinerte Gottkönigtum sich erhebende Prophetenmacht, und zugleich die Geburtsstunde einer spirituell-intellektuellen Revolution im Kampf mit der Moderne: Das Aufkommen einer sich erneuernden politischen Theologie des Orients. Der in diesen Band aufgenommene Essay über Foucaults Iran-Abenteuer gibt im großen und ganzen die ursprüngliche englische Fassung wieder. Die Kürzungen beziehen sich auf die Massenkultur-Aspekte, die Bestandteil von Foucaults Beobachtungen waren, aber hier zugunsten der verstärkten Hervorhebung der revolutionsphilosophischen Aspekte zurückgestellt wurden. Die Diskussion über Foucault und den Iran ist weitergegan- 
gen und hat sich, m.E. zu Unrecht, wie schon im Paris des Jahres 1979 auf Rettungsversuche Foucaults vor seinem »Irrtum« kapriziert.

Ich muß deshalb hier noch ein paar Worte zu Foucault und Iran sagen, vor allem weil ich mir eine die spätere implizite oder explizite Kritik aufgreifende Überarbeitung des Textes versagt habe. Die Bedeutung von Foucaults Iran-Unternehmungen liegt in ihrem zunächst in der Zeit der »reportages des idées « offen aktualisierten, später unterdrückten Zusammenhang zu seiner eigenen »politischen Theologie«. Es handelt sich dabei um einen im Zeichen von Louis Massignon stehenden Komplex einer Philosophie des »Transsozialen «, deren Elemente bereits in einer Studie über den sufitischen Heiligen und Märtyrer Hallaj (857-922) skizziert sind. Die Frage lautet, was denn die Existenzformen hoch spiritualisierter und methodisch durchorganisierter Körper, wie sie sich etwa im Kulturtyp des islamischen Sufismus prägten, für eine Utopie des »Geistes« moderner gesellschaftlicher Organisation bringen können. Die in Foucaults »Reportagen«Texten durchbrechenden Momente des philosophisch-utopischen Denkens in Richtung auf Auflösung und Fortentwicklung des modernen Individualismus und des in ihm ruhenden Gedankens institutioneller Macht beherrschen vor allem seine letzte Schaffensperiode, die in die Zeit nach dem Iran-Abenteuer bis zu seinem Tode 1984 fällt. Diese Tatsache läßt sich nicht einfach nur als Verfehlung gegenüber dem sonst im Werk durchgehaltenen pluralistischen Liberalismus kritisieren.

1979 fand in einem vorwiegend islamischen Land eine Revolution im Namen der Religion statt. Für das aufgeklärte Intellektuellentum bedeutete dies eine Umdrehung des modernen Revolutionsbegriffs. Es schien im Iran nicht mehr ummittelbar und programmatisch um das »historische Subjekt « einer unterdrückten Klasse zu gehen als vielmehr um die Idee der unterdrückten »authentischen« Kultur. Das beinhaltete eine Umdrehung des modernen funktionalistisch gereinigten Religionsbegriffs, und Foucault legte denn auch weniger den Finger auf die mögliche Instrumentalisierung der Religion, sondern vor allem auf das spirituelle Massenereignis, die Verkörperung religiöser Ideen. Für Foucault war das Zusammentreffen vom »Aufstand der Idee « mit der historischen Potentialität der politischen Spiritualität des Islams wie gesagt Überwindung und Fortführung des modernen Individualismus zugleich - das Thema dieser Revolution - und er wurde wegen 
dieser »rechten « Thematisierung von seinen »linken « Kollegen und Freunden in Paris dafür heftig kritisiert. Natürlich gab es eine Tradition der »Rechten « aus dem Collège de Sociologie, die sich gegen die »Inquisitionen « der Moderne richtete, aber es gab eben auch den Einfluß der beiden großen Orientalisten am Collège de France, Corbin und vor allem Massignon, die eine Art im Orient wurzelnde »Mythos-Politik « für das moderne Selbstverständnis betrieben. Foucault nahm die iranische Revolution als Anzeichen für die Rückkehr der Religion in die Politik. Seine Beobachtungen der iranischen Ereignisse suchten gewissermaßen nach Ausdrucksformen einer neuen, anderen, fast körperlichen Kulturbewußtheit der revoltierenden Massen. Er sah darin ein Anzeichen für revolutionäre Anwendungen eines »von unten « geläuterten Ursprungsdenkens der Iraner, das der »Leere «strategischer Instrumentalität ein Ende zu setzen habe. Immer wieder dringen Fragen durch, die sich von der Sprengkraft der iranischen Ereignisse Lösungen des modernen Individualismus erwarten, Beschreibungen der »organischen « Macht spiritueller Besessenheit und der Regelungspotenzen jener von Ideen besessenen Körper. In den »reportages des idées « werden die in die Entwicklungsgeschichte der islamischen Mystik hineingeschrieben Sozialphilosophien der großen Orientalisten Corbin und Massignon zum Thema der iranischen Revolution und damit auch zur Philosophie der konkreten Utopie einer neuen »Moderne « - dies ist in der Tat ein Problem-Feld, dem sich die aktuelle Soziologie des Islams noch in weit intensiverem Maße zu widmen haben wird. Die hier präsentierten Arbeiten können sich nur als Wegweiser hierzu verstehen.

Viele Personen und Institutionen haben dabei geholfen, die vorliegenden Arbeiten zu ermöglichen. Mein besonderer Dank gilt der Deutschen Forschungsgemeinschaft und der Volkswagen-Stiftung. Hans Dieter Evers in Bielefeld, Bryan S. Turner bei den verschiedenen Stationen in Australien und jüngst Thomas Bierschenk in Mainz haben mir in einer über das übliche Maß hinausgehenden Weise Gastfreundschaft gewährt. Viele ausländische Universitäten und Institutionen ich erinnere mich an die Diskussionen und Gespräche mit Studenten und Kollegen am St. Antony's College in Oxford, an Universitäten und wissenschaftlichen Einrichtungen in Singapur, Australien, Malaysia, Indonesien und Ägypten - haben mich über Jahre hinweg in einer 
Weise beherbergt, daß mich die Form der gegenwärtigen öffentlichen Diskussion über die Stellung von »expatriates « nur beschämen kann.

Die Anregung zu diesem Buch kam von Karin Werner, Roswitha Gost und Sigrid Nökel. Ihnen ist zu danken, daß der Begriff »Soziologie des Islams« hier so eine breit gefächerte Auslegung erfahren kann. Mein ungeteilter Dank gilt ebenfalls dem Verlag, der mir bei der $\mathrm{Zu}-$ sammenstellung dieser Texte die höchst mögliche Unterstützung gewährt hat. 


\section{Teil I}

\section{Der Islam und die »fundamentals « der Moderne}

"In sum I argue that the search for fundamentals - in so far as it exists on any significant scale - is to a considerable degree both a contingent feature of globalization and an aspect of global culture. In a sense ,fundamentalism within limits makes globalization work. Yet I would not insist that all of the search for fundamentals should be regarded or analyzed in those terms. We do need, for example, to make distinctions between fundamentalism-within-globalization and fundamentalismagainst-globalization, and between both pro- and anti-fundamentalistic globalism. Nevertheless my general point is that the concern with fundamentals is itself widely srounded.".

(Roland Robertson, Globalization, 1992) 



\section{Moderne Essentialisierungen des Islams}

Glaubte man dem immensen Ausstoß an Literatur zur Rolle und Bedeutung der Religion des Islams in der modernen Weltgesellschaft, so müßte man zu der Ansicht gelangen, es hätte sich seit 1979, dem Jahr der islamischen Revolution im Iran, eine Vielzahl von Wissenschaftlern aus ganz unterschiedlichen Disziplinen in kürzester Frist auf einem Gebiete kundig gemacht, das zuvor fast ausschließlich der exotischen Zunft hochspezialisierter und orchideenhaft sich zierender Experten vorbehalten war. Wer sich so beeindrucken ließe, machte sich leicht zum Opfer einer mit astrologischer Präzision und Bestimmtheit arbeitenden Mode-Disziplin: Die Islamologie ist in Mode und jeder, der einmal im Wüstensand geschürft hat, von Palmengehängen sich umsäuselt und von orientalischer Weiblichkeit sich inspiriert fühlte, glaubt offenbar, der wahren Tiefe des Orients erst auf die Spur gekommen zu sein, wenn er aus der Peripherie seiner jeweiligen fachlichen Abteilung heraus einmal in das alles verbindende Zentrum der islamischen Religion vorgedrungen ist.

Der vorliegende Ansatz macht es sich einfacher; er verweigert sich der Suche nach der tieferen Wahrheit dessen, was authentischer Islam und moderner Islamismus ist. Es ist jedoch nicht so, daß der Autor Mode-Zeiten zur tieferen soziologischen Betrachtung des Phänomens nicht für geeignet hielte - ganz im Gegenteil!

Die Skrupel, die mich letztlich von der Absicht abbrachten, mich an der Suche nach dem »authentischen « Islam zu beteiligen, kommen aus zwei unterschiedlichen Richtungen: Erstens kann man heute das Geschäft des Verstehens einer anderen Religion - und insbesondere das soziologische in bezug auf den Islam - nicht mehr so betreiben, als wären Begriffe und Perspektiven, die in einer solchen Betrachtung zur Anwendung gelangen, nicht bereits durch jene Diskurse geformt und kontrolliert, die zugleich auch die Formen der Beherrschung, Destruktion und sodann der Rekonstruktion der Kultur des anderen bestimmten. Eine Soziologie des Islams kann heute ernstlich nicht so tun, als hätte es den Diskurs über »Orientalismus « nicht gegeben. ${ }^{1}$

Zweitens, und viel stärker noch, bewegte mich die Einsicht, daß die historischen Leistungen der Islamwissenschaft und das Islambild, das sie vermittelt, als wissenschaftliche Konstruktion einer kulturübergreifenden Perspektive zunehmend aus dem modernen islamologischen 
Diskurs und damit auch aus dem Bewußtsein derjenigen herausfällt, die heute in scheinbar naiver Weise sich dem Phänomen Islam nähern. Mit dem historisch auf uns gekommenen Wissen der Islamwissenschaft, mit dem Einfühlungs- und Verständniswillen, ja mit der Hingabe, mit der weltbürgerlichen Bildung und Toleranz der klassischen Persönlichkeiten dieser Wissenschaft, wird heute durch Nichtkenntnis, Verdrängung und willkürlichen Zitaten-Selektivismus Schindluder getrieben. Daß die moderne Weltkultur auf die Schätze der islamischen Geschichte zurückgreifen kann, ist das unteilbare Verdienst dieser Gelehrten. Diese »Schätze« verdichten sich in einzelnen ihrer Werke zur Synthese unterschiedlicher wie immer noch offen gewirkter Bilder, die selbst im kulturübergreifenden Blick des Zeitgeistes zu entschlüsseln sind. Diese Bilder gewissermaßen auszublenden, die Soziologie aus dem historischen Kontext unseres Islamverständnisses zu lösen, schien mir ein Vergehen; im Gegenteil, sie einzuholen und aus den ideengeschichtlichen Diskursen ihrer Zeit heraus zu verstehen, eine Vorbedingung jeglicher Soziologie des Islams. ${ }^{2}$

Es ist deshalb meine Absicht, die Wissenschaft vom Islam wieder ins Bewußtsein der Sozialwissenschaften und der Soziologie zu bringen und zugleich die in ihr ruhenden Komponenten und Voraussetzungen der Soziologie des Islams aufzuzeigen.

Ich hätte es mir andererseits zu einfach gemacht, hätte ich mich mit dem bloßen Rekurs auf den historischen Wandel des Islambildes im 19. Jahrhundert aus dem »Diskurs der Moderne« verabschiedet (Habermas 1981b, 1983a, 1985). ${ }^{3}$

Die vorliegenden Studien wollen mit einer gewiß nicht zu verleugnenden Absicht an Überlegungen wirken, die der Bedeutung des "postmodernen « Verständnisses kulturübergreifender Kommunikation und Interaktion Rechnung tragen. An die Stelle einer Soziologie des Islams treten drei grundlegende Fragen, die sich an das soziologische Denken unserer Zeit wenden. Sie werden ganz pragmatisch als Rückfragen an die Islamwissenschaft gestellt:

Erstens die Frage nach dem Zusammenhang zwischen Innerlichkeit und universalistischer Kulturerfahrung. In soziologischer Sicht ist hier $\mathrm{zu}$ fragen, inwieweit die »konstitutive Subjektivität« des modernen Menschen gerade dann eines vertiefenden, auf das Innere und Wesenhafte gerichteten Verständnisapparates bedarf, wenn er auf intrakulturelle Welterfahrung gestoßen wird. Die Frage zielt auf den epistemi- 
schen, kulturklassifikatorischen Gehalt der Kategorie »Innerlichkeit« in der kulturübergreifenden Sozialforschung. ${ }^{4}$

Zweitens birgt Soziologie als Reflexion der Gesellschaft oder gesellschaftliche Selbstreflexion eo ipso einen Kern von Kulturkritik in sich. Das verborgene kulturkritische Element der Soziologie muß auch dann von Bedeutung bleiben, wenn Soziologie explizit auf kulturübergreifende Fragestellungen stößt. Die moderne Kulturkritik hat selbst an der Sublimierung und Essentialisierung des soziologischen Begriffsapparats gewirkt. Der Diskurs der Moderne brachte eine Reihe kontrastierender Unterscheidungsmerkmale hervor, die unsere eigene gewohnte Realität von derjenigen fremder Kulturen unterscheidet. Vor dem Hintergrund der modernen Kulturkritik werden Sozialstrukturen, soziale Bewegungen, Formen der sozialen Kohäsion, individuelle Lebenspraxis und Einstellungen zur Welt, von Entwicklungsgesellschaften etwa, klassifiziert. Die Frage lautet, welche spezifischen Folgen das kulturkritische Muster soziologischer Selbstreflexion in der Begegnung und Beschreibung anderer Kulturen und Glaubenssysteme hinterläßt. ${ }^{5}$

Drittens bringt die zunehmende Universalisierung der Kultur neue innere Formen der Kommunikation und Interaktion hervor, die eines aus der unmittelbaren Kulturerfahrung des Einzelnen heraus begründbaren Sinnzusammenhangs entbehren. Die moderne Weltkultur wird selbst entreferentiell, ritualistisch, formalisierend, simulativ und gegenüber den Betroffenheiten und Erfahrungen des Einzelnen als parasitär erfahren. Daß die Lokalkulturen und Glaubenssysteme Anderer, gerade vor dem Hintergrund universeller Erweiterung kultureller Kommunikation, weiterhin mit dem Stempel ritualistisch-legalistischer und deshalb eben oberflächlicher und spannungsloser Kultur versehen werden, bleibt unglaubwürdig. Wenn gerade eine christliche Wirtschaftsethik - auf innere Einstellung zur Welt, auf individuelle Erlösung, auf Prophetentum, auf Offenbarungserlebnis bauend - eine entreferentielle, sinnentleerte und ritualistische, äußerliche Form der kulturellen Kommunikation und Interaktion hervorbringt, so bleibt die wissenschaftliche Kategorisierung anderer Glaubenssysteme als pharisäerhaft, ritualistisch und affirmativ etc. wenig überzeugend.

Die Realität der neuen - der postmodern genannten - Formen der Kommunikation und Interaktion darf für die soziologische Analyse anderer Kulturen und Glaubenssysteme nicht folgenlos bleiben. Wo 
sich zeigt, daß die Essentialisierung, die die Moderne betreibt, nur eine geschicktere und auch viel fatalere Form sozialer Simulation ist - und diese Tatsache war schon einem Max Weber bewußt - so darf anderen Kulturen nicht unter einem scheinbaren Zwang zur Objektivierung und unter dem Vorwand, sie seien wesentlich nur simulativ, gerade diese verhängnisvolle Essentialisierung aufgezwungen werden. ${ }^{6}$

Die drei Fragen nach der innerlichen Weltsicht und ihren Folgen im interkulturellen Austausch, nach den Auswirkungen der modernen Kulturkritik auf jede kulturübergreifende Perspektive und nach den Folgen des objektiven Charakters simulativer Diskurse in der Weltkultur bewegen die folgende Arbeit wesentlich, ohne zugleich Gegenstand der Untersuchungen selbst sein zu können.

Die sich halbherzig postmodern gebende Kulturinterpretation, die sich so sehr auf Kontext, Sinn und Macht versteht, hat es sich zur Aufgabe gemacht, von den kontrastierenden Klassifikationsmerkmalen des »Orientalismus « hinwegzukommen und nun jene Forschungsstile zu entwickeln, die - wie sie meint - den erforschten Völkern weniger Ungerechtigkeit widerfahren läßt. Daß man nun mit den Völkern arbeiten will und nicht mehr nur primär über sie (»to explore possible styles of research which do less injustice to the peoples with whom rather than on whom - we work «; Hobart 1986a: 7), mag sicher neuen Spielraum für Forschungsimpulse eröffnen. Das kann jedoch so einfach und problemlos nicht sein.

Das Problem, das sich dabei stellt, ist unser ureigenstes Gefangensein in Innerlichkeits- und Essentialisierungsgedanken, aus denen heraus erst Utilitarsierung und Maximierung des Handelns sich uns erschließt. ${ }^{7}$ Ich möchte dieses unser Gefangensein im InnerlichkeitsSyndrom - religiös begründetes Verhalten anderer nur gegen den Wert strengster innerer Wahrheit, Geschlossenheit und in aller Härte nur auf das jenseitige, erlösende Schicksal gerichtete individueller Verantwortlichkeit zu messen, zu beurteilen und zu klassifizieren - an zwei Beispielen verdeutlichen. Sie beziehen sich auf zwei neuere Islam-Bücher, die von unterschiedlicher Bedeutung und Qualität sind und in unterschiedlicher Weise mit Innerlichkeit und Essentialisierung operieren: Michael Gilsenans »Recognizing Islam« und Bruno Étiennes »'islamisme radical«.

Michael Gilsenan führt in seiner »An Anthropologist's Introduc- 
tion « einen aufgeschlossenen jungen Europäer vor, der in dem Erlebnis der ungebundenen, spielerischen und sich in räumliche und zeitliche Sphären bewußt spaltenden Doppelmoral zweier Hadrami-Scherifen seinen als Anthropologe ersten Schock mit der islamischen Kultur erlebt. Es ist ein sicherlich nicht beabsichtigter Effekt der Beschreibung des Grußrituals zwischen den zwei Hadrami-Scherifen und einem jungen Intellektuellen ihres Stammes, daß deutlich wird, wie sich in einem traditionellen Ritual zwei völlig verschiedene moderne Lebensformen begegnen können, wie sie im rituellen Akt der Tradition selbst eine gewisse Versöhnung finden, zugleich aber auch in eine eigenartige Spannung zueinander treten. Gilsenan spielt mit seinem eigenen und mit unserem Innerlichkeits-Habitus, wenn er ganz $\mathrm{zu}$ Beginn seines Buches die folgende Situation beschreibt. Ich übersetze hier einige Teile seiner signifikanten Beschreibung.

»Ein Freund und ich waren in Seyyan, einer der antiken Städte des großen östlichen Wadi in Hadramaut. Sie wurde von einer von den Briten eingesetzten Familie von Sultanen regiert, in ihr herrschte ein sehr einflußreicher Clan von Scherifen, Abkömmlingen des Propheten Muhammad.

Wir trafen an einem heißen Morgen zwei junge Männer auf der Straße. Das grüne Band an ihren Turbanen, ihre wehenden creme-farbenen Umhänge und ihre gepflegten Bärte waren Zeichen der Heiligkeit und Insignien ihrer sozialen Stellung. Ihr Reichtum, der von großem lokalen Grundbesitz und von Geschäften aus Indonesien kam, drückte sich in der Qualität des Stoffes ihrer Kleider und in der Größe und entsprechenden Eleganz des luxuriösen Hauses aus, zu dem man uns geleitete.

Alles war Verzauberung, eine Wüste, eine Oase, eine heilige Stadt, eine uralte Tradition. Die Fülle von Heiligkeit und ein ritualisierter Sinn von guter Ordnung und Harmonie kamen hinzu, als einer meiner eigenen Studenten, dem wir auf der Straße begegneten, im Vorbeigehen sich respektvoll zum Handkuß niederbeugte und damit seine Anerkennung ihrer sozialen Stellung bezeugte. Die Welt war ein wunderbar geformter magischer Garten. Ich war beschwingt und alle meine Vorstellungen von Islam und arabischer Gesellschaft schienen unhinterfragt sich zu bestätigen.«

(Gilsenan 1982: 9)

Schließlich entdeckt Gilsenan aber in der privaten Atmosphäre des 
Hauses die wahre Lebenswelt der Scherifen in einem Grundig Tonbandgerät, Popmusik, Whisky und dem Bedürfnis, sich schnell westlich zu kleiden.

Mehr noch, er traf am nächsten Tag den Studenten, der ihm den zweiten Schock versetzte: Er entpuppte sich als ein linker Nasserist, der das vollzogene Grußritual so kommentierte: Wir küssen heute ihre Hände, aber warte nur auf morgen.

Gilsenan zieht den Schluß: »Der Handkuß war eine Show, die völlig im Gegensatz zum Sinn stand, den die Handelnden ihm verliehen. Mit ihm wurden verborgene Interpretationen, Reversionen und Negationen verheimlicht.«

Hier vertieft nun Gilsenan selbst den beschriebenen Handkuß von 1959 aus der Sicht der fundamentalistischen Wende von 1982 - und ich kann ihm hierin nicht folgen. Beide Parteien waren sich sehr wohl der inneren Haltung der anderen bewußt. Aber beide Parteien verzichteten aus der Akzeptanz des Rituals darauf, ihre Vorstellung von Islam und islamischer Lebensweise zum Gegenstand des symbolisch Getauschten zu machen. Die innere Haltung der Akteure blieb gegenüber dem rituellen Akt äußerlich. Niemand versuchte seine Haltung dem Ritus habituell aufzuzwingen. Die Konvention des Aktes leistete, was sie in der sozialen Situation von 1959 zu leisten hatte: die soziale Versöhnung zweier politisch unvereinbarer Haltungen zur Welt. Hier der legitime rituelle Konventionalismus als Rechtfertigung säkularer Modernität als individueller Lebensstil. Dort ein politischer Essentialismus, der auf sozialer Einheit von Ritus und Lebensform pocht und damit noch unbewußt einer religiösen Fundamentalisierung des Sozialen den Weg bereitet.

Am Beispiel des simulativen Innen- und Außen-Verhaltens der beiden islamischen Notabeln verwickelt Gilsenan uns in das Bilderspiel der Verwandlung einer magisch-religiös verklärten arabischen Landschaft in die entzauberte Welt der Moderne. Bevor er uns, die Leser, wissen läßt, was die andere Seite, der junge Student, aus seiner Unterwerfungsgeste macht, erfahren wir, wie »tief « den Autor die listenreiche, ganz auf die Durchsetzung so primitiv materiellen Interesses gerichtete häusliche Verwandlung der beiden Scherifen betroffen gemacht hat: 
»Für einen naiven Jüngling, der sich im Angesicht der Kultur dieser fremden und wunderbaren Gesellschaft, die sich ihm gerade auftat, fromm um nicht $\mathrm{zu}$ sagen frömmelnd verhielt, war der Schock groß. War die Straßenszene nur eine Szene? Eine Heiligkeitsschau, eine bloße Fassade einer Elite, die sich hinter den Zeichen und Pflichten ihrer Machtstellung zu verbergen hatte? Solche Zeichen der Religion und Hierarchie wurden dazu benutzt, andere zu beherrschen, aber, für einige der jungen Scherifen zumindest, waren sie in der Isolierung ihrer Häuser sicher eine kaum mehr zu unterstützende Last.«

(Gilsenan 1982: 10)

Jetzt erst erfahren wir, daß der ehrerbietig den Handkuß darbringende Student eine zweite, eine ganz private, interessengebundene Lesart für seine öffentlich vollzogene Geste hat:

»Einen Tag später traf ich den Studenten, ein Junge so wie ich knapp unter 20 Jahren. Er versetzte mir einen zweiten Schock, ’wir küssen heute ihre Hände, aber warte nur auf morgen $<$ Er war ein Nasserist, ein Wort, das für die britischen und die scherifischen Behörden gleichbedeutend war mit Subversion, Kommunismus und einem gänzlich zu widerstehenden Feind. Einer der ersten jener Bauerngeneration, die Bildung genas. Er war Mitglied in einem Kulturclub, in dem die meisten jungen Männer Sympathisanten des ägyptischen Präsidenten waren, damals auf der Höhe seiner Macht. Nassers Anliegen galt als dasjenige aller Araber gegen Imperialismus und die Kontrolle der reaktionären Kräfte. Er sprach zu mir, aber ich war auch nur ein Teil des Apparats der Kolonialverwaltung, eine Tatsache, die er sehr viel klarer sah als ich selbst. Der Handkuß war eine Schau, aber es war eine Schau mit diametral entgegengesetzten Bedeutungen für die Handelnden, mit geheimgehaltenen Interpretationen, Rückbindungen und Verneinungen.«

(Gilsenan 1982: 10f.)

Der praktische Interessengegensatz, den die sozialen Akteure in der in wie immer unterschiedlich vollzogenen Rollen - gemeinsamen Performanz des öffentlichen Aktes entwickeln, führt sie im »Innern« zu ganz verschiedenen Ausdeutungen des Sinnzusammenhangs zwischen dem »innen« konstituierten Interesse und dem »außen« vollzogenen symbolischen Akt: 
»Beide Seiten verfügten über starke Definitionen der wahren Religion. Die Position der Scherifen ruhte ganz auf ihrer Herkunft, rituellen Kompetenz, und dem Glauben an ihre Fähigkeit, Segen zu bringen, auf Bildung und Kenntnis des islamischen Rechts, die sich ganz in ihrer Kleidung symbolisierten. Für sie stand der Student dem Unglauben gefährlich nahe und war sicherlich dem Sozialismus verfallen. Die Whisky-Trinker mochten zwar ihr eigenes unvollkommenes Benehmen zugeben, aber darin jeden Zusammenhang mit dem Verlust ihrer Autorität leugnen. Für den Studenten waren die Hände des Mannes, die er küßte, nicht nur Hindernisse für die Unabhängigkeit, sondern hatten auch nichts mit wahrem Islam zu tun, der der Scherifen nicht bedarf und ebensowenig auch des Respekts für reiche Kaufleute und Grundbesitzer in grünen Turbanen oder der Akzeptanz religiöser Hierarchien. Der wahre Islam war frei von solchen Vermittlungen zu Gott und wurde nur von Koran und Traditionen verkörpert. Er stellte eine egalitäre Kraft für die Einheit aller Mitglieder der Gemeinschaft dar und war Teil eines weltweiten Kampfes, ein Islam, der Hand in Hand ging mit dem Kampf gegen die lokalen Quellen der Korruption und gegen die Fremdherrschaft.«

(Gilsenan 1982: 11)

Gilsenan interpretiert hier einen Akt, den er 1959 erlebt hat, im Kontext des Zeitgeistes von 1982. Daß und warum der separat geführte Disput über die Interessenlage der Partizipanten nun in einem Diskurs über »starke Definitionen wahrer Religion« ausgedeutet werden kann, mag vielmehr Gilsenans und unser aller Problem sein, ein Problem, das sich eher mit dem Bewußtsein des sich wandelnden Charakters religiöser Glaubenssysteme im modernen Diskurs kulturübergreifender Kommunikation und Interaktion als aus der faktischen und bewußten Erfahrung der Akteure von 1959 vermittelt. 1982 ist insofern erst das Nachspiel von 1959, und in diesem Nachspiel erst erfährt das Erlebnis interkultureller Kommunikation seine eigentliche Essentialisierung.

Die Bilder des bewußten, aber auch unabsichtlichen Spiels mit dem Heiligen und dem Profanen, mit den Wahrheiten des Lebenszyklus, der Virtuosität des Wissens und der praktischen Vernunft des Interesses, die uns Gilsenan aus dem Leben der islamischen Kultur vermittelt, entsprechen denn auch so ganz dem Geschmack einer neuen Generation von Zivilisationsflüchtigen, die in der Wahrheit dieser Religion ihre Sehnsüchte nach einem innerlich bestimmten Kulturerlebnis zu 
stillen suchen. Das Bedürfnis nach Innerlichkeit der Kulturerfahrung einer neuen Anthropologengeneration entspricht hier durchaus dem Bedürfnis nach innerlich bestimmter Welterfahrung einer jungen Generation politisch motivierter, global und universell denkender Intellektueller, etwa der arabisch-islamischen Gesellschaften, die das »Spiel« kennengelernt und verstanden haben. Im Gilsenanschen Werk deutet sich eine postmoderne Synthese der kulturübergreifenden Erfahrung, Kommunikation und Interaktion an. Das Mißverständnis, dem sie unterliegt, eröffnet sich vielleicht grundlegend in den beiden verschiedenen Formen der Essentialisierung, die eine solche Synthese in sich birgt: hier die nicht mehr nostalgische, nach innen einschnürende, nach außen körperbewußt beherrschende Perspektive des postmodernen Intellektuellen, dort die nostalgisch-fundamentalistische Essentialisierung von Kulturbeständen der Intellektuellenschicht einer des Übergangs harrenden vorindustriellen Gesellschaft.

Weniger spielerisch, eher ernst und finster stimmt das Bild, das uns Bruno Étienne in seiner Studie zum »radikalen Islamismus « vermittelt. Hier gewinnt jene neue Generation arabischer Intellektueller ihre moderne legitimatorische Kraft aus einer neuen, okzidentalen Essentialisierung der Geschichte: »Die Islamisten sind durch ihre Neuinterpretation der Geschichte des Orients und des Okzidents radikal (Étienne 1987: 22).

Wie schon in der Gilsenanschen Ausdeutung der inneren Lebenshaltung des jungen unterprivilegierten Studenten, der sich der globalen und lokalen Voraussetzungen des Prozesses politischer Emanzipation bewußt wird, bleibt auch Étiennes Bild vom Islam als »le seul véritable instrument de mobilisation des masses ", als das einzig wahre Instrument der Mobilisierung der Massen, an die Vorstellung vom Bedürfnis nach »wahrer Religion « geknüpft: »Die Errichtung einer islamischen Gesellschaft in Übereinstimmung mit der religiösen Moral bleibt das einzig erhaltbare zivilisatorische Projekt« (Étienne 1987: 25). ${ }^{8}$

Hier in der Arbeit Étiennes wird ein neuer Islam kreiert, ein Islam, der auf einer neuen, modernen, lebenspraktischen Lektüre des Koran aufbaut, der eine neue, moderne »Gemeinschaft « konstituiert (vgl. Étienne 1987: 197) und darin eine neue Praxis. Diese Praxis

»begünstigt die Heraufkunft von imaginierten im Verhältnis zu wirklichen Ereignissen ...; der Koran lehrt, was dabei der wichtigste Moment ist, dieser letz- 
te Tag, dem die vorhergesagten Katastrophen der Apokalypse vorhergehen. Die aktuelle Bedeutung des Islamismus liegt gerade in der Verbindung dieses eschatologischen Begriffs der Zeit, der angesichts dessen, was Weber die Entzauberung der Welt nannte, den Prozeß des Verfalls der Welt und der Korruption beschleunigt.«

(Étienne 1987: 54)

Hier wird dem Islam eine neue Kraft der postmodernen Verzauberung der Welt abgetrotzt. Es ist nun die Re-Lektüre des Korans und die Analyse der raumzeitlichen Ordnungen, die der Islam errichtet hat und in denen der Orient sich neu "comme pole mystique " (Étienne 1987: 57) konstituiert. Aus dieser neuen mystischen Kraft des Orients leitet Étienne seine - ganz von postmoderner Einfühlsamkeit getragene - These ab, daß

»die Islamisten sich einem Gesellschaftsprojekt widersetzen, das aus der Entzifferung des historischen Sinus abgeleitet ist, d.h. symbolisch aus der Vorwegnahme der letzten Ziele, denn die moderne Welt versinkt in eschatologischer Vulgarisierung dadurch, daß die Modernisierung zunehmend die Bedeutung eines Bankrotts gewinnt, je mehr sie in der Realität sich der Angeschlagenheit des developmentalistischen Projekts versichert und die Interpretation der Welt zu einer Verknappung des Sinns führt.«

(Étienne 1987: 59)

Hier wird von einem westlichen Politologen der Mythos des Orients gegen das gesellschaftliche Projekt der Moderne gewendet; es ist jetzt plötzlich die islamische Praxis, entdeckt und neu »verlesen « von einem westlichen Intellektuellen, von einem Gesellschaftstheoretiker daselbst. Dem gilt es als erstes Ziel, die »innere Logik « allen arabo-islamischen Geschehens zu entschlüsseln:

»Den Mythos der Einheit unterbewertend, haben sich die Abendländer wesentlich in einem Punkt getäuscht: wir haben dem Diskurs der transkulturierten Eliten zugehört (und geglaubt?), die nach unserer Vorstellung gebildet wurden, an unseren Fakultäten, oft bei uns selbst. Ein Diskurs, der unserer ideologischen Bequemlichkeit entgegenkam, so auch unseren Interessen: Fortschritt/Entwicklung, Technologietransfer, Entwicklungshilfe, Zusammenarbeit, als ob es dazu nicht Zweier bedarf. Um die interne Logik zu packen, 
wenn nicht den Zusammenhang der arabischen und arabisch-islamischen Strategie, muß man in der Tat dauernd den historischen Geist und die Geographie präsent haben und darf niemals vergessen, daß die Araber auf dieser Ebene weder die gleiche Vision noch das gleiche Gedächtnis wie die Okzidentalen haben.«

(Étienne 1987: 69f.)

Hier wird jetzt die Betonung auf die unterschiedliche Idee der Geschichte und das unterschiedliche Verständnis von geographischem Raum gelegt, auf die unterschiedliche Vision von Welt, auf unterschiedliche Formen des Gedächtnisses, das uns Europäer von den Orientalen trennt. In der Interpretation dieses westlich-rationalen Politologen sind es nun erst die islamischen Massen und der islamistische Radikalismus, die den Unterschied zwischen östlicher und westlicher Kultur zum Ausdruck bringen. Und gerade darin kann sich der europäische Intellektuelle erst so recht wieder mit der ihm sonst fremden islamistischen Idee verbinden: Sie hat eine eigene Tiefe des Verständnisses, eine »innere Logik «, die uns bisher nur deshalb verborgen blieb, weil wir den Mißinterpretationen der westlich akkulturierten Eliten aufsaßen - also unseren eigenen Geschöpfen - und ihnen, die ja nur Begriffe benutzten, die mit dem sozialen und historischen Kontext, auf den sie sie bezogen, nichts zu tun hatten, glaubten (Étienne 1987: 85). Ebenso wie Gilsenan führt uns auch Étienne weiter in die orientalistischen Räume des »tieferen Verständnisses«: »le salon ou, mieux, sbyt al-dhif«. Hier wird denn auch deutlich, wie sehr der modernistische Diskurs über Nationalstaat und Nationalismus die in der Geschichte fußenden Züge der materiellen Kultur des Orients verwischt, sie vor dem »tieferen Auge« des partizipierenden Anthropologen verbergen will:

»Eine gewisse Ethnophobie selbst seitens der Kollegen meines Alters und eine Verstimmtheit über meine Forschungen, so als ob ich mich mit etwas beschäftige, was sie gerne in einem ausradierten Gedächtnis begraben hätten oder gar doch auf dem Schutthaufen der Geschichte, einer unzeitgemäßen Geschichte, der sie gerne den Rücken zukehren würden. Aber die Schwiegermütter bleiben wach ...«

(Étienne 1987: 94) 
Dem auf seine Vertiefung der Fremdkultur eingestellten westlichen Feldforscher wird mit einer »Ethnophobie« begegnet, mit der hier seine Gesprächspartner und Kollegen die lokalen Traditionen der materiellen Kultur des Islams eher dem Müllhaufen der Geschichte anvertrauen als ihn selbst darin fischen zu lassen. Die westliche Interpretationsmacht wollen sich die lokalen Eliten so einfach nicht mehr nehmen lassen. Étienne schließt daraus seine bunt gewirkte, im Verlauf des Werkes immer wieder aufgegriffene These von einem aktuellen Prozeß der Reversion, der Überdrehung von Modernität, einer Retraditionalisierung, die zugleich einen Überschuß an Modernität hervorbringt (Étienne 1987: 95). In diesem Prozeß sieht er die Islamisierung der Modernität begründet, eine Zurückweisung aller Bestrebungen, den Islam zu modernisieren und statt dessen die Hervorbringung eines Willens, eine neue islamische Modernität zu begründen.

Die Vorstellung von der »Islamisierung der Moderne« mündet andererseits in eine anthropologische Vertiefung von Individuum, raumzeitlichen Beziehungen und einer Sakralisierung von Habitus, durch die erst Handeln in dem »dahinter liegenden Sinn (Eickelmann 1981: 7f.) als Sinnhaftes erschlossen werden kann. Solche anthropologische Vertiefung erschöpft sich nicht nur in der Vermittlung anschaulicher und sinnfälliger Bilder, in der Konstitution eines lesbaren und entschlüsselbaren Textes der Fremdkultur (vgl. Geertz 1986); sie arbeitet auch an der Entwertung eben derselben Kultur mit, deren sie sich bemächtigt. Gilsenans stilvolle Bilder arbeiten so an der von Étienne beschworenen Islamisierung der Moderne mit. Die Essentialisierung der Schlüsselsymbolik des Orients und seiner religiösen Ideenwelt - so reizvoll sie für den postmodernen, in universellen Spielen des symbolischen Tausches gefangenen Kulturmenschen sein mögen - entspricht so ganz auch einer Essentialisierung der Tradition in überschießender Modernität, wie Étienne sie uns von den radikalen Islamisten vermittelt.

\section{Anmerkungen}

1 Dieser Diskurs wurde in seiner aktuellen Bedeutung durch einen Aufsatz des in Paris lebenden ägyptischen Soziologen Anwar Abdel-Malek (1963) eröffnet.

2 So werden von Politologen zum Beispiel wiederholt astrologisch 
anmutende Skizzen angestellt von dem, was »Islam« oder »islamische Religionsstiftung « sei, ohne noch einen inhaltlichen Bezug zum islamwissenschaftlichen Diskurs über Gottesbegriff, Prophetie und Dogmengeschichte herzustellen. Vgl. z. B. Tibi 1981: 76ff., 1985: 30ff. Letztlich wieder Étienne 1987: 41ff., 62ff. Am offensichtlichsten aber auch bei Soziologen wie Charnay (1977), die beides ersetzen wollen: eine moderne muslimische Theologie und eine islamwissenschaftliche Gesamtschau.

3 Zum Habermasschen Universalismusproblem unter Einbezug der »Dritte-Welt-Perspektive« vgl. Schöfthaler 1983. Eine interessante sozialphilosophische Diskussion des Problems liefert A. Heller (1984/85).

4 Impliziert ist damit eine kulturübergreifende Erweiterung der Adornoschen Fragestellung nach der Konstitution des modernen Subjekts. So schreibt Adorno noch in der Vorrede zur »Negativen Dialektik «: »Seitdem der Autor den eigenen geistigen Impulsen vertraute, empfand er es als seine Aufgabe, mit der Kraft des Subjekts den Trug konstitutiver Subjektivität zu durchbrechen « (Adorno 1966: 10). Der ideengeschichtliche Hintergrund der Adornoschen Subjektproblematik wird in unserer Arbeit zum Verhältnis der modernen Gesellschaftstheorie zu Nietzsche näher beleuchtet. Vgl. Stauth/Turner (1988a).

5 Damit weisen wir auch kulturübergreifend über den Zusammenhang von »Melancholie und Gesellschaft « und »nostalgischer Gesellschaftstheorie« hinaus; vgl. etwa Lepenies 1981; Turner 1987. Dennoch können die vorliegenden Studien ausgereifte Reflexionen darüber, welche Position "post-moderne Gesellschaftstheorien" denn eigentlich »vor-modernen Gesellschaften« zuweisen müßten, nicht reflektieren. Hier erschließt sich in der Tat ein neues Feld für entwicklungssoziologische Theoriebildung.

6 Daß die mit dem Übergang von modernen zu postmodernen Kulturformen einhergehenden Essentialisierungsleistungen in den Theologien der Weltreligionen nicht notwendig unilinear in Fundamentalismus enden, hat Bryan S. Turner jüngst in einem Bielefelder Vortrag zum Thema »World Religions, Modernity and Postmodernism - Some Issues in Max Weber's Sociology « deutlich gemacht. Mir geht es hier nicht um Fundamentalismus schlechthin, sondern um die Übertragung der essentialistischen Haltung zur 
Welt, die sich in Reformismus ebensosehr niederschlagen kann wie in Fundamentalismus, in Korporativismus ebensosehr wie in kognitivistischem Individualismus.

7 »We need the kind of detailed knowledge of how people use their cultural representations which to date has rarely been considered necessary. There is evidence to suggest, for instance, that the Balinese use their ideas of human nature in different ways than we might be led to expect. The schemes they elaborate are not generally used to provide an efficient, or final, causal explanation of particular actions. Instead the models are used to provide a general account of the conditions under which actions take place. The Balinese - suitably in the light of the recent Western tendencies in the philosophy of mind and action - are inclined to treat the question of intentions or the reasons for doing something, as private, if indeed knowable at all, where we develop evermore sophisticated techniques for the examination and exposure of the person, under psycho-analysis and legal definitions of responsibility, the Balinese draw a polite veil. Some things they still leave to a person. There may be good professional grounds for our doing the same. For our illusion that we can explain the action of others is a product as much of our tendency to essentialize and simplify, as it is of any realistic possibility of being able to do so. Context is too complex to allow such certainties. If I am right, then the business of explaining others is likely to be much harder than we like to make out. If I am wrong, then, like Monsignor Quichote's illustrious ancestor, I am tilting harmlessly at windmills (Hobart 1986b: 151). Hier sind die Grenzen einer von Clifford Geertz inspirierten kulturübergreifenden Sozialforschung deutlich aufgezeigt. Über das eigenartige Schutzverhalten der lokalen Partizipanten in interkultureller Kommunikation gegenüber kommunalen Werten vgl. meinen Aufsatz in Stauth/Zubaida 1987.

8 Das gilt insbesondere auch für den aktuellen Diskurs der »linken« Islamisten in Ägypten; vgl. etwa Roussillon 1987. 


\section{Kultur und Lebenswelt. Der kulturelle Konflikt in peripheren Gesellschaften"}

\section{Zur Erläuterung vorweg}

Wir präsentieren Überlegungen zur Bedeutung von Kultur in einer sich neu formierenden Weltgesellschaft. Kultur wird, in bewußter Einseitigkeit, als bloßer Ausdruck praktisch gestalteter Lebenswelt begriffen, als Formenspiel, als symbolische Repräsentation von Alltagsordnungen. Dem setzen wir den Begriff der Weltgesellschaft gegenüber, verstanden wohlgemerkt in gleicher verallgemeinernder Einseitigkeit, als System. Soziale Prozesse, über die wir hier reden (und in weit umfassenderer Bedeutung, Entwicklung, über die wir nicht reden), möchten wir ebenso vereinfachend verstanden wissen als Prozesse des Übergangs zwischen jenen beiden Welten, als Formations- und Deformationsprozesse von Alltagsordnungen und ihren symbolischen Repräsentationsformeln.

Das folgende Kapitel setzt die Einsicht, daß Lebenswelt auch eine praktische Ordnung hat, jenen in der Nachfolge etwa von Schütz (1932) in der Soziologie vertretenen Lebenswelttheorien entgegen, die diese eher als Vision begreifen. Wir sprechen von einer Duplizität lokal eingebundener intersubjektiver Verhältnisse, von »materieller Lebenswelt« und von »idealisierter Lebenswelt«. Je mehr die Lebenswelt ihrer materiellen Basis beraubt wird, desto mehr wird sie (in jenem von Lukács geprägten Sinne) verdinglicht; viel banaler jedoch noch, sie wird entdinglicht, in dem Sinne eben, daß dem Individuum der praktische Sinn zur Erzeugung der »Ordnung der Dinge« genommen wird. In der »idealisierten Lebenswelt « verkommt die Praxis zur Floskel.

In den folgenden Gedankenentwürfen liegt uns jede Berufung auf Entwicklung im Sinne evolutionärer Prozesse fern. Unsere Überlegungen gehen von der Vorstellung aus, daß das Spannungsverhältnis, das zwischen materieller und idealisierter Lebenswelt besteht, noch jede Gesellschaft bewegte, die primitive ebenso wie die moderne: Die zur »hohen Kultur « idealisierte und stilisierte Lebenswelt hat sich selbst immer nur als der bessere Sachverwalter, als »das bessere Management« jener Lebenslagen verstanden, die von den Notwendigkeiten des Lebens selbst vorgezeichnet sind. Nur in diesem Sinne verstehen

* Dieser Aufsatz wurde gemeinsam mit Hans-Günter Semsek verfaßt. 
wir hier »entmaterialisierte Lebenswelt « in den Industriegesellschaften; sie präsentiert sich heute im globalen Maßstab selbst als die »hohe Kultur « gegenüber jenen Massen der Dritte-Welt-Gesellschaften, die eingebunden in kommunale Formen des Zusammenlebens und unter dem Diktat materieller Notwendigkeiten - ein Überleben fristen. Unser Begriff der »materialisierten Lebenswelt « zielt auf die Realität der »Hütten«, während die »Paläste« sich in der neuen Realität des »Weltsystems « $\mathrm{zu}$ verflüchtigen scheinen.

Es ist heute Mode geworden, von »Weltgesellschaft als System« zu reden, gemessen an den gegebenen universellen Verflechtungen $z u$ Recht! Dabei wird der institutionelle Charakter vonSystem, System eben als »hohe Kultur « selbst, leicht vergessen. Die Versuche, soziale Systeme möglichst nur aus der engsten Beziehung zwischen Menschen $\mathrm{zu}$ verstehen, wie etwa in einer handlungstheoretisch orientierten Systemtheorie, sind gescheitert; von diesem Scheitern kündet uns Luhmann (1984) mit seinem »Paradigmenwechsel « in der Systemtheorie.

Der folgende Text begreift System als repräsentierte Lebenswelt, als Repräsentationsspiel gewissermaßen, in dem unterschiedliche Grade von Realitätsgehalten als Lebenswelten widergespiegelt oder auch vorgespiegelt werden. System ist somit eine geronnene Form der Repräsentation von Lebenswelt, und es gewinnt seinen Realitätsgehalt in dieser Form; Religion, Recht und Politik sind solche geronnenen Formen, ebenso wie Ökonomie und mediale Kommunikation (als Austausch von symbolischen Äquivalenzen, wie Baudrillard [1982] das nennt).

Der folgende Text geht mit drei Ebenen der Systemrealität um: Religion, Recht und Politik einerseits, Ökonomie andererseits und schließlich mediale Kommunikation. Eine Theorie der Kontinuität und Bedeutung dieser Realitätsgehalte im System als Weltgesellschaft können diese Überlegungen nicht liefern. Es hängt von der ganz konkreten institutionellen und instrumentellen Erscheinung des Systems $\mathrm{ab}$, in welcher Weise und mit welchen Mitteln es auf Realitätsgehalte aus Lebenswelten (materieller und idealisierter Prägung zugleich) reagiert.

System hat Realität in seinem institutionellen und instrumentellen Charakter; es bedarf jedoch der Referenz: Es gewinnt seinen Realitätsgehalt nur in der Selektion, Widerspiegelung und Verteilung von un- 
terschiedlichen Intensitätsgraden lebensweltlicher Realität. In Geld, Glauben, Macht oder anderen »Medien« der Kommunikation transformiert sich der Realitätsgehalt von Lebenswelten in Formeln, Symbolen und Bildern. Wir sprechen hier von einer neuen Systemrealität (die derjenigen vorauseilt, die Jürgen Habermas noch reflektiert).

Unsere Überlegungen enden mit der Frage, wie wohl ein global ausgelegtes System der »Ordnung der Zeichen« als System der medialen Kommunikation auf die unterschiedlichen Realitätsgrade der praktischen Lebenswelten der Massen in Erster und Dritter Welt reagieren mag. Wir kommen zu dem Schluß, daß auch dieses System von den Intensitätsgraden der eingespielten lebensweltlichen Realitäten abhängig bleibt. Lebenswelt, will sie überleben, wird sich so verhalten müssen, daß ihre Realität vermittelbar, im »System « einspielbar wird (ein neues Nullsummenspiel der Formeln, der Zeichen, der Bilder, ein neues Nullsummenspiel oder ein Spiel der summierten Nullen, wie Nietzsche [1969 IV: 786] das noch meint).

In der Kulturanthropologie, ebenso wie in den verschiedenen Spielarten marxistischer Diskussion über Kultur, beherrscht die Idee einer Doppelstruktur der Kultur die Vorstellungen über den kulturellen Formationsprozeß. Sie findet ihren Ausdruck in den in ganz verschiedenen Kontexten gebrauchten Begriffspaaren, wie etwa »little and big tradition « (Robert Redfield), »erste und zweite Kultur « (Lenin), »Religion und Volksglaube (deutsche Volkskunde); wir finden ihn auch wieder in den in Soziologie und Ethnologie häufig gebrauchten Paarungen wie Alltagsleben und Institution, Lebenswelt und System.

Hier soll der Zustand der Lebenswelten städtischer und ländlicher Gemeinschaften in der Dritten Welt mit dem kulturellen Konflikt in Verbindung gebracht werden, der in vielen Peripherie-Gesellschaften heute offen zutage tritt. Dabei sollen jedoch die Bedingungen praktischen Lebens in den »modernen « Industriegesellschaften nicht ganz aus dem Blickfeld geraten; im Gegenteil, sie sind mit denen in den Peripherien auf das engste verbunden. Gerade in den Zentren der Weltgesellschaft stellt sich zunehmend die Frage nach dem Realitätsgehalt einer Kategorie, die auf Zusammenhänge praktisch erfahrbarer Intersubjektivität zielt, von denen wir jedoch wissen, wie unzweifelhaft sie Systembezüge widerspiegeln, ja eben auch selbst in sich tragen. Im konsumistischen Alltag der modernen Massenkultur scheinen prakti- 
sche Lebenswelt und »hohe Kultur« aufgehoben und versöhnt. Hier vollzieht sich die Verbrüderung des »Reiches der Freiheit« mit demjenigen »der Notwendigkeit« auf eine ganz banale Weise.

Lenins Vorstellung von »zwei Kulturen« innerhalb einer Nation kennt solche »Versöhnung « noch nicht; sie steht noch ganz im Zeichen des »Widerstands«, ja stärker noch, der systematischen Formierung von Widerstand.

In ganz spezifischer Weise wird Widerstand heute jedoch mit jenem Aufstand der Dörfer und Städte der Dritten Welt signalisiert, der sich so ganz aus der Kultur des Alltags, im Massenwohngebiet etwa, herausentwickelt und organische Zusammenhänge einer Lebenswelt aktualisiert, die noch in traditionellen, vorindustriellen Vergesellschaftungsmustern verankert scheint.

Der Kulturkonflikt der Dritte-Welt-Gesellschaften stellt sich dem Außenstehenden zunächst als nationaler Konflikt von widerstreitenden Ideen der kulturellen Orientierung einer Gesellschaft dar. Mit neuen Mitteln wird dabei aber auch um die alte Frage nach dem rechten, dem gerechten Leben und nach dem praktischen Überleben gestritten, um Probleme, die wir oft als »universelle« bezeichnen.

Wenn wir von kulturellen Orientierungen einer Gesellschaft reden, so meinen wir damit im allgemeinen jene Formen, in denen die religiösen, die rechtlichen und politischen Verhältnisse eines Landes in ganz spezifischer Weise - etwa gegenüber denjenigen anderer Länder - sich herausbilden. Daß sie sich gegen die nivellierenden, differenzierenden und regulierenden Kräfte eines ökonomisch-systemisch organisierten Weltzentrums durchsetzen können, mag einem programmatischen Systemtheoretiker wie Luhmann als eine Fehlentwicklung der Menschheitsgeschichte erscheinen. ${ }^{1}$

Daß Religion, Recht und Politik gegenüber der Ökonomie solche, gewissermaßen spezifizierende Bedeutung behalten, hat natürlich nicht mit ihrer, gegenüber der Ökonomie vergleichsweise beschränkenden d.h. eben nicht universalistisch angelegten - Regelungsmöglichkeit zu tun. Ihre Kraft ziehen diese restriktiven Regelungssysteme offensichtlich aus einer Restkategorie, die systemisch nur schwer auflösbar scheint. Wir umschreiben diese soziale Restkategorie mit dem inzwischen gängig gewordenen Begriff der Lebenswelt: eine raumzeitliche Ordnung der unmittelbaren Produktion und Konsumtion zur direkten 
Befriedigung von Bedürfnissen und ihrer symbolischen Besetzung, Umgestaltung und Verteilung im Verhältnis zu den großen Strukturen sozialer Ordnung.

An die Tradition jener Aufklärung anknüpfend, die noch die Emanzipation des Geistes von den Institutionen verlangte, zielen wir auf die soziologische Grundlegung von Strategien der Dekolonisation von Lebenswelten im heutigen Weltsystem. Dabei müssen jedoch Prozesse der Kolonisierung gleichermaßen reflektiert werden. Wir nähern uns diesem Vorhaben in drei Argumentationsschritten:

Anknüpfend an die Diskussion über Volkskultur und zweite Kultur wird zunächst das Argument entwickelt, daß Volkskultur eine Widerstandskraft erst als »zweite Kultur « gewinnt, d.h. als Kultur der bewußten Vertretung materieller Interessen gegenüber systemischer Kolonialisierung. »Zweite Kultur«, die Kultur des Widerstandes, wird hier jedoch anders als bei Lenin als eine in den Bindungen der Lebenswelt ruhende und aus dieser heraus entwickelte Widerstandskraft definiert. Lebenswelt bildet damit den Hintergrund materieller und symbolischer Produktion der Volkskultur ebenso wie der aus ihr wachsenden Widerstandskräfte.

Daraus folgt ein zweites Argument: Lebenswelt ist nicht nur kognitiv vermittelte Alltagsstruktur, als die phänomenologische Ansätze und in deren Folge auch Habermas sie vornehmlich begreifen; Lebenswelt hat einen eigenen ökonomischen Kern. Wir stellen diesen ökonomischen Kern in der Folge als den für die Lebenswelten der Dritte-Welt-Gesellschaften bestimmenden Faktor dar: es ist dies die Verbindung von Subsistenz- und kleiner Warenproduktion einerseits und den sich um diesen Kern herumgruppierenden sozialen Beziehungen andererseits.

Schließlich beschäftigt uns ein drittes Argument: Lebenswelt ist auch ein Konstrukt in den Köpfen der handelnden Subjekte, das eine doppelte Bedeutung gewinnt. Einerseits ist es die eigentliche »Umwelt « auf die sich die nichtökonomischen Regelungssysteme (Politik, Recht, Religion) beziehen, andererseits ist es symbolischer Bezugsrahmen für den Umgang der Subjekte miteinander. Auf der Ebene von Politik, Recht und Religion wird die systemische Radikalisierung virtuell destruierter Lebenswelten betrieben, während auf der Ebene intersubjektiven Handelns der Mythos einer Idylle entsteht, der an dem 
Bild längst aufgehobener Strukturen der Lebenswelt haftet. Lebenswelt wird zum Bildbezug, wird zu einem System, dessen Regelungsleistungen sich weitgehend über die Verteilung von Bildern vermittelt.

Das »Projekt der Moderne« verkümmert so in einem System, das seine Modernität in der »Intensivierung von Realität« durch »Repräsentanz « wie immer praktisch gestalteter Lebenswelten erhält. Das moderne System erfordert nicht Rationalisierung der Lebenswelt, sondern die Behauptung derselben in der systemischen Bildsprache.

Es ist gerade diese Form der Repräsentanz mit der die »Realität« der Aufstände der Dörfer und Städte der Dritten Welt Eingang in die Bildsprache finden, die die Dritte-Welt-Gesellschaften zu den wahren Gesellschaften der Moderne werden läßt.

\section{Erste und zweite Kultur}

»Es gibt zwei Nationen in jeder modernen Nation ... Es gibt zwei nationale Kulturen in jeder nationalen Kultur « (Lenin).

Nach marxistischer Auffassung sind die gesellschaftlichen Klassen Träger der kulturellen Prozesse; alle im Kapitalismus vertretenen Klassen haben ihre eigene Kultur sowie entsprechende Verhaltens- und Artikulationsweisen ausgebildet. Sie sind intentional gebunden; sie dienen entweder den Herrschenden zur Aufrechterhaltung ihrer Hegemonie oder den Unterdrückten zur Herausbildung des Widerstandes. Nach Lenin sind diese Kulturen auf die jeweils andere bezogen; sie sind Ausdruck des Klassenantagonismus. ${ }^{2}$

Die erste Kultur lebt im Bereich der kulturell-ideologischen Institutionen, die über Konsensstiftung auf die Reproduktion der Produktionsverhältnisse zielen. Sie ist das kulturelle Referenzsystem zur Begründung der Hegemonie der Bourgeoisie.

Demgegenüber ist die zweite Kultur Ausdruck der Existenz einer unterdrückten Klasse und ihres Aktivitätspotentials. Für sie ist Gramscis Definition von Kultur angebracht als »Organisation, Disziplin des eigenen Ichs, Besitz der eigenen Persönlichkeit, als Eroberung des Bewußtseins, mit dessen Hilfe es gelingt, den eigenen geschichtlichen Wert zu begreifen, die eigene Funktion im Leben, die eigenen Rechte und Pflichten»(Gramsci 1967: 24). Gramsci versteht zweite Kultur als Ausdruck der praktischen Lebenszusammenhänge unter- 
drückter Klassen und ihrer im Widerstand bewußten symbolischen Repräsentation.

Widerstand ist nicht nur eine politische Kategorie, sondern in erster Linie Selbstverwirklichung unter den Bedingungen der Repressionen. Peter Weiss (1978) und ähnlich Baudrillard (1983: 42f.) haben die Anpassung der unterdrückten Klassen als Selbstaufgabe beschrieben, Widerstand dagegen als notwendige Bedingung einer »Vertiefung des Sinnes« durch »Aufhebung des Scheins « und damit als Motor der zweiten Kultur.

Der Kampf zwischen erster und zweiter Kultur innerhalb der ideologischen Institutionen (dem kulturellen Kernbereich bzw. der societa civile) ist nach Gramsci der Kampf um die Hegemonie, um Herrschaft und um geistige und moralische Führung. Damit stellt sich ein neues Problem: das der Unterscheidung von moralisch-geistiger Führung und von Herrschaftslegitimation.

\section{Zum Doppelcharakter kultureller Hegemonie}

Der Kampf um Hegemonie hat seit Gramsci seine Arena gewechselt: von der Welt der politischen Ökonomie zur Ebene der symbolischen Repräsentanz. Die Globalität der Konflikte, die Transnationalität politischer Allianzen und die Universalität der Formen symbolischer Repräsentanz haben diesen Kampf seiner strukturalen Determinanten entledigt. Damit hat er sich seiner ursprünglichen ökonomischen Referenz entledigt, sich selbst totalisiert. Innerhalb der Industriegesellschaften sind die Klassenunterschiede verwischt und ihre Gegensätze verschleiert. Gorz' Metapher vom »Abschied vom Proletariat« (1980) hat ihre Vorläufer in Marcuse und dessen Rezeption durch die Studentenbewegung Ende der sechziger Jahre. Auf der Suche nach dem systemsprengenden, revolutionären Potential wurden damals die Massen der entprivilegierten und verarmten Bevölkerung der Dritten Welt »entdeckt«. Der Ruf nach dem Aufstand der Dörfer (in den Städten und) gegen die Städte, spiegelte den damals vorherrschenden Glauben wider, die sozialen Utopien, die in den pauperisierten Dorfgemeinden ruhen, könnten ein reales Potential der Systemüberwindung darstellen.

In den Dritte-Welt-Gesellschaften hatte sich der Hegemonie-Anspruch des Staates nur bedingt auf alle Schichten der Bevölkerung bezogen, da die Massen in Marginalisierung, Entrechtung, Ghettoisie- 
rung und Pauperisierung für den Formationsprozeß nationaler Staaten in der Dritten Welt politisch und kulturell bedeutungslos waren. Die Dörfer haben sich inzwischen jedoch in ganz anderer Weise gegen die Städte formiert: Der Spiegel ihrer eigenen »Lebenswelt«, der ihnen in den Reden der Politiker und den Medien vorgehalten wird, staatliche, unter dem Druck internationaler Agenturen vorgenommene Maßnahmen der ökonomischen Integration, die Zerstörung subsistenzorientierter Ökonomieformen und das allgemeine Aufbruchsklima, dessen der moderne Konsumismus zu seiner Durchsetzung bedarf, all dies sind Vereinheitlichungs- und Verbindungselemente, unter deren Druck bei gegebenen Anlässen Aufstände der moralischen Verteidigung »des Brotes und der Ehre« organisiert werden. ${ }^{3}$ Diese Aufstände haben sehr materielle Ursachen, aber sie haben auch eine symbolische Repräsentanz, die in die Waren- und Medienwelt aufgenommen und dort »durchgespielt« wird.

Sind diese neuen Bewegungen, sind diese spontanen Aufstände, sind diese Rückbezüge auf die "Ehre des Menschen« und die »Heiligkeit der Religion « Ausdruck einer zweiten Kultur, Ausdruck einer Widerstandskultur, mit der praktische, reale Lebenszusammenhänge bewußt verteidigt und symbolisch repräsentiert werden? Ein solcher Begriff der »zweiten Kultur « ist nicht identisch mit dem der Volkskultur, Alltagskultur oder proletarischen Kultur.

"Zweite Kultur « in diesem neuen Sinn ist ein Bewußtsein von Unterdrückung, das aus der Verbindung einer besonderen gesellschaftlichen Praxis resultiert: aus Lebensbedingungen und -weisen, die aus der Verbindung von Zusammenleben und Zusammenarbeiten entstehen.

Die »Dörfer « haben eine solche Einheit aber nur im Spiegel, den ihnen die konsumistische Medienwelt vorhält. Vereinheitlicht erscheinen sie aus der Perspektive des Staates, der ihnen neue Regelungs- und Abgabesysteme oktroyiert. Bauern und kleine Warenproduzenten verhalten sich in ihren Arbeitszusammenhängen noch in der Illusion der Kontrolle und Beherrschung ihrer Erfahrungswelt. Wenn zweite Kultur, wie wir von Puls (1979: 178ff.) erfahren, als Widerstand und Protestform erst dann entstehen kann, wenn Vereinheitlichung und Zusammenfassung der Menschen, sowohl am Arbeitsplatz als auch im Bereich der Nicht-Arbeit, zusammenfallen, so fehlt den Dörfern der Dritten Welt gerade der sie vereinende, aus ihrer Erfahrungswelt heraustretende Aspekt der sozialen Kommunikation. Zwar bestimmen die 
Gesetze der Gemeinschaft die Formen der Freizeit ebenso wie die Formen der Organisation der Arbeit und des häuslichen Lebens; das Leben, das zwar nicht im eigentlichen Sinn individuell ist, bleibt jedoch andererseits an die Bedingungen und die Grenzen der Gemeinschaft gebunden. ${ }^{4}$

Die unbedingte Notwendigkeit einer arbeitsbezogenen, einer in der über die lokalen Zusammenhänge hinausreichenden Arbeitswelt entwickelten Kultur als Grundlage von Protestverhalten und Widerstandspotential stellt auch die Sozialgeschichte der angelsächsischen Arbeiterklasse heraus. Dort wo, wie Stedman-Jones (1979: 345ff.) herausarbeitet, die arbeitsbezogene Kultur allmählich einer heim- und herdorientierten Kultur Platz macht, verschwinden alle äußeren Formen einer zweiten Kultur. Den Dörfern der Dritten Welt bleiben solche Erfahrungen heute entweder erspart (so zynisch sich dieses anhört) oder sie werden auf den individuellen Migrationspfaden in eine fremde Arbeitswelt vergessen und verdrängt. Die Formation der Dörfer in den neuen Aufständen entbehrt also dieses Zusammenhanges der zweiten Kultur.

Wo liegt dann das eigentliche Resistenz- und Widerstandspotential der Dorfgemeinden?

\section{Zweite Kultur als Strategie des praktischen Konflikts}

Zweite Kultur bezieht sich in dreifacher Weise auf kulturelle Praxis: Das Individuum steht in einem unmittelbaren Verhältnis zur Natur, zu den Dingen als seinem »Laboratorium «, und dieses Verhältnis determiniert in großem Maße die Form, in der es seine materiellen Bedürfnisse wie Nahrung, Kleidung, Wohnung etc. befriedigt. Einen weiteren Bereich geben jene Beziehungen an, mit denen das Individuum in ein praktisches Verhältnis zu anderen Individuen tritt: Verwandtschaftsbeziehungen im weitesten Sinne, ebenso wie Beziehungen, die sich aus der räumlichen und sozialen Bindung des Zusammenlebens ergeben. Die symbolische Umsetzung, die Produktion von Bildern, von Riten, von übersinnlichen Erfahrungswelten bilden einen dritten Bereich »produktiver « Tätigkeit.

Die intersubjektiven Beziehungen und die vielfältigen Verbindungen, die Individuen auf der Ebene dieser drei Bereiche eingehen, belegen wir hier mit dem Begriff der Lebenswelt. In der Unmittelbarkeit dieser Bindungen und Beziehungen, ihrer praktischen, utilitaristischen 
Philosophie des Alltags, in ihrer Kompaktheit als vorgestellte Tradition und in ihrer unendlichen Moral der Tat und des Leidens sehen wir nun in diesen praktischen Lebenszusammenhängen selbst, in diesen kleinen Territorien der intersubjektiven Kommunikation, einen »whole way of conflict « (E.P. Thompson), einen Widerstand als »way of life«, der sich in erster Linie als Selbstverwirklichung und Selbstidentifikation in einer unmittelbaren Umwelt begreift. Es ist dieser »way of life «, der eine lokale Tradition z.B. mit der »rough-music « (Katzenmusik) verteidigen läßt, wie Thompson dies am Beispiel der englischen Unterschichten des 18. Jahrhunderts beschreibt (Thompson 1980: 130-168). Sider gibt uns mit dem »christmas mumming (Weihnachtsmummenschanz) der kanadischen Fischer ein weiteres Beispiel der symbolischen Repräsentation der Resistenzen lokaler Traditionen (Sider 1976: 102-125). Ginzburg (1979) liefert uns eine Beschreibung der Welt eines Müllers im 17. Jahrhundert, in der sich Elemente einer christlich-offiziellen Kultur mit einer heidnisch-häretischen Volkskultur mischen und sich in dieser Form, wenn zwar verdeckt, so doch nicht minder bedrohlich, gegen die herrschende Hegemonie richten. Zweite Kultur, so lautet die These, ist zunächst und zuallererst Verteidigung des »way of life«, Verteidigung der praktischen Lebenszusammenhänge einer intersubjektiven, einer materiellen Kultur, ist Ausdruck einer spezifischen, von den gesellschaftlichen Individuen selbst kontrollierten Umwelt.

\section{Die materielle Welt der sozialen Integration}

\section{Der materielle Kern der Lebenswelt als Objekt des ökonomischen Systems}

Lebenswelt ist intersubjektiv beherrschender Raum! Er ist kognitiv vermittelt; die Generations- und Regenerationsfunktionen lebendiger Arbeitskraft, die in diesem Raum gewissermaßen transhistorisch organisiert bleiben, bezeichnen aber auch einen eigenständigen ökonomischen Kern. Je nachdem, wie dieser »Kern« verwertet wird, ändert er seine reelle Bedeutung. Am deutlichsten wird dies etwa in der Funktion lokaler Haushalte für die »run-away industries « in der Dritten Welt oder etwa für den computergesteuerten Einsatz von Heimarbeit in Süditalien. Andere Beispiele sind die Rollen, die Bauernhaushalte 
für die Industrialisierung spielen (Proto-Industrialisierung/Migration). Der »entdinglichte K Kleinbürgerhaushalt der Doppelverdiener zeigt eine andere, eine wahrhaft »proletarische « Funktion. Die virtuelle Auflösung und Bedrohung dieses Kerns durch systemische Integration (etwa durch »Entdinglichung des Haushalts«) (vgl. Schiel/Stauth 1981) oder eben durch systemische Auslagerung (etwa durch »Substitution«), korreliert offenbar mit dem Bedürfnis seiner bildhaften, ja seiner idealisierten Verteidigung.

Je »ärmer« die Lebenswelt, um so »reicher« die Formen ihrer ideologischen Verteidigung. Volkskultur, die Erzeugungsformel symbolischer Verteidigung des praktischen Lebens, ihrer materiellen Basis enthoben, wird ideologisch und verliert ihr Widerstandspotential.

\section{Rationalität und Systemreferenz}

Für Habermas ist der faktische Zustand der Entweltlichung von Lebenswelt eingebunden in rein rationale Systemprozesse; die ökonomische und administrative Rationalität überfordert die »sinnlich zentrierten zeitlichen und räumlichen Kapazitäten der Lebenswelt« (Habermas 1979 I: 27). Während Habermas die Verödung der kommunikativen Kapazitäten der Lebenswelt beklagt und dafür vor allem Prozesse der Monetarisierung, der Bürokratisierung und der Verrechtlichung in allen privaten und formellen Handlungsbereichen verantwortlich macht, während er in der Rationalisierung die systemisch induzierte Verdinglichung von Lebenswelt konstatiert und auf Verteidigungsstrategien sinnt, hat sich die komplexe Gesellschaft längst schon als System der totalen Kommunikation, als System präformierter und digital verteilter Kommunikation über Medien »vervollkommnet«. Innerhalb eines so zum Regelformalismus sich ausdifferenzierenden Systems sind Realbezüge nur mehr Referenzbezüge zur Verteilung symbolischer Ordnungen, zur endlosen indeterminierten Reproduktion simulativ eingespielter Wertreferenzen.

Während Habermas das System noch als »real« erlebt und damit lebensweltliche Verteidigungs- und Widerstandpotentiale zu aktivieren sucht, die »auf die Eindämmung formal-organisierter zugunsten kommunikativ-strukturierter Handlungsbereiche gerichtet sind « (Habermas 1981a II: 578), ist das System längst seiner eigenen »Hyperrealität« erlegen und läßt kommunikativ und kognitiv erfahrbare Räume 
gar nicht mehr zu. Alles ist schon - wie Baudrillard schreibt - »der reinen Objektivität überlassen, einer Objektivität, die endlich vom Objekt befreit ist« (Baudrillard 1982: 114).

\section{Praktische Lebenswelt als »Überlebensökonomie «}

Habermas faßt unter dem Begriff der Lebenswelt eine soziale und kulturelle Einheit, die den systemischen Zwängen insofern widerspricht, als sie sich nicht nahtlos in diesen auflösen läßt. Der von Habermas unterstellte Widerspruch von System und Lebenswelt enthält die These vom Gegensatz zwischen Ökonomie und Interaktion, deren materielle Bezugspunkte nicht berücksichtigt werden. Lebenswelt ist auf Kognition unterschiedlicher Räume und Zeiten reduziert. Lebenswelt wird so selbst zum systematischen Element. Dagegen halten wir an einer Marcuseschen Perspektive fest, die die Widerstandspotentiale aus der Unmöglichkeit der Trennung geistiger und materieller Produktivität begründet und in der Produktivität des Individuums den eigentlich unauflöslichen Kern praktisch lebendigen Arbeitsvermögens sieht (Marcuse 1967: 85, 178).

Der Erfahrungszusammenhang, in dem die Notwendigkeiten des Alltags zu regeln, in dem ein praktisches Nützlichkeitsprinzip und Überlegungen der Zwecke und des Kalküls zu entwickeln sind, hat eine eigene ökonomische Seite. Bourdieu hat dies in seinen Untersuchungen zur kabylischen Kultur herausgestellt und theoretisch reflektiert als Aufhebung der Dichotomie von ökonomischen und nichtökonomischen Handlungen (Bourdieu 1979: 356).

Im Kontext der materiellen, der praktischen Lebenswelten ist Arbeit immer

»lebendige Arbeitskraft, die

1. nicht zum Zwecke der Verkäuflichkeit entsteht,

2. nicht von ihrem Eigentümer zu trennen ist und

3. nur durch ihren Eigentümer in Bewegung gesetzt werden kann.«

(Offe 1979: 315)

Solche Produzenten erfahren »Unmittelbarkeit«. Ihnen scheint es, als übten sie die faktische Kontrolle über ihre eigenen Arbeitsbeziehungen aus, als seien diese faktisch zweckhaft nur von ihnen organisiert. Diese Unterstellung von Autonomie ökonomischer Handlungen wird 
auf der Ebene der Kultur des Alltags symbolisch repräsentiert. Diese Form individualisierter Ökonomie ist ein direkter Umgang mit Menschen und Dingen; sie wirkt lebensweltgestaltend, indem sie Ressourcen bereitstellt. Die Formen sozialer Integration bleiben so weitgehend an die Bedingungen der unmittelbaren Reproduktion angebunden. Sie werden so selbst zu zweckhaften, zu für den materiellen Lebenszusammenhang bedeutungsvollen »rationalen $\ll$ Mustern der Lebensgestaltung.

Die spezifische Bedeutung lebensweltlicher Ökonomie ist in besonderem Maße durch den Begriff der Subsistenzproduktion angesprochen. Diese Form der Produktion zum Zwecke der unmittelbaren Reproduktion und des unmittelbaren Konsums ist im Kapitalismus in Haushalten organisiert. Die strukturelle und ökonomische Dynamik, die sich zwischen der Institution des Haushalts und den systemischen Formen kapitalistischer Akkumulation ergeben, sind in jüngeren Untersuchungen stark betont worden. ${ }^{5}$

Die kapitalistische Deformierung bzw. Neuschaffung subsistenzorientierter Formen der häuslichen Produktion zielt auf die Einsparung von Reproduktionsleistungen durch das Kapital, auf die Externalisierung von Reproduktionskosten (vgl. Meillassoux 1976).

Subsistenzproduktion ist nicht bloß individualisierte Ökonomie: Gebrauchswertorientiert und subsistenzbezogen sind auch jene Verteilungselemente, die in den lokalen Vernetzungen eingebunden bleiben. ${ }^{6}$

Somit wird auch die kleine Warenproduktion zu einem Bestandteil des sozialen Integrationsprozesses im Kontext unmittelbarer Intersubjektivität. Die praktisch ökonomischen Zusammenhänge des materiellen Alltags, der materiellen Lebenswelten, sind in Handlungsmuster einbezogen, weisen in sich spezifische Regelungszusammenhänge auf, die, wie Bourdieu (1979) sagt, sich von großen ökonomischen Systemen unterscheiden. Gehlen hat ihnen ein »Ethos der Gegenseitigkeit« zugeschrieben (Gehlen 1979: 47ff.), dessen Moralität vom Ziel der praktischen Überlebenssicherung getragen ist. Die Binnenstrukturen praktischer Lebenswelten weisen eine Tendenz zur Abschottung nach außen und zur inneren Kohäsion auf. Dies wird auch auf der Ebene der symbolischen Repräsentanz deutlich: Lebenswelten sind intersubjektiv geteilte Erfahrungs- und Sinnwelten. Gesten, Farben, Muster etc. konstituieren einen symbolischen Sinnzusammenhang, der von 
den agierenden Individuen gleichermaßen akzeptiert wird. Berger/ Luckmann betonen die Integrationskraft »symbolischer Sinnwelten « und die ihnen zugrundeliegende kollektive Anerkennung, mit der »Alltagsrollen, Prioritäten und Prozeduren « geordnet und geregelt werden. Darüber hinaus vermitteln Symbole dem Individuum Gefühle der Sicherheit und Zugehörigkeit (Berger/Luckmann 1980: 106).

Wenn die Vernetzungen der subsistenz- und gebrauchswertorientierten Produktion als Überlebenszusammenhang der Individuen die Grundlage der sozialen Integration bilden, gewinnt der Begriff der Lebenswelt als eigene soziale Kategorie seine eigentliche Bedeutung. Mit ihm sind dann die Konstitutionsbedingungen sozialer Gemeinschaft umschrieben, die einerseits an erfahrbare Reproduktionszusammenhänge der Arbeitskraft gebunden, andererseits den vielfältigen Regelungsmechanismen der großen ökonomischen und politischen Systeme unterworfen sind. Diese sozialen Einheiten stellen das System vor das dauernde Problem ihrer Kontrolle. Unter systemischen Gesichtspunkten erweisen sich diese Sozialmilieus als »unregierbar « (Offe 1979: 313ff.). Als »inkapsulierte soziale Territorien « sind sie gewissermaßen nur als Ganzes gegenüber dem System repräsentierbar.

\section{Dritte Welt und der Nihilismus des Systems}

\section{Die neue "Irrealität des Systems}

Das Szenario, das Jean Baudrillard (1982) in Anspielung und Kritik post-strukturalistischer Theorie als eine neue Stufe der Systemrealität entwickelt (in seinem Zynismus allerdings gleich wieder auflöst), ist in den Habermasschen Termini nicht mehr zu beschreiben. Nach Baudrillard erliegt das System seiner eigenen »Hyperrealität«, die darin besteht, daß sie nicht mehr referentiell, nicht übertragend, daß sie undeterminiert ist (Baudrillard 1982: 9ff.). In einer so vorgestellten Systemrealität gibt es keine Territorien mehr, auch keine kognitiv zu fassenden Territorien der Selbstfindung, aus deren Repräsentanz heraus noch Konflikte auf der Basis kollektiver Willensbildung zu lösen wären. Das Szenario der Baudrillardschen Systemrealität heißt Totalität der Manipulation und Simulation. In diesem Szenario erweist sich »Befreiung « (und damit auch Selbstfindung) nur als Übergang zu einer neuen, allgemeineren Manipulation.

Lebenswelt wird selbst zum simulativen Modell, ist Simulation, 
Schein, Imagination. Die körperlich praktische Entfaltung des Individuums in seiner unmittelbaren Umwelt entsteht - weil faktisch nicht mehr vorhanden - nur als Bild. Gerade die Dritte-Welt-Gesellschaften, in denen die Utopie einer praktischen Lebenswelt unter den Bedingungen zunehmender Verelendung eine noch größere Bedeutung besitzt, zeigen uns in den Zentren die neue Systemrealität. Hier wird ganz unverblümt mit den »spielerischen « Möglichkeiten des Realen umgegangen; »intakte " Lebenswelten und lokale Gemeinschaften werden inmitten einer sozialen und ökonomischen Wüste als blühende Oasen bildhaft illusioniert und ideologisch verteidigt. Die Imagination, diese freche Simulation von Lebenswelt, erweist sich als neuer Dreh in der Spirale systemischer Integration.

Die Zeichen- und Bilderwelt des Konsumismus als Vehikel des Systems hebt die Einheit der gesellschaftlichen Individuen auf, splittet die soziale Gemeinschaft in eine neue Privatheit, fördert den Subjektivismus scheinbar autonomer Persönlichkeiten und setzt hedonistische Motive frei, die die moralischen Grundlagen solcher Gemeinschaft abund entwerten.

Der symbolische Charakter der Lebenswelt und die in ihm angelegten Steuerungs- und Regelungskapazitäten werden entzaubert. Die neue Permissivität eines so hergestellten Nebeneinanderlebens hat den Vernutzungsstrategien der großen Organisationen von Staat und Industrie nichts mehr entgegenzusetzen. Die Binnenstruktur der Lebenswelt sozialer Gemeinschaften zerbricht. Die Lebenswelt wird einer inneren Rationalisierungsdynamik beraubt; sie wird (von außen) rationalisiert. Damit verkümmert die gesamte Substanz der Lebenswelt einschließlich der an die spezifischen Formen der lebensweltlichen Kultur angebundenen Überlebensökonomie. Virtuell von außen rationalisiertes und formalisiertes Alltagsleben, kulturelle Verarmung und der Sieg der Organisation über die lokale Moral verhindern die notwendigerweise auf Konsens aufgebauten Verständigungsprozesse zwischen den Individuen, zerstören die intersubjektiv anerkannten Werte und Orientierungen, ersetzen sie durch die Wundermacht der neuen Sozialregulationen: der Allmacht der Welt der Ware und der mit ihr einhergehenden Modernisierung der Alltagspraxis.

Die Zeichensprache der Massenkultur baut sich so selbst gewissermaßen als simulierte Lebenswelt auf: Dem Individuum rekonstruiert sich der praktische Lebenszusammenhang als symbolische Besetzung 
von Umwelt und als imaginärer Reflex, als Produktion von Bildern über Lebenswelt. Lokale Gemeinschaften sind so als die eigentlichen »small territories « lebensweltbezogener Bildproduktion zu betrachten.

\section{Praktische Destruktion und bildhafte Rekonstruktion von Lebenswelt}

Unter den Bedingungen der externalisierten Reproduktionsstruktur der Dritte-Welt-Gesellschaften als einer spezifischen Form der Weltmarktintegration werden sowohl der Herrschafts- als auch der ideologische Apparat des Staates zu »Agenturen « systemischer Steuerungsmechanismen: Die Erschließung von Märkten und die Etablierung neuer Mediensysteme sind von externen, internationalen, westlichen »Symbolwelten « geprägt. Die Lebenswelten der lokalen Gemeinschaften spielen in diesen Systemen eine außerordentlich untergeordnete Rolle. Die kulturelle Repräsentanz der Tradition lokaler Gemeinschaften wird damit destruiert. Die Erosion moralisch-kultureller Werte wird durch eine neue phantastische Zeichen- und Bilderwelt, die Zeichen der Medien- und Warenwelt, eingeleitet. Den konsumistischen Imaginationen der neuen Massenkultur, den Illusionen der Regelung einer neuen Lebenswelt in Zeichen und Bildern, haben die praktischen Wertorientierungen des Alltagslebens wenig entgegenzusetzen.

Dabei sind es gerade diese praktischen Wertorientierungen des Alltagslebens, die nie wahrgenommene und akzeptierte kulturelle Repräsentanz der Graswurzelebene, eben die konkreten Konstitutionsmerkmale von Lebenswelt und lokaler Gemeinschaft, die jetzt zum Tragen kommen. Lebenswelt wird zur Ressource moderner Bildproduktion; dort, wo mit Sicherheit keine lebensweltlichen Regungen mehr wahrgenommen werden, läßt System das Hologramm einer Lebenswelt entstehen, das seinem Original nur gleicht, aber alltagspraktische Umsetzung nicht mehr ermöglicht.

\section{Lebenswelt als Ressource moderner Bildproduktion ${ }^{8}$}

Alles ist austauschbar. Der Politiker wird zum »local hero «, der Manager aus der Waffenschmiede zum "good fellow « von nebenan, der Kapitalist zum romantischen Verteidiger von Tradition und Natur.

Die begriffshistorische Konstruktion der Trennung von Lebenswelt und System setzt zugleich deren reale Trennung in moderner Gesell- 
schaft voraus. Beide, so macht uns soziologische Theoriegeschichte deutlich, stehen in gegenseitiger Referenz zueinander - beide bedingen die Reproduktion sozialer Systeme.

Die Genese des Systems moderner Massenkommunikation und dessen »Produktionen « dagegen zeigt uns eine andere Seite: es ist nicht mehr die theoriegeschichtliche »Wahrheit « sich aufeinander beziehender, in Abhängigkeit voneinander stehender Bereiche, deren Aufgaben fest definiert sind und deren soziologische Topographie bekannt ist; es ist vielmehr die generelle Vertauschbarkeit der Referenzbezüge: lebensweltlich oder systemisch, gesellschaftlich oder privat, real oder imaginär, praktisch oder symbolisch - alles ist austauschbar bei gleichbleibender Aussage. So entsteht die »Agonie des Realen « aus Bildern und Phantasmagorien, die das System produziert, verteilt und als Realität bestimmt. Alles, was wir unter unmittelbarer lebensweltlicher Perspektive sehen und noch als »soziales « Handeln gegen System zu begreifen versuchen, erweist sich längst als systemisch gesteuert durch die Imagination von lebensweltlicher Realität: individuelle, gruppenbezogene, klassenbezogene, gemeinschaftsbezogene und lebensweltverteidigende Aktionen, die soziales Handeln anstelle von subjektlosem Funktionieren favorisieren, sind längst in diesem Determinismus der Systemreferenz eingebunden. Das Reale hat sich schon in systemische Zeichensprache transformiert, bevor es noch »sich selbst « zu einem Begriff hätte drängen können, sich selbst hätte behaupten können. So wird gesellschaftliche Realität, die wir als unmittelbare Erfahrung, als geteilte Unmittelbarkeit und intersubjektiv anerkannte Lebenswelt begreifen, zur Quelle systemischer Bildproduktion: System bedient sich der Lebenswelt als Ressource, aus der heraus es seine Bilder schöpft - die Bilder, die wir sehen möchten: Arbeit, Leben, Liebe, Wahrheit. Lebenswelt, die nur noch als Ressource dient, quasi als Ideenreservoir für die Bildproduktion des Systems, in der sie selbst die Regie ihrer eigenen Imagination übernimmt, ist dabei natürlich auch schon Schein und Bild und hat sich im »Massengrab der Zeichen« verloren.

Andererseits: Das System bedarf der Referenz; die systemischen Einspielungen von Bildern entstehen erst im Kampf um das Reale, in der simulativen Besetzung des Realen. Somit ist nicht mehr das faktische Vorhandensein von Lebenswelt, sondern nur ihre simulative Erzeugung, die Erzeugung von Lebenswelt als Schein, die Systemrefe- 
renz. System erzeugt sein lebensweltliches Pendant selbst. Die Referenz ist nicht mehr lebensweltliche Realität, sondern systemisch produzierte Imagination. In dieser artifiziellen Repräsentanz des Realen ist die Realität praktischer Erfahrung des tätigen Individuums längst aufgehoben, dem Individuum aus der Hand genommen und an die systemische Ordnung gebunden. Lebenswelten werden auch damit ihres materiell-territorialen Zusammenhanges entledigt, werden selbst zu Schauplätzen der von außen eingespeisten Bildproduktionen, auf denen die agierenden Individuen selbst nur noch als Repräsentanten solcher Bilder und gesetzer Bildsprache erscheinen. Diese Einspielungen gründen sich auf den Mythos einer realen Lebenswelt. Sie setzen sich um, indem einerseits die einstige Praxis als Idylle erscheint und andererseits diese Idylle radikal verteidigt wird. So wird nicht nur einstige Realität in ihrer Idyllisierung simuliert, sondern sogar noch die Verteidigung des Scheins organisiert. Dies ist wahrhaft System in seiner perfidesten Form: es gaukelt uns eine soziale Realität vor und läßt diese Imagination von den $Z$ weiflern noch radikal verteidigen als Beweis lebensweltlicher Existenz.

Beide Formen der Bildproduktion, die Idyllisierung von Lebenswelt einerseits und die Radikalisierung des Mythos' der Lebenswelt andererseits, drücken zwei unterschiedliche Formen der Systembesetzung aus. Die idyllisierende Bildproduktion, die anheimelnde Zuweisung von Lebenswelt, dient durchweg der Verteidigung vor dem längst vorhandenen Zugriff des Systems. Dabei greift System schon gar nicht mehr nach Lebenswelt, sondern spielt selbst den Angriff, damit wir uns in radikaler Verteidigung ergehen, wo nichts mehr zu verteidigen ist. Die Verteidigung der Idylle, die idyllische Bildproduktion und die damit einhergehenden Absicherungen des produzierten Bildes auf der Ebene der Politik, des Rechts und der Religion dienen der Stabilisierung. Nur in diesem Drang zur Stabilisierung sind die in DritteWelt-Gesellschaften offen und oft pervers zutage tretenen Fetischisierungen der Lebensweltbezüge in Behauptungssprache zu erklären. Nirgendwo wird die Idylle der »community « höher gehalten als in den Amtsstuben der nationalistischen und sozialistischen Staaten der Dritten Welt, die sich längst zu Agenturen der modernistischen Massenkultur ausgeprägt haben. Diese Fetischisierung, dieser Mythos des gerechten, des materiellen, des praktischen Lebensweltbezuges eröffnet gerade die Möglichkeit radikaler Verteidigung als Überhöhung und 
Sublimierung der gerechten Ordnung. Die in den neuen sozial-religiösen Bewegungen der Dritten Welt entwickelten Bildproduktionen der Radikalisierung und Sublimierung des Lebensweltbildes stellen somit eine neue, eine andere Form der systemischen Transformation dar, mit der die politischen, rechtlichen und religiösen Systemeinspielungen benutzt werden, um neue Intensitäten der Verteidigung des Lebensweltbildes zu schaffen.

Das Bild des Imam Khomeini, einst die Gerechtigkeit der islamischen Lebenswelt symbolisierend, produzierte so eine andere Intensität der systemischen Einspielung als jene Idylle islamischer Lebenswelt, wie wir sie in den Bildern saudi-arabischer Scheichs dargestellt finden, die ganz aus dem Bestand systemischer Bildproduktion und -besetzung kreiert worden sind. In der Realität des Systems, in der Ordnung der flottierenden und undeterminierten Zeichen, verlieren sich die Bildproduktionen als austauschbare. Bilder gewinnen ihre Intensität dann, wenn sie leben, überleben, gerechtes Leben symbolisieren. Mediensprache ist szientifizierte, ist Expertensprache. Bilddesign, Bildfolge und Bildgeschwindigkeit heben das Zeichen aus dem praktischen Zusammenhang, in dem es geboren wurde.

Gerade in der Intensität ihrer Systemeinspielung unterscheiden sie sich jedoch außerordentlich: Die iranische Einspielung erschien getragen von den Massen systemisch Ungesicherter als Vertiefung von Sinn, während die saudi-arabische sich lediglich als professionelle, als ritualisierte, als verteidigende Einspielung erweist. Als systemische Einspielungen stellen sich beide Formen der Bildproduktion als Zeichen dar, die an den Sinn von Lebenswelt anknüpfen. In der Idylle, so könnte man anspielend auf ein Wort von Habermas sagen, verknappt sich allerdings die Sinnressource Lebenswelt. In ihrer symbolischen Radikalisierung dagegen erfährt sie ihre Erfüllung, ja Vertiefung. Den Realitätsgehalt, die Sinnvertiefung, erfährt die Bildproduktion im systemischen Außenbezug. Die aus dem Ausschluß ins System hineinwirkenden Intensitäten setzen sich noch ganz gegen systemische Aufhebung durch. Der Schador hatte bis zur Iranischen Revolution keinen systemischen "Sinngehalt«, stellte sich noch nicht als geronnenes Zeichen und damit als akzeptiertes Anagramm in der Systemsprache dar, so wenig wie das Bild des Arbeiters vor seiner Produktion mit der Entwicklung der Arbeiterbewegung. Es sind die Bilder als die historisch geronnenen Zeichen, als die mit ungeheueren Intensitäten des Reali- 
tätsbezugs und der Sinnvertiefung systemisch eingespielten Bilder, die Kulturen, Klassen, Rassen, Gemeinschaften, Gruppen, letztendlich Individuen $\mathrm{zu} »$ Partnern im System« oder $\mathrm{zu} »$ Feinden des Systems machen. Das Bild vietnamesischer Bauern, war es einmal produziert, $d$. h. zugleich auch systemisch eingespielt, war es, das die amerikanische Kriegsmaschine besiegte.

Lebenswelt bleibt so eine Ressource moderner Bildproduktion. In ihr formiert sich der Mythos sozialer Praxis, aus dem die Bildproduktion des Systems ihre Referenz schöpft. Wehe jenen Lebenswelten, die sich als zu »knappe Ressource« moderner Bildproduktion erweisen!

\section{Die Dritte Welt als "moderne «ebenswelt}

Die neue Systemrealität fordert Repräsentationen von Lebenswelt, die in die dominante Sprache der Zeichen, Bilder und Formeln umsetzbar sind. Realität vermittelt sich hier als Abbild oder als Scheinbild, das der Sprache des Systems genügt. In den Inszenierungen der modernen, universellen Massenkultur wird praktische Lebenswelt simuliert. In der Systemsprache - in der flottierenden Bild-, Formel- und Zeichenfolge, wie Baudrillard das noch sieht - hebt sich jedoch zugleich noch jede Referenz zwischen System und Lebenswelt aus den Angeln: nicht was "gesprochen « wird ist wichtig, sondern $d a \beta$ "gesprochen " wird.

Die Dritte-Welt-Gesellschaften sind auf solche Simulation und Nicht-Referenz auf das Beste eingestellt. Das einst in kolonialer Herrschaft sich repräsentierende System zeichnete sich gegenüber den praktischen Lebenswelten der Massen ohnehin durch Nicht-Referenz aus. In dieser Hinsicht entspricht die »moderne "Systemrealität eben auch den ganz praktischen Vorstellungen von "System « unter jenen Völkern, deren Kultur so systematisch unterdrückt wurde. Sie haben gelernt, ganz »souverän« damit umzugehen. Während wir, die Modernisten, der »Entweltlichung der Lebenswelt « (Jaspers) nachtrauern, während wir unsere Ideen von Befreiung und Emanzipation in den Verwirrspielen des Systems in Zeichen der Manipulation verdreht sehen, während wir noch unser bloßes Dasein als »rationalisierte Lebenswelt« im System zu erhöhen suchen, spricht dieses schon mit einer ganz anderen Sprache. Die Dritte Welt ist dieser Sprache offenbar in ganz originärer Weise mächtig.

Das »going native « der »natives « ist bewußte, dem System vor- und nachgespielte Lebensweltreferenz, die bildhaft eingesetzte Lebenswelt- 
Idylle als Simulation des Realitätsgehalts praktischer Lebenswelt. Was wirklich Sache ist, das spielen wir dann, wenn wir »unter uns « sind. Daß dieses "unter uns « erhalten bleiben soll, daß das System hier abgeschaltet wird, das ist das eine, die reelle Seite von systemischer Auslagerung und Unterentwicklung. Daß »wir uns « auf den Realitätsgehalt, die Ordnung des jeweiligen Systems einstellen müssen, das ist die andere Seite, das hat »uns « der Kolonialismus gelehrt. So spielen »wir« die »Dritte-Welt-Menschen«, Tradition, Nation, Rasse, Religion, »wir« spielen Ökonomie, ja Krieg spielen wir auch, vor allem aber spielen wir Wissenschaft und Moral, weil das System es verlangt. Verantwortung übernehmen wir dort, hinter den Kulissen im Dickicht lebenspraktischen Interesses oder in Verteidigung der praktischen Lebenswelt.

\section{Anmerkungen}

1 Vgl. die Habermassche Diskussion eines Artikels von Luhmann über »Die Weltgesellschaft« (1971), in: Habermas (1976: 112ff.).

2 Zur Kritik dieser rein klassenantagonistischen Perspektive, wie sie etwa noch in Lukács Anbetung der Maschinerie als Solidaritätserzeuger in der Arbeiterklasse ihren Höhepunkt fand, vgl. Berger (1975).

3 Über den ursächlichen Zusammenhang solcher Aufstände mit einem sogenannten Subsistenzlimit vgl. etwa Scotts Ausführungen (1976) sowie Moore (1982), die beide die »moralischen« Ursachen von Widerstand und Rebellion beleuchten.

4 Über die Einheit von Arbeit und Freizeit im Alltagsleben vgl. Lefèbvre (1977: 37-51).

5 Vgl. hierzu Arbeitsgruppe Bielefelder Entwicklungssoziologen (1979), weiterhin Smith/Wallerstein/Evers (1984) und Stauth (1983a) Kapitel 6.

6 Vgl. hierzu Meyers (1983), Ulshöfer (1983), Stauth (1983b).

$7 \mathrm{Zu}$ den »small territories « vgl. Benedict (1966).

8 Vgl. Baudrillard (1983); Lyotard (1979) sowie die Diskussion in »Tod der Moderne«(1983). 



\section{Foucaults Abenteuer im Iran ${ }^{\mathrm{I}}$}

\section{Ideen als politische Ereignisse studieren}

Es ist an sich erstaunlich, daß Foucault die während des Iran-Projekts gesammelten Erfahrungen und die in seinen »Reportagen « entwickelten Vorstellungen über Islam, Revolution in "geistloser « (sprich religionsbeladener) Zeit und in einem peripheren Land in seinem wissenschaftlichen Euvre nicht weiter verfolgt und nicht weiter verarbeitet hat. Man darf dennoch annehmen, daß die vor allem im »Corriere della Sera « und im »Nouvel Observateur « erschienenen Reportagen über die islamische Revolution im Iran einigen Einfluß auf das Spätwerk Foucaults hatten. Sicherlich beeinflußten sie auch die ersten sozialwissenschaftlichen Interpretationen und Studien zum islamischen Fundamentalismus.

Gegenstand des vorliegenden Essays sind die »reportages des idées «, mit denen Foucault die iranischen Ereignisse begleitete. Hier sollen einige Parallelen zu seiner politischen Theorie aufgezeigt werden. Eine Studie der Wirkung, die diese Berichte auf die Soziologie des islamischen Fundamentalismus gehabt haben mögen, kann hier jedoch nicht vorgelegt werden.

Es ist behauptet worden, daß man Foucaults »infantilen Linksradikalismus « von seiner politischen Theorie trennen müsse (Walzer 1986). Ich teile diese Meinung nicht. Foucaults Interesse, unmittelbare Rebellion zu verstehen, ist in seiner Machttheorie ebenso präsent wie in seinen Reportagen über den Iran und seinen vielseitigen, oft auch nur pamphletistischen Interventionen in praktische Auflehnung. Im Iran suchte er, die Motive und Werkzeuge der sich als bloße Menschen im Aufstand begegnenden Massen zu untersuchen. Dabei blieb, wie ich zeigen will, seine politische Theorie der eigentliche Fokus des Interesses. Es ist dies der Versuch, als Ganzes zu verstehen, warum Menschen in bestimmten Situationen den Kampf der Unterwerfung vorziehen.

Man kann deshalb auch nicht von einem »Irrtum « Foucaults in der Beurteilung der iranischen Ereignisse sprechen, wie manche seiner Freunde ihm vorhielten. Foucault hat einen solchen Irrtum nie zugestanden. Und die Pariser Kollegen, die ihn gerne zu einem solchen $\mathrm{Zu}-$ geständnis bewegt hätten, haben die unterliegende theoretische $\mathrm{Ab}$ - 
sicht des Unternehmens mißverstanden. Sie sahen nur das scheinbar Offensichtliche: Foucaults Sympathie für den islamischen Aufstand. $\mathrm{Daß}$ sie Foucault so einstimmig verurteilten, hat sicher dazu beigetragen, daß die Texte, über die dieser Essay handelt, so gröblich vernachlässigt wurden. Die harte Kritik der Freunde aber blieb für Foucault eine Enttäuschung (vgl. Eribon 1989: 309-13; Rondeau et al. 1984: 19), und er selbst scheint das Iran-Projekt nach 1979 völlig von der Agenda gestrichen zu haben.

\section{Umfang und thematische Schwerpunkte des Projekts}

Drei Themenbereiche von theoretischer Reichweite markieren Foucaults Beschäftigung mit den iranischen Ereignissen. Erstens verfolgen die Reportagen eine Reihe von Themen, die sich auf das in »Überwachen und Strafen. Die Geburt des Gefängnisses« entwickelte Paradox von "physis « und Organisation beziehen oder auf die Frage der strukturellen Bipolarität des modernen Projekts menschlicher Herrschaft, wie Gordon (1980: 254) dies ausdrückt.

Zweitens sind eine Reihe von Themen dem spezifischen Verhältnis des Irans und des Islams zu hegemonialen Strategien gewidmet. Islam erscheint hier als ein Prozeß der Auflehnung eines unterdrückten lokalen Wissens gegen die etablierten hegemonialen Wahrheiten (vgl. Foucault 1980: 81f.; Taylor 1986: 95). Es ist der Islam, der Spiritualität als eine völlig neue, aus der Geschichte geschöpfte und in die Zukunft weisende, religiöse Technik der Formation der Macht von unten einführt. Hier ist bemerkenswert, daß der Begriff der Spiritualität im Werk Foucaults erst nach den iranischen Ereignissen eine gewisse Bedeutung gewinnt und in den Vorlesungen über eine Hermeneutik des Selbst dem politisch utopischen Kontext, den er in den Iran-Texten noch hat, weitgehend entzogen wird (vgl. O’Farrell 1989: 74, Fn. 28; Hacking 1986).

Drittens sind eine Reihe von Themen auf den Begriff der relativen Neutralität von Herrschaftstechniken bezogen, der gleichfalls in »Überwachen und Strafen. Die Geburt des Gefängnisses« entwickelt wird. Foucault betont die erfahrungslose Leere von Machtstrategien und Techniken der Herrschaft und spricht von der Anonymität und Absichtslosigkeit bestimmter Formen der Konstruktion von Macht. ${ }^{2}$

Im folgenden will ich zeigen, daß die Bedeutung der Reportagen 
über die revolutionären Ereignisse im Iran in der ungeteilten Aufmerksamkeit liegt, die Foucault diesen drei in seinem theoretischen Werk verankerten Themenbereichen und Ideen widmet.

\section{Das Unternehmen Iran}

Im Sommer 1978 formierte sich um Michel Foucault eine Gruppe von Journalisten und Intellektuellen, unter ihnen auch André Glucksmann und Allain Finkielkraut, mit dem Ziel, in einem journalistischen Unternehmen den Charakter der revolutionären islamischen Bewegung im Iran zu bestimmen (vgl. Eribon 1989: 299; CdS, 12.11.1978: 1). Das Projekt figurierte unter dem aufregenden Titel »reportages des idées «. Die Absicht war, den Ideen der gemeinen Menschen und von Minoritäten mehr Beachtung zu schenken als den offiziösen Ideen und Vorstellungen der Intellektuellen. Es galt, die Relevanz der Ideen von tätigen Menschen zu bestimmen, die nicht daran gewöhnt waren, Geschichte sprechen zu lassen oder besonders auf die Geschichte zu hören:

»Es gibt mehr Ideen auf dieser Erde als Intellektuelle sich möglicherweise vorstellen können. Und diese Ideen sind viel wirkungsvoller, stärker und widerstandsfähiger und leidenschaftlicher als >Politiker begreifen können. Es ist notwendig, bei der Geburt der Ideen und den Explosionen ihrer Formen dabei zu sein und nicht nur durch Bücher, die sie formulieren, sondern bei den Ereignissen, in denen sie ihre Macht manifestieren, bei den Kämpfen, die für oder gegen Ideen geführt werden.«

$(\mathrm{CdS}, 12.11 .1978: 1)$

Foucaults Untersuchungen über die Ideen der islamischen Bewegung im Iran des Jahres 1978 folgen keinem Muster akademischer Vorgehensweise oder methodologischer Reflexion und Praxis kulturübergreifender Forschung. Lediglich unter Mithilfe persischer Freunde in Paris, insbesondere von Ahmad Salamatian, der später zum stellvertretenden Außenminister aufstieg, aber bereits 1981 wieder ins Exil ging, wurde er eilig mit Literatur, Dokumentationen und einer Adressenliste von Kontaktpersonen ausgestattet (Eribon 1989: 300, 309). Man darf bei diesem Unternehmen eine gewisse allgemeine Faszination französischer Intellektueller für die exotische Vorstellungswelt der orientali- 
schen politischen Kultur unterstellen, wie sie etwa bereits in Montesquieus »Lettres persanes « bestens bezeugt ist. Doch Foucaults überhohes Interesse an den iranischen Ereignissen scheint eher auf die Anziehungskraft des besonderen Charakters dieser Volksbewegung und schließlich Revolution zurückzuführen zu sein. Daß Ideen - hier die religiösen islamischen Ideen eines Volkes -, deren historische Bedeutung so systematisch geleugnet wurde, die bewegende Kraft eines Volksaufstandes werden konnten, mußte untersucht werden und zwar im Kontext der gesellschaftlichen Ereignisse dort selbst:

»Es sind nicht Ideen, die die Welt leiten. Doch vielleicht gerade weil die Welt Ideen hat (und weil sie kontinuierlich eine Vielfalt von ihnen produziert) wird sie nicht einfach passiv von jenen geführt, die die Befehlsgewalt haben oder von jenen, die sie das Denken ein und für alle Mal lehren wollen.

Dies ist der Sinn, den wir diesen Reportagen geben wollen: wo die Analyse dessen, was man denkt, mit der Untersuchung dessen, was passiert, verbunden sein wird. Intellektuelle werden mit Journalisten an dieser Kreuzung von Ideen und Ereignissen zusammenarbeiten.«

(CdS, 12.11.1978: 1)

Es ist darauf hinzuweisen, daß für Intellektuelle das nostalgische Interesse an dem, was sich ereignet und an dem Charakter der verschiedenen gesellschaftlichen Erfahrungen in Zeiten der Volkserhebung oder Revolution, gewissermaßen eine natürliche Konsequenz, ja in vielen Fällen auch eine Bedrohung ihrer professionellen Existenz darstellt. Sie wollen dann oft ihre professionelle Distanz überwinden und jene Entfremdung gegenüber den wirklichen Kräften, die die Menschen bewegen, beenden. Foucault scheint hier von einem großen Druck und einer Art Neugierde bewegt gewesen zu sein, die historischen Anzeichen der Eruption unterdrückter Ideen unter den Menschen und die Formen ihrer Erscheinung in der gesellschaftlichen Wirklichkeit zu untersuchen.

Die methodologischen und konzeptuellen Vorüberlegungen des Projekts der »reportages des idées « scheinen dabei ganz bewußt auf die Interpretation des Zusammenhangs von dem, was Menschen denken, und von dem, was passiert, beschränkt gewesen zu sein. Dieses Ziel signalisiert natürlich in gewisser Weise eine Verabschiedung von professioneller Wissenschaft und von Forschung, die der strikten Dis- 
ziplin einer abgehobenen wissenschaftlichen Form Rechnung zu tragen hätte. ${ }^{3}$ Der besondere nichtakademische Charakter des Unternehmens rechtfertigt sich für Foucault aus der Form dessen, was untersucht werden soll: Die Zusammenarbeit von Intellektuellen und Journalisten wird in solchen Zeiten notwendig, in denen sich die Grenzen zwischen Ideen und Ereignissen überschneiden und sich neue Passagen zwischen ihnen öffnen.

Wenige Tage nach dem "Schwarzen Freitag", dem 8. September 1978, dem Tag des Massakers auf dem Jaleh Platz in Teheran, reiste Foucault zusammen mit Thierry Voetzel in den Iran. Die konkreten Vorbereitungen für diese Reise werden in Didier Eribons Biographie (1989: 298-309) kurz beschrieben, sie sind hier nicht von besonderem Interesse. Wir sollten jedoch vermerken, daß Foucault zwei sehr intensive, obwohl offensichtlich nur kurze Aufenthalte im Iran hatte: zuerst einen Aufenthalt von etwa einer Woche, Mitte September 1978 also; sodann einen zweiten Aufenthalt, der etwa Mitte Oktober 1978 begann, wobei die Umstände der Rückreise nach Paris offensichtlich im Dunkeln geblieben sind.

Alles in allem datieren Foucaults Auslassungen über den Iran aus der Zeit zwischen dem 28. September 1978 und dem 11. Mai 1979. Sie lassen sich in drei Kategorien unterteilen:

Erstens handelt es sich um die Reportagen, die in unmittelbarem Zusammenhang mit den jeweiligen Aufenthalten Foucaults im Iran in der Mailänder Tageszeitung »Corriere della Sera « oder im Pariser Wochenmagazin »Nouvel Observateur « erschienen sind (CdS, 28.9.; CdS, 1.10.; CdS 8.10.; NO 726, 16.10.1978, im Zusammenhang mit dem ersten Aufenthalt; CdS 7.11.; CdS 19.11.; CdS 26.11.1978 im Zusammenhang mit dem Aufenthalt im Oktober).

Zweitens haben wir die Reaktionen auf Leserbriefe und verstreute analytische Bemerkungen, die in der Zeit nach der Rückkehr vom zweiten Aufenthalt im Iran (sehr wahrscheinlich Ende Oktober 1978) bis zum Zeitpunkt des absoluten Verstummens über die iranischen Angelegenheiten nach dem 11. Mai 1979 datieren, also in eine Periode von 5 Monaten fallen (NO 731, 13.11.1978: 26; NO 753, 16.4.1979: 46; LMa 647, 26.4.1979: 15).

Drittens finden wir eine Reihe von Texten, die ebenfalls in die letztgenannte Periode fallen, aber aus einer Perspektive der Distanz die Ereignisse und die eigene Eingriffnahme reflektieren. Diese Notizen 
und Kommentare sind ganz offensichtlich stärker auf die eigene philosophische Perspektive abgestellt. Es handelt sich um die Aufzeichnung eines Gesprächs mit Claire Brière und Paul Blanchet, zwei Pariser Journalisten der Tageszeitung »Libération «, die Foucault bereits während seines ersten Iran-Aufenthaltes im September 1978 getroffen hatte. Dieses Gespräch wurde als Anhang im Iran-Buch von Brière und Blanchet (1979a: 227-241) publiziert. Hierzu gehören auch die Überlegungen zum Projekt der »reportages des idées « (CdS, 12.11.1978) sowie seine letzte Rechtfertigung des Projekts gegenüber seinen Kritikern (LM, 11.5.1979).

Obwohl Foucaults Betrachtungen zur iranischen Revolution keinen direkten Bezug zu den inneren philosophischen Fragen seines Werkes reklamieren und sicherlich auch nicht in einer Form gestaltet sind, die einen solchen Anspruch rechtfertigen könnte, ist es doch angebracht, darauf hinzuweisen, daß sowohl die Umstände der Vorbereitung der iranischen Expedition als auch der Versuch, die »Tiefe« (ein Wort das Foucault sicherlich zurückweisen würde) der Ereignisse zu beschreiben und zu reflektieren, die große "philosophische « Herausforderung anzeigen, die diese Revolution im Namen der Religion für ihn darstellte. Die Betrachtungen Foucaults zum Iran sind, wie der Rest seines Werkes, brillant geschrieben, und man mag darin einen Grund sehen, warum diese Texte - jenseits des akademischen Bannes, der sie traf so einflußreich geblieben sind. Die schicksalhaften Verflechtungen des Iran-Abenteuers mit dem akademischen Werk Foucaults lassen sich aber vielleicht am besten in der Tatsache erspüren, daß Foucault in der Mitte der Iran-Affäre im Collège de France einen Vortrag für den 10. Januar 1979 ankündigte, der den Titel »Bio-politique« trug, sich also mit der Darstellung eines aus dem 19. Jahrhundert herrührenden Herrschaftskonzepts beschäftigte (NO 738, 30.12.1978-7.1.1979: 13).

\section{Die Entkörperung der Institutionen: Der Schah, die Armee und die Mullahs}

Journalistische Reportagen eines Philosophen unterscheiden sich möglicherweise auf den ersten Blick nicht sehr vom herkömmlichen Journalismus. Sie müssen, anders als eine Philosophie, die sich der Umdeutung der historischen Grundlagen des Prozesses der ganzen westlichen 
Zivilisation verschreibt, der Breite des Zeitungslesertums zugänglich bleiben. Foucaults »reportages des idées « bilden hier keine Ausnahme. Wie viele, die damals über den Iran schrieben, scheint Foucault sich auf den ersten Blick vor allem mit der logischen Konsistenz der den Institutionen des Schah-Regimes verbliebenen Strategien des Machterhalts zu beschäftigen. Zugleich behandelt Foucault aber auch die organisatorische Logik der islamischen Volksbewegung.

Hier werden beim näheren Hinsehen bereits Parallelen zu seiner in »Überwachen und Strafen« entwickelten Analyse des »Ancien Régimes" und des Begriffs der Herrschaft traditioneller politischer Or-

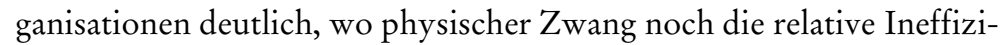
enz, die Mikrobedingungen der Herrschaft in den Orientierungen individuellen Verhaltens zu kontrollieren, auszugleichen, ja zu ersetzen hat (vgl. hierzu Dreyfus / Rabinow 1982: 126ff.).

Foucaults erster Bericht erschien im »Corriere della Sera« (CdS, 28.9.1978) ${ }^{4}$. Er handelt von der Rolle der Armee in der persischen Gesellschaft. Hier sind seine Beobachtungen über den »Körper« der Armee von Bedeutung: Unter dem Gesichtspunkt der organisatorischen Konsistenz unterscheidet er zwischen internen (Offiziere und Soldaten) und externen (Gesellschaft, Alltag) Formen der Legitimation. Dies bleibt jedoch im Rahmen journalistischer Standards, denn insbesondere in Zeiten sozialer Unruhe haben Fragen nach der Stabilität oder möglichen Erosion der Sicherheitskräfte eine klare Priorität. Im Kontext der verschiedenen späteren Berichte wird jedoch deutlich, daß Foucault hier mit einem allgemeineren Problem des Verhältnisses zwischen Alltagsbeziehungen der Menschen und den Zielen, der Logik und der Konsistenz, sowohl sich auflösender als auch sich formierender institutioneller Kräfte, hier das Regime des Schah, dort die losen Kommunikationsstrukturen der Mullahs, beschäftigt ist (vgl. die Artikel in CdS, 7.11.1978 und NO 726, 16.-23.10.1978: bes. S. 49). Diese Themen sind mehr oder minder direkt in Foucaults Philosophie eingebaut und bedürfen deshalb genauerer Betrachtung.

Der erste Iran-Bericht beginnt mit einem Versuch, die verschiedenen Reaktionen der Politiker, der Armee und der Massen auf das Erdbeben in Tabas und auf das Massaker vom »Schwarzen Freitag «, dem 8. September 1978, wiederzugeben. Man wird durchaus an prophetische Worte erinnert, Worte, die zumal vom exilierten Ayatollah Khomeini hätten stammen können, wenn man die folgenden Passagen liest: 
»Die Erde, die bebt und Dinge zerstört, kann in der Tat das Volk vereinigen, doch sie teilt die Politiker und läßt die Gegner als unversöhnliche erscheinen. Das Regime denkt, daß es die Schicksalhafigkeit der Natur umgehen und einen Umweg um den großen Schrecken der Massen machen kann, die durch die Massaker des Schwarzen Freitag zwar geschwächt, aber nicht entwaffnet wurden. Es wird keinen Erfolg dabei haben. Die Toten von Tabas stehen in einer Reihe mit den Opfern auf dem Jaleh Platz; sie vermischen sich mit ihnen.«

(CdS, 28.9.1978: 1)

In dieser spannungsgeladenen Situation, wo der Tod eines Muslims durch die Hand eines anderen Muslims mit einem Mythos beantwortet wird (»e risposto con uno mito«), stellt Foucault sich die Frage, warum die persische Armee nicht die Macht der politischen Intervention hat. Er stellt sich diese Frage vor dem Hintergrund der spezifischen historischen, geopolitischen und ideologischen Bedingungen des Landes: Erstens besteht die Armee nicht aus einem einheitlichen, kohärenten Organismus, sondern aus vier von einander getrennten Körperschaften, die alle dem Schah unterstehen. Diese sind: (1) die traditionelle Armee, die sowohl für die administrative Kontrolle des Territoriums als auch - eine Folge der »Weißen Revolution« des Regimes - für öffentliche Arbeiten zuständig ist; (2) die Palastgarde des Schah, eine geschlossene Körperschaft, Relikt der orientalischen Geschichte; (3) die kämpfende, mit den besten Waffen ausgerüstete Truppe; schließlich (4) die amerikanischen Berater, deren Anzahl Foucault auf etwa 30.00040.000 schätzt (CdS, 28.9.1978: 1). In seiner Beschreibung dieser Organisation betont Foucault zweitens die Intensitäten formalisierter militärischer, technologischer und kontrollierender Macht, die letztendlich nur eine geringe Sensibilität gegenüber spezifischen lokalen und sozialen Bedingungen entwickelt.

Der hohe Grad organisatorischer Formalisierung einerseits bedingt andererseits einen Mangel an praktischen und ideologisch begründeten Zielen. Die ungeheure technologische und organisatorische Wirksamkeit der Armee scheint in Ermangelung eines äußeren Feindes auf die militärische Kontrolle des eigenen Volkes gerichtet zu sein und dabei zugleich den geopolitischen und strategischen Interessen einer fremden Hegemonialmacht, der USA, zu unterliegen.

Ohne der persischen Militärgeschichte größere Aufmerksamkeit zu 
schenken, behauptet Foucault drittens, daß die Armee in ihrem modernen Konstitutionsprozeß über keine Geschichte politischer Intervention verfügt habe, die als ideologischer Bezugspunkt für politisches Handeln dienen könnte. Viertens stellt der offene Anti-Marxismus der Armee keine "physische « Opposition gegenüber einer Volksbewegung dar, die nach Foucault selbst über keine klare moderne Ideologie verfügte. Foucault sprach mit zwei hochrangigen Offizieren, die sich selbst zur Opposition zählten. Dabei konnte er beobachten, daß der Anti-Kommunismus der Armee nicht an sich zur entschlossenen $\mathrm{Zu}-$ rückweisung des von unten entwickelten Volkswillens führte. Indem sie sich der Opposition anschlossen,

»hatten sie bald die Gelegenheit zu entdecken, daß sie es nicht mit dem internationalen Kommunismus zu tun hatten, sondern daß alles nur mit dem Mann auf der Straße zu tun hatte, den Händlern des Bazars, den Angestellten und den Arbeitslosen, so als wären es ihre Brüder oder sie selbst, wenn sie keine Soldaten geworden wären.«

(CdS, 28.9.1978: 3)

Es ist die organisatorische, technologische und ideologische Leere, die die Armee so empfänglich für die politischen Gefühle des Volkes machte. Politische Manipulation, fremde Strategien und die Widersprüche der internationalen Szene haben in der Armee eine institutionelle Körperschaft ohne »physis « hinterlassen. Foucault zeigt, wie wenig wirksam die beschworene Loyalität zum Herrscher blieb und wie die Erosion der »Ideen « zum Entstehen einer neuen »physis « beitrug, die sich an den Ideen der islamischen Volksbewegung orientierte. ${ }^{5}$

Es gibt eine Reihe weiterer kontrastierender Aspekte des Arguments, daß der Prozeß der Erosion institutioneller Macht gewöhnlich mit dem Fehlschlag, über »Ideen« zu verfügen, einhergeht:

»So scheint die Armee selbst nicht über die Macht politischer Intervention zu verfügen. Es ist wahr, daß der Schah nicht ohne sie sein kann, aber die Armee selbst ist von Kräften belagert oder vielmehr von innen her paralysiert worden, die den Schah bedrohen. Die Armee kann eine Lösung zulassen oder verhindern. Aber sie kann weder eine Lösung aufzwingen noch eine entwickeln, außer derjenigen, die sie in sich selbst finden könnte. Sie ist mehr ein Schloß als 
ein Schlüssel. Und von den zwei Schlüsseln, die vorgeben, sie zu öffnen, scheint zur Zeit nicht der amerikanische Schlüssel des Schah der passende zu sein. Es ist der islamische Schlüssel der Volksbewegung.«

(Ibid.)

In seinem Bericht vom 7.11.1978 veranschaulicht Foucault den Prozeß der Auflösung institutioneller Macht anhand von zwei Beispielen: der Schah und die Mullahs. ${ }^{6}$

Welche strategischen Reaktionen auf die unkontrollierten und vielleicht sogar manipulierten Ausbrüche der Militanz und des Vandalismus unter den Teheraner Studenten sind seitens des Schah möglich? Auf den ersten Blick scheint er über die »Idee der Ordnung « zu verfügen, und das verschafft ihm möglicherweise den Vorteil internationaler Unterstützung im Osten wie im Westen. Darüber hinaus könnte dies die Armee veranlassen, zu seinen Gunsten zu intervenieren. Doch unter Hinweis auf das Ausmaß der Mobilisierung der Massen verwirft Foucault den Gedanken, daß die »Idee der Ordnung « allein überhaupt noch eine Option sein könnte, mit der die gesellschaftlichen Körperschaften noch zu inspirieren gewesen seien. Von hier schließt er, daß es dem Schah unmöglich sein wird, seine frühere Autorität wieder herzustellen. Seine Verteidigungsposition bleibt strategischer Natur und versetzt ihn deshalb nicht in die Lage, die Körperschaften der Regierung in ihren Operationen wieder miteinander und mit der Gesellschaft zu verbinden.

»Sollte diese Kalkulation des Souveräns aufgehen, wäre es nötig, daß das Land so unbeweglich bleibt, wie es Teheran gestern morgen war. Die Armee, oder zumindest ihr sicherster Teil, ist in der Lage, die großen Städte zu beherrschen, aber kann sie das über das ganze Land hinweg tun - ich meine damit nicht nur das ganze Territorium, sondern auch die Masse der Bevölkerung.«

(CdS, 7.11.1978: 2)

In einem weiteren Schritt wird jedoch erkennbar, wie die Intervention der Armee diese selbst für den politischen und religiösen Willen des Volkes, das seinen Widerstand fortführen konnte, empfänglich machte. Hier verband sich die Idee der Ordnung selbst mit den Ideen der Menschen in den Straßen, die zunehmend sich Bewußtsein darüber 
verschafften, daß das System von ihren eigenen tätigen Ideen abhängig wurde.

Gelegentlich taucht ein drittes Beispiel auf: die in seiner abschließenden Verteidigung wieder aufgenommene Vorstellung, daß diese Revolution, die seine ungeteilte Begeisterung fand, sich in ein Mullah-Regime verwandeln könnte. ${ }^{7}$ Er drückt dies in einem Vergleich der leeren Rhythmen des Schreckens und Strafens aus: auf der einen Seite die Folter der Savak, auf der anderen Seite das Blutvergießen und Schlachten der Strafmaßnahmen der Mullahs. Foucaults Dialektik der organisatorischen »Körper «, die er in der Analyse des Aufstiegs und Zerfalls institutioneller Macht im Verlauf der iranischen Ereignisse verwendet, bleibt insofern ambivalent, als er die Vorstellung des »omnipotenten Regimes « mit derjenigen eines Aufstands eines "Volkes ohne Waffen« miteinander in Einklang zu bringen sucht. Er weigert sich, den Aufstieg des neuen Mullah-Regimes mit dem ewigen Gesetz der Revolutionen zu erklären, daß die Tyrannei, die bereits mit dem blinden Enthusiasmus insgeheim verbunden war, nun aufs neue auferstehen könnte. Für ihn stellte die iranische Revolution etwas ganz Neues, etwas ganz Spezifisches dar:

»Die Spiritualität, die jenen zugesprochen wird, die starben, steht in keinem Verhältnis zum Blutvergießen einer von rigiden fundamentalistischen Klerikern geführten Regierung. Die religiösen Iraner wollen ihr Regime durch die Bedeutung, die ihm durch den Aufstand gegeben wird, authentisch machen. Wir würden uns in unserer Argumentation nicht von ihnen unterscheiden, wenn wir die Tatsache des Aufstands nicht würdigten, nur weil es sich heute um ein Mullah-Regime handelt. In einem Fall wie im anderen gibt es >Angst<. Angst vor dem, was im letzten Herbst sich im Iran ereignete und was die Welt seit langem nicht mehr als Beispiel erlebt hat."

Hier wird eine spezifisch orientalische Dimension der Deutung der Ereignisse klar, als wäre es jene "Spiritualität « gegenüber den Toten des Aufstands, die den iranischen Fall vor dem allgemeinen Gesetz der Dialektik von Plebs und Formation institutioneller Macht retten sollte. Hier ließe sich gewissermaßen am Rockschoß eine neue Revolutionstheorie jenseits der Spirale zu immer neuer Formation institutioneller 
Macht ergreifen, eine Theorie, die aus dem gewohnten Dualismus von Individuum und Gesellschaft, Plebs und Institution herausspringt. Mit dem Begriff der Spiritualität wird eine neue Form der Subjektivierung der Macht verbunden, die in sich keine Genealogie trägt und deshalb den westlichen Rahmen der Motivationsbildung durch neue individuierte Netzwerke der Macht ersetzen sollte. Diesen Zipfel einer neuen revolutionären Utopie zu ergreifen, war jedoch für die Freunde in $\mathrm{Pa}-$ ris ebenso zuviel wie für die Massen in Teheran.

\section{Verkörperte Ideen: Die politische Spiritualität des Islams}

Sein erster französisch-sprachiger Bericht aus Teheran (NO, 16.10.1978) ist nicht einfach nur eine Zusammenfassung der zuvor in Italienisch veröffentlichten Artikel, wie Eribon meint. ${ }^{8}$ Foucault stellt hier den Islam, die Stärke religiöser Ideen und ihre mögliche politische Funktionsweise in den Vordergrund. Wenn es ein westliches Vorurteil ist, orientalische Regime grundsätzlich des Mangels der funktionalen Trennung zwischen politischer Macht und religiösem Charisma zu bezichtigen, so geht Foucault diesem Vorurteil insofern aus dem Weg, als er das konventionelle Bild des Königs als eines Heiligen in das Bild des gegen den Schah revoltierenden Propheten transformiert.

»Die Situation im Iran scheint sich in eine große Spannung zwischen zwei die traditionellen Symbole repräsentierenden Persönlichkeiten aufzulösen: der König und der Heilige, der König in Waffen und der entwaffnete Mann im Exil; der Despot mit einem Mann vor ihm, der unter dem Applaus der Nation sich in bloße Hände kleidet. Dieses Bild hat eine natürliche Anziehungskraft, aber es verschleiert eine historische Realität, die durch Millionen von Toten besiegelt ist.«

(NO, 16.10.1978: 48)

Man könnte auch hier zunächst normalen Journalismus vermuten, denn wie Foucault waren viele andere Journalisten in diesem Stadium der Entwicklung der iranischen Ereignisse darüber beunruhigt, daß die Religion zu einer möglichen Quelle der politischen Erneuerung der politischen Regime im Nahen Osten werden könnte. Auch war bekannt, daß die Regierungen selbst den Islam strategisch als ideologische Waffe gegen den Marxismus einzusetzen versuchten. Man hat 
sich in den Sozialwissenschaften seit langem mit dem spezifisch modernen Status dieser Religion und besonders mit der Frage, ob der Islam einem westlichen Muster der Säkularisierung und Modernisierung folgen könnte, beschäftigt. Streitbare Orientalisten haben dagegen immer wieder auf die starken politischen Dimensionen des Islams hingewiesen. Foucaults Berichterstattung scheint hier auf den ersten Blick nur ein weiteres Beispiel der konventionellen Vorstellung vom Islam zu liefern. Doch führt Foucaults hier entwickelte Denkfigur über das, was die Iraner selbst meinen, wenn sie von einer »islamischen Regierung « sprechen, zu einer völlig neuen Formulierung der Beziehung von Religion und Politik: Man ist versucht zu behaupten, Foucault habe nach einer für ihn im Westen längst verloren gegangenen "politischen Theologie« »von unten « gesucht. Seine ganze Aufmerksamkeit richtet sich auf religiöses Verhalten und den Ausdruck religiöser Ideen der Massen auf den Straßen im Demonstrationsprozeß unmittelbarer politischer Aktion. Der in Zusammenhang mit dem russischen Gulag-System von 1917 entwickelte Begriff der »Plebs «als das einer jeden Unterwerfung und Revolte zugleich unterliegende $\mathrm{Maß}^{9}$ wird im Falle Irans mit dem unberechenbaren Faktor der religiösen Spiritualität ergänzt. Spiritualität wird hier zu einem Begriff, der in der Form der islamischen Volkserhebung zugleich die Realitäten des islamischen Alltagslebens zu identifizieren sucht.

Am deutlichsten wird Foucaults Sensibilität in bezug auf diese Konstruktion eines politischen Islams »von unten« - eine Denkfigur, die heute immer noch in apologetischer Absicht sowohl unter Islamisten als auch unter westlichen Sozialwissenschaftlern weit verbreitet ist - in seiner Antwort auf den kritischen Brief einer in Paris lebenden Muslimin. Sie warf Foucault vor, einem dem romantischen Orientalismus verhafteten Enthusiasmus über den Islam zu verfallen und dabei die lange Geschichte moderner Errungenschaften in den Gesellschaften des Vorderen Orients zu vernachlässigen (vgl. NO, 731, 6.11.1978: 27).

In seiner Antwort stellt Foucault den bloßen Fakt dagegen, daß Leute sich für die Idee einer »islamischen Regierung « töten lassen. Dies ist für ihn Anlaß dafür, »daß es ihm zu einer grundlegenden Aufgabe wurde, danach zu fragen, was der Inhalt ist, der diesem Ausdruck gegeben wird, und was die Kraft ist, die ihn belebt« (NO, 731, 13.11.1978: 26). 
Aber bedeutsam in diesem Zusammenhang ist für Foucault auch, daß wir sowohl die tausend Jahre alte Verunglimpfung der Muslime als Fanatiker ablegen als auch gegenüber jenen Okzidentalen kritisch sein müssen, die am Islam nur soweit interessiert sind, als sie ihre Verachtung für die Mohammedaner bestätigt finden. »Das Problem des Islams ist ganz wesentlich ein Problem unserer Zeit und für die Jahre, die noch kommen werden. Die erste Bedingung für eine Diskussion ist, auch wenn man nur über geringe Intelligenz verfügt, nicht damit zu beginnen, ihm mit $\mathrm{Haß}$ zu begegnen « (ibid.). Diese bemerkenswert strenge Zurückweisung eines Kommentars einer intelligenten und beunruhigten Frau bedarf der ungeteilten Aufmerksamkeit. Foucaults apodiktisches Urteil fußt auf der Annahme, daß der Gehalt der politischen Bewegung im damaligen Iran ausschließlich »islamisch « gewesen sei, und daß für ihn der schlagendste Beweis für dieses Phänomen in dem Grad lag, in dem die Massen bereit waren, den Tod in Kauf zu nehmen. Dies bleiben auch in den Berichten die beherrschenden Themen.

Wie oben bereits angedeutet versucht Foucault, die islamische Bewegung in einem Bild zweier Figuren aus der traditionalen Heraldik aufzulösen: der Heilige, der die Macht des Königs herausfordert. Ein Bild, das dann in den Widersprüchen der iranischen Geschichte als eine »Realität « aufgelöst wird, die durch die "Signatur von Millionen von Toten « besiegelt ist (NO 726, 16.10.1978: 26).

Eine zweite, vertiefende Anspielung auf die iranische Geschichte besteht darin, daß Foucault die Kräfte des heiligen Mannes in der Tatsache seiner Abwesenheit eher verstärkt sieht. Das Bild des alten Mannes, der einsam in Paris sitzt und von hier zu seinem Volk im Iran spricht, kann in verschiedener Weise inspirierend wirken. Es spielt auf eine wichtige Denkfigur Foucaults an: das abwesende Zentrum des Diskurses. Es bezieht sich aber auch auf einen Topos des schiitischen Glaubens: der verlorengegangene Imam, dessen Rückkehr erwartet wird. Auch wird der Hintergrund der Wirkungsweise der modernen Kommunikationsmedien deutlich, durch die diese Abwesenheit so zauberhaft aber zugleich so bestimmt und unmittelbar erscheint. Im Zentrum dieser spannungsgeladenen Beziehungen steht die Idee der »islamischen Regierung «. Was sind die Charakteristiken, mit denen sich dieser, zumindest für den westlichen Geist Ende der 70er Jahre so mysteriöse Begriff definieren läßt? 
Foucault folgt der vertiefend wirkenden Perspektive einer historischen Hermeneutik. Er setzt den Begriff der »islamischen Regierung « ganz wesentlich mit der verlorenen Vergangenheit in Bezug. Sie ist so die Repräsentation eines »Ideals «, das auf die Geschichte gebaut ist, und eine »Utopie« zugleich;

»etwas sehr Altes und etwas das weit in die Zukunft hineinreicht: zurückzugehen zu dem, was der Islam zur Zeit des Propheten war; aber auch voranzuschreiten hin zu einem leuchtenden und weit entfernten Punkt, wo es möglich sein sollte, Vertrauen wiederzufinden anstelle Gehorsam üben zu müssen.«

(NO 726, 16.10.1978: 49)

Die bloße Tatsache jedoch des revolutionären Ereignisses verlangt nach weiteren Kriterien, mit denen die Bedeutung von »islamischer Regierung « zu bestimmen wäre, vielleicht auch einen anderen Typ der Hermeneutik. Die Betonung liegt hier nicht mehr auf »Geschichte«, sondern auf der Dynamik sozialen Handelns.

»Auf der Suche nach diesem Ideal, so scheint es mir, fällt das Mißtrauen gegenüber dem Legalismus mit der Kreativität des Islams zusammen.«

Auf einer dritten Ebene versucht Foucault, die Rhetorik einer Eigentlichkeit zu entlarven, die den Begriff der »islamischen Regierung « unter Bezug auf westliche Werte zu erklären versucht, eine Rhetorik von interviewten Klerikern, Intellektuellen und Studenten, die einen authentischen Islam in Begriffen der Aufklärung erläutern will: Demokratie und bürgerliche Revolution als Ausdruck authentischer islamischer Werte und der Effizienz des Korans. Eine islamische Autorität erzählt ihm: »Islam bewertet die Arbeit; niemandem können die Früchte seiner Arbeit weggenommen werden; das, was allen gehört (Land, Wasser), kann nicht von irgendeinem angeeignet werden" (ibid.). Foucault bleibt dieser Rhetorik gegenüber außerordentlich kritisch und wendet ein, daß ein solcher Begriff der »islamischen Regierung « den Begriffen der Aufklärungsphilosophie des 18. Jahrhunderts in nichts nachstünde: »und wir wissen ja, wozu diese geführt haben «. Dennoch arbeitet er selbst am Authentischmachen der Begriffe von Demokratie und Revolution mit: 
»der Koran hat diese Prinzipien lange vor euren Philosophen verkündet, und wenn für den christlichen und industriellen Okzident ihre Bedeutung verloren gegangen ist, dann sollte der Islam da sein, um ihren Wert und ihre Wirksamkeit zu erhalten.«

Man mag unschwer erkennen, daß Foucault hier selbst einen eher symbolischen, wenn nicht rhetorischen Umgang mit diesen Begriffen pflegt, doch was ihn wirklich bewegt, ist die Unaufhebbarkeit der Tatsache der sozialen Akte, die jenseits der Islamisierung der Begriffe der Aufklärung vor sich gingen: Unter Hinweis auf die Straßenschlachten erkennt er, daß

»sie bei dem Risiko des Blutvergießens vielleicht doch noch etwas anderes in ihren Köpfen haben als diese politischen Formeln, die überall und nirgendwo gut klingen. Und etwas anderes in ihren Herzen: Sie denken, glaube ich, über die Realität als etwas, was ihnen sehr nahe steht, denn sie sind es, die die Handelnden in dieser Realität sind.«

Für Foucault ist die Idee »islamische Regierung « mit den mikroskopischen Anschauungen und Interessen der Massen im Alltag revolutionärer Aktion verbunden. Hier entdeckt er die »Spiritualität des Islams«, mit der er eine neue Qualität politischen Handelns verbindet. Es ist dabei nicht die Idee als solche, die ihn beeindruckt, sondern die Tatsache, daß sie einen politischen Willen mobilisiert, der

»eine Antwort auf wirklich existierende Probleme und ungelöste soziale und religiöse Strukturen darstellt; sie hat mich auch als ein Versuch beeindruckt, eine spirituelle Dimension in der Politik zu eröffnen.«

Foucault glaubt, hier etwas völlig Neuem auf der Spur zu sein, einer sozialen Konstruktionsform, die weder nur die Aussöhnung mit der orientalischen Vergangenheit noch mit ihrem okzidentalen Gegenbild sucht: das Ende einer nur strategisch begründeten Politik ohne Spiritualität! Hier suchte er nun selbst eine weit über die iranischen Ereig- 
nisse hinausreichende, in der aktuellen Auseinandersetzung mit Foucault heute fast vergessene politisch-philosophische Utopie:

"... in das politische Leben eine spirituelle Dimension einzuführen: zu begründen, daß das politische Leben nicht immer nur ein Hindernis für Spiritualität sei, sondern ihr Überleben garantiere, ihre Erscheinung, ihre Blüte.«

In seiner 1982 gehaltenen Vorlesung über Spiritualität wird jedoch der Begriff seines utopischen Gehalts völlig entleert. Foucault geht es hier um Praktiken der Subjektivierung oder, wie er es in einem Gespräch mit Dreyfus und Rabinow in einem schlagkräftigen Begriff ausdrückt, um Techniken des Selbst (Foucault 1984). ${ }^{10}$

Hier beschäftigt sich Foucault - scheinbar den utopischen Aspekt einer durch Spiritualität regierten menschlichen Gesellschaft vernachlässigend - ausschließlich mit Spiritualität als Prozeß einer sich in unterschiedlichen Stufen und Formen konkretisierenden Individuierung (Hacking 1986).

\section{Technologien der Macht von unten: Körper, Werkzeuge und ihre Netzwerke}

Im Lichte der religiösen, islamischen Zeichen der Zeit alleine kann nicht verstanden werden, warum die kollektiven Selbstdarstellungen, die in dieser Situation der äußersten Spannung und Unterdrückung sich Ausdruck verschafften - ganz anders als strukturierter kultureller Sinn, ja im Gegensatz dazu -, den Grund einer eigenen und vielleicht sogar tieferen Art des politischen Aufstands in "geistloser Zeit « darstellen. Wo Foucault die iranische Revolution losgelöst von ihrem lokalen Kulturkontext betrachtet, signalisiert sie für ihn einen neuen Typ der Revolution. Sie gilt ihm als

»der erste große Aufstand gegen das planetarische System, die am massivsten populäre und zugleich modernste Form des Aufstands.«

(CdS, 26.11.1978: 3) 
Um diesen neuen Typ der Revolution zu verstehen, bedarf es einer dritten Dimension in Foucaults analytischer Strategie. Ein sich wiederholendes Thema der Reportagen ist die absolute Selbstbestimmtheit der Massen in ihrem praktischen Kampf ohne Waffen und organisatorische Mittel, während sie zugleich einem überorganisierten staatlichen Unterdrückungsapparat gegenüberstanden. Die Frage, die Foucault hier am meisten bewegte, ist, wie die Menschen durch das bloße Riskieren ihres Lebens die organisierte Gewalt, die sie unterdrückt, entmachten können.

Foucault versuchte empirisch zu bestimmen, welche gemeinsamen Erfahrungen die Menschen, hier als »Plebs«, dort als organisierte Macht, in einem Raum machen, in dem sie die gleichen sozialen Technologien miteinander teilen. Der soziale Raum der Interaktion von Regierung und gemeinen Leuten war im Iran durch harte Unterdrükkungsmaßnahmen und Zensur der Medien gekennzeichnet, eine gemeinsame Erfahrung spezifischer Form vermittelnd. Aus dieser Erfahrung heraus ergibt sich die Möglichkeit des Umdrehens der Waffen, die Integration von Techniken und Kommunikationsmedien und ihre Vereinnahmung in eine innere, abgeschottete Logistik der Volksbewegung: des spezifischen Gebrauchs des Telefons, der Minikassetten, der Moscheen und der Gebete, des Einsatzes von Rechtsanwälten und der Treffen der Intellektuellen-Zirkel (CdS, 19.11.1978).

Für Foucault sind moderne Herrschaftsformen nicht so sehr durch Bürokratisierung gekennzeichnet als durch den Grad, in dem sie die politischen Techniken monopolisieren. Der Effekt dieser Monopolisierung ist, daß wenige der klassischen Organisationen den Massen unmittelbar zugänglich bleiben. Im Iran hatte dies zur Folge, daß neben dem ambivalenten Gebrauch der neuen Kommunikationsmedien den Massen nur noch die Demonstration der »Gefühle des Volkes « als eine politische Technik von unten verblieb. Für Foucault war die Revolution im Iran von 1978-79 ein Aufstand ohne Organisation, ohne Partei, ohne Avantgarde (vgl. Brière/ Blanchet 1979b; Foucault 1988a). Wo die Synchronisation der Gefühle einen Schlüssel zur revolutionären Aktion darstellt, liegt die Bedeutung unmittelbarer Verbindungen auf der Hand. Foucault versucht, dies in seinem Artikel »Rivolta con le mane nude«, »die Revolte mit den nackten Händen «, zu erklären. Er unterscheidet hier drei Paradoxien dieser Revolution, die einen völlig neuen Typus kennzeichnen: 
Erstens identifiziert er das Paradox des »entwaffneten Volkes mit bloßen Händen «, das gegen eines der bestausgerüsteten Regime der Welt kämpft. Die Revolution bezeichnet einen Prozeß der Entwaffnung des Regimes durch die unmittelbare Vermassung der Körper der Leute auf der Straße: der Aufstand einer entwaffneten Gesellschaft als Ganzes.

Als zweites Paradox beschreibt er, daß trotz der schrittweisen Integration der verschiedensten Schichten in die Bewegung keine Widersprüche zwischen den verschiedenen Gruppen entstanden. Die Ausweitung und Verallgemeinerung des Kampfes hat nicht zu neuen Antagonismen zwischen den verschiedenen sozialen Segmenten der Bewegung geführt. Alte und neue Oppositionsgruppen, Arbeiter und Händler, die Angestellten des Ölsektors und die Straßenverkäufer hielten zusammen.

Das dritte Paradox liegt in der Tatsache, daß der Mangel an weitreichenden Zielen sich nicht als ein Schwächefaktor erwies. Je mehr sich die Ereignisse häuften, zeigte sich, daß es eine Stärke der Bewegung war, daß es kein Programm für eine Regierung gab, sondern nur den politischen Streik gegenüber einem etablierten System (vgl. CdS, 5.11.1978: 1).

Die Unmittelbarkeit der menschlichen Verbindungen im Kampf konstituierte eine schwer zu treffende Einfachheit des politischen Willens als bloßen Demonstrationseffekt, der eine unmittelbare Herausforderung für die etablierte Politik darstellte. Was philosophisches Denken nicht für möglich hielt, passierte: »kollektiver Wille« manifestierte sich als eine wirkliche Kraft, als konkreter, absoluter Wille eines Volkes in einer realen historischen Situation (vgl. Foucault 1988a: 215).

\section{Die Spiritualität der iranischen Revolution in "geistloser Zeit«}

Eines der erstaunlichsten Probleme, die - neben dem interessanten und unter Bezug auf die osteuropäischen Ereignisse von 1989 geradezu zukunftsweisenden Versuch, einen neuen Charakter der Revolution in unserer "geistlosen « Zeit zu bestimmen - das Iran-Abenteuer im Zusammenhang mit dem philosophischen Werk Foucaults eröffnet, ist der hier erstmals diskutierte - und später völlig negierte - Zusammenhang zwischen religiöser Spiritualität, Revolution und Individuierung als utopischer Konstitution einer neuen gesellschaftlichen Dynamik. 
Es scheint, als versuchte Foucault, das sakrale Element der Versubjektivierung, das immer in den unterschiedlichen Formen liegt, in denen sich das Individuum zur Welt und seinen Mitmenschen begreift, als einen einzigen revolutionären Prozeß zu begreifen, als eine utopische Form wahrer Vergesellschaftung:

»Vor allem aber müssen wir uns selbst ändern. Unsere Art zu sein, unsere Beziehungen mit andern, mit Dingen, mit der Ewigkeit, mit Gott usw. müssen sich vollständig ändern und es wird nur eine wahre Revolution geben, wenn dieser radikale Wandel in unserer Erfahrung stattfinden wird. Ich glaube, daß es hier liegt, wo der Islam eine Rolle spielte. Es kann sein, daß die eine oder andere seiner Vorschriften, der eine oder andere Code eine gewisse Faszination ausübte. Vor allem aber in bezug auf den Lebensstil, der der ihre war, war Religion für sie etwas wie ein Versprechen und eine Garantie, etwas zu finden, das ihre Subjektivität radikal verändern würde. Der Schiismus ist genau eine Form des Islams, die in ihrer Lehre und in ihrem esoterischen Gehalt zwischen dem unterscheidet was bloß äußerer Gehorsam gegenüber dem Code und was das tiefe spirituelle Leben ist.«

(Foucault 1988a: 217f.)

Zunächst liegt der Angelpunkt, an dem absolute Individuierung in einen revolutionären Prozeß der Vergesellschaftung umspringen kann, für Foucault in einer Eigenschaft des Schiismus, daß nämlich der formale und externe Vollzug des Ritus, gerade auch in seinem esoterischen Gehalt, die Tiefe des spirituellen Lebens in keiner Weise behindert - eine Idee, die bereits von Henri Corbin, einem der Lehrer Foucaults, mit seltener orientalistischer Akkuratesse vertreten wurde. ${ }^{11}$ Es wird deutlich, daß der Umsprung von spiritueller Individuierung in einen neuen Prozeß der Vergesellschaftung nur unter einer Bedingung denkbar ist: Indem die religiöse Spiritualität sich in eine politische verwandelt, wird sie zu einem »Vokabular«, einer »Zeremonie«, aber auch

"zu einem zeitlosen Drama, in das das historische Drama eines Volkes hineinpaßt, das sich in seiner wirklichen Existenz gegenüber derjenigen seines Souveräns bemitleidet.«

(Foucault 1988a: 214) 
Dieser Gegensatz verbindet sich sodann mit der Tatsache, daß der okzidentale Diskurs der Macht alles, noch die kleinsten Mechanismen der Unterwerfung und der Subjektivierung beherrscht und damit diese selbst zum Gegenstand globaler Reversionen macht. So läßt sich verstehen, daß die Spiritualität einer »unzeitgemäßen « und unterdrückten Religion zur eigentlich kulturellen Quelle des Aufstands wird und damit die Zukunft für Dynamiken der Umsetzung spiritueller Formen der Individuierung in neue Formen der Vergesellschaftung weist. Ausgehend von einer utopischen Theorie der Macht werden im Verlauf der iranischen Ereignisse Züge einer im Spätwerk wirkenden, aber noch weitgehend unterdrückten »Utopie« der Gesellschaft deutlich: Gegen den entspiritualisierten »Geist der Zeit « richten sich, wie die machtvolle Präsenz einer abwesend gemachten Vergangenheit, die Technologien des Selbst auf eine egalitäre und doch würdevolle - ja im Fall der iranischen Ereignisse sakrale - Spiritualisierung der menschlichen Dinge und gesellschaftlichen Verhältnisse.

\section{Anmerkungen}

1 Dieser Essay ist die verkürzte deutsche Fassung eines 1991 in »International Sociology « erschienenen Aufsatzes. Ich möchte mich auch an dieser Stelle bei Norbert Neumann, Rebecca Habermas und dem Fischer Verlag für die zur Verfügung gestellten Materialien bedanken. Leider blieb die mir damals von Elizabeth King zuteil gewordene Unterstützung bei der Gestaltung des Textes unerwähnt. Dies sei hiermit nun auf das herzlichste getan.

2 »... ich glaube, daß die Art analysiert werden muß, in der die Erscheinungen, Techniken und Verfahren der Macht auf den untersten Ebenen wirksam sind, daß sicher gezeigt werden muß, wie diese Verfahren sich verlagern, ausweiten, verändern, doch vor allem, wie sie von globaleren Phänomenen besetzt und annektiert werden und wie allgemeinere Machtformen oder ökonomische Vorteile sich in das Spiel dieser zugleich relativ autonomen und unendlich kleinen Technologien der Macht einfügen können« (Foucault 1978: 83f.).

3 Foucault spricht aber schon in einem 1976 gehaltenen Vortrag von einer >neuen` wissenschaftlichen Analyse der Macht, die auch 
den Konstruktionsformen von sunten< zu folgen hätte (vgl. Foucault 1978: 83).

4 Die Chefredaktion der Zeitung kündigte den Artikel wie folgt an: $»$ Michel Foucault comincia la sua collaborazione al >Corriere della Sera $<$ con questa sua prima inchiesta sull'Iran ...«. - »Michel Foucault beginnt seine Zusammenarbeit mit dem >Corriere della Sera mit dieser seiner ersten Untersuchung über den Iran. Der französische Essayist und Philosoph ... wird seine Zusammenarbeit mit weiteren Berichten fortsetzen, die von einer Gruppe vorbereitet werden, die offensichtlich in Paris auf seine Anregung hin gebildet wurde. Mit dieser Reise wird eine Reihe origineller und unabhängiger Berichte eröffnet, die sowohl ihrer Form nach als auch von ihrem politischen Urteil her eine Neuheit im europäischen Journalismus darstellen; wir nennen sie >Die Untersuchungen< des Michel Foucault« (CdS, 28.9.1978: 1).

5 Es läßt sich hier durchaus vergleichend an einige von Foucaults früheren Aussagen über die Techniken der Normalisierung der Herrschaft erinnern, die er in bezug auf die 1917 beginnende Entwicklung des Gulag-Systems machte: »No doubt, it would be mistaken to conceive of the plebs as a permanent ground for history, the final objective of all subjections, the ever smouldering centre of all revolts. The plebs is no doubt not a real sociological entity. But there is indeed always something in the social body, in classes, groups and individuals themselves which in some sense escapes relations of power, something which is by no means a more or less docile or reactive primal matter, but rather a centrifugal movement, an inverse energy, a discharge. There is certainly no such thing as sthe plebs; rather there is as it were, a certain plebeian quality of aspect (de la plebe). There is plebs in bodies, in souls, in individuals, in the proletariat, in the bourgeoisie, but everywhere in a diversity of forms and extensions, of energies and irreducibilities. This measure of plebs is not so much what stands outside relations of power as their limit, their underside, their counter-stroke, that which responds to every advance of power by a movement of disengagement. Hence it forms the motivations for every new development of networks of power!«(Foucault 1980: 137f.).

6 Die Chefredaktion des Corriere della Sera leitet den Artikel vom 7.11.1978 mit den folgenden Schlagzeilen ein: »Die Regierung tritt 
zurück, schwarze Zeiten für ein großes Land «, »Iran gehört dem Militär: die letzte Karte des Schah «. Sie fügte auch einige Bemerkungen über die politische Situation hinzu: Nach zwei Tagen exzessiver studentischer Demonstrationen, Plünderung der Banken und offizieller Gebäude berief der Schah einen Armeegeneral als Premierminister, Panzer besetzten Schlüsselpositionen in Teheran.

7 Vgl. LM 11.5.1979: »Es braucht keine Scham, wenn man seine Meinung ändert; aber es gibt auch keinen Grund zu behaupten, man habe seine Meinung geändert, wenn man heute gegen das Abschneiden der Hände ist und gestern gegen die Folterungen der Savak war.«

8 Vgl. Eribon (1989: 302): Der Artikel stellt eine völlig neue Form der Beurteilung der Ereignisse dar. Die Herausgeber leiten den Artikel wie folgt ein: »De notre envoi special: A quoi rèvent les Iraniens? par Michel Foucault. Peut-être les sujets révoltes du chah sont-ils en train de rechercher cette chose que nous avons oubliée depuis longtemps en Europe: une spiritualité politique?« - „Von unserem Sonderkorrespondenten: Wovon träumen die Iraner? von Michel Foucault. Vielleicht sind die Untertanen, die sich gegen den Schah auflehnen, auf der Suche nach etwas, das wir in Europa seit langem vergessen haben: eine politische Spiritualität?« - Auf Seite 49 ist in den Text ein Bild des Ayatollah Khomeini eingebaut, das ihn im Exil auf dem Rasen des Gartens seiner Pariser Residenz liegend zeigt.

9 Vgl. Anmerkung 4.

10 Es ist hier eine Reversion des theoretischen Interesses Foucaults zu bemerken, die durchaus auf den iranischen Erfahrungen aufbaut: Foucault beschäftigte sich nach der Iran-Affäre und besonders während seines Amerika-Aufenthaltes vor seinem Tod zunehmend mit okzidentalen Formen der Spiritualität als Gegenstand eines Projektes zur »Hermeneutik der Technologien des Selbst im heidnischen und frühchristlichen Gebrauch « (Foucault 1988b: 17).

11 Henri Corbin war Schüler und Übersetzer Heideggers. Unter seinen vielen, in letzter Zeit wieder aufgelegten Werken zur schiitischen Mystik und persischen Philosophie kann in diesem Zusammenhang auf den »Prologue « zur englischen Fassung des »Spiritual Body and Celestial Earth« hingewiesen werden, wo diese spezifi- 
sche Form der Spiritualität des schiitischen Islams entwickelt wird (Corbin 1977: XIf.).

\section{Foucaults Texte zur iranischen Revolution 1978-1979}

Abkürzungen:

CdS = Corriere della Sera, Mailand

$\mathrm{NO}=$ Le Nouvel Observateur, Paris

$\mathrm{LM}=$ Le Monde, Paris

$\mathrm{LMa}=$ Le Matin, Paris

CdS, 28.9.1978: 1-3. »Taccuino persiano: L'esercito, quando la terra trema « (Persisches Tagebuch: Die Armee, wenn die Erde bebt).

CdS, 1.10.1978: 1 und 3. "Le shah a cent ans de retard « (Der Schah, hundert Jahre zu spät). (Zitiert nach Eribon 1989: 372; der Text soll in NO 726 zusammengefaßt sein, vgl. Eribon 1989: 302).

CdS, 8.10.1978: 1 und 3. »Teheran: la foi contre le shah « (Teheran: der Glaube gegen den Schah). Nach Eribon (1989: 372) hatte der Text den originalen französischen Titel: »Iran. Dans l'attente de l'Imam《 (Iran. In Erwartung des Imam).

CdS, 22.10.1978: 3. »Taccuino persiano: Ritorno al profeta?« (Persisches Tagebuch: Rückkehr zum Propheten).

NO 726, 16.-22.10.1978: 48-49. »A quoi rèvent les Iraniens? (Wovon träumen die Iraner?).

NO 731, 13.-19.11.1978: 26. »Réponse a une lectrice Iranienne« (Antwort auf eine iranische Leserin). Es handelt sich um eine Antwort auf den Leserbrief von Atoussa H., Paris, der in NO 730, 6.12.11.1978: 26-27 unter dem Titel »Une iranienne écrit« (Eine Iranerin schreibt) veröffentlicht wurde.

CdS, 5.11.1978: 1 und 3. »Una rivolta con le mani nude (Ein Aufstand mit nackten Händen).

CdS, 7.11.1978: 1-3. »Sfida all'opposizione« (Die Herausforderung der Opposition).

CdS, 12.11.1978: 1. »L'reportages' di idee« (Die Reportagen der Ideen).

CdS, 19.11.1978: 1 und 3. »La rivolta dell'Iran corre sui nastri delle minicassette« (Die Revolution im Iran läuft über die Bänder der Minikassetten). 
CdS, 13.2.1979: 1. »Una polveriera chiamata Islam« (Ein Pulverfaß, das Islam heißt).

NO 753, 16-22.4.1979: 46. »Lettre ouverte a Mehdi Bazargan«(Offener Brief an Mehdi Bazargan).

LMa 647, 26.4.1979: 15. »Réponse« (Antwort). Antwort auf eine Kritik von J. Broyelle, LMa, 24.3.1979: 13, »A quoi rèvent les philosophes? (Wovon träumen die Philosophen?).

LM, 11.5.1979: 1 und 3. »Inutile de se soulever? (Ist es vergeblich, sich $\mathrm{zu}$ erheben?). Auf English erschienen als »Is it useless to revolt? On Revolution «, Philosophy and Social Criticism I, 1981: 5-9. 



\section{Teil II}

\section{Modernität, Globalisierung, Islam}

"In fact the Islamic position is the very opposite of relativism.... This absoluteness of Islamic culture did not make it intolerant of the ethnic sub-cultures of its adherents, of their languages and literatures, of their folk customs and styles. But it has distinguished the culture of Islam from 'adah, literally, the local custom, the provincial content, which Islam tolerated even to the point of regarding it juristically acceptable, but which it has always kept in the place proper to it. Such position is one of subservience to the culture of Islam, which was assigned the status of determining the essence and core Islamic civilization in toto."

(Ismail Raja Faruqi, Islam and Culture, 1980) 



\section{Globalisierung, Modernität, nicht-westliche Zivilisation}

Das Unternehmen Soziologie ist angesichts der Wandlungen, die die Welt in den letzten vier Jahren vollzogen hat, zunehmend ratlos. Mit dem realpolitischen Ende des Sozialismus scheint das Ende einer als genuin »sozial « bestimmten Motorik der modernen Welt angebrochen und damit eine neue Form der kaum mehr rein soziologisch bestimmbaren Dynamik herangewachsen zu sein: Die zivilisationsgebundenen und kulturellen Unterschiede gelten mehr denn je als die bestimmenden Komponenten der weltgesellschaftlich definierten »neuen « Dynamik (Tiryakian 1994). Das Folgende versteht sich - mit der einschränkenden Bescheidung auf Konfigurationen, die das Beispiel der neuen zivilisatorischen und weltgesellschaftlichen Bedeutung des Islams setzt - als Beitrag zu einem sich immer stärker als dringlich erweisenden soziologischen Analyse-Projekt, das sich Austauschprozesse zwischen den Zivilisationen und Kulturen und über Nationalstaatsgrenzen hinweg zum Gegenstand zu machen hätte (vgl. etwa Albrow 1990; Archer 1991; Smart 1994).

Eine Facette der Wirkung des Weberschen Paradigmas in der Theorie der Moderne ist die Vorstellung, daß Rationalisierung und Differenzierung die bestimmenden Komponenten des modernen gesellschaftlichen Prozesses sind (Eder 1992: 320f.; Tiryakian 1992: 79). Kann sich diese Vorstellung im Zeichen des globalisierten kulturellen Diskurses erneuern? Bevor man nach Überlegungen und Ansätzen zur Harmonisierung der durch Beschwörung zivilisatorischer Traditionen in den einzelnen Kulturen eingeleiteten Identitätssuche einerseits und den Kernelementen moderner sozialer Differenzierung sucht, ist die Frage nach der kulturübergreifenden, transnationalen Vergesellschaftung zu radikalisieren: Welche »Eigenlogik« entwickelt sie? Danach stelle ich mir die Frage: Was haben Identitätspolitik und soziale Differenzierung miteinander zu tun?

Wenn sich im Orient und im Okzident soziale Welten zunehmend »orientalisieren «, so ist damit eine Bewegung angedeutet, die man nur ungenau mit dem Begriff der "Wertsimulation« einfangen kann. Nichts was noch »Wert « und »moralische Norm « erheischt, kann sich noch ungebrochen auf kulturelle Urvisionen beziehen. Am Beispiel des Islams ist zu fragen, in welche Richtung die Simulation religiöser 
Urvisionen sich im Zeichen des kulturübergreifenden Diskurses entwickelt. Kann das instrumentelle Umspielen und Nachspielen solcher Visionen noch auf Rationalisierung in jenem von Weber in die Soziologie eingeführten Sinne bezogen werden?

Schließlich will ich auf einer dritten Ebene zeigen, wo die Spannungen liegen, die möglicherweise neuen Richtungen und Widersprüchen den Weg öffnen. Wenn es auch unmöglich scheint, daß diese zu neuen politischen Blockbildungen führen, so ist doch die relative Bedeutung der dauerhaften Konstitution von Symbolwelten, jenseits von Funktion und Regulierung eine sich offenbar durchsetzende "alternative" Form der Modernität.

\section{Identitätspolitik, soziale Differenzierung, Modernität}

\section{I}

»Identitätspolitik « ist ein Schlüsselwort des modernen sozialtechnischen und politischen Krisenmanagements. Die ökonomisch begründete Interessenpolitik der gesellschaftlichen Schichten und Gruppen erscheint dagegen fast als eine historische Kategorie von heute minderem Rang. Als hätte sich die westliche Moderne einer alten Devise ihrer östlichen Kritiker gebeugt: Modernität gilt mehr denn je als eine den bloßen Materialismus überwindende Bindung der Interessen an kulturelle Werte.

Aus der Literaturflut, die diese These nahelegt, sei Charles Taylors streitbarer Essay » The Ethics of Authenticity « von 1992 hervorgehoben: Für Taylor stellt die Forderung nach kultureller Anerkennung eine eigenlogische Dimension gesellschaftlicher Integrationsprozesse dar und hat selbst höheren Kohäsionswert als der Überlebenskampf und die Befriedigung ökonomischer Bedürfnisse. Anerkennung, ja Gleichstellung, die kulturelle und ethnische Minoritäten ebenso wie strukturell Marginalisierte heute stellen, schlummern, wie Taylor überzeugend argumentiert, tief in den Strukturen der modernen Form der Vergesellschaftung. Wo sich traditionelle symbolische und askriptive Muster der Statuszuweisung auflösen, sieht der Einzelne sich in einer unbestimmten und anbivalenten Stellung gegenüber der Gesellschaft, »Beruf« und »Geld « können, so scheint es, Ehre und moralische Sicherheit nicht ersetzen. So werden Forderungen nach kultureller Identität und sozialer Anerkennung laut. Sie funktionieren auch als Bin- 
demasse für neue Formen sozialer Kohäsion. Kulturelle Selbstbestimmung wird als Mittel der Anerkennung von Gleichwertigkeit zu einem Problem sozialer Ordnung (Taylor 1992: 59).

II

Identitätsdenken ist in vieler Hinsicht jedoch noch viel radikaler als Taylor annimmt. Denn wenn man den philosophischen Diskurs der modernen Ethik verläßt und sich konsequent seiner soziologischen Wirkungsweise annimmt, verdichtet sich die Vorstellung, daß Identitätspolitik letztendlich einem alles umfassenden Gesetz gesellschaftlicher Konstitution folge, ja selbst Ausdruck eines solchen Gesetzes sei. Dieser Idee scheint Niklas Luhmann in einem bisher unveröffentlichten Aufsatz nahe zu kommen, indem er über kulturelle Einbezugsund Ausgliederungsmechanismen bestimmte soziale Differenzierungsprozesse als Formen der Systemintegration der Gesellschaft identifiziert. Luhmanns Beschreibung der Effekte der Inklusion und Exklusion läßt sich als soziologischer Versuch verstehen, das Konzept der sozialen Differenzierung unter den Gesichtspunkt kultureller Eingliederungs- und Ausgrenzungsprozesse zu stellen. Es wird damit ergänzt und erweitert, indem erstmals unterschiedliche Formen sozialer Differenzierung aus den Wirkungen der selbst- und fremdreferentiellen Mechanismen herzuleiten sind (Luhmann 1992). Luhmann sieht dabei das Problem, daß die Inklusions- und Exklusionsmechanismen im Prinzip »auf Kosten der funktionssystemspezifischen Rationalitätschancen« wirken (ibid.: 16). Wie schon in seinen Studien zu Vertrauen und Religion (Luhmann 1973, 1982) wird auch hier nochmals deutlich, daß Luhmanns Differenzierungsbegriff ein Kulturbegriff ist, als wäre er gewissermaßen aus den einleitenden Paragraphen der Weberschen Religionssoziologie im V. Kapitel von »Wirtschaft und Gesellschaft « gewonnen (Weber 1980: 245-381). Luhmanns Begriff der Differenzierung hält im Grunde an Sinndeutungsprozessen, also an kulturellen Austauschprozessen fest. Inklusions- und Exklusionsmechanismen sind auf Identitätsbestimmung gerichtete Prozesse der Sinndeutung. Das soziale Funktionssystem, von Sinndeutung abhängig, ist deshalb auch von Inklusions- und Exklusionsmechanismen her bestimmt. Aus diesem Zusammenhang der Inklusion und Exklusion mit Identitätsdenken einerseits und sozialer Differenzierung andererseits erschließt sich der Radikalisierungseffekt des Identitätsdenkens an der 
Basis gesellschaftlicher Dynamik: Die Differenzierung scheint auf eine strukturelle Dualisierung des »in« und »out « hinauszulaufen. Diese Dimension des Luhmannschen Ansatzes ist für das Verständnis kulturübergreifender Prozesse außerordentlich bedeutsam. Nicht nur läuft das Ganze auf die Schwächung funktionssystematischer Rationalitäten hinaus, sondern aus der Position des »out « werden andere, als Alternative gedachte Rationalitäten entwickelt, die in einem medialen, gewissermaßen technisch-instrumentellen Zusammenhang zum »in « stehen.

\section{III}

Luhmanns Begriff der komplexen Gesellschaft ist jedoch keineswegs auf jenen Bruch zwischen moderner und vormoderner Kultur hin gedacht, den etwa Louis Dumont in so resoluter Rigidität konstatiert hat und der heute noch in gewisser Weise den Diskurs zwischen westlichen und nicht-westlichen Gesellschaften bestimmt. Dieses Spannungsverhältnis hat sich in allen Gesellschaften durchgesetzt. Kulturelle Globalisierung setzt die Gegensätze zwischen »Ost« und »West«, modern und vormodern, in jeder Einzelgesellschaft durch, so daß sich Gesellschaft nicht mehr nur als kulturell eindimensionales, monolithisches Agglomerat bestimmen läßt. Der höchst komplexe interaktive Prozeß der Sinndeutung durch Selbst- und Gegenperzeption über Kulturgrenzen hinweg bedingt eine neue Systemrealität: Homogenität der Kommunikationsstruktur produziert die bipolare Aufteilung von holistisch verstandenen Symbolen und Grundideen westlicher Kultur und nicht-westlicher Gegenkultur. Wenn für Luhmann noch Inklusions- und Exklusionsmechanismen ein Medium, »das die ständige Neubildung von Formen « hervorbringt (ibid.: 14), darstellen, so läßt sich dies nicht auf die Bedingung der Komplexität multikulturaler Gesellschaften übertragen, denn hier kann die Homogenität des Kommunikationsmediums nicht vorausgesetzt werden (obwohl die komparative Zivilisationsanalyse gerade ein homogenes, weil universalistisch klassifikatorisches System der Kommunikation unterstellt und dauernd reproduziert). Die über interkulturelle Interaktion konstituierten Formen der Eigen- und Fremdbestimmung sind selbst noch auf die Kodifizierung des Mediums gerichtet, wodurch ständig ein neues über absolute Kulturgrenzen hinweg sich entfaltendes Sinn- und Wertrepertoire wechselhaft flottiert. Es handelt sich um ein Wechselspiel, das 
einerseits basiskultureller Bindungen und damit dem Wertgefüge der Weltreligionen völlig enthoben ist, andererseits dieses aber gerade erst wieder $\mathrm{zu}$ reproduzieren hat. Im weltgesellschaftlichen Zusammenhang hat sich der Dualisierungseffekt der Inklusion und Exklusion in den Polen westlicher Moderne einerseits und nicht-westlicher Zivilisationen andererseits manifestiert. Globalisierte interkulturelle Interaktion löst diesen Gegensatz des polarisierten Referenzrepertoires tendenziell nur technisch, indem sie mediale Instrumentarien schafft, die die Gleichläufigkeit der Wirkungsmuster kultureller Rekonstruktion nur virtuell durchsetzt. Andererseits garantiert die relative technische Kohärenz der Interaktionsmedien, daß die Prinzipien und Wertgefüge der alten Zivilisationen sich unter einem nun peinlichst territorial zu denkenden Gesichtspunkt der Abgrenzung neu formieren. Der Fluß dieser Formenbildung mit seinen sich ablagernden Perzeptionsmustern und Grenzziehungen nimmt auf die Gestaltung des Funktionssystems einer Gesellschaft entscheidend Einfluß; sie rekonstituieren auch den diesem unterliegenden operativen Rationalitätsbegriff.

\section{Orientalisierungen}

IV

In dieser Reversion der Verhältnisse manifestiert sich zugleich ein Verlust des Zentrums. Damit ist Modernität nicht mehr aus der Form des Selbstbezugs abendländischer Kultur (oder jedes anderen Zentrums) heraus zu begreifen. Sie hat - wenn man hier gegen ein Wort von $\mathrm{Ha}-$ bermas argumentieren darf - ihre »exzellente Stellung « verloren. »Universalisierung des Eurozentrismus« (Amin 1989) schafft Europa als Zentrum ab. Paradoxerweise gewinnt dadurch der Bezug auf das »Orientalische« an kultureller Kraft. Der einseitigen Vorstellung der Okzidentalisierung der Welt, so wie sie noch Serge Latouche (1990) versteht, steht ein zumindest gleich wichtiger Prozeß der symbolischen und intellektuellen »Orientalisierung « gegenüber.

Blickt man auf die Wechselbeziehungen im Kulturaustausch mit Europa zurück, so wird deutlich, daß die nicht-westlichen Zivilisationen von Anfang an einerseits über die Negation abendländischer Affirmativität (d.h. Zurückweisung des westlichen Orientalismus und Aufbau eines eigenen »intrinsischen « Modernismus - Rahman 1982) oder andererseits über subtile Formen der fremdkulturellen Bestäti- 
gung westlicher Kulturkritik (d.h. durch modernitätskritische Affirmation orientalistischer Visionen der eigenen Kultur - Iqbal 1954/ 1927; vgl. auch al-Attas 1978) in das Wechselspiel von Fremd- und Eigendefinition, das das Projekt der Moderne hervorbrachte, eingeschlossen waren (siehe hierzu das Kapitel »Islam als Selbstbegriff nicht-westlicher Moderne«, S. 103ff.).

In den einzelnen Weltreligionen wurden dabei auch Instrumentalisierungsmechanismen aktiviert, die über den äußeren Rahmen der symbolischen Dualisierung, Okzidentalisierung hier und Orientalisierung dort, hinwegsprangen.

Bisher hat man häufig die kulturelle Instrumentalisierung vor allem dem Medium der sich universalisierenden Massen- und Konsumkultur zugesprochen (Pasolini 1978; Baudrillard 1982); neuerdings gewinnt man diesen Effekten der Massenkultur auch wieder Rückverzauberungswirkungen ab (Featherstone 1990, 1991).

Wir haben zu zeigen versucht, daß die Suche nach dem Authentischen jene Entwertungsmechanismen der radikalen Bindung des Jenseitsdenkens an diesseitiges Interesse im Sinne des absoluten westlichen Rationalismus auch in nicht-westliche Zivilisationen einbaut. Identitätsdenken gibt dem Instrumentalismus auf der Ebene der »Hochkultur « freien Lauf (Abaza/Stauth 1990). Wer den aus diesem Paradox der Orientalisierung erwachsenden Instrumentalismus ernst nimmt, darf eigentlich auch nicht hoffen, daß die moderne Identitätspolitik noch auf irgendwie ungebrochenes Kulturerbe, Werte und Visionen der alten Weltreligionen zurückgreifen kann. In diesem entscheidenden Punkt halte ich Eisenstadts These, daß das aus den Negationen sakraler Macht erwachsende Wertproblem der Kulturen der Achsenzeit und die säkularen Institutionalisierungen weltlicher Eschatologien in den Großen Revolutionen des 18. und 19. Jahrhunderts die Antinomien der Moderne auch in den nicht-westlichen Einzelkulturen noch bestimme, für ergänzungsbedürfig. So sehr Eisenstadt einerseits das Achsenzeit-Problem und die in den Revolutionen institutionalisierte Legitimität von Protest als Momente kulturtechnischer »Revolutionen « begreift, so sehr bleibt er andererseits bei der Vorstellung, man könne innere islamische Kulturvisionen insbesondere des Sektenwesens für den modernen islamischen Fundamentalismus noch als bestimmend heranziehen. Die sprachlose »Militanz«, die alles nicht-islamisch Kodierte ausradieren will, wird so zum spezifischen Wirkungs- 
problem des an symbolischen Gewalttechniken haftenden islamischen Sektenwesens umgedeutet. Es geht hier nicht darum, Eisenstadt zu unrecht des einseitigen »Orientalismus « anzuklagen. $\mathrm{Zu}$ sehr ist er sich der Universalität der jakobinischen Techniken gegenüber allem »falsch« Kodierten, jener sprachlosen Militanz gegen alles »andere« in allen modernen Regimen bewußt. Doch bleibt diese Universalität gegenüber der Spezifität des einzelnen Kulturausdrucks von sekundärem Charakter. So erhellend Eisenstadts Analyse der Kulturinstrumente des »Fundamentalismus « ist, der kulturübergreifende Konstruktivismus bleibt als Komponente des Kultur- und Traditionsradikalismus unterbelichtet (vgl. Eisenstadt 1998). Dies gilt gleichermaßen für die Analyse der charismatischen Zwänge und der Erlösungsproblematik. Sie werden fast immer nur noch aus dem Kontext der »alten«, »originären « Grundprinzipien der Einzelkulturen heraus zu verstehen versucht. Wie nun aber sind in die Analyse der diskursiven und dialogisch-interaktiven Dimensionen der Rekonstruktionen »innerer « Werte der verschiedenen Zivilisationen die modernen reflexiven Techniken einzubeziehen? Die historisch-geistigen Tiefenstrukturen etwa des Islams können doch nur als Objekte solcher Techniken und Vermittlungsprozesse verstanden werden, nicht als Prinzipien, aus denen heraus sich die eigentlich mobilisierenden Kräfte kultureller Rekonstruktionsbewegungen, wie z. B. der Fundamentalismus, entwickeln. Lassen Sie mich dies im folgenden weiter erläutern.

\section{$\mathrm{V}$}

Der konstante Zwang zum Wechselspiel zwischen interkulturell definierten Wir-Gefühlen ist - wie ich behaupten möchte - zum entscheidenden Faktor sozialen Wandels geworden. Zunächst drückt sich dies in den verschiedenen Formen der Rekonstruktion der alten Wertgefüge und Grundprinzipien der Weltzivilisationen aus. Es sind dies Rekonstruktionen des Selbstverständnisses, die über den Zugang zu den Machtzentren entscheiden, Nähe oder Ferne zum Zentrum kodieren. Dies alles begann mit dem Kampf um die »eigene«, »nationale« Geschichte und um die Rekonstitution der Grundprinzipien religiöser Orientierung. Die postkolonialen Eliten hatten sich darin noch ganz am Selbstbild der Unterdrücker von einst zu richten.

Die Art, wie »Europa« im Kontext islamischer Länder perzipiert wurde, ist ein spezifischer, in gewisser Weise jedoch auch ein modell- 
hafter Fall, von dem ausgehend sich die Globalisierung kultureller Diskurse in der Nord-Süd- bzw. Ost-West-Dimension umfassend beleuchten ließe.

Das Bild Europas beeinflußte die auf die Ausformung nationalstaatlicher Strukturen gerichteten Interessen der »nationalen « Eliten. Für die institutionellen Prozesse, die rigide Säkularisierung des öffentlichen Lebens und die hierdurch vermittelten Prozesse der sozialen Differenzierung stand Europa Pate (vgl. Lapidus 1985). Es ist die perzipierte Vision »Europas«, die das Eigenverständnis der islamischen Welt tiefer geprägt hat als das eigene historische Gedächtnis oder deutlicher: Es ist das von Europa appropriierte Geschichtsbild, das alle Rekonstruktionen der eigenen Geschichte prägt (Laroui 1977). Die appropriierte Geschichte wirkt technisierend und instrumentalisierend zurück. Entsprechend sind »Orientalismus « (Said 1977) und »Eurozentrismus « (Amin 1989) universelle Effekte der kulturellen Deprivation. Wenn europäische Identitätspolitik erst die Kolonisierung der nichteuropäischen Welt möglich machte, so mündete die provozierte Forderung nach kultureller Anerkennung der Kolonisierten in einen radikalisierten Zwang zur Selbstbehauptung. Sie trieb die Nichteuropäer nicht nur zur Nachahmung, sondern auch in den Sog eines komplementären Wechselspiels: »Europa « heißt auch, die Suche nach einer »eigenen ", einer verlorengegangenen, "großen" Vergangenheit politisch und kulturtechnisch zu radikalisieren. Symbole und Inhalte der »eigenen« Kultur werden so dauerhaft mit »fremden « Mitteln rekonstruiert. Die Politik der Gleichberechtigung hat im Zeichen antikolonialen Protests neue Orientierungspunkte in den alten Zivilisationen gesetzt. Webers alter Gedanke, daß die Wertneutralität des modernen rationalistischen Funktionssystems die Suche nach und den Wettstreit über letzte Werte erneut provoziert, nimmt solche Prozesse reflektierend vorweg. Dieser Wettkampf erklärt, warum aus dem antikolonialen Kampf heraus in letzter Instanz die religiösen Traditionen der »eigenen « Zivilisation als alternative Wertorientierung zum Westen wieder aufgenommen werden mußten. So trägt der moderne Kampf um letzte Werte auch dazu bei, den bildlichen und normativen Zivilisationsbestand zu totalisieren, selektiv einzuholen, zu erneuern und zu befestigen. Im Rückbezug auf letzte Werte werden neue »Rationalitäten« als Orientierungspunkte für politische, wirtschaftliche und gesell- 
schaftliche Entwicklungen gesetzt. Dies ist ein Effekt Europas. Nichtwestliche Kultur macht ihn sich zu eigen.

\section{VI}

»Orientalisierung « ist bereits ein soziologisch instrumentalisierter $\mathrm{Be}-$ griff des europäischen Identitätsdenkens und mit dem Kulturwertballast europäischer Kontinuitäten behaftet. Aber es geht mir hier vor allem um die kulturtechnische Seite der »Orientalisierung «, um kulturübergreifende »orientalistische « Konstruktionen.

Neben »Geschichte « ist - wie oben bereits angedeutet - »Religion « eine zentrale Komponente der Identitätspolitik. Zieht man die spezifisch humanwissenschaftlichen Begründungen seit dem frühen 19. Jahrhundert in Betracht, so kann man feststellen, daß Begegnung und Auseinandersetzung mit den Religionen der nicht-abendländischen Welt - der Islam hat hier eine bedeutende Sonderstellung - eine ganz entscheidende Dimension der Aufklärung darstellt. Nicht nur wurde, wie von Lessing, die Toleranzidee als kulturübergreifend ausgelegt, sondern die Entwicklung der Menschheit als Ganzes in historisch und religiös begründeten Zivilisationsebenen erstmals durchdacht. Die Universalgeschichten Herders, Schlegels und Hegels setzen die perspektivischen Grundlagen, mit denen ein standardisiertes Zivilisationsdenken global angewandt wird. Von hier an sind es immer nur normative Standards, die Vergleich und Interaktionsform zwischen den Kulturen universell beherrschen. Man kann die instrumentellen Folgen dieses Denkens am Beispiel der spezifisch deutschen humanwissenschaftlichen Begegnung mit dem Islam erläutern. Von Anfang an stand der Islam in einem komplementären Verhältnis zu den Innerlichkeitskonstruktionen der Aufklärung und in einem spezifischeren Sinne der Romantik. Dabei zeigt sich, daß der deutsche Orientalismus, gerade weil er nur mittelbar der praktischen politischen Dominanz diente, den Schwerpunkt nicht so sehr auf die äußerliche, selektive Inkorporation exotischer Gebilde und Symbole setzte, sondern auf der Affirmation eigener, innerer Kulturprinzipien beruhte. Die auf Text gebaute, hermeneutisch orientierte Fremderfahrung führte zur Essentialisierung und sodann Kategorisierung der eigenen Werte gegenüber dem Fremden. Ja, das Fremde war dann nur in solchen Kategorisierungen denkbar, die Selbsterfahrung zuließen. Von Schlegel bis hin zu 
Weber läßt sich eine Denkfigur verfolgen, mit der einerseits der frühe Islam als »natürliche Religion, als Religion der Kulturerneuerung rational begreifbar, andererseits aber der auf Basis eines wissenschaftlichen Lehrsystems begründete Islam der Orthodoxie und der Blütezeit als alt-orientalisch, despotisch und irrational zurückgewiesen wurde (vgl. Stauth 1993: 101ff.). Das Beispiel des deutschen Orientalismus des 19. Jahrhunderts vermittelt auch, daß die selektive Bestimmung von Kulturprinzipien in der Fremdkulturerfahrung zugleich auf nach innen wirkende Formen der Selbstkonstitution zielt. Das in dieser Zeit aufkommende soziologische Denken blieb davon nicht unberührt. Es hat das theoretische Verhältnis zum Islam in abstrakten Tiefenstrukturen des Abendlandes zu reflektieren versucht (ibid.: 154ff.).

Der marokkanische Historiker Abdallah Laroui hat zum Beispiel in einem erstmals 1967 erschienenen Buch "L'idéologie Arabe contemporaine « festgestellt, daß das moderne arabische Denken sich selbst immer nur durch das Sichabheben vom Okzident, durch die Negation des Anderen, definiert habe und leitete davon die Forderung ab, daß die arabische Suche nach dem Selbst eine fundamentale Kenntnis der Geschichte des Begriffs des Okzidents beinhalten müsse (Laroui 1977: 4). Daß nun seinerseits der Okzident sich durch die Abgrenzung zum Orient selbst begriffen habe, war eine mit Vehemenz vorgetragene These des Arabo-Amerikaners Edward Said (1977). Und die Verkettung geht so weit, daß die Araber auf der Suche nach ihrem Selbst affirmativ ein vom Okzident geprägtes orientalistisches »Selbst «-Bild übernehmen und einem »Orientalism in reverse« (al-Azm 1981) anzuhängen scheinen.

\section{VII}

Unzweifelhaft schufen die wachsenden globalen Intensitäten und Interaktionen zu den neuen Begriffen von »Geschichte « und »Religion« eine internationale Arena kulturellen Wettbewerbs, in der ein Spiel der Entwertung des Fachorientalismus in instrumentalisierbare Bilder der kulturellen Rekonstruktion vor sich ging. Webers selbstreflexive Sichtweisen stellen ein eigenes Feld der Entfaltung dieses Instrumentalismus dar. Die doppelt gelagerte Wirkungsgeschichte des Weberschen Werkes unter nicht-westlichen Intellektuellen zeigt den Weg, auf dem sich dieser Mechanismus kulturübergreifend durchsetzte. Einerseits bezieht sich diese Wirkungsgeschichte durchaus auf Webers 
»Scheinobjektivismus «. Durch ihn wurden »verstärkt nativistische, die eigenen Kulturwerte verteidigende Strömungen gegen die Abwertung der eigenen Traditionen « wach gerufen (Schmidt-Glintzer 1988: 82). Man kann hier auch auf den generell affirmativen Charakter der Kultursoziologie Webers hinweisen. Sie stellt in der Tat eine bedeutende Wende zur Konstruktion eines modernen Gesellschaftsbildes und der Bezeichnung der Charaktereigenschaften des modernen Menschen dar (Stauth 1993a). Auf der anderen Seite ist Webers Einfluß so groß, daß eben nicht nur sein Scheinobjektivismus, sondern gerade auch jene andere, gegenüber der Entwicklung des okzidentalen Rationalismus so skeptische, ja pessimistische Haltung schon lange in den Abwehr- und Rückwendungstendenzen der nicht-westlichen Intelligenz wirksam war. Dieser alternative Bezug zu Weber läßt sich schon früh etwa bei so einflußreichen Orientalen wie z. B. Muhammad Iqbal, Fazlur Rahman und Syed Naguib al-Attas verfolgen (Stauth 1993c). Die Art, wie sowohl Webers affirmativ-objektivistische Kultursoziologie als auch sein Kulturpessimismus die traditionalistischen Revitalisierungsströmungen beeinflußten, ist Ausdruck des sich universalisierenden Instruments selbstreflexiven Denkens und bedarf sicher der detaillierteren Beachtung in der Begründung jeder kulturübergreifenden Soziologie.

\section{VIII}

Eine dritte Ebene orientalisierender Rekonstruktion deutet sich jenseits des west-östlich verlaufenden Bandes kultureller Wechselbeziehung an. Unterhalb des Mantels, den die historische Dominanz des Westens auf die Beziehungen der Kolonialvölker untereinander legte, fanden Austauschbewegungen zwischen den beherrschten Völkern und ihren Kulturen statt. Die Verteilung selbstreflexiver Fragestellungen fand also auch ohne den unmittelbaren Einfluß »Europas « statt, obwohl, wie etwa im Falle des niederländischen Islamgelehrten Snouck Hurgronje, bei der Entwicklung einer Vorstellung von einem richtigen Islam im Zentrum (Mekka) und einem lernbedürftigen Islam an der Peripherie (Indonesien) dies oft nicht ohne europäische Einmischung vor sich ging. Aber der Begriff der Modernität hat dabei eine gewisse Erosion erlitten. Es handelt sich nicht mehr um eine Einbahnstraße auf westliche Standards hin. Vielmehr muß die Diversität interregionaler und interkultureller Interaktionen auf der Süd-Süd-Schiene stärkere Beachtung finden. Ägyptische und indische Sozialphiloso- 
phen und Literaten des 19. und frühen 20. Jahrhunderts spielten eine entscheidende Rolle bei der Ausbreitung selbstreflexiven Denkens in Asien und Afrika. Später, wie etwa nach der Konferenz von Bandung, war der institutionalisierte Erfahrungsaustausch zwischen verschiedenen Modernisierungsprozessen ein entscheidender Faktor gegenseitiger Perzeptionen (Abaza 1994). Wie der Austausch über Modernisierungspfade in Fragen an »eigene Kultur und Geschichte umgesetzt wurde, entzog sich westlicher Dominanz. Das breite Feld der gegenseitigen Übernahme bestimmter politischer Prinzipien, Regierungsund Legitimationstechniken, Definitionen von Religion, Nation etc. stellt hier eine eigene Dimension der Modernität dar (Robertson 1992).

Die instrumentellen und simulativen Auswirkungen der vermittelnden und interaktiven Aspekte des Modernitätsdenkens sind noch nicht in einer Weise untersucht worden, die den faktischen Intensitäten der Globalisierung interregionalen und kulturübergreifenden Austausches Rechnung trägt.

\section{Globalisierung als Standardisierung von Kulturtechniken}

Vielleicht lassen sich aus dem, was bisher zum Interaktionsverhältnis von Islam und westlichem Rationalismus gesagt wurde, einige generalisierbare Wirkungsweisen der globalisierten Identitätslogik bestimmen.

Alle drei Komponenten der Rekonstruktion »innerer « Kulturwerte, die selbstreflexive Rückblende des Fachorientalismus, die Wirkungsgeschichte von Webers Fragen an nicht-westliche Religionen und die perzeptiven Austauschmuster in der Süd-Süd-Dimension zeigen, daß, wenn das Wechselspiel der Identitätspolitik einmal gesetzt ist, es immer eigentlich nur sekundär um innere historische Kontinuitäten geht. Hauptelement der modernen Kulturdynamik bleibt der Konstruktivismus, der sich aus dem offenen, strategisch-instrumentellen Kontext des Kulturaustausches heraus entwickelte.

Wir können einerseits festhalten, daß in allen Weltreligionen selbstaffirmative Formationsprozesse in Prozesse der alternativen Modernitätsbildung münden. Andererseits ist die Bedeutung solcher kultureller Transformationen für den Strukturwandel der Gesellschaften zu bestimmen.

Der instrumentell-strategische Apparat der kulturellen Rekon- 
struktion und der Apparat der rekonstruierten Werte treten in Gegensatz zueinander. Man scheint vor einem schier unauflöslichen Dilemma zu stehen: Einerseits haben wir die verschiedenen »inneren« Visionen von Charisma als Grundvoraussetzung der Souveränität in den verschiedenen Einzelkulturen, andererseits die Vorstellung, die Moderne lasse nur noch gebundenes, gewissermaßen bürokratisch »routiniertes « Charisma zu, reproduziere aber dabei einen fast allgemeinen Zwang zum Charisma. Einerseits haben wir die alten soteriologischen Visionen der Weltreligionen, andererseits ist das, was Tiryakian als säkulare Eschatologie bezeichnet, ein wichtiges Element der »Technology of Governance « des universell etablierten Nationalstaats.

Einerseits haben wir die universelle Reduktion der sozialen Kommunikation auf Symbol und Vision durch die neuen Medien, andererseits gilt gerade das visionäre und symbolische Potential als das eigentliche Reservoir »vormoderner « und nicht-westlicher Zivilisationen. Lassen sich diese Widersprüche analytisch lösen? Es scheinen mir ein paar vorläufige Bemerkungen angebracht.

\section{IX}

Zwang zum Charisma: Um erläuternd anzuzeigen, worum es geht, sei auf Adorno verwiesen, der ja schon in einer frühen Schrift auf die Gegensätze zwischen dem in Tat und Leid sich mit der Natur versöhnenden Menschen einerseits, und dem verinnerlichten, sich abhebenden, selbstreflektierten, im Grunde aber »objektlosen« Menschen herausstellt. Die Eigenlogik der Entwicklung von Modernität ist für Adorno im Grunde diesem Gegensatz geschuldet. Das Paradox des Identitätsdenkens ist, daß es sich gewissermaßen um eine in der Not der Vereinsamung und Abgehobenheit geborene Erfindung des »objektlosen Subjekts " handelt: Um ein notwendiges, aber immer wieder alles »Wirkliche« verfälschendes Instrument kultureller Produktion (Adorno 1969/1974). Zur Konstitution des »objektlosen Subjekts« ist ein generalisiertes, routinisiertes, charismatisches Selbstverständnis notwendig, das erst die ekstatische oder ersatzekstatische Herauslösung des Menschen aus der gegebenen Welt der Objekte und dem gelebten Alltag ermöglicht.

Ein Beispiel der intermediären, orientalisierenden Wirkungen der Moderne ist das generalisierte instrumentelle Verhältnis, das der durch die von der universellen Einrichtung des Nationalstaats ausgehende 
Zwang zur Charismatisierung schuf. Teilhabe an Modernität konnte so oft nur über diesen $Z$ wang vermittelt werden.

Weber hat diese Wirkung der Moderne früh erkannt. Gesellschaftliche Transformation läßt sich, folgt man Weber, in einer schicksalhaften Entwicklungsgeschichte des Charismas bestimmen. Das sich im Sinngebungsprozeß selbstversichernde Ich bedarf der äußerlich gestützten, habituellen Dauerhaltung. Hierin begründen sich in abendländischer Durchsetzungsform des Charismas unveräußerlich gewordene Rechte des Individuums. Der moderne, von der Aufklärung geprägte Vernunftbegriff trägt dem in säkularisierter Form des Charismas Rechnung und instrumentalisiert zugleich das sozial immer breiter verankerte Charisma im Dienste der Bürokratisierung. Über das so routinisierte Charisma können normative Standards im Interesse sozialer Bewegungen und intellektualisierter Gruppen gegen heteronome Akteure, Handlungszusammenhänge und Traditionen geschützt werden (Robertson 1982: 9). Für die komparative Bestimmung der Rolle der Weltreligionen in diesem für die Moderne so entscheidenden Transformationsprozeß ist von Bedeutung, daß auch die modernen buddhistischen, hinduistischen, konfuzianischen und islamischen Revitalisierungsbewegungen, wie immer die konkreten Formen ihrer gesellschaftlichen Einbettung auch sein mögen, eine moderne Reorientierungs- und Ordnungsfunktion übernehmen. Sie dienen, wie Riesebrodt zu recht behauptet, der ambivalenten Funktion "Strukturprobleme moderner Gesellschaften, die keineswegs als gelöst bezeichnet werden können « zu benennen (Riesebrodt 1990: 251). In den vertikal stark segmentierten islamischen Ländern etwa - alle mit einem hohen agrarischen Bevölkerungsanteil und großen ethnischen und religiösen Minderheitsgruppen - stehen heute Fragen des Schutzes normativer Standards als Integrations- und Ordnungsinstrumente ebenso auf der Tagesordnung wie Stabilisierungs- und Delegitimierungsprozesse. Dies ist keine Frage der inneren charismatischen Orientierung und der Rationalisierungspotentiale des Islams, sondern eine Frage der Potentiale seiner Instrumentalisierung. So steht der rationale Buch-Fundamentalismus, der an Traditionen der Orthodoxie anknüpft, heute unter dem gleichen nivellierenden Zwang der Nationalstaatskultur wie der im Sufismus begründete charismatische Erlebnis-Fundamentalismus. Entscheidend ist, daß der institutionalisierte, kompetitive Zwang zum Charisma die Instrumente der verschärften Trennung und Ab- 
grenzung solcher Traditionen erst liefert (Riesebrodt 1990: 22; vgl. auch Gellner 1981: 131-48).

Im routinisierten Charisma des Amtes - um das es hier geht - wird in nicht-westlicher Zivilisation ein abendländisches Kulturwerkzeug mit allen parodistischen und simulativen Effekten wirksam. Es wird nunmehr aber nur als intuitives und symbolisches und nicht als instrumentell destruktives Charisma interpretiert.

Die komparative Soziologie der Zivilisationen blickt an der Intensität solcher Effekte vorbei, weil sie Charismaformen aus inneren Rationalisierungen von Basisprinzipien herleitet und nicht aus generalisierten instrumentellen Zwängen.

Die charismatischen Notwendigkeiten der Moderne sind deshalb neu zu bestimmen: Sie folgen einer Doppellogik. Einerseits erscheinen die im Zeichen der modernen Selbstbehauptung aufgenommenen selektiven Bezugspunkte als unbelastete, »innere « Rekonstruktionen traditioneller Kulturbestände, andererseits folgen sie jedoch formalen, technischen und simulativen Mechanismen der Ausgrenzung, d.h. einer rigiden Logik der Dualisierung westlicher und östlicher Orientierungen.

\section{Kollektivierte Diesseitigkeit der Heilserwartung}

$\mathrm{X}$

Wie erklären wir uns das Entstehen diesseitsgerichteter Heilsbewegungen in einer außerweltlich orientierten Obligationenreligion? $\mathrm{Zu}-$ nächst scheint es plausibel, daß der soteriologische Heterodoxismus der Achsenzeit auch im Islam gewirkt und ein totalistisches Sektenwesen, auf gewaltmäßige Umsetzung des Heilsdenkens, hervorgebracht habe (Eisenstadt 1994). Andererseits ist das islamische Sektenwesen für den modernen islamischen Fundamentalismus völlig irrelevant. Ich neige deshalb dazu, den intermediären und universell instrumentellen Charakter des fundamentalistischen Heilsdenkens hervorzuheben. Dies ist keine Frage der inneren Grundmuster des Islams oder der einzelnen Weltreligionen oder der inneren Instrumentalisierung der in ihnen angelegten Heilserwartungen und Erlösungsrichtungen. Heilssuche und der Hinweis auf die Transzendenz weltlichen Handelns, die Sakralisierungsversuche von Wissenschaft und Politik, sind Ausfluß 
des globalisierten soteriologischen Diskurses der Moderne, nicht Ergebnis ungebrochener innerer Entwicklungen religiösen Denkens. Die Instrumente der säkularen Transposition von unterschiedlichen Formen der Heilsgewißheit in Recht und Wissenschaft etwa, die die Moderne anbietet, ist eine Lösungstechnik, die in allen Weltreligionen wirkt. Die Richtungen der kulturellen Lösungen, die sie hervorbringt, stellen auch noch die orientalischen sakral-spiritualistischen Revitalisierungen unter den kompetitiven Bedeutungszusammenhang universellen Ringens um säkulare Wertrationalitäten. Es ist diese Doppelstruktur, die kulturelle Globalisierung bedingt, nicht einseitiger Säkularismus.

\section{XI}

Im Wechselspiel des Kulturaustausches werden Basisprinzipien der Zivilisationen zu Hülsen, zu leeren Formeln der Selbstbestätigung der Akteure. Sie verlieren damit auch ihren inneren orientierenden Charakter. Mir scheint es gerade aus dieser Perspektive notwendig, kulturübergreifende Sozialforschung an der Tatsache dieses Formenwandels festzumachen, d.h. an den referentiellen Techniken interkulturell geprägter Rekonstruktionen. Damit steht auf verschiedenen Ebenen sozialen Wandels der sich eigenlogisch durchsetzende, selbstreferentielle Mechanismus des Authentizitätsdenkens mit seinen selektiven Mechanismen der Inkorporation und Ausgrenzung im Zentrum der Beobachtung.

Orientalisierung bedeutet neue lokale und nationale kulturelle Rekonstruktionen, die die Religion über den durch ihren globalen Status vermittelten Begriff erfährt: Das eigentliche Beobachtungsfeld bleibt dabei auf Techniken der Säkularisierung und der Resakralisierung beschränkt.

Luckmanns an Troeltsch und Simmel geschultes Paradigma der Säkularisierung ist symptomatisch: Säkularisierung des öffentlichen Lebens steht in engem Zusammenhang mit eigenartigen Resakralisierungsprozessen, insbesondere der inneren, lebensweltlichen Konstitution des modernen Individuums. Es handelt sich um eine verborgene, in den modernen Lebensstil eingebettete Sakralität, die, wenn sie sich in kollektive kulturelle Konstruktionsmechanismen transformiert, das Prinzip der inneren Heiligkeit des Individuums in ein Problem der sozialen Rekonstruktion der Religion verwandelt. 
Es ist kaum zu übersehen, daß Orientalisierung nicht nur in den islamischen Ländern vorherrscht. Religion wird auch in anderen Regionen in den Kampf für nationale Interessen und in den Kampf um Partizipation am modernen Lebensstil und strategische Affiliationen im internationalen Wettbewerb eingebunden. Dabei spielen die Eintrittsund Öffnungspunkte in den Weltmarkt eine gewisse Rolle. Säkularisierungstechniken wie die Verbannung des religiösen Ritus aus dem öffentlichen Leben, die selektive Aufnahme einzelner religiöser Begriffe im Dienste säkularer institutioneller Begründungen, aber auch politische Strategien des Antikommunismus sind zunächst für nationale Formierungskämpfe kennzeichnend. In diesen Kämpfen wurden aber auch bereits die Grundlagen für Prozesse der Resakralisierung gelegt: Ökonomische Liberalisierung und soziale Selbstregulierung von unten führten auch zur symbolischen Überfrachtung des öffentlichen Lebens und Kollektivierung des religiösen Ritus. Am Staat vorbei wurden religiös bestimmte Formen der sozialen Regulierung rehabilitiert. Lokale Schlichtungstraditionen wurden neu in den Dienst des religiösen Rechts gestellt. Hier müßte ein systematischer Vergleich notwendig aufzeigen wie stark sich die unterschiedlichen sozialen Einbettungen der islamischen Bewegungen auf die Formen der Resakralisierung auswirken.

\section{XII}

Charismatisierung und Instituierung des religiösen Heilsdenkens behalten einen selbstreferentiellen Eigenwert und verbinden sich nicht mit funktionssystemischer Rationalität, wie die Apologien einiger Fundamentalismus-Forscher uns glauben machen wollen (vgl. Binder 1988; vgl. auch Stauth 1993b). Im Zentrum stehen deshalb Techniken symbolischer Rekonstruktion als Instrumente der Nationalstaatsbildung und der Durchsetzung bürokratischer Herrschaft. Regulative Techniken sind sekundär. Es ist kein Widerspruch, daß die Instrumentalisierung von Charisma und Erlösung mit der imaginären Aneignung und symbolischen Transformation der sinnlich wahrnehmbaren Welt einhergeht: Das bloß Konkrete, reale soziale Not und natürliches Leiden verschwinden hinter dem Schleier ästhetischer und symbolischer Repräsentationen. Perzeptionsformen natürlicher und sozialer Realität sind als Bargainingprozesse vor allem in der semiologischen Anthropologie diskutiert worden. Dabei wurden die lokalen Wissenssysteme 
einer Rehabilitation unterzogen. Ist der Wissenspartikularismus erst einmal universell legitimiert, so trägt er zur Retraditionalisierung bei. Andererseits setzt sich dieser Partikularismus selbst nur über Monopolisierungen der interpretativen und imaginativen Macht durch. Es lassen sich ganz unterschiedliche Bargainingprozesse der »Realität« bestimmen: Wie sind Alltagsstrukturen, materielle Bedürfnisse und strukturelle Konflikte in diese Prozesse eingebunden? Liegt die Betonung der sozialen Kodes auf der Konstitution von Außeralltäglichkeit und religiöser Spiritualität, so gerinnt der Diskurs über Realität zur Farce symbolischer Repräsentation. Der Absolutismus visueller Reproduktionen der Realität bedingt so eine relative Immunisierung des Zentrums gegenüber alternativen Interpretationen. Der hier neu einsetzende Soziozentrismus läßt nur für kollektive Formen der Selbstinterpretation Raum. Malaysia ist der exemplarische Fall, in dem sich über solche Prozesse eine Spiritualisierung des politischen Diskurses im Zentrum durchgesetzt hat. Ein neues Entwicklungsmodell? 


\section{Islam als Selbstbegriff nicht-westlicher Modernität ${ }^{\mathrm{I}}$}

\section{Einführung}

Die neueren Konzeptualisierungen des Verhältnisses zwischen Islam und Moderne, nämlich, daß der Fundamentalismus eine ähnlich wichtige Modernisierungsfunktion übernehme, wie sie der Protestantismus im Europa des 16. und 17. Jahrhunderts und in Amerika im ausgehenden 19. und beginnenden 20. Jahrhundert gehabt habe, bilden den Hintergrund der hier aufgenommenen Beschäftigung mit islamischen Neo-Modernisten. ${ }^{2}$ Meiner Meinung nach sind solche Darstellungen des Islams, wie sie jüngst in den verschiedensten Schattierungen vorgetragen wurden, ideologisch einem affirmativen Okzidentalismus zuzurechnen; sie verteidigen gleichzeitig, direkt oder indirekt, den islamischen Fundamentalismus als notwendige und einzig legitimierte Erneuerungskraft islamischer Länder. ${ }^{3}$

Vor diesem Hintergrund ist es wichtig, darauf hinzuweisen, daß die universelle Anwendung des Begriffs der Modernität deren doppeldeutigen Charakter als säkulare Kultur, die ungeachtet dessen ihren Ursprung in der Christenheit und in christlich-theologischen Begriffen behält, eher verschleiert hat. Modernität als westliche Weltsicht beinhaltet religiöse Haltungen, die im soziologischen Diskurs der Moderne und der Modernisierung nicht-westlicher Kulturen in gewisser Hinsicht hintangestellt, ja geleugnet wurden. Auf diese Weise wurde Säkularität als ein Gut den westlichen, und Religiosität als unauflösliches Element den östlichen Kulturen zugeordnet, und gewissermaßen auf einer subtileren Ebene der eigene historische "Fundamentalismus" (der Säkularisierung erst ermöglichte) in die Prinzipien des kulturell »anderen « hinein konzeptualisiert. ${ }^{4}$ In dieser Form des wissenschaftlichen Dialogs liegt noch ein zweites Problem. Modernisierungstheoretische Darstellungen des Verhältnisses von Islam und Modernität nehmen die intrinsischen Versuche muslimischer Denker, eine eigenständige islamische Modernität zu konzeptualisieren, kaum ernst und überlassen diese dann selbst dem breiten Feld fundamentalistischer Aneignungen. Es gab eine Generation islamischer modernistischer Denker der späten 60er und der frühen 70er Jahre, die dazu bereit waren, einen modernisierenden Standpunkt innerhalb des Islams zu entwickeln, indem sie die Positionen von früheren Modernisierungsver- 
suchen sowie die Entwicklungsnotwendigkeiten und emanzipatorischen Ansprüche früherer Perioden überdachten. Es ist kennzeichnend für die Form des Dialogs zwischen Islam und westlicher Moderne, daß dieser Standpunkt weitgehend vernachlässigt worden ist. Man läßt es geschehen, daß er stillschweigend vom Fundamentalismus vereinnahmt wird, so als wäre nichtfundamentalistische Modernisierung ein nicht zu realisierendes Paradox.

Mit diesen Ausführungen möchte ich auf Fazlur Rahman ${ }^{5}$, Malik Bennabi ${ }^{6}$ und Ali Shari'ati ${ }^{7}$ hinweisen, die eine Generation intrinsisch islamischer Theoretiker der Moderne mit einer einmalig unabhängigen Haltung vertreten. Sie haben je individuell verschiedene Methoden der modernen Konzeptualisierung des Islams entwickelt, indem sie Grundbegriffe soziologischer Theorien der Moderne aufgriffen und islamisches Denken vor dem Hintergrund dieser Begriffe neu bestimmten. Zum besseren Verständnis werde ich mich darauf beschränken, Fazlur Rahmans akademisches und pragmatisches Konzept der islamischen Modernität zu skizzieren und die Befreiungsphilosophien von Malik Bennabi und Ali Shari'ati nur bruchstückhaft zu konnotieren.

In Fortführung zu meinen Ausführungen über die doppeldeutige Verbindung zwischen Religion und Modernität möchte ich den Begriff der islamischen Modernität untersuchen und die Frage aufgreifen, warum seine fundamentalistische Aneignung so ungebrochen möglich ist. Ich schlage hier, ausgehend von Fazlur Rahman, drei theorierelevante Bereiche, nämlich »islamische Rationalität«, »islamische Identitätsbildung " und »islamische Sozialordnung « als die zentralen Diskussionspunkte vor, die die islamischen Modernitätstheoretiker selbst beschäftigt haben. Ich beginne mit dem Punkt des Verhältnisses von Islam und sozialer Ordnung.

\section{Modernität und die Krise sozialer Ordnung}

Soziologische Betrachtung als Ausgangspunkt und die Konstruktion islamisch-sozialtheoretischer Begriffe als Gegenstand setzen voraus, daß wir uns des ambivalenten Verhältnisses bewußt bleiben, das die Soziologie in bezug auf die Vorstellung der sozialen Welt der Moderne selbst hat. Sie ist gewissermaßen eine » Krisendisziplin «, erwachsen aus einer Krise des Übergangs und belastet mit dem Versprechen, diese zu 
lösen. Sie ist somit aufs engste mit dem Problem Krise und Ordnung in der modernen Gesellschaft verbunden.

Die sehr entschlossen universalistischen Modernitätsforschungen eines Louis Dumont und eines Shmuel N. Eisenstadt etwa haben selbst das Ordnungsproblem in der modernen Gesellschaft als ein Ergebnis komplementärer Beziehungen und Spannungen zwischen modernen und vormodernen Grundorientierungen betrachtet (Dumont 1986b: 236; Eisenstadt 1979). Das bedeutet eine deutliche Kritik unilinearer Fortschritts- und Modernisierungskonzeptionen. Das Problem moderner sozialer Ordnung verlagert sich auf das Ausbalancieren der Spannungen zwischen Moderne und Vormoderne. Die Suche nach Begriffen moderner Ordnung steht dann ganz im Zentrum dieses Spannungsverhältnisses. Dies impliziert aber auch, daß die soziologischen Modernitäts- und Ordnungstheorien selbst in diesem Paradox einer »nostalgischen" Erneuerungssuche verhaftet sind (Stauth/Turner 1988a: 27-59). Es ist deshalb kaum verwunderlich, daß der Diskurs über Modernität und Islam von ähnlichen Problemlagen gekennzeichnet ist.

Talcott Parsons stieß auf ein zusätzliches Problem. Die inneren Gefühlsmodulierungen und kulturellen Ausdrucksweisen, die ihre spezielle Bedeutung in einem Teilbereich gesellschaftlicher Organisation haben, verlieren gerade durch die spezifische Angepaßtheit an diese differenzierte Gesellschaftswelt das Potential, als allgemein formende Muster in einem standardisierten System breiterer gesellschaftlicher Organisation zu fungieren. Letzteres hätte aber die Instinkte und Emotionen der Individuen über die verschiedenen spezifischen Interaktionsbereiche der modernen Gesellschaft hinaus generell zu regulieren. Aus diesem Grunde war Parsons der Auffassung, daß soziale Differenzierung und die differenzierten Segmente der modernen Gesellschaftsstruktur nur durch einen koinzidierenden Differenzierungsprozeß von Normen und von Verallgemeinerungen rekonstruierter Werte aufrechterhalten und integriert werden kann.

Wenn man die moderne Welt als eine Welt ansieht, die sich aus getrennten, aber sich gegenseitig durchdringenden Feldern sozialer Ordnung zusammensetzt, dann besteht die Schwierigkeit darin, die integrativen und flexiblen Wertmuster zu bestimmen, die über die Grenzlinien der verschieden konstituierten Einzelbereiche hinaus, wie z.B. ursprünglich so gegensätzlich strukturierte Bereiche wie der Haushalt der Großfamilie und das Unternehmen, Gültigkeit haben. Nach Auf- 
fassung von Parsons werden solche Wertmuster durch normative Komponenten wie die Restrukturierung familialer Werte, die Religion und das Bildungssystem neu gebildet. Sie haben sowohl eine religiöse als auch eine weltliche Bedeutung (Parsons 1971; Parsons 1991: 37-65).

Andererseits beschreibt Jürgen Habermas, der sich weniger mit Ordnung als mit der Gültigkeit der modernen Lebensweise befaßt, Modernität als eine Kulturform, die die Spannung und die gründliche formale Trennung zwischen verschiedenen praktisch sich durchdringenden Gesellschaftsbereichen, wie etwa Recht, Moral und Kunst, zu einem wesentlichen Bestandteil gesellschaftlicher Organisation gemacht hat (Habermas 1983: 11). Nach Habermas ist es das differenzierte Zusammenspiel von individuellen Lebensmustern und institutionellem Recht, das Modernität ausmacht (Habermas 1983/1984).

In beiden Vorstellungen moderner Ordnungen, sowohl derjenigen von Parsons als auch in der von Habermas, stellt sich das Problem der Spannung zwischen formaler, rechtlicher Verallgemeinerung durch Differenzierung auf der einen Seite und auf der anderen Seite das Problem, in welchem Verhältnis die moralische Integration der Gesellschaft durch Wertegeneralisierung zur rechtlichen Seite, zur Regelungsstruktur, steht. Man darf deshalb davon ausgehen, daß das Spannungsverhältnis zwischen der Art der Verrechtlichung und der Form der Wertegeneralisierung ein Grundproblem moderner Gesellschaftsordnungen darstellt. Es gibt einen fundamentalen Punkt, in dem Parsons und Habermas nicht übereinstimmen. In diesem Dissens deuten sich zugleich zwei verschiedene Lösungen an. Während für Parsons sich das Verhältnis von Recht und Moral rein funktional gestaltet - die Moral, Dinge miteinander verküpfend, die das Recht sorgfältig voneinander trennt -, ist für Habermas die materiale Bindung von Moral und Recht, die innere Verschränkung von Wertegeneralisierung und rechtlicher Formalisierung, eine notwendige Voraussetzung für den Bestand von moderner Gesellschaft überhaupt. Habermas interpretiert Weber in Hinblick auf Parsons' funktionales Schema der Wertegeneralisierung und weist darauf hin, daß Weber und Parsons in der Form, in der sie die Institutionalisierung zweckrationalen Handelns von den Komplexen normativen Handelns trennen, an den notwendigen Integrationsbedürfnissen der modernen Gesellschaft vorbeigehen. Dies gelte auch für ihre Trennungen der motivationalen Grundlagen von den moralischen und praktischen Wertbereichen. Nach Auffassung 
von Habermas gefährdet oder zerstört die materiale Rationalisierung, die über soziale Bewegungen und die Umsetzung der in der Lebenswelt sozialer Akteure verankerten Werte verursacht wird, weder die kognitive Rationalisierung noch die Rationalität des Rechts. Habermas insistiert statt dessen auf dem inneren Zusammenhang zwischen der progressiven ethischen Rationalisierung und der vollen Entfaltung aller Ebenen institutionellen Handelns (Habermas 1983: 267ff.).

Es ist hier nicht mein Interesse und wäre sicherlich an dieser Stelle zu weit gegriffen, die weitreichenden Implikationen der Habermasschen Lesart des Begriffs der materialen Rationalität zu entwickeln. Es ist jedoch offensichtlich, daß Habermas gewissermaßen in einem affirmativen Akt die moderne Notwendigkeit der funktionalen Verflechtung von materiellen Interessen und moralischer Orientierung beschwört, denn - wie Habermas ja in anderem Kontext durchaus anerkennt - die formalisierende Selbstlogik einer Rechtsordnung steht doch immer in einem starken Gegensatz zur kreativen Vielfalt des kulturellen Lebens. Habermas macht sich aber mit seinem ideellen, dadurch aber nicht weniger einseitigen Kommunitarismus gegenüber Parsons in doppelter Weise verdächtig: Erstens scheint er hier eine Gegebenheit moderner Lebensweise, nämlich das Problem der Vermittlung von Kultur und Recht, gewissermaßen als Theorie der Erneuerung durch neue Formen sozialer Bewegungen affirmativ zu bestätigen. Zweitens läuft er Gefahr, die normative Kraft formeller Lösungen prinzipiell zu unterschätzen. Er baut auf die fundamentale Verschränkung von Wert- und Zweckrationalität. Dies ist um so problematischer, als Nietzsches Kritik der Moderne gerade wegen jener »fundamentalistischen « Verbindungen der »letztendlichen Werte« mit »niederem Interesse in der Dritten Welt zunehmend rezipiert und dort zur Basis einer anti-westlichen Kritik gemacht wurde. Habermas' Konzeptualisierung der Moderne mündet in diesem Punkt in eine fundamentalistische Lösung. Der materiale Rationalitätsbegriff, den Habermas verfolgt, stimmt mit einer fundamentalen westlichen Aussage überein, die sich zwar auf eine Lösung der Doppeldeutigkeiten des moralischen Ursprungs der westlichen Modernität bezieht, die sogleich jedoch unter nicht-westlichen Prämissen betrachtet in eine Politisierung und Fundamentalisierung der Religion als moderne Ideologie (der Auslagerung »niederer Instinkte«, i.e. westlich instrumenteller Werte) münden muß. 
Parsons' Aussage über die Integrationsfunktion generalisierter Werte bezieht sich dagegen offensichtlich auf ein viel umfassenderes Modernitätsmodell und ist wesentlich auf ein allgemeines Muster der Modernisierung abgestellt, nicht auf die Kraft spezifischer Werte. Im Gegensatz zu Habermas stärkt Parsons Max Webers formalen Rationalitätsbegriff und unterstreicht die Verfahrenstechniken der modernen Rechtssysteme als neutrale Instanzen und Bewahrer allgemeiner Prinzipien sozialer Organisation. So schließt er unter diesem Gesichtspunkt die Möglichkeit, die vormodernen Klassifikationssysteme der Anwendung Talmudischer Gesetze und des traditionellen Islamischen Rechts, gewissermaßen ungebrochen auf die Stufe der formalen Generalisierung zu heben, aus. Doch sieht er durchaus das Potential, nichtwestliche moralische und kulturelle Problematiken als Gegenstände moderner Generalisierungen umzusetzen (Parsons 1975: 48).

Fazlur Rahmans Interesse an einer innerislamisch begründeten Ordnung der Moderne in einer nicht-westlichen Gesellschaft galt gerade dieser Problematik. Es ist dabei wichtig, sich zu vergegenwärtigen, daß er selbst mit den Grenzen, Spannungen, Windungen und Antagonismen der westlichen Konzeptualisierungen der Modernität vertraut war. Es ist deshalb keineswegs unbegründet zu fragen, vor welchen Orientierungsproblemen ein islamischer Denker etwa am Scheideweg der Begründung eines modernen islamischen Staatswesens zu Beginn der 60er Jahre stand. Sollte er einem essentialistischen und spezifisch westlichen Modernitätskonzept folgen, das Recht und Moralität einer inneren Notwendigkeit entsprechend verknüpft, oder sollte er sich an einem generalistisch funktionalen Begriff des Rechts orientieren, wonach Moral nur an die Erfordernis gebunden ist, ausdifferenzierte Bereiche sozialen Handelns zu integrieren, Recht aber ein eigenständiger formaler Bereich der Notwendigkeit von Ordnung bleibt? Habermas und Parsons sind nur die signifikantesten Protagonisten solch unterschiedlicher Auffassungen zur modernen Gestaltung des Verhältnisses von Moral und Recht. Beide gehen von Weber aus und es ist dieses spezifisch Webersche Paradoxon zwischen formaler und materialer Rationalität, das die Doppeldeutigkeit des Konzepts der Moderne ausmacht. Paradoxerweise scheint der Wechsel in der Betonung von ethischer zu utilitaristischer Handlungsorientierung mit der Notwendigkeit einherzugehen, die emotionale Welt mit ethischen In- 
halten zu erfüllen und der Wertbildung ein neues, moralisch-praktisches Gewicht zu verleihen.

Es ist nun darauf hinzuweisen, daß dieses Paradoxon zwischen materialem rationalem Anspruch und formalrechtlicher Notwendigkeit sozialer Integration sich noch spannungsvoller in Ländern entwickelt, in denen das formale Recht gewissermaßen von außen aufoktroyiert wurde: In vielen islamischen Ländern wurde den vormodernen lokalen Rechtsauffassungen schon früh eine moderne, wenn auch koloniale Staatsverfassung übergestülpt. So konnte es, wie zum Beispiel in Ägypten, dazu kommen, daß der Code Napoléon als das bürgerliche, die Shari'a, das islamische, als das Familienrecht, und lokale Traditionen als das Recht der sozialen Gemeinschaften, 'urf, nebeneinander existierten, ohne eine rationalistische Verrechtlichung zu ermöglichen, weil auf Interessenausgleich ausgerichtete Institutionen fehlten. Dies hat natürlich leicht zu Vorstellungen von einem illegitimen, weil »fremden« Recht geführt, während leicht alles, worin unter der Willkür der Geschichte die Volksseele sich wiederfand, als rechtlich legitim, weil authentischen moralischen Werten entsprechend, verteidigt wurde. Wie immer man die Frage nach legitimen oder authentischen Lösungen beantworten will, die Existenz eines tiefen sozialen Widerspruchs in der formellen Anwendung des Rechts und des Rechtsbewußtseins im allgemeinen förderte die Suche nach immanenten Regulierungen durch kulturell gestützte Formen oder von Authentisierungen derselben. Hier treten in der Tat die Widersprüche zwischen beiden Auffassungen des Verhältnisses von rechtlicher und moralischer Modernisierung in Kraft: die äußere funktionale Auffassung und die innere substantielle. Beide sind für einen weiterführenden Diskurs über Islam und Modernität höchst bedeutsam. Beide Auffassungen haben auf das Entstehen des Modernismus im Islam einen sehr großen Einfluß. Die Generation von Modernisierern wie Malik Bennabi, Ali Shari'ati und Fazlur Rahman scheint besonders in diesen Antagonismus verwickelt zu sein. Bei ihrem Versuch, die Funktionalität des Islams in bezug auf die Moderne zu verstehen, warfen sie neue ethische Fragen auf, die die gegebene emotionale Welt des Sozialen in Frage stellten. Sie versuchten, im Spannungsfeld zwischen formaler und substantieller Rationalisierung stehend, sowohl die moderne ethische Vision des Islams als auch die gegebene emotionale Welt der modernen 
Massengesellschaft in ein Rechts- und Regelungssystem zu harmonisieren, das sie aus islamischen Vorstellungen heraus entwickelten.

Sie legten so das Fundament für ein spezifisch islamisches Modernitäts-Projekt, das die inneren Entwicklungen der islamischen Weltsicht mit den dynamischen und existentiellen Modernitätserfordernissen zu verbinden suchte. Mit Bezug auf die gegebene Problematik, eine im postkolonialen Umschwung begriffene Gesellschaft zu führen oder zu lenken, ging es um die Frage, ob der Islam bei der Bewahrung gewisser standardisierter Formen des emotionalen Lebens unter den extrem vielfältigen Bedingungen von gesellschaftlicher Organisation der Moderne funktional sein kann. Es ging also um eine Form islamischer Wertegeneralisierung. Dabei stellte sich das Problem, ob und wie Islam als Religion, die islamischen gesetzlichen und moralischen Prinzipien sich überhaupt den modernen gesellschaftlichen Notwendigkeiten öffnen können. Fazlur Rahman wies hier erstmals bewußt auf die Notwendigkeit der Verbindung von utilitaristischem Denken und islamischer Moral hin und suchte bewußt die dynamische Konvergenz von nebeneinander existierenden, jedoch häufig antagonistischen modernen und vormodernen Strukturen.

Rahman hielt das traditionelle islamische Recht, wie es von einer rückständigen Schicht kasuistisch denkender, orthodoxer Rechtsgelehrter praktiziert wurde, für ein Hindernis und gerade unter dem Gesichtspunkt moderner gesellschaftlicher Kohärenz für der Generalisierung gegenläufig. Er befürwortete deshalb eine Neuinterpretation des Koran und optierte für die Kritik der mittelalterlichen Rechtstheorie und Gerichtsbarkeit, die nach seiner Meinung im Widerspruch zum Islam selbst und seinen Lehren standen. Bezeichnenderweise hat Fazlur Rahman dies als ein Dilemma zwischen islamischem Modernismus und formeller, wenn man so will, hohler Islamisierung säkularer modernistischer Strukturen bezeichnet. Die Moderne zu suchen hieß für ihn, »das Gesetz direkt vom Koran abzuleiten « und zwar in soziologischer Manier und in intellektuell redlicher, wahrhaftiger und praktischer Weise oder - eine andere Lösung, die er verwarf, die heute aber allseitige Praxis fundamentalistischer Politik ist - »die gesetzlichen und institutionellen Elemente, die einmal von außerhalb im Islam übernommen wurden, zu islamisieren« (Rahman 1970: 317). Er verwarf auch die dritte mögliche Lösung, nämlich die Umsetzung einer strategisch-geplanten westlichen Modernität in die nicht-westliche soziale 
Umgebung des Islams, die diese nur stärken würde, indem nur falsche Ergebnisse und moralische Schwäche aufgrund eines »fremdartigen « westlichen Standpunkts erzeugt würden (Rahman 1966c: 222f.).

Aus diesem Dilemma heraus konzentriert sich Rahmans Theorie einer modernen islamischen Gesellschaft auf drei Punkte:

1. Kritik an der »mittelalterlichen Scholastik « der religiösen Orthodoxie, an ihrer ritualistischen Interpretation des Korans und an ihrer formalistischen Anwendung des islamischen Rechts.

2. Entwicklung einer dynamischen Neuinterpretation des Korans, die eine diesseitige und immanente Vorstellung von Gott aufzeigt.

3. Wiedereinsetzung - wie er es meint - des ursprünglichen ethischen Utilitarismus im Islam.

Die intellektuelle Promiskuität des islamischen intellektuellen Orthodoxismus, wurde Rahman dadurch deutlich, daß in Folge der Abgehobenheit der 'ulama, des traditionellen islamischen Rechts- und Gottesgelehrtentums, hier nur in unbeholfener Form auf die Moderne eingegangen und lediglich auf unverbindliche Rationalität, auf bloß äußere Wissenschaft und Technologie, auf abstrakte Freiheit, Liberalismus und Individualismus spekuliert wurde, in toto auf etwas, das man in katholischer Manier problemlos inkorporieren könnte, ohne damit Ritus und Ethos des »wahren « Islams ernsthaft zu tangieren. Nach Rahmans' Ansicht fehlt es einem so verstandenen Modernismus »an jeglicher Rechtfertigung über sich selbst hinaus (Rahman 1966c: 223). Aus diesem Grunde glaubte er, daß die 'ulama nur die moralische Grundlage für die militanten Reaktionen jener frühen Fundamentalisten wie der Salafi-Bewegung in Ägypten und der »Moslem-Bruderschaft « legte. Rahmans Gedanken in bezug auf ein mögliches islamisches Fundament moderner Gesetzgebung führen zu einer komplizierten rationalen, aber antisäkularen Konstruktion; antisäkular aus der instrumentellen Überlegung, daß Säkularismus unter den gegebenen Bedingungen nur die Positionen der Orthodoxen und der Fundamentalisten stärkt.

Unter diesem instrumentellen Gesichtspunkt sollte der Islam nicht als anti-westliche Ideologie dienen. Der Islam darf nicht zum Mittel verkommen, die Welt vor den Fehlleistungen des Westens zu retten. Und doch tritt Rahman gegen den Universalismusanspruch der westli- 
chen Moderne an und empfindet es als einen Skandal der Geschichte, daß das kulturelle System des Westens sich als »eine ideale Kultur für die gesamte menschliche Rasse « darstellt und sich zugleich ohne Scham »allen anderen aufdrängen kann« (Rahman 1980a).

Er sucht geschickt nach einem Mittelweg zwischen dem westlichen Säkularismus und den katholischen, »modernen « Antworten der traditionellen religiösen Orthodoxie. Für ihn sind weder Säkularisierung des Islams noch der unverbindliche Katholizismus der Orthodoxie Lösungen, die als Basis für die Entfaltung einer spezifisch islamischen Modernität herhalten können. Der intellektuell interessante, schwierige Weg, den er statt dessen beschreitet, führt zunächst zu einer kritischen, historischen, aber islamisch begründeten Neu-Interpretation des Korans. Er folgt damit der Forderung seines Lehrers, H.A.R. Gibb, des großen englischen Orientalisten, nach mehr theologischem Gehalt, der dem religiösen Modernismus des Islams fehle. Gibb hatte behauptet, »daß dieser (der religiöse Gehalt des islamischen Modernismus) in den Argumenten und Polemiken der 'ulama gegen die Verbreitung des Säkularismus « eher zum Ausdruck komme »als in den aktuellen Büchern und Aufsätzen modernistischer Denker« (Gibb 1975: 60).

Rahman wollte dieser Sachlage zweifellos mit dem Entwurf einer programmatisch theologischen Modernität ein Ende setzen. Er beruft sich auf die ungebrochene Lebendigkeit des Islams. Weltliche Erziehung und die westlichen Lebensgewohnheiten haben die Akzeptanz der grundlegenden theologischen Doktrinen des Islams nicht beeinträchtigt. Er ist deshalb der Meinung, daß die bloß äußerliche Aufnahme des westlichen Rationalismus in die islamische Theologie für den Gläubigen nur den Wahrheitsgehalt der Religion reduzieren müßte. Islamischer Modernismus heißt deshalb nicht Übernahme des westlichen Rationalismus, die Konzeptualisierung des Projekts »islamischer Modernismus « bedarf vielmehr einer spezifisch nicht-westlichen islamischen Antwort. Es sollte sich also um eine nicht-westliche Neuschöpfung von Denkweise und Lebensform handeln.

Wenn Gibb beobachtete, daß der Islam durch die Übernahme von »humanistischen oder anderen Werten, die sich in der westlichen Welt manifestiert haben « (Gibb 1975: 51), eine Art von »doppelter Gesinnung « entwickelt habe, so stellt Rahman dieser »doublemindedness « 
der konventionellen moslemischen Modernisten den Versuch entgegen, den Standort des islamischen Modernismus nicht nur auf der Ebene einer »neuen Spannung, die von außen in die islamische Gedankenwelt hineingebracht wurde «, zu bestimmen, sondern vielmehr vermittels einer »neuen theoretischen Fragestellung (Gibb 1975: 51). Es handelt sich dabei um die grundlegende Frage einer modernen islamischen Lebensordnung und um die damit verbundene innere ethische Orientierung. Es sei damit aufzuhören, daß man im Namen des Islams jede Neuformulierung ethischer Prinzipien zurückweise und damit jeden gesellschaftlichen Wandel ablehne. Wenn man sich dem Utilitarismus in der Ethik widersetze, dann sei Modernität, die gesellschaftliche Ordnung des modernen Menschen, mit einer spezifisch moslemischen ethischen, philosophischen und dogmatischen Begründung nicht mehr möglich. Die orthodoxen Dogmatiker, die die Heiligkeit der traditionellen gesellschaftlichen Institutionen verteidigen, stehen so für Rahman in starkem Gegensatz zur großen Anzahl moderner Muslime, die ihre Religion praktizieren und zugleich die Notwendigkeit zur Veränderung der praktischen Verpflichtungen in der modernen Welt sehen und die gewillt sind, über sozialen Wandel und den Wandel der Stellung islamischer Institutionen in der Gesellschaft zu diskutieren.

Gibb hatte noch die islamischen Modernisten als diejenigen definiert, die bereit sind, die Glaubensgrundlagen zu überprüfen. Fazlur Rahman, Malik Bennabi und Ali Shari'ati stellen dagegen die Glaubensgrundlagen des Islams in den Kontext innerer rationalistischer Affirmationen. Rahman beharrte - in der Sache der pragmatischen Sicht eines angelsächsischen Gelehrten verpflichtet - auf der islamischen Fundierung der Errungenschaften des modernen Lebens und moderner Institutionen, während die »Befreiungs-Theologen « Bennabi und Shari'ati beide während ihres Studiums in Frankreich eine entschiedenere Vorliebe für die philosophische Fundamentalkritik der westlichen Moderne entwickelt hatten (Shari'ati 1980a; Bennabi 1980). Neben der Kritik am frivolen Monopol der orthodoxen 'ulama auf den »Text« verfocht Rahman die Idee einer dynamischen Rekonstruktion der Gesellschaft, die auf einer tragbaren Verbindung mit der islamischen Vorstellung der Gegenwart Gottes gegründet ist. ${ }^{8}$ Mit der Auffassung von einem Gott, der in dieser Welt immanent, ja präsent ist, be- 
schränkt sich Rahman auf eine substantivistische islamische Sichtweise der Moderne, die den Säkularismus, nicht aber die Funktion säkularer Institutionen zu ihrem Feind erklärt. ${ }^{9}$

Dennoch ist darauf hinzuweisen, daß Rahmans Forderung nach einer Auseinandersetzung des islamisch-ethischen Prinzips mit den Notwendigkeiten der modernen Welt aufrichtig die Forderung nach einem ethischen Fundament moderner gesellschaftspolitischer Mechanismen beinhaltet. Aber er muß dies in eine - wenn auch fachorientierte - theologische Sprache übersetzen. Hier wird das Dilemma seines Modernismus deutlich, denn in der Verbindung von kartesianischen Technologien mit einer anti-westlichen Religionskultur liegt der fundamentalistische Sprung. In der Praxis ist es immer die Religionskultur, die die Techniken des Denkens zu absorbieren vermag.

Rahman z.B. folgt einem instrumentellen Pragmatismus, wenn er den Monotheismus im Sinne eines modernen Egalitarismus definiert:

»In den Augen des Korans wird Monotheismus nur sinnvoll, wenn er in die moralische Konsequenz der grundsätzlichen Gleichheit der Menschen mündet. Ohne diese Konsequenz wird der Monotheismus sinnlos und er ist in der Tat monolateral, d.h. Anbetung nur eines einzigen Wesens. ${ }^{10}$

(Rahman 1967a: 105)

Aber damit wird ein unmittelbarer Anspruch der Religion nach Gestaltung der gesellschaftlichen Wirklichkeit geweckt. In voller Übereinstimmung mit Iqbals soziologischer Rekonstruktion des Islams und damit doch weit hinter den faktischen Grad gesellschaftlicher Säkularisierung zurückfallend - insistiert Rahman darauf, daß »der Islam ursprünglich eine `Gesellschaftsreligion ist « (Rahman 1966b: 319) und daß es »das Hauptziel des Korans ist, eine moralische Gesellschaftsordnung zu schaffen" (Rahman 1966c: 222). Rahmans' Anregung", die Gesellschaft als eine göttliche Institution zu sehen, wird auch von den islamischen Fundamentalisten geteilt (z. B. Faruqi 1980).

Schließlich verfolgt Rahman aber die Absicht, den moralischen Utilitarismus des frühen Islams wiederauferstehen zu lassen. Ohne diesen wäre die Weltanpassung des Islams in der Nachzeit der frühen Eroberungen und die »Islamisierung « der beherrschten Völker und Kulturen nicht möglich gewesen. Es war die instrumentelle Machtgestaltung der 
frühen Muslime in den Jahrhunderten der Eroberung und der Dogmenformulierung, die das Überleben des Islams und den Aufbau der islamischen Zivilisation ermöglichten. Es darf hier nicht vergessen werden: Auch in dieser neuen Begründung des ethischen Utilitarismus im Islam bleibt das Überleben der Religion höchstes Ziel.

Ähnliche soziologische Tendenzen und kartesianische Technologien sind bei Bennabi und Shari'ati zu finden (Bennabi 1991a: 111; Shari'ati 1979). Der Koran stellt gewisse fundamentale gesellschaftliche Organisationsprinzipien auf: Soziale Gerechtigkeit, Kooperation, Brüderlichkeit und Selbstaufopferung zum Wohle der Allgemeinheit. Er ist damit auf eine sinnvolle und positive Gleichheit unter den Menschen gerichtet. Nur von hier aus kann sich der Islam behaupten und sich utilitaristisch in weltlichen Bereichen mit einer diesseitsgerichteten Anschauung entwickeln. Um die anvisierte Gesellschaft zustandezubringen, müssen effektive Institutionen geschaffen werden, die ein geeignetes Instrument zur Durchsetzung gesellschaftlicher Werte und Ideale sein können.

»Die vom Islam angestrebte Gesellschaft ist eine entschlossen geführte Gesellschaft und nicht eine bewußt alleingelassene oder vernachlässigte ('freie<) Gesellschaft, in der jeder denkt, er sei auf sich gestellt, wie das in einigen der sogenannten Wohlfahrtsstaaten des zeitgenössischen Westens der Fall ist. Soziale Gerechtigkeit bedeutet im Islam ein positives Eingebundensein in die Gesellschaft.«

(F. Rahman 1966: 320)

Von diesem Standpunkt aus betrachtet wird der Islam zu einer neuen kommunalistischen Ideologie, mit der ein neues, ein modernes Sozialgefüge geformt werden kann (Shari’ati 1980a).

Es wäre zu naiv zu behaupten, daß Rahmans' Anti-Säkularismus auf einer Fehlinterpretation von Gibbs' subtiler moralischer Bestimmung der Moderne beruhe. Doch in der Tat, Gibb nahm spätere Neuinterpretationen des Verhältnisses von Tradition und Moderne vorweg und wirkte hier auch für Rahman mit Aufforderungen wie der folgenden befruchtend: daß Moderne auch bedeute, »den Geist der hohen Werte und das innere moralische Gefühl, das wir die 'Stimme des Gewissens` nennen, am Leben zu erhalten« (Gibb 1975: 53f.). 
Wenn Rahman versucht, in soziologisch einwandfreier und intellektuell redlicher Manier »das Gesetz direkt vom Koran abzuleiten«, so liegt darin eine unzutreffende Identifizierung von Säkularismus mit Unmoral. An dieser Stelle verfällt er doch in eine Methode, »legale und institutionelle Gegebenheiten, die einfach von außerhalb des Islams übernommen wurden, zu islamisieren " (Rahman 1970: 332f.), die er andererseits zurückwies und die heute Dreh- und Angelpunkt für die fundamentalistischen Bewegungen sind: weg von der Modernisierung der Religion hin zur Islamisierung der Modernität.

Er selbst blieb dennoch der Auffassung treu, daß die intellektuelle Umsetzung dieser Probleme in eine kritische Neuformulierung des Islams münden müsse; nicht in eine religiös begründete Abschaffung der Moderne. Bei seiner Suche nach »einer geeigneten Darstellung des Islams, die für eine moderne Anschauung akzeptabel und relevant sein könnte« (Rahman 1966a: 253) verstärkte jedoch der modernistische Immanismus und Antisäkularismus, der in seinen späteren Werken offensichtlicher wurde (Rahman 1980a; Rahman 1982), die Dreh- und Angelpunkte des heutigen fundamentalistischen Diskurses, auch wenn das ganz unbeabsichtigt und indirekt geschah.

Am Problem der gesellschaftstechnischen Umsetzung solcher Prinzipien wird deutlich, wie kritisch heute die stillschweigende Übereinkunft von Orientalisten und christlichen Theologen zu sehen ist: Sie interpretieren Fundamentalismus als fundamentalen religiösen Rationalismus und bleiben doch blind gegenüber den verheerenden irrationalen, sozialen und politischen Auswirkungen der unreflektierten Umsetzung islamischer Urvisionen. Rahman wußte in der Tat, was der radikale Gebrauch seines islamischen Rationalismus bedeuten könnte, und glaubte doch, er könne dem mit Forderungen wie dieser zuvorkommen:

»Bei der Durchführung dieser Aufgabe der Reformulierung (des Islams und der Gesellschaft) wird ein fundamentaleres Bedürfnis befriedigt werden müssen, wenn die islamische Theologie und islamisches Recht nicht einfach den Forderungen des modernen Menschen und der modernen Gesellschaft mit den nihilistischen und demoralisierenden Wirkungen des krassen Säkularismus erliegen sollen: Die Reform muß den spezifisch moralischen und religiösen Emo- 
tionen einen gebührenden Platz einräumen und sie müssen als ein integrales Element ihr einverleibt werden.«

$(\text { Rahman 1966a: 254) })^{12}$

\section{Das Vermächtnis von islamischer Rationalität und Vernunft}

Gibt es etwas, das man »islamische Rationalität« nennen könnte? Im islamischen Denken ist das menschliche Streben und Trachten mit dem Willen Gottes unmittelbar verbunden. Gott ist das Vordringlichste und Wichtigste. Er beinhaltet alles und ist doch erst durch den Menschen der wirkliche Inhalt der Natur (Rahman 1966a). Es ist für die westliche Auffassung schwierig, in einer solchen Gottesvorstellung, in der die göttliche Bestimmung des menschlichen Verstandes zur Bedingung und der Mensch zu einem unmittelbaren Vollstrecker des göttlichen Willens wird, einen redlichen modernen, rationalen und autonomen Standpunkt des Individuums zu erkennen. Rahman geht einen Schritt weiter: Die Ordnung im Universum setzt die Immanenz Gottes voraus (Rahman 1967b). Hier sucht Rahman eine religiöse Plattform, von der aus er das rationale Prinzip für sozialen Wandel und für Kontinuität und Ordnung umsetzen kann. Er fundiert einen inneren islamischen Rationalisierungsprozeß im Dogma, in der Entwicklungsgeschichte der islamischen Institutionen und in den Weltanschauungen der sozioreligiösen Bewegungen des 18. und 19. Jahrhunderts, wie die Wahabi-, die Senussi- und die Babi-Bewegungen. Etwas scheint in diesen islamischen Bewegungen dem zu entsprechen, was sich zwei Jahrhunderte früher in der Christenheit ereignete, nämlich das SichDurchsetzen eines neuen Geistes der Freiheit.

Iqbal hatte vor Rahman diese Bewegungen als die Heraufkunft eines arabischen bzw. persischen »Protestantismus « angekündigt (Iqbal 1954: 12). Dies ist insofern interessant als in den letzten Jahren die Orientalisten und Soziologen eine gewisse Vorliebe für Themen wie "Islamischer Protestantismus « und »Islamische Rationalität " gezeigt haben. Iqbal hatte »seinen Weber « gelesen, und hier wird in der Tat deutlich, wie sehr die wissenschaftliche Betrachtung solcher Themen von kulturübergreifenden Wechselbeziehungen zwischen islamischen Denkern und dem Westen abhängig ist (Peters 1987; Goldberg 1991). 
In der Begründung des Begriffs der islamischen Rationalität gibt es starke Parallelen zwischen Iqbal und Rahman. Für beide spiegeln diese islamischen "protestantischen « Bewegungen erstens eine - objektiv eigenständige - innere islamische Reaktion auf die Dekadenz der Orthodoxie sowie einen inneren Drang zur Revitalisierung des klassischen islamischen Rationalismus wider, der auf $\ddot{j} t i b a d$ und einer freien Interpretation des Korans beruht. Iqbal und Rahman sind zweitens der Überzeugung, daß der Sufismus den islamischen Asketismus, die Freidenkerei und Spiritualität des islamischen Rationalismus (hier auf die persische Tradition anspielend, mit der sie sich beide beschäftigt hatten) gegenüber der totalen und fatalistischen Außerweltlichkeit des orthodoxen >Klerus wiedererweckt habe. Sie verstehen die ritualistischen Auswüchse der Orthodoxie aus dem Zwang heraus, seit dem 13. Jahrhundert in Zeiten des Niedergangs und der Invasionen Fremder ein geregeltes gesellschaftliches Leben zu erhalten. Sie sind deshalb drittens der Ansicht, daß der in diesen Bewegungen zum Ausdruck kommende Rationalismus sich gegen die Nachteile dieses Ritualismus der Orthodoxie wende. Von hier aus entwickelt Rahman die Forderung nach einer Konvergenz zwischen Prophetie und Rationalität, wobei die prophetischen Kräfte im Islam als eine Quelle der Individuation verstanden werden. ${ }^{13}$ Unter diesem Blickwinkel bedeutete die sufistische Vorstellung des sich im Geiste des Propheten auf sich selbst besinnenden Menschen eine rationalistische Entwicklung und den historischen Durchbruch von geistigen Prinzipien, die das Potential dafür lieferten, daß eine unbewegliche und überorganisierte orientalische Gesellschaft zu überwinden ist (Iqbal 1954: 149ff.). ${ }^{14}$

In der spiritualistischen Tradition der dem Protestantismus ähnlichen Erneuerungsbewegungen und Schulen im Islam des 17. und 18. Jahrhunderts wurden so innere Grundlagen für einen eigenständigen islamischen Rationalismus gelegt, der lange vor der Einwirkung des westlichen Modernismus im Islam wirkte. Darin liege eine besondere nicht-westliche Form des Rationalismus, die sich auf asketische Diesseits-gerichtete Spiritualität, Freiheit und Individualität als authentische islamische Prinzipien beruft. ${ }^{15}$ So wird hier in bezug auf die islamischen sozialen Bewegungen eine Theorie islamischer Modernität entwickelt, die sich über die Denkanstöße des klassischen, vor allem in Ägypten entwickelten islamischen Modernismus hinwegsetzt. Es ist dies ein sich im Werk Iqbals schon ankündigender Entwurf, der isla- 
mische Modernität neu, gewissermaßen in einer methodischen Verbindung von indisch-persischer Spiritualität und dem pragmatischen Denken angelsächsischer Orientalisten zu begründen sucht.

Die islamische Orthodoxie hat lange Zeit jeden Hinweis auf rationalistische Tendenzen im Islam als »Griechenland-versessen « oder »West-versessen« abgelehnt. Iqbal entwickelte dagegen einen neuen Trend, der den islamischen Institutionalismus, Dynamismus und Existentialismus mit kulturkritischen Strömungen im Westen in Verbindung brachte (Rahman 1972: 43ff.). Rahman stand dieser kulturkritischen Tendenz eher kritisch gegenüber. Im Vorgriff auf seinen eigenen Versuch, Islam mit rationalem Pragmatismus auszustatten, kritisierte er Iqbals kulturkritische Neigungen als eine Wiederbelebung eher rückständigen Denkens, das nicht in der Lage sei, Vernunft und modernen Dynamismus miteinander in Einklang zu bringen (Rahman 1972: 45). Rahman argumentierte, daß die Idee der zweckorientierten Rationalität, die Iqbal für den Islam zu gewinnen suchte, andererseits seiner aus Bergsons Lebensphilosophie übernommenen Vorstellung von einer Welt ohne Ziel und Zweck widerspreche. Solche Kritik zeigt Rahmans Intention, Bergson - wie überhaupt jedwede als irrational verstandene Kulturkritik, die unter anderem durch Iqbal unter modernen islamischen Denkern großen Einfluß gewann ${ }^{16}$ - aus dem Diskurs der islamischen Moderne herauszuhalten.

Man könnte Iqbals Philosophie in gewisser Weise als eine Vorwegnahme des modernen Konstruktivismus bezeichnen. Im Begriff des Prophetentums sieht er die Vorstellung entwickelt, daß das Selbst die einzige Realität in der Welt sei. Iqbal suchte nach einem rationalistischen Begriff der Prophetie, der als eine Vorform des modernen Selbstbewußtseins begründet werden könnte. ${ }^{17}$ Von hier aus ließe sich ein spezifisch islamischer Vernunftbegriff konzipieren, der nichtrationale Bewußtseinszustände und Erkenntnissteigerungen einbeziehen kann (Dar 1972). Andererseits war sich Iqbal sehr wohl der Grenzen bewußt, einen derartigen islamischen Modernismus mit der Doktrin der absoluten Wahrhaftigkeit des Korans als Gottes Wort und der von der Orthodoxie formulierten islamischen Lehre insgesamt in Einklang zu bringen. So sehr Gibb später mit seiner Forderung nach einer islamisch gehaltvollen Moderne intrinsisch islamische Optionen provozieren sollte, so sehr machte er sich hier über fruchtlose Denkversuche kultureller Habenichtse lustig: islamische Utopien mit einer »romanti- 
schen Wolke« verhängt. Gibb nimmt einiges von jenen Fehlentwicklungen vorweg, denen der Neo-Modernismus Iqbals und Rahmans unterlag. Für ihn trug der Diskurs über islamischen intellektuellen Integrismus nichts dazu bei, den Kardinalfehler allen modernistischen (islamischen) Gedankenguts zu korrigieren, aber viel, ihn zu bestätigen, »d.h. nämlich, man mag sich seine eigene Religion schmieden können, aber solange man mit einer historisch gewachsenen religiösen Gemeinschaft zu tun hat, ist die Tatsache, daß man solche Ideen schmiedet, selbst ein Zeugnis von Unreife und geistiger Anmaßung « (Iqbal 1954: 84). ${ }^{18}$

\section{Individualismus und die Bildung des modernen Selbst}

Der fundamentalistische Diskurs über gesellschaftliche Islamisierung, sofern er überhaupt intellektuell orientiert ist, hat sich Rahmans Konzeptualisierung der islamischen Moderne stillschweigend zu eigen gemacht. Untergegangen sind dabei allerdings Rahmans Vorstellungen zur gesellschaftlichen Stellung des Individuums als primärer Topos sozialer Verantwortung. ${ }^{19}$

Rahmans islamischer Begriff bestimmt das Individuum als eine von Gott eingesetzte, eine beauftragte Person, die im taqwa, in Gottesfurcht, in Frömmigkeit und Selbstdisziplin lebt. Sie ist dazu bestimmt, für eine höhere Wahrheit einzutreten. Dies ist ein höchst religiöser und zugleich intellekteller Begriff des Individuums. Rahman insistiert zugleich auf der Spannung zwischen Individuum, Gott und Gesellschaft. Aus dieser Spannung will er ein fortschrittliches Entwicklungskonzept entwickeln: taqwa als ein dynamisches Konzept, das auf die Lösung dieser Spannung hinarbeitet, und damit für das Individuum ein Element der Kraftschöpfung wird (Rahman 1966a: 322).

Es ist diese Spannkraft, die, ähnlich wie Webers Spannung zwischen Kirche und Staat, weltlicher und außerweltlicher Orientierung, das progressive Element in Rahmans Konzept des islamischem Modernismus ausmacht. Dieses wird jedoch in den fundamentalistischen Perzeptionen der Moderne weitgehend unterdrückt. Dort gilt nicht Spannung zwischen Widersprüchen, sondern Konstruktion einer Gesamtheit der menschlichen Gemeinschaft und des Sozialen als ein dem Wesen der Menschheit entsprechendes Prinzip (Faruqi 1980).

So hat Rahman eine interessante These über den Egalitarismus in 
bezug auf die absolute monotheistische Auffassung von Gott ausgearbeitet, die als Antwort auf Webers Abschaffung der Theodizee im Islam betrachtet werden könnte (vgl. Weber 1947: 550). Obwohl der Monotheismus, so sein Hinweis, als Begriff essentielle Gleichheit voraussetzt und so notwendig Auswirkungen auf die Entwicklung sozioökonomischer und philosophischer Begriffe der Gerechtigkeit hat, ${ }^{20}$ impliziert er im Islam die islamische Komplementarität von Gleichheit und gesellschaftlicher Verantwortung des Individuums, die zu einer Spannung zwischen den Forderungen des einzelnen und denen der kollektiven Institutionen, besonders des Staates und seiner Gesetzgebung, führt. Sufismus ist nach Henri Corbin Ausdruck einer großen individuellen Rebellion gegen den übersozialisierten Ethos der offiziellen Orthodoxie; dieser wird letztendlich in der Überregulierung des Lebens einem moralischen Nihilismus unterworfen, den der Sufismus zu überwinden sucht. Wie Corbin definiert Rahman den Sufismus als Reaktion auf die »Gesellschaftsreligion «, die der Islam ist (Rahman 1966a: 325; Corbin 1958). Hierin konstituiert sich ein kulturell kreativer Antagonismus zwischen dem allmächtigen Gott und dem Individuum, das die Wahl hat und dem Eigenverantwortung gegeben ist. In diesem Widerspruch sieht Fazlur Rahman die höchste Ebene moralischer Integrität begründet - in der Reaktivierung dieses Widerspruchs eine geeignete Maßnahme gegen den Ritualismus und die Selbstgerechtigkeit des orthodoxen islamischen Intellektualismus (vgl. auch Shari'ati 1991). Viel umfassender noch: das Universum offenbart im Widerspruch zwischen Individuum und Gesellschaft eine ursprüngliche dynamische Kraft, die zweckvoll und gut ist, eine Wendung des Problems, die derjenigen der philosophischen Anthropologie etwa Gehlens durchaus vergleichbar ist.

Das Schicksal des Individuums ist so mit einer islamisch evolutionistischen Perspektive verbunden. Der Mensch ist gezwungen, seine eigene »Lebenssunna « herauszuarbeiten. Das Ziel des Menschen ist es, das Universum, die Gesetze der eigenen inneren Konstitution und den geschichtlichen Prozeß zu erforschen und dann sein Wissen in den Dienst Gottes zu stellen. Das ist die Schöpfungsabsicht (Rahman 1967b). ${ }^{21}$

Hier kündet sich sich eine neo-islamische Theologie an, die heute vor allem in den Ländern der islamischen Peripherie viele Nachahmer gefunden hat. 


\section{Islamischer Fundamentalismus: Umsetzung instrumenteller Ideen und kultureller Technologien}

Zwischen Modernität und Fundamentalismus besteht eine gewisse ambivalente Affinität. Während im Westen ein großes Interesse am islamischen Fundamentalismus besteht, ${ }^{22}$ werden die wichtigen und autonomen Entwürfe des islamischen Neo-Modernismus weitgehend vernachlässigt. Der im Westen gängige, oft apologetische immanistische Diskurs über Islam und Liberalismus, Islam und Demokratie, Islam, Protestantismus und Rationalität versucht andererseits, den modernen politischen Islam mit der Soziologie der Moderne zu erhellen. Beide aber, der islamische Neo-Modernismus und die westlichen Projektionen des Islams stehen im Zeichen des gleichen Paradoxes, daß nämlich die Moderne in einem hohen Grade ihr Entstehen selbst dem Aufkommen des religiösen Fundamentalismus verdankt. Dieses Paradox der fundamentalistischen Konstruktion der Moderne ist heute einer radikalen islamisch-fundamentalistischen Politik sehr förderlich.

Rahman, Bennabi und Shari'ati sind Antisäkularisten. Sie wenden sich jedoch auch gegen die intellektuellen Traditionalisten, die in fundamentalistischer Manier den orthodoxen Klerus idealisieren. Was sich in Khomeinis Postulat der wilayet-e faqih, der Forderung nach prophetischem Respekt für die traditionellen Rechtsgelehrten, anbahnte, das realisiert sich heute in der verhängnisvollen Konvergenz von plebiszitärer Aneignung der Religion, postmodernem Intellektualismus und institutionalisierter Orthodoxie. Demgegenüber sucht der NeoModernismus eines Fazlur Rahman nach pragmatischen Lösungen moderner Ordnung. Er richtet sich deshalb auch dagegen, dem Islam einseitig den Nimbus des alternativen intuitiven und symbolischen Wissens aufzusetzen. Er wendet sich auch gegen den Versuch, Islam zum Instrument der kollektiven Selbsternennung zu machen und durch Instrumentalisierung sufistischer Spiritualität einem neuen Kollektivismus zu frönen.

Das Projekt »Islamische Modernität« möchte das Monopol der Orthodoxie abschaffen, für eine rationalistische, utilitaristische und funktionale Reinterpretation des Textes eintreten und die unaufhebbaren Spannungen zwischen Individuum und Gesellschaft, Prophetentum und Reich Gottes erhalten, weil diese Spannungen kreativ, dynamisch und dem Fortschritt förderlich sind. 
Das aber macht das Projekt so verletzlich. Wie frühere Generationen islamischer Modernisten muß auch der Neo-Modernismus erfahren, daß das intellektualistische Projekt der islamischen Modernität, der fundamentalistischen Infektion und der neo-traditionalistischen Massenrhetorik unterliegt. Ijtihad, die freie Neuinterpretation des Koran, und die Neustellung der traditionellen Religionsgelehrten sind für die militanten Erneuerer und ihre traditionalistischen Gönner kein Tabu. Gleichzeitig treten sie aber mit einer Ummatismus-Utopie an, die gegen die Idee der produktiven Wendung innerer Spannungen und der dynamischen Entwicklung des Verhältnisses zwischen modernem Selbst und der Staats- und Rechtsordnung die Vision einer kollektiven islamischen Selbstversicherung - durch revolutionäre und konventionelle Vermittlungen der Tradition - errichten will.

Es ist notwendig, solche begrifflichen Transformationen und Gegensätze in den breiteren Rahmen des globalisierten Diskurses über Religion und Moderne zu stellen. Die islamischen Modernisten sind sich der technischen Reduktionen der westlichen kulturellen Prinzipien auf formale und instrumentale Mechanismen der Übernahme von Werten und Ideen bewußt und suchen deshalb nach inneren Alternativen. Diese inneren Alternativen aber sind es, durch die sie politisch überrannt werden.

Der einmal in den Osten exportierte Westen wurde oft mittels »schrecklicher Simplifizierungen « in ein rein instrumentelles, technisches und materielles Moment der kulturellen Entwicklung übertragen. Man hat solche Formen des Modernismus kritisiert: »Er bezieht alle seine technischen Überlegungen aus der westlichen Kultur, und das hauptsächlich und besonders durch die ägyptische Erweckung. Diese technischen Denkvorgänge beeinflussen nicht nur das neue materielle Leben der Gesellschaften, in denen sie auftauchen. Tatsächlich ist es bemerkenswert, daß die meisten Muslime heute ihre religiöse Ausbildung und sogar manchmal ihren religiösen Impetus durch die Schriften europäischer Spezialisten erhalten« (Bennabi 1991a: 9). Bennabi hält dies für die Übernahme »Kartesianischer Methoden« (Bennabi 1991a: 11).

Ich möchte in dieser Frage einen Schritt weitergehen: Es zeigt sich nämlich, daß in der Übertragung der Moderne die instrumentelle Seite der kulturellen Rekonstruktion in einer absoluten Weise zur Wirkung kommt. Paradoxerweise führt die Übernahme des Utilitarismusbe- 
griffs als bloßes Mittel des kulturellen Selbsterhalts nur zu einer rekonstruierten absoluten Moral und zu einem religiösem Essentialismus der Selbstbehauptung. Die Thematisierung moderner Ich-Konstruktionen und des Selbst und individueller Verantwortung kann den Begriff eines allmächtigen Gottes und den Zwang zur moralischen Konformität innerhalb des Kollektivs nicht neutralisieren. Die Entdeckung der islamischen Rationalität geht mit der Berufung auf den Glauben einher, der die letztendliche Irrationalität des Lebens und der Erfahrungen in der materiellen Welt bestätigt, nur die in Gott gesetzte Rationalität bringe Ausgleich, ermögliche Gleichgewicht.

Fazlur Rahman und die islamischen Modernisten treten für eine islamische Zivilisation ein, die solche Widersprüche und Spannungen in Kräfte des modernen Fortschritts verwandeln will. Man muß sich aber der destruktiven Wirkungsweise der Aneignung solch intellektualistischer Theologien in der praktischen Modernitätspolitik bewußt bleiben.

Ich kann hier keine Lösung anbieten. Für den Soziologen bleibt die Aufgabe, die Auswirkungen angewendeter »Kartesianischer Methoden « auf den Islam zu untersuchen und diese in den allgemeineren Kontext nicht-westlicher Konzeptualisierungen der Moderne in einer sich zunehmend globalisierenden Welt zu stellen.

Ziele und Gegenwirkungen des islamischen Modernismus sind jedoch schwer voneinander zu trennen. Der Fundamentalismus ist ein unausgegorenes und massenwirksames Resultat des islamischen Modernismus, doch hat letzterer selbst - wenn auch unbeabsichtigt - erheblich zur sozialen und intellektuellen Grabesstille beigetragen, die heute in vielen, nicht in allen muslimischen Ländern herrscht. Kulturelle Globalisierung setzt moderne Formen der Selbstbestimmung und Authentisierung von sogenannten Urvisionen als Mittel des modernen Erneuerungskampfes voraus. Damit stehen nicht so sehr diese Visionen, sondern vielmehr die Auswirkungen der sich globalisierenden Moderne und der kulturelle Rekonstruktionsprozeß, den die Globalisierung dem Islam aufzwingt, im Zentrum soziologischen Interesses. Oft ist dieser Prozeß sowohl von westlichen Soziologen als auch von islamischen Modernisten nur als innere Parallele zur westlichen Entwicklung fehlgedeutet worden.

Die konventionellen Modernisierungstheoretiker haben nicht erkannt, daß jeder Prozeß gesellschaftlicher Differenzierung und Verän- 
derung auch dem Zwang des Erhalts von Hierarchien unterliegt. Es entsteht dadurch eine komplementäre Beziehung zwischen Weltanschauung und Akzeptanz der zugewiesenen sozialen Rollen, die jede Kultur entwickelt. Louis Dumont hat darauf hingewiesen, daß die westliche Modernisierung auf das Paradoxon einer komplementären Beziehung zwischen gesellschaftlicher Differenzierung und Gleichheitsdenken aufgebaut ist. Durch diese spezifische Verbindung wird hier die Intoleranz gegen alle Abweichler zur integrativen Kraft des gesellschaftlichen Diskurses. Die Abschwörer gegebener Hierarchien werden sozusagen zum verborgenen Zentrum des Diskurses über Hierarchie. Der Diskurs über Gleichheit wird zum einzig verbleibenden Mittel der Hierarchiebildung.

Das ist in islamischen Ländern gewiß anders. Hier wurden konventioneller Weise die Abweichler deshalb mit stillschweigender Toleranz behandelt, weil sie aus dem Zentrum des Diskurses über Hierarchiebildung ausgeschlossen waren, sie sind die wirklich »Ausgeschlossenen«, die sie zu sein vorgeben. Dies führt notwendig zu mangelnder Systemdifferenzierung. Die den Menschen in seiner Alltagspraxis beherrschenden Ideen, die über die Form der Akzeptanz zugewiesener sozialer Rollen bestimmen, sind in entscheidender Weise von der Intellektualisierung des Wunsches nach Kultur und nach einem kohärenten Weltverständnis abgekoppelt. Anders als Weber, der es universalisierte, hat Dumont die Möglichkeit der Umdrehung dieses Verhältnisses erkannt (Haferkamp 1989). Modernität kann deshalb solche kohärenten Orientierungen nicht völlig aufheben oder ersetzen. Sie bewirkt vielmehr nur einen gewissen notwendigen Modus, mit dem diese vorgegebenen Orientierungen weitertransportiert und im kulturübergreifenden Austausch verfälscht und umgedreht werden.

Sie macht ein komplementäres Verhältnis zwischen sozialer Differenzierung und der Suche nach Verallgemeinerung solcher verlorener Grundorientierungen zur Bedingung moderner Existenz. Es kann deshalb keinen Widerspruch zwischen einem vormodernen Glaubenssystem sowie instrumentellen und sinnentleerten Modernitätsstrukturen geben, wie man als Orientalist gerne anzunehmen geneigt ist. Die Frage nach der Vormoderne und ihre idealisierte Wiedererweckung ist ein eigentliches Problem der westlichen Moderne: ein Problem der eigenen modernen Ordnungskrise. Wie der Westen stehen heute auch nicht-westliche Gesellschaften dem Problem Ordnung gegenüber. 
Mein Anliegen ist es, auf die Notwendigkeit der Analyse der Wirkungen der Moderne auf die Idee der vormodernen Kultur hinzuweisen: der Versuch, sie als synthetische Fiktion eines standardisierten Verhaltenssystems zu fassen. Mit den äußeren Errungenschaften intensivieren sich die inneren Probleme.

Betrachtet man soziale Ordnungen als synthetische Fiktionen standardisierter Verhaltenssysteme, dann beruhen sie notwendig auch auf Grundmustern der alten Zivilisationen, die die Instinkte und Emotionen der Menschen erobern. Deshalb beschäftigen wir uns mit den nicht-westlichen Grundorientierungen, die als einzelne Schematisierungen des generalisierten Sinns kultureller Existenz die Pluralität moderner Stile ersetzen wollen. Hier geht es nicht darum, ob die islamische Religion als solche globalen Standardisierungen feindlich gegenübersteht. Es ist vielmehr wichtig, weiterzugehen und zu erkennen, $\mathrm{da} ß$ die historisch generalisierten Grundorientierungen, wo sie auf der Ebene von formaler Rationalität und formaler Technologien gesellschaftlicher Repräsentation wirken, umgekehrt erst die substantiellen Fragen nach »Differenz« provozieren. Von Beginn solcher Austauschformen an gab es kulturelle Wechselwirkungen, die die formale und nicht die materiale Seite solcher Orientierungen in den Vordergrund globaler Standardisierung gestellt haben: Man glaubt, sich über Inhalte und Werte auszutauschen, tatsächlich zählt nur die technologische Seite der Formalisierung.

Das faszinierende Auftauchen des islamischen Fundamentalismus ist ein Ausdruck dieser Notwendigkeiten der sich globalisierenden Moderne. Sie ist deshalb nicht einfach als die Substitution von kohärenten Weltanschauungen anderer Zivilisationen durch moderne westliche Prinzipien und Werte zu verstehen. Die Globalisierung von Modernität hat jedoch eine maßgebende universale Wirkung, d.h. sie rekreiert die dominanten Vorstellungen von verschiedenartigen Kulturen als Grundmuster innerhalb eines formalisierten Systems egalitärer Teilhabe. Sowohl der islamische Modernismus als auch der islamische Fundamentalismus müssen heute genau innerhalb dieses Transformationsprozesses der kulturellen Grundmuster verortet werden.

In der Zusammenfassung einzelner wesentlicher Punkte von Fazlur Rahmans Theorie der islamischen Modernität sollten die Widersprüche und Doppeldeutigkeiten der praktischen islamischen Modernisie- 
rung im Wechselspiel mit der westlichen Moderne explizit gemacht werden.

Heute wird in einigen islamischen Ländern die Theorie der islamischen Moderne durch ein anderes Projekt vereinnahmt: durch die Politik einer islamisierten Modernität. Ich wollte hier deutlich machen, daß eine solche »Politik « zumindest das Ende der produktiven Ambivalenz des theoretischen Diskurses über islamische Modernität bedeutet und das definitive Ende seiner intellektuellen Potentiale darstellt.

\section{Anmerkungen}

1 Dies ist die überarbeitete deutsche Fassung eines auf englisch erschienenen Aufsatzes (Stauth 1993e). Bei dieser Neufassung, in der im großen und ganzen nur wenige neue Gewichtungen und einige Ergänzungen vorgenommen wurden, lag mir die Übersetzung von Frau Christa Jaeger, Bielefeld, vor, der ich an dieser Stelle herzlich danken möchte.

2 Das in Malaysien und Indonesien so freundlich aufgenommene Buch von Ernest Gellner (1992) kann wohl als eine geschickte westliche Projektion des islamischen Neo-Modernismus bezeichnet werden, obwohl es sich mit diesem wider Erwarten kaum auseinandersetzt. Gellners Buch erschien erst nach der ursprünglichen Fassung dieses Papiers.

3 Symptomatisch sind in dieser Hinsicht Argumente für eine Art Annäherung zwischen Fundamentalismus und Liberalismus und gleichermaßen Versuche, die fundamentalistischen Formen der kulturellen Selbstbehauptung lediglich als eine defensive islamische Antwort auf die Herausforderung Europas zu definieren. Mit solchen Aussagen wird der Islam als ein geschlossenes »kulturelles System « definiert. Im Gegensatz dazu sieht die Perspektive, die ich in diesem Papier vorschlage, Fundamentalismus und die verschiedenen Arten von Selbstbehauptung, die er bewirkt, als eines der modernen kulturellen Konstruktion als solcher und der Modernität selbst inhärenten Instrumente. Ein klares, konzeptuelles, weltumfassendes Verständnis würde es uns in der Tat ermöglichen, die Universalisierung solcher »Instrumente « von der selektiven Form $\mathrm{zu}$ befreien, in der sie traditionelle kulturelle Ressourcen rekonstruieren und bejahen. 
4 In diesem Papier mache ich den Versuch, die Perspektive über Wirkungen des »Orientalismus « in der Soziologie in einen Ansatz zur Analyse der Wirkungen von »Modernitätstechnologien« in nicht-westlichen oder gar anti-westlichen Begründungen der Kultur umzukehren.

5 Fazlur Rahman lebte von 1919-1986. Er absolvierte sein Graduiertenstudium an den Universitäten Punjab und Oxford, wo er mit einer Arbeit über Avicenna promovierte. Diese Arbeit wurde unter der Supervision von S. Van den Berg geschrieben und mit der Unterstützung von H.A.R. Gibb 1949 in Oxford vorgelegt und dann als »Avicenna's Psychology« veröffentlicht. Eine englische Übersetzung von Kitab al-Najat, Buch II, Kapitel VI mit historisch-philosophischen Anmerkungen und Textverbesserungen der Kairo-Ausgabe wurde in London veröffentlicht (Cumberlege 1952). Er lehrte dann an den Universitäten Durham und McGill. Von dort kam er nach Karachi als Direktor des Zentralinstituts für Islamische Forschung. Das Institut wurde durch die Verfassung von 1956 einem Mandat unterstellt und eng mit dem Beirat für Islamische Ideologie verknüpft, der von Ayub Khan als ein spezialisiertes Laiengremium für die Ausarbeitung von Gesetzgebungsvorschlägen in Übereinstimmung mit modernistischen islamischen Prinzipien ins Leben gerufen wurde (Eposito 1987). Rahman wurde im Jahre 1966, als er sein Buch »Islam« veröffentlichte, durch eine von den traditionellen religiösen Führern angestiftete Massenbewegung dazu gezwungen, von seinem Amt zurückzutreten. Diese Bewegung war im großen und ganzen gegen die laizistischen und modernistischen Reformen von Präsident Ayub Khan gerichtet. Im Jahre 1968 übernahm er den Lehrstuhl für Islamische Studien an der Universität von Chicago, wo er 1986 starb. Fazlur Rahman hat uns zahlreiche Publikationen hinterlassen, von denen viele als Aufsätze in den IIslamic Studies< des Zentralinstituts für Islamische Forschung in Karachi erschienen sind und die später, besonders zu der Zeit, als er dort Direktor war, in Islamabad wieder aufgelegt wurden. Seine Hauptwerke sind »Islam« (1966, 2. Auflage 1975), »The Major Themes of the Qur'an« (1980) und »Islam and Modernity: the Transformation of an Intellectual Tradition « (1982).

6 Malik Bennabi lebte von 1905-1973. Er wurde in Algerien gebo- 
ren und verbrachte einen großen Teil seines Lebens in Europa und Ägypten. Er promovierte im Jahre 1937 in Paris als Elektroingenieur. In den späten 50er und in den frühen 60er Jahren lebte er in Nassers Ägypten. Im Jahre 1963 kehrte er nach Algerien zurück. Zu seiner Biographie vgl. Asma Rashid (1988: 2-26).

7 Ali Shari'ati lebte von 1933-1977. Er war eine charismatische Erscheinung des Widerstands gegen das iranische sancien régimer. Von 1959 bis 1964 verbrachte er fünf Jahre an der Universität von Paris. Nach seiner Rückkehr in den Iran und während der Zeiten der Haftentlassung lehrte er an der Universität von Mashad. Nachdem er dort ausgeschlossen worden war, lehrte er an einem religiösen Zentrum in Teheran. Er starb in England am 19.6.1977. Höchstwahrscheinlich wurde er von der Savak umgebracht. $\mathrm{Zu}$ seiner Biographie siehe Shari'ati (1979).

8 Das zeigt bereits eine "grundlegende Einstellung von Iqbal, die ihn dazu bringt, die transzendente Auffassung von Gott zurückzuweisen. Er sieht Gott nunmehr, getreu der Sufismus-Tradition folgend, als ein in der Welt immanentes Wesen « (Rahman 1972).

9 Hier stimme ich nicht mit K. Cragg überein, der Rahman selbst in die Ecke der Säkularisten stellt: »Fazlur Rahman tritt nicht wie Ali Shari'ati oder José Miranda für eine >Befreiungstheologie< ein. Er bezeichnet lediglich das islamische Gottesbewußtsein als das ausschließliche Korrelat des ethischen sozialpolitischen Handelns in der Welt«(Cragg 1985: 100).

10 Wir sollten uns darüber im klaren sein, daß der fundamentalistische Islamisierungsdiskurs diese Grundsätze in militante Programme zur Veränderung verwandelt hat.

11 »Diese Auffassung von Gott entstammt natürlich dem Glauben von Dr. Rahman, daß der Islam im wesentlichen eine gesellschaftliche Reformbewegung ist, deren Hauptinteresse in der Fürsorge und im Wohlergehen der Menschen liegt - immer vorausgesetzt, daß auch moralische Fürsorge gemeint ist, und es sich nicht nur um die Befriedigung der Grundbedürfnisse handelt« (Siddiqi 1970: 158).

12 Vgl. ebenfalls Cragg (1985: 93).

13 Rahman hatte die These, daß philosophische Rationalität ohne "prophetische « Rationalität nicht auskomme und daß es diese Rationalität sei, die den Orthodoxen so verdächtig war, schon 1957 in 
einem lehrreichen Vergleich der Standpunkte der Orthodoxie und der Philosophen zur Prophetie geliefert (vgl. Rahman 1957).

14 In bezug auf das Wiederauftauchen dieser Themen s. Bennabi (1991) und Shari'ati (1979).

15 Vgl. hierzu den Essay von Ernest Gellner (1992), der an die zentralen Ideen Rahmans anknüpft. Leider nimmt Gellner an keiner Stelle auf Rahman Bezug und setzt sich nicht systematisch mit ihm auseinander.

16 Iqbals Grundsätze sind in frühen Werken von F. Rahman noch lebendig, z.B. in Rahman (1964). Zu dem Versuch, eine »modernistische« Tradition in dieser Art des Denkens zu etablieren s. alAttas (1985) und ebenso Sardar (1989).

$17 »$ Prophetisches Bewußtsein nenne ich eine Methode, in der das individuelle Gedankengut und die Wahlmöglichkeit durch das Liefern von vorgefertigten Urteilen, Optionen und Handlungsweisen ökonomisiert wird « (Iqbal 1954: 125).

18 Man hätte sich bei der Verfolgung des neo-modernistischen Projekts insgesamt die Bewußtheit solcher Einsichten gewünscht, ganz sicher aber auch Gellners (1972) apodiktische Bestimmung des Verhältnises von Islam und Moderne.

19 Z. B. Sonderausgabe über Fazlur Rahman, »Islami Arastirmalar «, Bd. IV, 4, 1990.

$20 \mathrm{Zu}$ einer positiven Verbindung zwischen dem moralisch-geistigen Ideal des Monotheismus auf der einen Seite und der Vorstellung von Gleichheit und einer gerechten Gesellschaft auf der anderen Seite s. F. Rahman (1966a: 223).

21 In bezug auf ähnliche evolutionistische Auffassungen vgl. A. Shari'ati (1980b: 97ff.).

22 Für eine Zusammenfassung der Themen der kürzlichen Diskussionen und den Austausch zwischen dem Mittleren Osten und Südostasien siehe Abaza (1991). 


\title{
Religiöser Fundamentalismus zwischen Orient und Okzident: Religiöse Identitätspolitik und ihr Verhältnis zur Demokratie
}

\author{
Globalisierung und Fundamentalismus
}

I

Das Phänomen »Fundamentalismus« ist mit dem modernen Schicksal der Weltreligionen auf das engste verknüpft. Re-Ideologisierung und -Politisierung der Religion spiegeln ein ungelöstes Problem der Moderne wider, das selbst der »neuen Linken« wieder zum Thema wurde: die »politische Theologie«(Telos 1987). Denn auch in der säkularen, modernen Demokratie können Politik und Wissenschaft nicht gänzlich des religiösen Kerns entkleidet werden, mit dem einst ihre besondere Stellung im Wesen des modernen Nationalstaats begründet wurde. Fundamentalismus ist auch Ausdruck der Globalisierung dieses Widerspruchs.

Es ist dies in einen noch breiteren Rahmen zu stellen. Selbst wenn wir sie uns ohne den christlich-abendländischen Hintergrund denken, so sind die Dynamiken, die heute »Weltgesellschaft « formen, doch auf jenes soziale Segment der Aufklärung zurückzuführen, das sich unter der Prämisse der allgemeinen Gleichheit der menschlichen Natur und der Ziele des Menschen bildete und seither paradoxerweise kontinuierlich die Vielfalt partikularer Ausformungen von Kultur und Gesellschaft auch in der nicht-westlichen Welt weiterentwickelte.

Die konventionelle Soziologie, die Gesellschaft als nationalstaatliche soziale Ordnung versteht, tut sich schwer, globale Ordnungsprobleme und Gesellschafts-Dynamiken zu erfassen. Im allgemeinen herrscht in den herkömmlichen Sozialwissenschaften die Vorstellung von einer tintenklecksartigen Ausbreitung der in der westlichen Moderne entwickelten Gleichheitsidee vor. Man vergißt dabei die kulturgeschichtliche Besonderheit der Entstehungsgeschichte Europas, die Dumont (1986) noch betont. Wie schwer es aber ist, diese Besonderheit zurückzustellen, zeigt sich in den vielen höchst konträren Schattierungen, in denen im Zeitalter der postkolonialen Transformation die Staatsform der nationalen Demokratie heute weltweit verfaßt ist. 
Der westliche, der nationalstaatliche Demokratiebegriff, der bürgerlich-wissenschaftliche Begriff von Religion, Zivilisations- und Modulierungsprozesse unter Bedingungen moderner Konfigurationen von Staat und Gesellschaft etc. sind in all den vielen Varianten postkolonialer Emanzipation auf die äußere Form von Werkzeugen reduziert, mit denen heute überall auf der Welt Ordnungsprinzipien und Visionen lokaler Kulturen in Begriffe wie Nation, Gesellschaft, Zivilisation, Demokratie etc. gepreßt und dementsprechend verändert werden. Wenn man nun aber von »Weltgesellschaft « spricht, so kann man sich solche Prozesse in dieser doppelt gelagerten Dimension vorstellen: einerseits die technische Reduktion westlicher Kulturbegriffe und ihr Export in die nicht-westliche Welt und andererseits das außerordentliche Spannungsverhältnis zwischen postkolonialer Selbstbestimmung und lokaler Kulturgeschichte, das durch Reduktion und Export westlicher Kultur hervorgerufen wird. Dieses löst eine kulturelle Motorik aus, deren explosiver Charakter schwer zu verstehen ist. Denn die Prinzipien und Visionen der lokalen Kulturgeschichte, die die großen, alten Zivilisationen - Hinduismus, Buddhismus, Konfuzianismus und Islam - hervorgebracht haben, bleiben gewissermaßen nur das Material, an dem die neuen emanzipatorischen Werkzeuge arbeiten, ohne die Ideen dieser Geschichte je auslöschen oder aus dem sozialen Gedächtnis verbannen zu können.

In bezug auf den Islam und die Ausbreitung der Moderne im 19. Jahrhundert ist diesbezüglich von der Entstehung eines »islamischen Substrats" gesprochen worden (Nagel 1996: 92ff.). In Anlehnung an Hourani, den jüngst verstorbenen libanesischen Historiker, weist der deutsche Islamwissenschaftler Nagel auf die Tatsache hin, daß das moderne islamische Denken auf die Herausforderung Europas vornehmlich mit "Aufnahme, Umdeutung und Abwehr« reagierte. Man erkennt hier, daß es nicht mehr um ungebrochene islamische Kontinuitäten geht, auch nicht um die bloße Durchsetzung des modernen Europas. Doch denken die Kulturhistoriker vornehmlich in Kategorien des Kampfes oder der Vermischung von Ideen. Sie können dabei nur schwer begreifen, wie sehr die technische Wirkung etwa der Verallgemeinerung der Gleichheitsidee eine neue, explosive Kulturentwicklung in Gang setzt. Sie führt zur zwanghaften, kontinuierlichen Ausarbei- 
tung alternativer Varianten, höchst partikularistischer, modern-strategischer (und zugleich modernitätskritischer) Adaptionen historisch geprägter Selbstbestimmungen des Islams. Die Perversionen, die die technische Umsetzung der Modernitäts-Konzepte hervorrief und weiterhin unerschütterlich hervorruft, sind mit dem Begriff des »islamischen Substrats« sicherlich nur unzureichend zu umschreiben.

\section{III}

Entscheidend ist, daß die Kulturen der Welt im 19. Jahrhundert in eine Form des Dialogs eigener Art gezwungen wurden. Die sinnentleerten Techniken der westlichen Kulturentwicklung - man könnte sie zusammengefaßt unter den Begriff der Aufklärung stellen - waren einmal innerer Bestandteil der Kultur- und Wertewelt des Abendlandes. Der monströse Verlauf der Wirkungsgeschichte des Dialogs mit der nichtwestlichen Welt ergibt sich aus der Doppelrolle der westlichen Begriffstechniken: Sie sind auf das rein Technische reduzierte Leerformeln der gesellschaftlichen und kulturellen Erneuerung und damit weltoffen, sie geben sich andererseits als wichtige Errungenschaften und den Zielen und der Natur des Menschen entsprechende "hohe«, in der abendländischen Geschichtsentwicklung bestätigte Werte.

Diese Koinzidenz von »Wert « und »Instrument« stellt nun aus der Sicht der alten Hochkulturen eine unberechenbare geistige Doppelseitigkeit dar. Und gerade darin liegt die Ambivalenz der Lagerungen des »Ost-West-Dialogs«. Wird Kultur- und Gesellschaftswandel einmal auf die Ebene des wechselseitigen Austauschs zwischen den Kulturen gestellt, so vereinseitigt sich der instrumentelle Charakter alles Westlichen. In den so eintretenden Rückspiegelungen der eigenen verlorengegangenen Hochkultur wird aber nur der geistige Charakter betont. Die Kreationen der technisch-strategischen Kulturerneuerung lassen den Westen gegenüber den »authentischen « Werten der »eigenen «, alten Kultur nur noch als die »niedere« Form materialistischer Zweckorientierung und geistiger Instrumentalisierung erscheinen (Iqbal 1954; al-Attas 1985).

Man hat den Prozessen, durch die der westliche Vernunftbegriff, aber auch allgemeine soziologische Begriffe wie beispielsweise der durch »Sinn « fundierte Webersche Handlungsbegriff, Begriffe wie Gesellschaft, Nation, Zivilisation und Religion etc. sich universalisierten, 
bisher wenig Beachtung geschenkt. Und doch trugen sie zur partikularistischen Ausarbeitung moderner Selbst-Begriffe überall auf der Welt bei.

Mit dem vorliegenden Beitrag schlage ich vor, das Phänomen des religiösen Fundamentalismus, insbesondere auch des islamischen, unter dem Gesichtspunkt der gewissermaßen multivariaten Produktion moderner Selbst-Sichten, unter dem Gesichtspunkt der partikularistisch angeeigneten strategischen Rückspiegelungen abendländischer Formen der kulturellen Erneuerung (Protestantismus, Aufklärung, Verwissenschaftlichung sind hier am eingreifendsten) zu betrachten.

\section{IV}

Sind die jihad-Gruppen zum Beispiel, die in Ägypten und Algerien so viel Unheil anrichten, »islamische Fundamentalisten «? Sind das Fundamentalisten, die sich in Analogie zu jenen Sekten und Klerikern so beschreiben lassen, die zu Beginn dieses Jahrhunderts in den USA die Fundamente protestantischer Gemeinden gegen die herrschende liberale Theologie und Bibelkritik verteidigen wollten? Lassen sich diese Gruppen etwa aus der spezifischen Kulturgeschichte der islamischen Sektenbewegungen erklären? Man ist heute bereit, auch in wissenschaftlicher Analyse den Vergleich zu akzeptieren. Und doch verständigt man sich insgeheim darüber, daß er eigentlich unangemessen ist (vgl. etwa Riesebrodt 1990).

Andererseits hat man in Anlehnung an eine Tradition der klassischen Islamwissenschaft wieder damit begonnen, vom pragmatischen Pluralismus, Liberalismus und von der Toleranz der islamischen Orthodoxie zu sprechen. Sind die orthodoxen muslimischen Kleriker der heutigen al-Azhar Universität in Kairo, der Zaituna in Tunis oder der Medresse von Qoum, Iran, sind die Scheiche und Imame, die Kiyais und 'Ulamas und ihre Gemeinden von Indonesien bis Marokko, von Kasachstan bis Mosambik, sind die modernen Orthodoxen alle etwa dem theologischen Pluralismus und der Liberalität der alten orthodox-islamischen Gelehrtenschulen verpflichtete Geister?

Sind dies heute wirklich die Kulturebenen, die sich nur aus den inneren Transformationen und Weiterentwicklungen des traditionalen islamischen Intellektuellentums verstehen lassen?

Die Verwirrung ist groß, wenn man der herrschenden politischen Philologie folgt und versucht, aus der Kulturgeschichte des Nahen 
Ostens und der Geschichte seiner Ausbreitung in Asien und Afrika neue Grand Narratives des Islams als Einheitsreligion und Religion des orientalischen Humanismus zu schaffen. Eine dieser großen Erzählungen ist die von der islamischen Orthodoxie als Begründerin islam-demokratischer Utopien des Pluralismus, der Toleranz und der Liberalität. Schon wird hier wieder unter dem Zwang der demokratischen Legitimität der modernen nationalstaatlichen Verfassungen allein die politisch-theologische Notwendigkeit gesehen, die Kluft zwischen Staat und Islam, zwischen säkularer Demokratie und religiösem Holismus zu überbrücken. Nimmt man den (islamischen) Holismus und den (westlichen) Individualismus einfach nur als »partiale Repräsentationen der Welt«, wie jüngst Todorov (1993: 398) vorgeschlagen hat, dann könnte man beide als komplementäre, den gegenseitigen Horizont der Ordnungsvorstellungen ergänzende Prinzipien verstehen. Kann man das?

Die neue politische Theologie des Orthodoxismus wird nun selbst von westlichen Gelehrten als Voraussetzung für die Demokratisierung des säkularen Staates begriffen. Ein - wie ich meine - schicksalhaftes, ja verhängnisvolles Paradox. Es suggeriert, der Islam sei das echte Lösungspotential der Legitimierung der modernen säkularen Wertrationalität in Staat und Gesellschaft (vgl. Lewis 1997; Mottahedeh 1993). Die säkularen Dimensionen der kolonialen und postkolonialen Geschichte werden vernachlässigt, wenn nicht völlig entwertet.

\section{$\mathrm{V}$}

Die dem Ordnungshandeln verpflichtete Weltöffentlichkeit zeigt sich durch die Ereignisse, die der im Namen des Islams auftretende Terror in vielen Teilen der islamischen Welt hervorbringt, schockiert und ratlos zugleich. Als unterlägen sie selbst einem Zauberbann der explosiven Kraft, mit der das »Religiöse« zum politischen Akt wird, gilt der Islam den Islamologen nun als das einzige politische Lösungsangebot der postkolonialen Sozialordnung. Es hat sich hier eine Profession von »Orientalisten " gebildet, die ganz im Stile fundamentalistischer »Denker « nunmehr auf wissenschaftlicher Basis den Theoremen der historischen, politischen Theologie des Islams nachgehen und unter dem Gesichtspunkt moderner Lösungen neue islamische Staatstheorien entwickeln. Damit gewinnt der politische Diskurs der Moderne, nicht nur im islamischen Raum, sondern durchaus in weltgesellschaft- 
lichem Maßstab, unweigerlich einen kulturantagonistischen Charakter. Fundamentale Lebensstil- und Glaubensdifferenzen werden auf WeltKonflikte hin ausgelegt. Dies hat Rückwirkungen auf das Demokratieverständnis und das Grundrechtsempfinden im Westen selbst.

Diese Mißverständnisse zu überwinden, kann nur gelingen, wenn man eine breitere Meßlatte anzulegen bereit ist, mit der auch die paradoxen Bezugsprobleme, die sich aus den gegenseitigen begrifflichen Projektionen ergeben, einbezogen werden können. Aus der je dem Anderen unterstellten Selbstzentriertheit der Kultur lassen sich nicht einmal die kulturproduktiven Umsetzungen von »Differenz « erkennen. Schon gar nicht die neuen Ausgrenzungsformen des »Anderen « oder gar die absolut kulturaffirmativen Sinnlosigkeiten und Perversionen eines im referentiellen Wechselspiel um das »eigene« Menschenbild totalisierten »Anderen«. Hierin deuten sich die Themen an, mit denen »Fundamentalismus « als die neue Dimension kultureller Produktion, auf der breiteren Meßlatte der Globalisierung zum Forschungsgegenstand zu verstehen wäre.

\section{VI}

Die Erfolgsgeschichte der westlichen Aufklärung und der Moderne ist auf das engste mit der Vorstellung verknüpft, der moderne, wissenschaftlich-technisch gebildete, professionelle Mensch habe die Suche nach der Erfüllung seines praktischen Lebens in den Visionen des Göttlichen aufgegeben. Ein geschichtliches Gesamtleben sei auch als Vorstellung nicht mehr möglich. Für den Islam wird dagegen insbesondere von Bernard Lewis, dem Doyen der amerikanischen Orientalistik, das Bild von der absoluten Einheitlichkeit der islamischen Kultur verbreitet, von Kohärenz und Konvergenz der öffentlichen und privaten Sphären, des Heiligen und Profanen, von Politik und Religion. Dies sind parallel zum Vorwurf des westlichen Materialismus Affirmationen des östlichen Spiritualismus.

Die Kultur der Moderne hat von Anfang an jedoch die - wenn auch abstrakte - religiöse Bindung des modernen Subjekts betont. So spricht Ernst Troeltsch noch von der modernen »religiösen Einzelsubjektivitä «, die in einem längst verflossenen Zeitalter wurzele, in dem sich - vermittelt durch die geschichtliche Person des Propheten - die Idee eines historischen Gesamtlebens noch substantiell umsetzen ließ 
(Troeltsch 1911: 50). In der von Troeltsch bemühten "Sondereigentümlichkeit « des Christentums liegt »das Bild einer lebendigen, vielseitigen und zugleich erhebenden und stärkenden Persönlichkeit« begründet, »die lebendige Grundlage eines undefinierbaren persönlichen Lebens (ibid.: 42). Nach Troeltsch hat der moderne europäische Individualismus seine Wurzeln in der religiösen Herausgehobenheit der Persönlichkeit aus der Welt (in Bild und Dogma der Person Christi).

Hier schließt auch die neuere Religionssoziologie an und spricht vom europäischen Sonderweg der »Privatisierung der Religion « (Luckmann 1996; Casanova 1994). Dadurch wird ein innerer Zusammenhang von Individualismus und Egalitarismus, von privatisierter Religion und demokratischer Persönlichkeit begründet, gewissermaßen ein innerer fundamentalistischer Anspruch auf die authentische Verbindung von Demokratie und Christentum.

Die dagegen entwickelten Auflösungen verfolgen das Ziel, auch die Religionen der nicht-westlichen Welt in einen funktionalen Zusammenhang zur modernen Demokratie zu stellen. Eine dieser Auflösungen zielt darauf, "privatisierte « Religion als europäischen Sonderweg auszuweisen. Für die Religionsentwicklung in den USA, in Lateinamerika, in islamischen Ländern und in Asien wird dagegen der Begriff der »öffentlichen Religion« reklamiert. Man meint damit eine durchgreifende Lenkungsfunktion des Religiösen im öffentlichen Leben, in Wirtschaft, Massenkultur und im symbolischen und politischen Verhalten der Menschen. Indirekt unterstellt man damit eine neue, deprivatisierte Religionsfunktion, die sich nun auch in Europa Durchbruch verschaffen soll (Casanova 1994).

Eine weitere Auflösung will den demokratischen Mythos Europas abschaffen. Sie bezieht sich unmittelbar auf den Islam, der so eine der neuen dominanten Ideologien kultureller Emanzipation in der nichtwestlichen Welt wird. Man behauptet die unmittelbare DemokratieEigenschaft der islamischen Glaubenslehre und weist auf den pluralistischen Charakter der Dogmengeschichte des Islams und der islamischen Gesellschaftsentwicklung hin (z. B. Mottahedeh 1993).

Mit solchen Aufhebungen soll die alte Polarisierung zwischen Ost und West, zwischen sogenannter okzidentaler materialistischer Instrumentalisierung des Heiligen und orientalischem, außerweltlichem Spiritualismus entkräftet werden. Der religiöse Gedanke des Christen- 
tums wird aus dem Zusammenhang des westlichen Kulturimperialismus herausgelöst, der Islam aus der Phalanx anti-westlicher und rückschrittlicher Kulturemanzipation herausgenommen.

\section{VII}

Gehen wir eine weitere Stufe zurück: Das »postmoderne« Islamverständnis wurde von keiner Metapher stärker beeinflußt als von der des Propheten, der den König in die Knie zwingt. Michel Foucault formte sie noch 1978, als er Khomeini im Pariser Exil interviewte. Dem Werte auflösenden, nihilistischen und materialistischen, instrumentell-strategischen Charakter der abendländischen Kultur setzte Khomeini den Glauben an die weltverwandelnde Kraft des islamischen Spiritualismus entgegen. Das moderne Paradox, auf das Foucault hinwies, ist das Exil. Khomeini beschwor damals, auf dem Rasen einer Pariser Villa liegend, die »Revolution« in Teheran. Der orientalische Prophet weilte im weltlichen Exil, bevor er den säkularen, vom Westen unterhaltenen Despoten stürzte (vgl. Stauth 1991a). Man könnte hieran anknüpfend viele Parallelen darüber spinnen, wie sehr die fundamentalistischen Versuche der heiligen Erneuerung des Islam als der tragenden Zivilisation des Orients sich aus den Vorstellungen des "Exils « in der verderbten heidnischen Welt des Westens, der jabiliyya, speisen. Der Name der bekanntesten, inzwischen aufgelösten ägyptischen Fundamentalistengruppe, takfir wal-higra (Verderbtheit der Ungläubigen und Migration), nimmt den Zusammenhang zwischen Exil und Wiederkehr des Heiligen auf. Es gibt kaum einen der großen, modernen Führer der Idee des politischen Islams, der nicht einmal an einer westlichen Universität studiert hat. In den Schriften der großen islamistischen Denker, Sayyed Qutb, Malik Bennabi, Ali Shari'ati, verkehrt sich der Begriffsapparat der Aufklärung als »islamische Emanzipation« gegen die Aufklärung selbst. Religion, die die Aufklärung abzuschaffen trachtete, soll nun plötzlich selbst Aufklärung bringen.

Die "postmodernen « Kulturstrategien machen Religion wieder zum Heilmittel. Die Wunden der homeless mind der Moderne sind zu stillen. Auch darin liegt die anerkennende Kraft des Islamismus. Im Zeichen der kulturellen Anerkennung des Islams stehen auch Forderungen nach der radikalisierten Kontinuität alter orientalischer Lebensformen, ja Lebenskünste. Wenn vom Schutz der Mystik, Schutz des Eros, Schutz instinktiver und symbolischer Erkenntnisformen, vom 
Schutz exotischer Welten, von der Macht des symbolischen Tauschs heute gesprochen wird, dann sind fundamentalistische Kulturerneuerungsprogramme immer präsent. Der unverzichtbare Kern der Menschenrechte wird auf Traditionen hin entwickelt, die diesem Kern fremd gegenüberstehen. Es geht hier bereits um im Denken des Westens vorbereitete Reversionen der Aufklärung. Sie setzen sich auch im islamischen Denken durch. Die wilden politischen Aktionen und Ideen deprivierter Jugendlicher in den armen, islamischen Ländern des Vorderen Orients, Afrikas und Südostasiens stehen im Kontext globalisierter Reversionen: Kulturtechniken erstarren zu mörderischen Befreiungsideen.

Von hier aus läßt sich erkennen, wie der Fundamentalismus im kulturübergreifenden Feld operiert. Er erschließt eine Ebene der paradoxen Umsetzungen westlicher Kulturtechniken und orientalischer Ideen und Prinzipien. Der Islam steht im Zentrum dieses breiten Feldes des Kulturaustauschs. Der Emanzipation fordernde Begriffsapparat der Aufklärung und des in ihr begründeten Nationalstaats setzte das Gerüst, auf dem die alten Ideen, Prinzipien und Lebenskünste fortwirken, ja oft genug in ihr Gegenteil pervertiert werden.

\section{VIII}

Welche Rolle spielen in diesem Zusammenhang die Kosmogonien, Visionen und Prinzipien der alten Hochkulturen? Fernand Braudels Studien über die Austauschbeziehungen des Mittelmeerraums, jenes Raums, in dem die Idee des einen Gottes geboren wurde, stellen die ungebrochene Kontinuität der "Zivilisation « des alten Orients heraus. Louis Dumonts Untersuchungen über vormoderne und moderne Modelle sozialer Organisation und ihre relative Gegenseitigkeit wurden am Beispiel des Vergleichs Indiens (das Land, an dessen Kultur sich die Romantik so tiefschürfend bereicherte) mit dem Christentum entwickelt. Sie zeigen, wie die Prinzipien und Lebensformen der alten $\mathrm{Zi}-$ vilisationen in einem einmal gesetzten geographischen Raum über Jahrtausende hinweg wirksam bleiben können. Sie zeigen aber auch die relative Ambiguität der Kulturgrenzen (Braudel/Duby/Aymard 1990; Dumont 1986). Auf die Geisteswissenschaften können solche Tiefensichten nicht ohne Wirkung bleiben. So beschwor Muhammad Arkoun noch kürzlich den Mittelmeerraum als eine geographisch-politische Einheit der Geburt und des Dialogs der drei großen Weltreli- 
gionen, als den eigentlichen Ort der westlichen Zivilisation (Arkoun 1996).

Der beidseitig selbstzentriert ausgelegte Dialog zwischen Ost und West führt zwangsläufig zu dem Eingeständnis, die alten Hochkulturen schrieben einseitig die moderne Geschichte fort. Das war auch die Antwort der zivilisationsvergleichenden Analysen Max Webers. Doch dessen Botschaft war eher so zu verstehen, daß die säkularen, öffentlichen Kulturen der modernen Nationalstaaten durch die inneren Rationalitätslagen der Weltreligionen mitgeprägt sind. Eine Theologisierung der Konstitutionen von modernem Staat und Politik konnte sich Weber nicht vorstellen. In den 20er Jahren, kurz nach Webers Tod, haben Carl Schmitt (1922) und Martin Buber (1932) aus unterschiedlichen Blickwinkeln heraus die moderne Kontinuität des »Königtum(s) Gottes " gewissermaßen wiederentdeckt, und heute scheinen christliche Demokratie, Zionismus und Islamismus jenseits aller bürokratisch-technischen Rationalität die Bedingungen für neue polito-religiöse Wahlverwandtschaften im Spannungsfeld kultureller Globalisierung zu setzen.

Doch liefern die Kosmologien der alten Weltreligionen nur abstrakte Formeln, auf die sich Fundamentalismus und kulturelle Globalisierung beziehen. Wenn gemeinhin Fundamentalismus und Globalisierung unter den Gesichtspunkt des Erstarkens autoritärer Regime gestellt werden, so ist daran zu erinnern, daß die Ambivalenzen und Ambiguitäten, die die Reversionen der kulturübergreifenden Eigenlogik hervorbringen, an sich eher eine Vielfalt der faktischen politischen Gestaltung zulassen. Letztere steht hier nicht zur Diskussion.

Man darf dabei nicht außer acht lassen, daß es die Transgressionen der Ordnungspraxis (Werte-Umwertung, Lebensstil, Visionen) sind, die die globalisierten Segmente der »Weltgesellschaft«, konstituieren. Fundamentalismus wird hier gewissermaßen zur kulturellen Produktionsweise der Moderne unter den Bedingungen ihrer Globalisierung. Aus der Beurteilung des Grades inhärenter Zwänge zum Fundamentalismus und seiner politischen Repräsentationsformen läßt sich erst diskutieren, welche praktischen Chancen die Demokratie in der muslimischen Welt hat. Wenn es aber länderspezifische Modelle der demokratischen oder autoritären Einbindung des Islams gibt, wird man an einer reduktionistischen These des kulturübergreifenden Zusammen- 
hangs von Fundamentalismus und Globalisierung nicht festhalten können.

\section{Die kulturelle Eigenlogik des Gesellschaftlichen in der Globalisierung}

IX

Die Kultur- und Zivilisationsforschung ist seit dem Ende des »Realen Sozialismus «, insbesondere durch die damit verbundene neue strategische Stellung der nicht-westlichen Welt, in eine Phase der vergleichenden Interaktion eingetreten: Ihre Stellungnahmen und Ergebnisse werden selbst kulturproduktiv. Bild und Gegenbild setzten eine neue Form der Wandlungsdynamik, die nicht mehr funktions- und strukturorientiert ist. Nach dem amerikanischen Religionssoziologen Tiryakian ist das Ende der ideologischen Auseinandersetzung mit dem Sozialismus auch das Ende der inneren gesellschaftlichen Motorik des Westens überhaupt. Tiryakian glaubt, daß das, was bisher das Soziale war, nämlich das, was sich im Innern der Gesellschaften ereignet, nicht mehr unter die herkömmlichen soziologischen Begriffe zu stellen sei. Er behauptet, daß kulturelle und kulturübergreifende Differenzierungsaspekte die alten funktionalen Wandlungsmodelle aufhöben ( $\mathrm{Ti}$ ryakian 1994). Hinzu kommt, daß die Symbolwelten der uralten nichteuropäischen Zivilisationen (wie zuvor Griechenland und Rom) nun als nostalgische Ressourcen in den Sinnbildungsprozeß der Moderne eingespielt werden. Das symbolische Kapital der »Armen dieser Welt « wird zum Bestandteil des postkolonialen Wertepotentials der Moderne.

Die aus dem antiken Orient überkommenen Prinzipien der jenseitigen Bestimmtheit diesseitiger Ordnung werden in der nostalgisch gewendeten Emanzipation der orientalischen Kulturen wieder zu entscheidenden Komponenten des modernen Selbstverständnisses. Diesem Faktum wird in der komparativen Analyse des modernen Fundamentalismus Rechnung getragen. Der Fundamentalismus wird aus dieser Sicht zu einem spezifischen Problem der Entstehungsgeschichte der Weltreligionen und der Psychologie des religiösen Intellektualismus. Man erinnere sich nur, wie in Max Webers Religionssoziologie zum Beispiel schon der Zauberer in den genealogischen Zusammen- 
hang des modernen Berufsmenschentums tritt (vgl. etwa Weber 1980: 246). Nietzsches Lebensproblem, die priesterliche Macht und die Umwertung der Werte, wird hier aufgegriffen und kulturaffirmativ gewendet. Die Vorstellung, daß in allen Hochkulturen religiöse Intellektuelle als eine relativ autonome, professionelle Zunft auftreten, die sich eigens der Interpretation der heiligen Schrift und der Definition des Verhältnisses von Mensch zu Gott annehmen, ist Ausgangspunkt des Zivilisationsvergleichs. Aus den unterschiedlichen Gottesvorstellungen lassen sich die Verschiedenheiten des Menschenbildes bestimmen. Die "Kulturen der Achsenzeit « (Eisenstadt 1982, 1987) bringen alle einen Typus des Intellektuellen hervor, der über transzendentale Visionen und von daher bestimmte ethische Maximen und Leitbilder in das Zentrum der politischen Entscheidungsmacht einzugreifen versucht. Dadurch setzen sich religiöse Intellektuelle virtuell immer in ein Spannungsverhältnis zur politischen Macht, derer sie sich selten ganz bemächtigen können, von der sie aber oft ins gesellschaftliche Abseits verbannt werden. Sektenbewegungen, millennarische Erlösungsbewegungen, mystische Orden und Geheimbünde sind Antworten auf die politische Marginalisierung der religiösen Intellektuellen. Der zeitgenössische Fundamentalismus gilt so, geschärft durch die Grenzerfahrungen des Politischen in den Großen Revolutionen des 18. und 19. Jahrhunderts und den neueren Protestbewegungen, die mit der Formationsgeschichte des modernen Nationalstaats entstehen, als Fortführung der vormodernen Sektenbewegungen. In der Perspektive der historischen Soziologie Eisenstadts lassen sich die modernen fundamentalistischen Bewegungen unter Bezug auf alle Weltreligionen und den Zeitpunkt der nationalen Unabhängigkeit und des Eintritts der einzelnen Länder in das internationale System überall auf der Welt vergleichend untersuchen (Eisenstadt 1998).

Was sind die wichtigsten Erkenntnisse, die wir aus dem komparativen Ansatz zum Fundamentalismus-Verständnis gewinnen können? Zunächst vermittelt dieser Ansatz einen wohltuenden Zwang zur Gleichbehandlung der fundamentalistischen Bewegungen in den unterschiedlichen Kulturen. Dieser Egalitarismus in der herkömmlichen sogenannten vergleichenden Zivilisationsanalyse ist aber zugleich von Webers und Durkheims Fragestellungen nach der modernen Rolle der Religion beeinflußt. Für den Islam hat sich das dahingehend ausgewirkt, daß ihm fast immer ein relativer Mangel an funktionaler Äqui- 
valenz zum Protestantismus und folglich westlichem Rationalismus unterstellt wurde. Inzwischen weiß man, daß es um solche Funktionen der Religion gar nicht mehr geht. Es ist erkannt worden, daß der Grad der Transgression einmal gesetzter Normen- und Ideengefüge für die Öffnung einer Gesellschaft wichtiger ist als der Gehalt dieser Prinzipien- und Ideensysteme selbst. Der Transgressionsgrad steht in enger Beziehung zur Globalisierung und Intensivierung interkultureller Interaktion. Wo, wie noch im Weber-Paradigma, immer nur innere Begriffe und Kulturvisionen als Voraussetzungen eines Formations- und Reformprozesses zum Gegenstand gemacht werden und deren Rationalisierung sodann vergleichend untersucht wird, werden die interaktiven Transgressionsmechanismen kaum beachtet. Es ist deshalb durchaus angemessen zu konstatieren, daß die hier ansetzenden kulturvergleichenden Analysen nur »die Affinitäten der verschiedenen hochkulturellen Durchbrüche miteinander sowie mit dem Grundmuster der kulturellen Modernisierung einseitig akzentuieren « (Arnason 1989: 82).

Das absolute Recht des sich selbst versichernden Individuums, die Gründung aller institutionellen Macht auf Legitimation »von unten« und die damit einhergehende gewissermaßen antizipatorische Institutionalisierung der Protestbewegung im Staat, die Reversion des »Panoptikums « in seiner Dezentrierung, all dies sind legitime Programme, die sich aus der Globalisierung des Nationalstaats heraus heute in allen Kulturen und Gesellschaften ergeben. Der Zivilisationstheoretiker Eisenstadt hält in evolutionistischer Sicht zwei welthistorische Lagen als Kreuzpunkte von Religion und Politik für bestimmend: Das ist erstens der Zusammenhang von Jenseitsdenken und Diesseitsordnung. Die Ambivalenz dieses Verhältnisses spürt Eisenstadt im Achsenzeitbegriff Karl Jaspers' auf. Es handelt sich dabei um die Reflexion der Spannungen und Wertprobleme, die sich aus dem Sturz der altorientalischen Reiche ergaben. Die Okzidentalisierung des altorientalischen Kulturerbes (der Ägypter, Phönizier, Assyrer, Perser) besteht in der sukzessiven, virtuellen Auslagerung des Heiligen aus der Sphäre politischen Handelns. Damit treten nun Jenseitsvisionen stärker in Gegensatz zu den weltlichen Ordnungen. Eine neue, relativ autonome Klasse religiöser Spezialisten, und in deren Folge auch von Rechts- und Kunstexperten, tritt hervor. Sie versucht, die Interpretation der Spannungen und der allgemeinen Voraussetzungen des Verhältnisses von Trans- 
zendenz und Immanenz $\mathrm{zu}$ monopolisieren. In dem einsetzenden Kampf der Ideen entstehen die heterodoxen, sektiererischen und peripheren Gruppen, die mit puristischen und radikalisierten Ideen und Transzendentalvisionen Eingang in den vom staatlichen Zentrum abhängigen, orthodoxen Hauptstrom in Dogma und Ritus finden wollen. Zweitens arbeitet Eisenstadt heraus, daß sich die Ideen der großen Revolutionen des 18. und 19. Jahrhunderts, die Utopien und Grenzüberschreitungen, die der Jakobinismus im in der »Revolution « neugeborenen Nationalstaat, im Denken und in der Verfassung institutionalisierten, ja selbst in den bürokratischen Organisationen des Staats und in den routinisiert-charismatischen Welthaltungen der bürokratischen Eliten ihren Niederschlag fanden, gewissermaßen als intellektualisierte Transgressionen des Religiösen darstellen. Die Universalisierung des nachrevolutionären Nationalstaats brachte überall auf der Welt eine Art säkulare Neuformulierung der religiösen Prinzipien und Visionen der alten Zivilisationen hervor.

Mit dieser doppelten Lagerung der globalen Bedingung des Fundamentalismus wird es immerhin möglich, diesen nicht nur einseitig als Ausdruck der Religion des Anderen, etwa bloß der Sektengeschichte des Islams, zu begreifen. Die kulturellen Techniken, die sich aus der Achsenzeit heraus in das Zeitalter der großen Revolutionen entwickelten, waren von universeller Dimension. Kolonialismus und Imperialismus sowie die Universalisierung der nationalstaatlichen Verfassungen verhalfen der Religion zu einer neuen, modernen Bedeutung. Der universell auftretende Fundamentalismus spielt in der Genealogie der Moderne eine entscheidende Rolle, so auch in der Moderne der nichtwestlichen Gesellschaften. Eisenstadts Perspektive führt den genealogischen Zusammenhang von Fundamentalismus und Moderne auf das Problem der inneren Rationalisierung zivilisatorischer Ursprungsvisionen zurück. Der kultur-technologische und instrumentelle Aspekt der Vermittlung von Tiefensichten und ihrer Politisierung im globalisierten Austausch mit der Kultur des Anderen bleibt sekundär.

Für den Islam und die Entstehungsgeschichte des islamischen Fundamentalismus sieht Eisenstadt immer noch die Sektengeschichte als das bedeutendste Element. Er führt die sprachlose Gewalt, die ja doch nicht weniger sprachlos ist als die koloniale Herrschaftsform und die Zwangsregime der nationalen Emanzipation, die Sprachlosigkeit der islamistischen Gruppen, die sich gegen alles richtet, was sich nicht in 
islamischen Bildern kodifizieren läßt, auf frühislamische Sektenbewegungen zurück. Ohne Zweifel ist der Begriff des jihad, zum Beispiel, geprägt durch die Sichten der Kriegerethik der beduinisch-islamischen Kämpfer, und ohne Zweifel spielt dies heute unter islamischen militanten Fundamentalisten eine Rolle, doch sind die frühislamischen Bedeutungen dieses Begriffs - der fast mehr als tausend Jahre für die muslimische Welt kaum von Bedeutung war - erst in der Nationalstaatssprache der authentischen Kodifizierung und Purifizierung von Kulturgeschichte und Religion ein Mittel der sprachlosen Ausgrenzung des Anderen geworden. Man muß verstehen, wie wenig der fundamentalistische Begriff des jihad - geprägt auch durch die wissenschaftliche Verständigung der Orientalisten darüber - mit dem koranischen Begriff zu tun hat, um zu sehen, wie die »Islampolitik « selbst diesen Begriff für die moderne politische Sprache instrumentalisiert hat.

Eisenstadt entwickelt ein starkes Gespür dafür, wie die modernen jakobinischen Techniken der Eliminierung des Nicht-Authentischen, des Nicht-Korrekten, zum inneren Bestandteil moderner Herrschaftstechniken geworden sind. Die Bedingung der Moderne hat eine kulturtechnische Universalität geschaffen, das zeigt er. Die inneren Ausarbeitungen kultureller Spezifität, die Ausarbeitungen der Differenz, werden zum inhärenten Bestandteil jener Universalität der Kulturtechniken.

$\mathrm{X}$

Die Vermittlungen, Simulationen und Konfrontationen, die sich aus dem gegenseitigen Anerkennungs- und Differenzierungszwang des kulturübergreifenden Wechselspiels ergeben, lassen sich analytisch nur einfangen, wenn man einen Schritt weitergeht. Die Formel, der Fundamentalismus sei eine kulturelle Reaktionsform vormoderner Kultur auf schnelle Modernisierung und wirtschaftliche Globalisierung, also eine Form der lokalen Widerstandskultur gegen die Globalisierung der Moderne, ist im Kern falsch, wenn auch nostalgische Visionen einer verlorengegangen Zeit Bestandteil des Wechselspiels der Kulturen sind.

Nur wenige Autoren haben so konsequent und systematisch wie Roland Robertson (1992) gezeigt, daß der Fundamentalismus nicht nur eine Reaktion auf die Globalisierung der Konsum- und Mediengesellschaft ist, sondern daß das Auftreten fundamentalistischer Ideolo- 
gien und Bewegungen ein tragender innerer Bestandteil der Globalisierung und der kulturtechnischen Umsetzung des Begriffsapparats der Aufklärung ist. Er erklärt dies damit, daß die begrifflichen Universalisierungen des 19. Jahrhunderts - etwa die Fixierung der Begriffe wie Nation, Religion, Zivilisation - zu ganz spezifischen, partikularistischen Ausarbeitungen und Transformationen lokal kultureller Selbstvorstellungen geführt haben. Der im Westen entwickelte humanwissenschaftliche Apparat - Geschichte, Philosophie, Soziologie, Religionswissenschaft etwa - habe generalisierte und standardisierte Wissenschaftsbegriffe von Geschichte und Religion als Form einer staatsbürgerlichen, zivilen Emanzipation entwickelt, die notwendig zu partikularisierten Selbstbestimmungen lokaler Kulturen führen muß.

Robertson begreift das Entstehen der fundamentalistischen Bewegungen als eine entscheidende Komponente des doppelten Prozesses von Universalisierung und Partikularisierung kultureller und religiöser Ideen. Die vermittelnden Mächte sind Generalisierung und Standardisierung der Begriffe Nation, Zivilisation, Zivilgesellschaft, Bürgerlichkeit etc. Sie schaffen eine »stählerne « Struktur der Wiedererweckung kultureller Ideen und Prinzipien. Dabei werden zugleich die fundamentalistischen und essentialistischen Formen offengelegt, mit denen die Globalisierung der Moderne insgesamt einhergeht. Robertsons Globalisierungstheorie impliziert ein neues Paradigma der gesellschaftlichen Differenzierung. Relativierung, Ich-Aneignung und Vergesellschaftung von kulturellen Ideen konstituieren eine neue Lage des Gesellschaftlichen. Globalisierung heißt, daß sich das globale Segment von Gesellschaft aus den Spannungen zwischen Selbstbegriff, Menschheitsidee und Daseinslagen, zwischen Gemeinschaft und Gesellschaft ergibt. Globalisierung ist also ein Konstrukt von Weltgesellschaft, das über die Moderne hinausreicht und aus dem Zusammenspiel und der Vielfalt lokaler Traditionen erwächst.

Robertson stellt die alte Frage »wie ist soziale Ordnung bei Vielfalt der sich dann ergebenden kulturellen Interessen möglich? «Wie also ist eine globale Gesellschaft möglich, die die Welt als ihren »single place« versteht? Robertson kommt hier über die Vorstellung eines Chaos gemischter, konfligierender, globaler Interessen und Strategien nicht hinaus. Differenzierung, Relativierung und Konflikt scheinen für ihn ganz in der Tradition Simmels - eine neue evolutionäre Stufe der menschlichen Entfremdung zu bedingen. So läuft Robertsons Frage- 
stellung in bezug auf den Fundamentalismus auf die Vergesellschaftungsformen hinaus, die dieser im Spiel des globalisierten Kulturprozesses durchsetzt. Es geht ihm jedoch nicht um Vergesellschaftung als eigenständiges und totales Moment des weltumspannenden Prozesses - wie noch Turner (1994: 113) meint -, sondern vielmehr auch um eine ethische Soziologie auf Basis eines evolutionistischen Optimismus.

Sicher spielt dabei der Hintergrund Talcott Parsons' eine Rolle (vgl. Turner 1994: 105-114) und die Differenzierungen zwischen universellen und partikularistischen Ausarbeitungen kultureller Ideen werden von Robertson als eine neue Form, ein entscheidender Sprung der Rationalisierung und sozialen Differenzierung betrachtet, die sich aus dem Wechselspiel der Zivilisationen heraus in allen modernen Gesellschaften gleichzeitig, wenn auch mit Verschiebungen, ergeben.

Hier stellt sich die Schwierigkeit ein, wie sich die diversifizierten Anwendungen des »Selbst «, der »Religion«, »Nation« und »Welt als vorgestelltes Ganzes « durchsetzen. Kann sich aus diesen Gegensätzen der kulturellen Fassung des Partikularen und Universellen überhaupt ein kohärenter Prozeß der Vergesellschaftung der Welt entwickeln, wenn man die strukturellen und materialen Probleme der Auflösung des Nationalstaats nicht mitdenkt? Selbst in einem konstruktiven Sinn bleibt die »single-world-society « Robertsons im Bild des "global village « befangen und der Fundamentalismus ein Mittel, dasselbe zu konstituieren.

\section{XI}

Die multikulturellen Konstitutionsbedingungen des Fundamentalismus werden in der Sicht des Kommunitaristen Charles Taylor sehr deutlich beleuchtet. Der hier unterliegende Begriff des kulturübergreifend bestimmten "Sozialen « hat, wie auch die Luhmannsche Vorstellung von der Absolutheit eines neuen kulturell bestimmten Kampfes um Inklusion und Exklusion, eine neue Qualität. Die Totalisierungsmaschine des Fundamentalismus läßt sich über Charles Taylor auf einer Ebene einfangen, die aus dem funktional-rationalistischen Diskurs des »social engineering « heraustritt. Symbolische, funktional nicht mehr wirksame Strategien und Machtspiele der sozialen Anerkennung kultureller Differenz ersetzen die funktionalistische Rationalität. Der konventionelle Kommunitarismus lehrt, daß moralische Selbstvergewisserung ein konstitutives Element der Vergesellschaftung des Indi- 
viduums ist. Das aber impliziert die Notwendigkeit der Instrumentalisierung von Moral. Der Fundamentalismus steht genau im Spannungsfeld zwischen sozialem Spiel und Absolutheitsanspruch auf Moral. Die moralische Selbstbegründung des Individuums wird hier ein Werkzeug im Kampf um soziale Anerkennung und Gleichbehandlung. Wo die traditionalen symbolischen und askriptiven Muster des gemeinschaftlichen Lebens aufgehoben sind und das »stählerne Gehäuse funktionaler Rationalität sich durchsetzt, bedarf es bald einer dritten Dimension des Sozialen: »Identitätspolitik « hat nun den Ersatz für die alten Statuszuweisungen und den Kitt der alten Gemeinschaftsbeziehungen zu liefern. Wenn die Not der sozialen Kohäsion erst den Hintergrund für den Kampf um kulturelle Anerkennung liefert, dann stellt sich aber das Problem der sozialen Ordnung ganz neu. Denn im Anerkennungskampf selbst wird das »Gut « - in der Regel das Prinzip des Moralischen und Authentischen -, das Ordnung schaffen soll, selbst zum Prinzip des Kampfes um Ordnung, also selbst zum Ordnungsproblem, wie Charles Taylor dies ausdrückt (Taylor 1992: 59). Taylors Essay »The Ethics of Authenticity « macht dieses Paradox des kommunitaristischen Diskurses zum Zentrum der Frage nach der sozialen Rolle kulturübergreifender und multikultureller Kommunikation. Die Theorie der moralischen Fundierung des Sozialen und damit die Legitimation des Fundamentalismus als demokratische Form der moralischen Selbstvergewisserung liefert so eine Art kommunitaristischer Apologie des Fundamentalismus. Denn die Idee der Ordnung als moralisch begründete soziale Kohäsionsform ist Kulturwerkzeug im Kampf um Anerkennung. Sie ist nicht in den Tiefen der Ursprungsmoral geboren, auf die zu bauen sie vorgibt. Die Instrumentalität des »Ursprungs«, immer authentischer als der Andere sein zu müssen, ist die fundamentalistische Ordnungsidee, eine moralische Überschreitung tradierter Überlieferung und Normen; sie erst gibt sich als die absolut neue kulturelle Erfindungskraft. Man hat sich - wenn sie nicht gar in Blutbädern wie jüngst in Luxor ins Licht der Kamera treten - an solche Erfindungsspiele längst gewöhnt, und solange es nicht der »eigene « Staat ist, ist man zunehmend bereit, den Islamismus als legitime Überwindung des säkularen und funktionalen Nationalstaats hinzunehmen. Man vergißt dabei, daß in Ländern wie der Türkei oder Ägypten die Geschichte des Nationalstaats in der Tat so weit zurückreicht wie diejenige einiger europäischer Länder. 
Das Dilemma des Kommunitarismus läßt sich lösen, wenn man Moral nur aus ihrer sozialen Funktion heraus betrachtet: Nur weil Moral sozial konstitutiv ist, kann sie in ihrer Funktion betrachtet werden. Soziologie muß deshalb aus dem Wertungszusammenhang der Moral heraustreten. Niklas Luhmanns Analysen des moralischen Diskurses kommen den kommunitaristischen Befunden durchaus nahe, indem sie Selbstreflexivität und Identitätspolitik in ihrer Funktion als Konstitution einer neuen - kulturellen - Eigengesetzlichkeit des Sozialen bestimmen. Es ist der Grad der Selbstreflexivität und des Authentischen, der über Inklusion oder Exklusion entscheidet. Luhmann sieht hierin eine neue Form der Systemintegration, die die herkömmlichen Inklusions- und Exklusionsformen, die noch auf funktionaler und institutional wirksamer Rationalität beruhen, aus den Angeln hebt. Der kulturelle Prozeß der Inklusion und Exklusion ergibt sich zugleich als eine neue Form der sozialen Differenzierung, die sich nur noch über kulturelle, nicht mehr über funktionale Definitionen herstellt. Inklusions- und Exklusionsmechanismen operieren auf eine Weise, daß funktionale Chancen der Rationalität unmittelbar aufgehoben oder unterminiert werden (Luhmann 1994). Auch hier läßt sich das oben bereits bemühte Argument erneuern, daß die von den fundamentalistischen Bewegungen beanspruchte Ordungsfunktionalität obsolet ist, weil sie selbst aus jedem funktionalen Kontext herausspringt - auch dann, wenn sie noch vorgeben, soziale Dienste zu entwickeln.

\section{Globalisierung und Fundamentalismus zwischen Autoritarismus und Demokratie: Praktische Konsequenzen für die Zukunft des Islamismus}

\section{XII}

Über Kultur und Religion läßt sich Funktionalität nicht definieren. Hier werden die irrationalen Komponenten des fundamentalistischen Diskurses deutlich. Inklusions- und Exklusionsmechanismen machen noch selbst jeden Kulturbegriff zu einem bloß technischen, medienöffentlichen und selbstreferentiellen Zeichen im Kampf um soziale Anerkennung. Das gilt in erhöhtem Maße für alle Formen der kulturübergreifenden vergleichenden Interaktion. Über die - wie ich anzudeuten versuchte - inneren Widersprüche und die Kritik hinsichtlich ihrer möglichen apologetischen Funktion hinaus scheinen die Theorie- 
angebote der Soziologie auf die These einer eindimensionalen Umsetzung des Fundamentalismus in den sich globalisierenden Segmenten der Gesellschaft hinauszulaufen.

Eisenstadts These von der allgemeinen Durchsetzung des fundamentalistischen Heterodoxismus in alternativen Formen der Moderne, auch den nicht-westlichen, beinhaltet eine solche Konstitution des globalisierten Segments.

Robertsons Theorie der universellen Umsetzung der modernen Kulturtechniken - Fundamentalismus hier als eine Hauptkomponente mit der Funktion der partikularistischen Ausarbeitung nicht-westlicher Kulturen - weist auf eine zweite Durchsetzungsdimension hin.

Taylors und Luhmanns Befunde der interaktiven konstituierten Notwendigkeit zur Differenz setzen als Form sozialer Anerkennung und Inklusion eine neue Ebene des Sozialen voraus, über die Fundamentalismus zum unausweichlichen Faktor moderner sozialer Rekonstruktion wird. In der totalen und abstrakten Gegenseitigkeit der Bestimmung zur Differenz wird eine dritte Lagerung der Globalisierung deutlich, nämlich der radikal offene, irrationale, fließende, ja hybride Charakter der sich im Globalisierungsprozeß affirmierenden Kultur: eine Kultur ohne Namen, ohne Ort, ohne Prinzipien, einzig durch den Grad der Transgressions- und Rekonstruktionskraft bestimmt.

\section{XIII}

Wer nun aber die sozialen und kulturellen Dimensionen der Umsetzung des Fundamentalismus zu einer Prognose des politischen Sieges fundamentalistischer Gruppen machen wollte, liegt fehl. Ich schlage als vorläufiges Fazit vor, Fundamentalismus in Ost und West als »Transgression« im Sinne der Überschreitung gelebter Wertewelten und Lebensformen zu begreifen. Nichts, was der Islamismus heute will, hat etwas mit der von Toleranz und Liberalität geprägten islamischen Tradition zu tun. Auch kann man den politischen Islam heute schlecht mit der praxisfernen Weltverneinung der scholastischen Gelehrtenwelt oder mit den traditionalen Rechts- und Denkschulen in der Hochphase der islamischen Zivilisation erklären. Was außer einer abstrakten Vorstellung von der politischen Klugheit des Propheten in der Phase des nationalen Befreiungskampfes oft genug noch zur kulturellen Begründung der säkularen Revolution angeführt - läßt sich aus der Zeit umma, der Gemeinschaft der ersten Muslime um den 
Propheten, auf die nationalstaatliche Realität beziehen? Die malaysischen Politiker Mahatir Mohammad und Anwar Ibrahim haben 1983 noch der islamischen Öffentlichkeit ihres Landes zugerufen: "Wir sind die islamischen Fundamentalisten « und damit zugleich eine in der islamischen Welt einmalige Inklusionskampagne einer militanten Jugendbewegung ebenso wie des traditionalistischen, »fremden «, orthodoxen Schrift-Islams in einen erfolgreichen Prozeß nationaler Emanzipation, wirtschaftlichen Wachstums und der Globalisierung der Gesellschaft eingeleitet (vgl. Teik 1995; Ibrahim 1996). Unter anderen Bedingungen und mit unterschiedlichen Gewichtungen von Tradition und moderner Weltauslegung versuchen islamische Denker in Indonesien, dem größten muslimischen Land, eine progressistische, sozialemanzipatorische Rolle zuzuweisen, indem sie einerseits einer vollen Verwestlichung Einhalt gebieten wollen, andererseits aber die »islamische Lebensform (syari'ah)« nur im Rahmen der gegebenen säkularen Ordnung des Nationalstaats legalisieren wollen (Wahid 1996). Dies geht, wie man das längstens aus den Erfahrungen der Länder im Nahen Osten kennt, nicht ohne Widersprüche (vgl. Ibrahim 1988). Um die politischen Umsetzungen der Zwänge und Notwendigkeiten, unter denen die Muslime heute mit purifizierten, »authentisch « gemachten Visionen des Islams eine moderne Lebensform begründen müssen, tobt überall in der islamischen Welt ein offener, insgesamt aber fruchtbarer Kampf um Neuordnung und Transgression. Fundamentalismus war lange ein zu diffuses Wort, mit dem man die verschiedenen Schattierungen des modernen politischen Islams ausgrenzen konnte. Andererseits haben westliche Inklusionsstrategien nur selbst zu Ausblendung der Widersprüche der postkolonialen Geschichte und zu falschen Affirmationen vorkolonialer Traditionen geführt. Fundamentalismus und islamischer Liberalismus werden heute als innere Gegensätze des zeitgenössischen muslimischen Denkens bezeichnet. Binder (1988) hat jedoch gezeigt, wie nah sie in Wirklichkeit beieinander sind. Dies sind nur unterschiedliche Selektionsmechanismen, mit denen die Kulturbestände des Islams neu verlesen werden. Fundamentalismus wie Liberalismus unterliegen den gleichen kulturtechnischen Zwängen. Globalisierung mündet nicht nur in einen Prozeß der Generalisierung und Differenzierung kultureller Techniken und Ideen. Die Wirkungen des kulturübergreifend vergleichenden Interaktionsprozesses sind allumfassend. Als Beispiele seien hier nur die Gründungen anti- 
orientalistischer Orientalismus-Schulen (Aufbau konkurrierender islamischer Wissenschaftszentren zur Begründung einer international durchsetzungsfähigen politischen Philologie des Islams), des protestantischen Islamismus (etwa die Gründungen nichtstaatlicher Organisationen mit dem Ziel der Durchsetzung islamischer Arbeitsethiken und Methodologien asketischer Lebensformen), des anti-westlichen Spiritualismus und instinktiv begründeten oder symbolischen Rationalismus (die Sufismus-Bewegungen) oder der Islamisierung der Wissenschaft (etwa die Gründung internationaler islamischer Universitäten auf der Grundlage einer islamischen Wissenschaftstheorie) genannt (Abaza 1998). Solche Bewegungen liefern die Transformationskraft zu neuen Sozialisationsformen, sie gehen mit dem Fundamentalismus Hand in Hand, ohne militant zu sein. Es entsteht hier eine neue, kulturelle Eigengesetzlichkeit des Sozialen, das sich gegen die herkömmlichen kommunalen oder rationalen Organisationen der Lebenswelt und die funktionale Differenzierung auf institutioneller Ebene durchsetzt.

Im Gegensatz zu den Vorstellungen einer blockbildenden Vereinheitlichung der islamischen Welt im Zeichen des Fundamentalismus und der Globalisierung und über die Befunde des soziologischen Theorieangebots hinaus läßt sich nach nunmehr über 20 Jahren praktischen Experimentierens mit fundamentalistischen Ordnungsvorstellungen zeigen, daß sie zu einer Vielfalt und eben keineswegs zu einer fundamentalistischen Geschlossenheit der islamischen Welt beigetragen und von einem islamischen Land zum anderen zu oft konträren Erfahrungen und Ergebnissen geführt haben. 


\section{Teil III}

\section{Islamisierung und materielle Kultur}

"The country, the place where the fellabeen lived, I had seen from the windows of the train as we went from Cairo to Alexandria for summer bolidays..."

(Hassan Fathy Gourna, A Tale of Two Villages, 1969)

"Le village égyptien n'est pas une commune au sens civique du mot, pas un organisme, mais une masse."

(S.J. Henry Ayrout, Fellahs d’Égypte, 1943) 



\section{Materielle Not, kulturelle Globalisierung und sozialer Konflikt. Reflexionen zur Hermeneutik symbolischer Idealisierung}

Dies ist kein rigider und autoritativer Entwurf eines methodischen Ansatzes. Vielmehr will ich mit diesem Beitrag eine Reihe praktischer Forschungsschritte darstellen, die zu pragmatischen Lösungen führten.

Als ich die vielseitigen Bedingungen des sozialen Wandels der materiellen Kultur des ägyptischen Dorfes zu untersuchen begann, war ich von der Frage eingenommen, wie sich die beobachtbaren Handlungszwänge praktischer Intersubjektivität in ein repräsentatives Bild der Dynamik sozialen Wandels transformieren lassen: die Interdependenzen zwischen Marktformen und Gemeinschaftshandeln. Es wurde der Versuch gemacht, diese Interdependenzen und ihre Transformation in drei Dimensionen darzustellen: (a) die historischen Beziehungen zwischen »Geld « und »Gemeinschaft« bestimmen die aktuellen Erfahrungen der Akteure (b) »Theorie« systematisiert und transformiert Beobachtung in mikro-ökonomische Struktur (c) es besteht die Komplementarität zwischen Mikro- und Makrostrukturen (Stauth 1983a: 1-16, insbes. 14).

Es lassen sich zwei Einwände gegen diese Perspektive formulieren: (1) Sie macht lokale Handlungszusammenhänge ausschließlich zum Gegenstand externer Intervention. (2) Sie reduziert Handeln auf strukturelle Bedingungen. Der ideelle Nexus, den die Imaginationswelt von Reinheit, Sitten und Regeln auf »Geldverhalten« und »Gemeinschaftshandeln « ausübt, bleibt unerforscht. Der gesamte soziologische Analyseapparat, indem er Geld implizit zum Störfaktor von Gemeinschaft macht, reflektiert in sich und vollzieht - gewissermaßen stellvertretend - eine Art Endogenisierung der Lokalkultur. Man wird sich heute solcher nostalgischer Determinanzen des strukturalen soziologischen Forschungsapparats zunehmend bewußt (Stauth/Turner 1988b; Mitchell 1990).

Mitte der 80er Jahre hatte ich die Gelegenheit zur erneuten Feldforschung in ägyptischen Dörfern. Die simple Dualität zwischen »cash «und »community«-Nexus sollte durch Einführung eines »image«Nexus durchbrochen werden. Was wird damit gewonnen? 
Positiv formuliert, konnte mit den Studien der späten 70er Jahre gezeigt werden, daß der Mangel an Marktintegration notwendig und auf materieller Basis Gemeinschaftsintegration erfordert. Hier wirkt die Struktur der ländlichen Unterentwicklung auf die Materialisierung der Gemeinschaft hin. Es bedarf keiner gesonderten »Idee«, dem Diktat des Überlebenszwangs zu folgen (Stauth 1983a). Läßt sich umgekehrt Entmaterialisierung von Gemeinschaft durch wachsenden Geldverkehr, als Zwang zur Idealisierung von - in der Regel - verlorengegangener Gemeinschaft darstellen? Das mußte in eine kritische Reflexion des einseitigen Dualismus zwischen Geld und Gemeinschaft münden. Dualismus unterstellt einen im Prinzip ungewandelt rationalen Akteur, der entsprechend seinen Anwendungsbedingungen kontinuierlich zwischen zweiStrukturformationen zu entscheiden hat und im Zuge der Rationalisierung dieser Entscheidungen eine aufgelöste Vergangenheit idealisiert. Die Ideologisierung von Idiosynkrasien des verlorengegangenen Alltags rückt ins Zentrum sozialer Konflikte. Aus dem rationalen Maximierer von Vorteilen, wird ein »cultural dope« (so etwa bei Elster 1989). Islamisierung, Endogenisierung etc. erschienen so nur als Kritik des Geldes, das die Gemeinschaft zerstört.

Wo die Dualität von »cash «- und »community «-Nexus als alleiniger Faktor symbolischer Idealisierung hingestellt wird, entsteht das Paradox, daß sozialer Wandel nur durch von außen induzierte strukturelle Zwänge und Ideenwandel zugleich nur als Reflex auf »innere« Kulturbestände erkennbar bleibt. Läßt sich dies durch Einführung einer Stratifikationsperspektive, die soziale Gruppen an Netzwerke der strategischen Vernutzung lokaler Ressourcen bindet, aufheben? (vgl. etwa Evers/Schiel 1988). Auch das Gefangensein im Netzwerk strategischen Denkens bleibt eindimensional auf bloß interessenverstricktes Handeln bezogen. Es kontextualisiert Handeln nicht, sondern identifiziert es mit den jeweils strukturell definierten Determinanten. Der hier eingeführte Begriff des »Nexus« hilft, Handeln und Struktur zu separieren und dient zugleich der Kontextualisierung von Handeln in bezug auf Strukturformation. Solche Kontextualisierungen können sowohl im Mikro- als auch im Makrobereich, im qualitativen, und im quantitativen Bereich vorgenommen werden. »Nexus « kann als Element der Selbst-Reflexion aus einem nicht-westlichen in einen westlichen Kulturkontext im Sinne etwa von Asad (1982) angewandt werden. Einzelne Strukturmerkmale können so in einen dynamischen 
Verstehenszusammenhang überführt werden. Sie werden nicht absolut gesetzt. Man kann sich eine Reihe solcher »Nexen« denken, die in soziale Anwendungsfelder überführbar sind. Hier wurde »Ideen- und Vorstellungswelt« als zusätzlicher Nexus gewählt. Er zielt darauf, den einseitigen strukturalen Dualismus aufzuheben.

Nein, so einfach ist es sicher nicht; es kommt auf die Korrelationen an. Der Imaginations-Nexus hilft uns zunächst nur zu zeigen, daß die mechanische Überleitung von Strukturwandel in Ideenwandel die Folge eines ungelösten Basis-Überbau-Schemas ist, das der Dualismus zwischen Geld-Nexus und Gemeinschafts-Nexus transportiert. Der »image«-Nexus reflektiert, daß wir in einem ganz materiellen Sinne ebenso Gefangene von »Grundideen « sind wie von »Geld «, »lokalem Naturalienhandel « und Notwendigkeit zur »Subsistenz « (Dweyer 1982). Ideenwandel impliziert Subjektwandel, und ist dieser einmal vollzogen, so ist die "freie « Rationalität der Entscheidung zwischen »Natur « und »Gemeinschaft « einerseits und »Markt « und »Gesellschaft « andererseits nicht mehr gegeben. Der Rückfall wird zum Tabu neuer »Vorstellungen « und »Moralen«. Strukturwandel als Konfrontation von Markt und Subsistenzformationen mündet also nicht in einen homogenen Ideen- und Subjektwandel, sondern führt zur Pluralisierung scharf getrennter und so widerstreitender Imaginations- und Moralwelten (vgl. Berger et al. 1973).

Aus der Kontextualisierung sozialer Realität in den »Nexen « von »Geld «, »Gemeinschaft « und »Grundidee « ergibt sich eine Hermeneutik der Zwänge zur Alltagsbewältigung, in der ideelle und materielle Zwänge gewissermaßen gleichrangig figurieren, nicht aber ursächlich sozial korreliert werden. Was bedeutet dies methodisch? Unter Hermeneutik verstehen wir klassischerweise Kontextualisierung von Text. Man hätte also zu fragen, wie sich solche $\mathrm{Z}$ wänge in einer Reihe unterschiedlicher » Texte « kontextualisieren. Bezogen auf ein Feld differenziert gelagerter sozialer Realitäten wären bestimmte »Größen « zu nennen, die hypothetisch unterschiedliche Segmente sozialer Realität aktualisieren. Für den Kontext des ländlichen Ägyptens wurden: Migration (Individuum, Haushalt, Dorf, Außenbeziehung), Massenkonsum (Subsistenz, Ware, Arbeit, Eigentum), Geschlecht (Segregation, Wissen, Ordnung, Reinheit) und Religion (Selbst, Glaube, Ritus, Habitus, Regel) als soziale Felder bestimmt. Die Kontextualisierung erfolgt in einem Dreiecksverhältnis zwischen »cash «-Nexus, der die ver- 
schiedenen Lagerungen der Außenbeziehungen repräsentiert, »community «-Nexus, der die Lagerungen der Binnenbeziehungen bezeichnet und »image «-Nexus, der das Feld der Ich-Repräsentation in der Welt, Ich-Formation und Außenbeziehung als Kontext, symbolisiert.

Das Problem war: lassen sich solche Beziehungen in ein Instrumentarium zur empirischen Forschung überführen?

\section{II}

Im Oktober 1985 hatte ich in Kairo Gespräche mit Freunden und Kollegen aus den soziologischen Abteilungen der Ain Shams und der Cairo Universität. Es wurde verabredet, ein großes, umfassendes soziologisches Projekt über den Zusammenhang von Migration und sozialem Wandel im ägyptischen Dorf durchzuführen; es sollten sich darin die ökonomischen und kulturellen Wandlungs- und Konfliktpotentiale des neuen Verhältnisses zu den Golfstaaten widerspiegeln. Sechs Dörfer in unterschiedlichen Regionen Ägyptens sollten untersucht werden. Im großen und ganzen geht die Aktualisierung der Untersuchungsfelder auf diese Gespräche zurück (Stauth 1986, 1987b). Als das Projekt schließlich im Juli 1986 bewilligt wurde, standen meine Gesprächspartner für die Forschung nicht mehr zur Verfügung: einer war inzwischen auf eine hohe Position der Universitätsverwaltung aufgestiegen, die anderen waren selbst an Universitäten in die Golfstaaten »emigriert«. Eine ganz evidente Aktualisierung des Forschungsthemas.

Frau Dr. Laila Shukry El-Hamamzi, damals Direktorin des Social Research Centers (SRC) der American University in Kairo sprang nach kurzer Bedenkzeit als Kooperationspartnerin ein.

Die folgenden Fragen mußten gelöst werden: (a) Welche Dörfer? (b) Separierung der Gegenstände quantitativer und qualitativer Analyse (c) Fragebogen und Leitfäden (d) Forschungserlaubnis (e) Zeitplan.

Das SRC verfügte über Forschungserfahrung in den Dörfern Shanawan und Kafr Shanawan in der Minufiyya Provinz (westliches Delta), ich selbst hatte über frühere Forschungsaufenthalte und Kontakte Zugang zu den Dörfern Kafr Yusuf und Kafr Tambul in Daqakhliyya (östliches Delta) und Abu Girg und Bani Walims in Minya (mittleres Oberägypten). Die Erfahrung lehrt, daß die beste Forschungserlaubnis nichts wert ist, wenn es Konflikte im Feld gibt. Darin waren wir, Frau El-Hamamzi und ich, uns einig. Das Auswahlprinzip »Zugang durch 
vorherigen Kontakt « ist das einzig mögliche und pragmatisch anwendbare Prinzip. Unsere sozialwissenschaftliche Forschungstradition überbetont rationale Forschungsstrategien und tendiert dazu, solche pragmatischen Prinzipien geflissentlich zu vergessen.

Das SRC errichtete auf Basis informeller Kontakte und in Zusammenarbeit mit den lokalen Behörden einen formellen Forschungsapparat. Die quantitative Untersuchung bestand: 1. aus einem Haushaltssurvey, mit dem in den 6 Dörfern 8.620 Haushalte (Haushaltsvorstände oder eine andere erwachsene Person des Haushalts) befragt wurden; 2. aus 640 teilstandardisierten Interviews mit Rückkehrern aus den Golfstaaten (200 in Shanawan, 40 in Kafr Shanawan, je 100 in den restlichen Dörfern); 3. aus unstandardisierten Gesprächsmitschriften der Interviewer zu verschiedenen Themen: Dorfstruktur, Wandlungsklima, signifikante Einzelbeobachtungen.

Die gegebenen privaten Kontakte ermöglichten es darüber hinaus den Mitgliedern des Bielefelder Teams, sich als Gäste der Dorfkultur in den unterschiedlichsten lokalen Lebensbereichen frei zu bewegen.

Nicht Forschungssystematik, sondern Pragmatismus hatte auch bei der fundamentalen Frage zu obwalten, was Gegenstand standardisierter Verfahren werden sollte und was andererseits Gegenstand mehr oder weniger offener Feldforschung bleiben mußte. Das Orakel einer antizipierten Zensur - der behördlichen ebenso wie derjenigen der zu Befragenden - wog schwerer als die Systematik des Ansatzes: Obwohl Strukturwandel und Einstellungswandel in einen, wenn auch sehr differenzierten und variablen Bezug gebracht waren, verhinderte das Orakel der Selbstzensur jede Möglichkeit, beide Dimensionen, die Institutionen der materiellen Kultur und die Typen der ideellen Repräsentation, zum Gegenstand eines einheitlichen standardisierten Verfahrens zu machen. Wenn andererseits ausschließlich kulturelle Handlungsmuster im Zentrum der qualitativen Untersuchung stehen mußten, waren dann noch »Tiefenbilder « der materiellen Zusammenhänge empirisch einzuholen? Vieles blieb dem Zufall und dem Geschick der einzelnen Forscher überlassen. Arbeitsteilung und Zeitdruck stellten uns vor Zwänge, die Systematik im Forschungsprozeß kaum zuließen. Nichts symbolisiert solche Zwänge krasser als der Unterschied zwischen dem hochklimatisierten Computerraum des SRC und der hitzigen Atmosphäre des in sonnenvergoldetem Staub dahintreibenden Dorflebens. Hinzu kommt, daß die Zugangs- und Lebensbedingungen 
für die Mitarbeiter in den einzelnen Dörfern sich völlig verschieden gestalteten. Nur der Eros der Unmittelbarkeit schafft erträgliche Forschungsverhältnisse. Dieses Paradox muß erst verstanden werden. In der sozialen Welt des ägyptischen Dorfes gibt es keine Privatheit. Man wird durch ständige »Versozialisierung « ohnehin zu einer Art kollektiver Erhebungsmethode gezwungen (vgl. auch Hopkins 1987: 13). Ein Stück pragmatischer Utilitarismus ist deshalb angemessen: Nur die "Wahlverwandschaften «, nicht aber die "Wahlfeindschaften « sind in einem solch offenen Forschungsprozeß dienlich. Erstere bilden meist den Grundstock späterer Objektivierung. Es sind die wichtigen und wenigen Ausnahmen, wenn die letzteren noch aufgearbeitet und in den Darstellungsprozeß eingebracht werden können: Basiskonflikte mit Gastgebern im Dorf, die Gruppendynamik des Forschungsteams, Sprachprobleme, Verständnisprobleme, Interpretationsprobleme. Die Brisanz der Hermeneutik der Zwänge der Alltagsbewältigung der »Forscher « überwiegt meist diejenige der »Lokalen«. Nur wenigen ist - wie es Clifford Geertz (1973: 412-454) im »balinesischen Hahnenkampf « beschreibt - das erlösende »Ereignis « vergönnt, daß Forschungsperspektive und lokales Leben praktisch miteinander verschmelzen. Es sollte dennoch der Versuch gewagt werden, durch Ineinanderschwenken von Semiotik (des morphologisch einprägsamen Bildes) und Biographie (der herausragenden Persönlichkeit) Ruhe in dieses Chaos bringen, das der Wille zum System produziert!

\section{III}

Vielleicht kann ich kurz am Beispiel der semiologischen Soziologie zeigen, wie sehr die strukturale sozialwissenschaftliche Erforschung materieller Institutionen der Erweiterung und Ergänzung bedarf. Die einfache Stratifzierung strategisch-funktionaler Mechanismen ist nicht geeignet, die kulturell vermittelten Dynamiken sozialen Wandels einzufangen. Man muß Zugang zur Vorstellungs- und Ideenwelt finden, in der die Subjekte leben, um Aussagen darüber machen zu können, wohin sie sich bewegen wollen, ob sie sich selbst und wie sie sich verändern wollen (Boon 1982: 116). Webers implizite Annahme, daß Charisma - jenseits aller statischen Morphologie individueller Eigenschaften und kultureller Konventionen - zu einem festen Bestandteil moderner Rollen, institutionellen Lebens und Motivationen wird, ver- 
deutlicht selbst die Fragwürdigkeit eines jeden Ansatzes, der "Sinn« lediglich aus überkommenen, endogenen Kulturbeständen zu lesen versteht. Geertz' einseitig semiotischer Ansatz, der Soziologie auf eine Wissenschaft der Symbole und Zeichen reduziert, neigt dazu, »Vertiefung « nur in den Strukturen lokalen Wissens und endogener Symbolik zu suchen: die charismatische Dynamik des Willens zur Modernität in einer symbolisch überladenen Hermeneutik der »Eigentlichkeit« aufzulösen.

Eine ergänzende Perspektive liefert Bourdieus Semiologie des Habitus. Bourdieu $(1974,1979)$ unternimmt den Versuch, das Unbewußte, Gefühlsstrukturen und Ausdrucksformen des Einzelmenschen in Verschmelzung mit raumzeitlich gesetzten Stilelementen als bestimmende Dimensionen des sozialen Arrangements einzubeziehen.

Die Alltagswelt des Individuums, als System der symbolischen Repräsentation verstanden, unterstellt immer eine gewisse Homogenität des sozialen Konsensus, die sich in der Kommunikation über die Kontexte der sozialen Mikroebene des individuellen und emotionalen Ausdrucks vermittelt. Kleidung, Geste, Blick sowie die körperlichen und persönlichen Akte des Individuums gelten hier als die tiefsten Spiegel des höchst Sozialen. Die Akte körperlicher Selbstentäußerung reflektieren eine soziale Realität, die über die Grenzen hinweg verläuft, die Weber noch in der Unterscheidung zwischen Alltäglichkeit und Außeralltäglichkeit setzt. Bei Weber ist Habitus notwendig nur eine ekstatisch hervorgerufene Form der sozialen Repräsentation und ist nur Menschen mit herausgehobener sozialer Stellung eigen. Weber sah im Amt und der damit verbundenen herausragenden sozialen Stellung den Ort, der notwendig die kulturelle Evokation außeralltäglicher Situationen und sakraler Gefühle erfordert (Weber 1980: 324ff.). Selbst in diesem Weberschen Verständnis des Habitus ist der professionelle Mensch ein gewissermaßen dauerhaft zu Habitus geforderter, charismatischer Mensch. Die kulturelle »Grundidee«, die er vermittelt, zwingt ihn zum Habitus. In den Zentren professioneller Kommunikation wird Habitus, wenn man Weber ernst nimmt, zu einer Angelegenheit dauerekstatischer Alltäglichkeit (Stauth 1991b). Dagegen kann man natürlich Habitus als eine ganz alltägliche Gewohnheit verstehen, die im Sinne etwa von Marcel Mauss so etwas wie ein Konstituum des sozialen Lebens ist: Ein Repertoire von Abrufbarem, in den Körper eingeschriebenem Wissen, das sich unmittelbar in Gesten, kodierten 
Verhaltenssituationen, Ritualen, ja in ganz einfachen Volksgewohnheiten und kollektiven Erfahrungen äußert. Es gibt hier etwas je Eigenes, das sich auf Personen, Gruppen, ethnische, religiöse, nationale, soziale Einheiten, Berufsgruppen und Standespersonen beziehen läßt, eine Art, in der Personen und Gruppen sich in ihren je typischen Eigenschaften äußern. Hier liegt die Möglichkeit der Unterscheidung von Habitustypen, die von sozialer Bedeutung sind. Die Perspektive, die sich etwa in Bourdieus begrifflicher Reformulierung des Habitus ergibt, ist die Wende hin zur Bestimmung der typischen Eigenarten alles dessen, was aus dem alltäglichen Leben kommt. Habitus wird zum Ort der Bestimmung sozialen Handelns, zum Ort, an dem sich die verschiedenen Sphären sozialen Handelns rückbestimmend in Figuren und Ausdrucksformen des Alltags einholen lassen. Und wo dieser Ort heute zum Gegenstand soziologischer Analyse wird, hebt sich in der Forschungsperspektive die Dualität zwischen Individuum und Gesellschaft auf.

In dieser mikrosozialen Konstitution der Gesellschaft deutet sich zugleich ein Paradigmenwechsel in der Soziologie an. Die Formen, wie sich Individuen als Formulae sozialer Ideen im Alltag konstituieren, können zugleich als Ausdruck der äußersten Vermassung der Gesellschaft begriffen werden. Der Umschlag von gesellschaftlicher Totalität in soziale Kreativität ist hier von außerordentlicher Bedeutung geworden. Perspektivisch schließt dieser paradigmatische Wandel in gewisser Weise eine Überbewertwng sozialer Partialität ein: Man versucht, gesellschaftliche Totalität in partialen Einheiten - die gesellschaftliche Kreativität ausstrahlen - zu erfassen und in diesen die Kohärenz der Gesellschaft selbst zu erschließen. Dies führt einerseits zur Überpointierung des Alltags des Individuums und seiner Biographie, es führt andererseits auch zur Überidentifizierung des Beobachters mit seinem Objekt. Ist diese Überidentifizierung nur Ausfluß der Erkenntnis der kulturellen Gleichzeitigkeit in globalen Kulturkontexten oder ist sie ein Kunstgriff der Darstellung von Forschungsergebnissen und der intendierten Überzeugung des Lesers?

In Bauernstudien, in denen biographische Methoden leicht Anwendung gefunden haben, werden solche Identifizierungen aus den Darstellungen des »Bauern als Philosophen « als Ausdruck der eigentlichen sozialen Realität eines Landes deutlich. Solche Überidentifizierungen mögen auf die Idee der Einheit des Menschen zurückzuführen sein 
(Dumont 1967). Der Forscher, der als Objektifikateur auftritt, setzt sich mit dem identisch, was er objektivieren will. Ausdrucksmittel und methodischen Rückbezug bilden dabei meist Aufzeichnungen autobiographischer Äußerungen der sozialen Akteure und als typisch begriffene Interaktionen mit dem Forscher. Biographische Aufzeichnung und biographische Interaktion mit den sozial Handelnden sind heute gängige Werkzeuge anthropologischer Forschung und man muß sich fragen, warum diese Forschungsmittel so stark an Bedeutung gewonnen haben. Die Überidentifizierung mit dem praktisch sozial Handelnden hat ihren Grund in ständig sich intensivierender, kulturübergreifender Kommunikation. Sie vermittelt Zwang zur Selbstaffirmation durch den kulturell Anderen. Wir wollen sehen, wie andere Leute leben und inwieweit dieses Leben Sinn für uns macht. Gerade dadurch setzen wir die Gleichzeitigkeit ihrer kulturellen Existenz mit uns.

Dieses Sich-in-eins-setzen mit dem kulturell Fremden, sei es »Verständnis « durch innere Verbundenheit oder sei es auf machtvolle Präsenz gestellte »Vereinheimischung «, wird Bestandteil eines Kulturkampfes mit dem kulturell Anderen.

Es gibt eine Art der Auflösung und Vermischung der Grenzen zwischen Forscher und sozial Handelndem, die dessen bestimmende, begreifende und setzende Rolle zu verwischen sucht. In dieser Verwischung wird »Struktur « ausgeblendet. Es werden so leicht soziale Grenzbereiche, Individuen und Dinge ausgeschlossen, die als Gegenstand von Identifikation nicht in Frage kommen. Sie sind atypisch für unseren eigenen kulturellen Sinn und »guten Geschmack«. In der Überbetonung und Überidentifizierung verwischen wir leicht die Obskuritäten lokaler Kultur, ebenso wie die kahlen Strukturen praktischer Materialität. Es scheint, als gäbe es nichts, als was seinen Ausdruck in einer bestimmenden Stilisierung finden kann. Das Individuum wird als Produkt seiner Gleichheit von Subjekt und Objekt gelesen. Diese Gleichzeitigkeit ermöglicht eine Rehabilitation des Objekts sozialwissenschaftlicher Forschung (Mafesoli 1985). Sie stellt zugleich jedoch das Problem, daß das Subjekt nicht mehr seinen historischen Bedingungen gegenübergestellt wird.

Struktur-funktionale Analyse hat ländliche Transformation immer als Strukturwandel der ökonomischen Grundlagen der Gemeinschaft und - gewissermaßen als Folge dessen - des sozialen und institutionellen Lebens begriffen (vgl. etwa Vidich/Bensman 1968). Der hier er- 
zwungene methodologische Pragmatismus dagegen stellt Strukturdaten in den Kontext des Anwendungsfelds des Subjekts. Dies führte zu der Überlegung, daß es möglich sein müßte, eine hermeneutische Analyse der Anwendungsfelder und der Zwänge zur Alltagsbewältigung des Subjekts durchzuführen, in der quantitative und qualitative Materialien gleichbedeutend gewissermaßen als »Texte « der Verschlüsselung des individuellen Akteurs lesbar werden. Die vorgeschlagene Hermeneutik betrachtet das Subjekt allerdings nicht als Ort der kulturellen Eigentlichkeit des Ich und der Selbst-Identifizierung, sondern als Ort der Objektivierung sozialer Prozesse. Während die Habitusforschung die Fiktion der Geburt symbolischer Repräsentation im Subjekt aufrechterhält, gehen meine Überlegungen davon aus, das Subjekt lediglich als Ort, als Spannungsfeld, oder auch als Vehikel zu betrachten, über das hinweg sich unterschiedliche Handlungszwänge artikulieren. Habitus ist nur eine Ausdrucksweise von Handlungszwang. Handlungszwang vermittelt sich über Einkommensressourcen (Lohn, Markt, Rente, Subsistenz, Transaktion), Konsumverhalten, Beziehung zum anderen Geschlecht, über Formen der ideellen SelbstPerzeption.

(1) Unter Handlungszwängen sind nicht von `Oben-nach-Unten<, von Zentrum zur Peripherie etc. verlaufende Zwänge abstrakter, institutioneller Art zu verstehen, sondern sich als Übergänge im Subjekt artikulierende Zwänge der Not, im Alltag zu handeln. (2) Insofern stehen weder Migration, noch Wandel im Konsumverhalten, weder neues Verhalten zum anderen Geschlecht noch Repräsentation von »Grundidee« als Übergänge, die als bewußte, intentionale Entscheidungen zu analysieren wären. Nicht die strategische Vernetzung der Individuen in einzelnen Gruppen etc., konstituiert Trennungs- und Konfliktlinien sozialer Transformation, sondern das unmittelbare, fluktuierende Anwendungsfeld der Individuen, die ideelle / materielle Konstitution dieses Anwendungsfeldes. (3) Soziale Transformation ist nie definitiv, sondern zugleich etwas Bedrohendes und Bedrohtes, das heißt im Anwendungsfeld des Subjekts etwas potentiell Zirkulierendes: man kann anders, wieder zurück etc. Es stellt sich hier Handlungszwang als Paradox zwischen der sozialen Tabuisierung des Anderen oder des zurück etc. und der Vorstellung der potentiellen Selbstrealisierung her. das ist es, was Repräsentation von »Grundidee « als Handlungszwang artikuliert. 
Kann eine Hermeneutik der Überwindung der Zwänge der Alltagsbewältigung unter Bedingungen der ländlichen Unterentwicklung hier ansetzen?

\section{IV}

Abu Girg ist eine "grosse bougarde« (Berque 1955). Es hat eine bis in die Antike zurückreichende Geschichte. Davon zeugen nicht nur pharaonische Sagen, sondern auch die Präsenz einer beträchtlichen christlichen Bevölkerung. Es hat eine moderne Geschichte, die Landhäuser einer Familie, die mehrere große Islam-Gelehrte und Minister hervorgebracht hat. Der räumlichen Größe und Anzahl seiner Einwohner (ca. 15.000) nach ist es fast eine Stadt, und doch blieb es äußerlich ganz von der bäuerlichen Produktions- und Lebensweise geprägt. Von den über 3.600 Haushalten werden fast 1.500 in einem kurzen Survey erfaßt. Ca. 800 (ca. 60 Prozent) Haushalte sind völlig durch eine agrarische Einkommensstruktur (Subsistenz, Markt, Tagelöhner) geprägt. Nur weniger als 10 Prozent der Haushalte liegen über dem Subsistenzniveau. Über 40 Prozent der Haushalte weisen in den letzten 10 Jahren zumindest einen Migranten aus. In der Mehrzahl gingen diese nach Saudi-Arabien (ca. 63 Prozent) und Irak (ca. 27 Prozent). Die Mehrzahl war mehr als fünf Jahre unterwegs, ca. 30 Prozent noch zum Zeitpunkt der Untersuchung (1988). Die Mehrzahl der Migranten sind arme Fellachen, meist Analphabeten (ca. 60 Prozent), aber immerhin 20 Prozent sind als Lehrer und in anderen professionellen Berufen ausgebildet. Nach den Intentionen gefragt, wollen 91 Prozent ihren Lebensstandard verbessern, 12 Prozent ein Haus bauen oder erneuern, 11 Prozent das Geld für die Heirat verdienen. Danach gefragt, was sie faktisch mit dem Geld machen, rangieren die Anschaffung von elektrischen Dauerkonsumgütern (84 Prozent) und Hausbau bzw. -renovierung (86 Prozent) mit Abstand am höchsten. Es handelt sich dabei in der Regel um den Umbau des Hauses von sonnengebrannten Lehmziegeln auf roten Backstein. Immerhin waren 1988 noch ca. 58 Prozent der Häuser in Abu Girg mit Lehmziegeln gebaut. Der Bauboom und andere investive Verwendungen der Rimessen führen zu einer weiteren ökonomischen Öffnung des Dorfes: erstmals ergeben sich lokale Marktbeziehungen, die als subsistenz- und gemeinschaftsunabhängige Größen erscheinen. 
Soweit, auf ihren Kern reduziert, die Ergebnisse der sehr sorgfältigen, arbeitsaufwendigen und umfangreichen quantitativen Analyse. Die Daten aus den anderen fünf Dörfern weisen Unterschiede auf, die nicht nur für den wirtschaftsgeographischen Spezialisten von Interesse sind. Würde man diese Daten in einem ersten Schritt auf der Ebene der oben eingeführten »Nexen« der Alltagszwänge kontextualisieren, so käme man zu der Aussage eines allenthalben stark bejahten »cashnexus «, der sich auf der Ebene der Lokalstruktur unterschiedlich artikuliert. Der »cash-nexus « und die durch ihn vermittelten Transformationen sind angenommen worden. Der Strukturkonflikt zwischen Marktorientierung und Subsistenzproduktion wird tendenziell aufgehoben. Als konfliktträchtig erweist sich der »cash-nexus « nicht dort, wo er zur tendenziellen Auflösung des »community-nexus « geführt hat, sondern wo er unter den letzteren tentativ subsumiert und reintegriert wird: in den mariginalen und kleineren Dörfern, Bani Walims (Oberägypten) und Kafr Yusuf (östl. Delta). Exemplarisch läßt sich dies in der Gegenüberstellung von Abu Girg und Bani Walims zeigen. Letzteres liegt in der gleichen Region (Minya) nicht sehr weit entfernt von $\mathrm{Abu}$ Girg. Hier vor allem findet sich eine sehr hohe Korrelation in der Verwendung der Rimessen zwischen Kauf von Dauerkonsumgütern, Landkauf und Tierkauf, Investitionen in Agrarmaschinen, eine sehr große Neigung zur Häuserrenovierung und -neubau, jedoch kaum unternehmerische Verwendung von Rimessen. Der Bauboom geht auf kollektive Anstrengungen zurück: die roten Ziegelsteine werden mittels pharaonischer Techniken von Selbsthilfegruppen gebrannt. In Bani Walims sind bewaffnete Konflikte an der Tagesordnung. Die Auseinandersetzungen zwischen Muslimen und Christen bilden das Hauptproblem. Familienclan und religiöse Gemeinschaft bleiben dominante Faktoren von Rechtsschutz und sozialer Stellung.

In Abu Girg, wie in den anderen großen Dörfern, werden z.Zt. oder wurden dagegen bereits Distriktverwaltungen eingeführt: eine klare Minderung der lokalen Macht der Clans und Großfamilien. Die Verwaltung hat ihren Sitz in der Distriktstadt. Konflikte bleiben auf der symbolischen Ebene. Ein neues islamisches Bildungsbürgertum versteht es etwa, die Dorföffentlichkeit für sich zu mobilisieren. Hier korreliert ein hoher Anteil an Dauerkonsumgütern mit Rimessenverwendung für Kindererziehung, Heirat, Sparguthaben etc., konfliktlo- 
sem Übergang in der untersuchten Phase, Möglichkeit der abstrakten politischen Repräsentation von »Grundideen« in Parteien etc.

All dies sind, auf einen groben Nenner gebracht, Ergebnisse der quantitativen Analyse, die die Vorurteile und Hypothesen nur bestätigten. Lassen sich der qualitativen Analyse neue Dimensionen des lokalen sozialen Wandels abgewinnen?

Ganz dem Gebot des Pragmatismus (was ist machbar?) gehorchend, erbrachten die Feldforschungen in den einzelnen Dörfern folgende ergänzende Erhebungsfelder und Materialien:

1. Materielle Struktur von Migranten und Bauernhaushalten in Shanawan / Kafr Shanawan / Kafr Yusuf

2. Bauern/Migranten-Haushalte/Frauenrollen in Kafr Yusuf, Bani Walims

3. Biographien herausragender Persönlichkeiten außerhalb des bloßen Kontexts von Migration/Islam (Abu Girg/Bani Walims), Frauenbiographien (Kafr Yusuf)

4. Biographien und Habitus-Typen im Kontext von Migration/Islam (Kafr Tambul)

5. Transformation dörflicher Riten (Abu Girg)

Ich beschränke mich im folgenden auf den dritten Bereich und kann hier aus dem Kontext der Strukturdifferenzen der beiden Dörfer Abu Girg und Bani Walims, wenn auch nur skizzenhaft, das Bild zweier ganz verschiedener »Charaktere« entwerfen. In beiden Subjekten verkörpert sich, bedingt durch die strukturelle Differenz der sozialen Anwendungsfelder im Dorf, die Idee der Islamisierung des Alltags, auf radikal verschiedene Weise.

\section{V}

Hypothetisch war davon auszugehen, daß die Idee der Ver(klein)bürgerlichung, der Typus »westliche Mittelklasse« als Typus sozialer Aspiration vorherrscht und die »Ideenwelt« der Subjekte bestimmend prägt (Stauth 1987b: 736-740). Modernität als Problem der materiellen und ideellen Selbstkonstruktion setzt einen bestimmten Zwang der Alltagsbewältigung gegen den Typ des Fellachen: Moralische Integri- 
tät, Reinheit der Frau, sauberes Haus und Teilnahme am Massenkonsum, gerechter und legitimer Staat. Wie also und wo aktualisiert sich diese Idee im Alltag des Individuums?

Abu Girg liegt nur wenige Kilometer von der Nord-Süd-Achse Kairo-Assuan entfernt. Es zählt einen Landstrich am Ufer des Nil zu seiner Gemarkung. Bani Walims gilt dagegen als wildes Dorf: $15 \mathrm{Ki}-$ lometer im Landesinnern westlich des Nil am Bahr Yusuf gelegen, dem parallel zum Nil verlaufenden Kanal, den die Engländer noch gegen Ende 19. Jahrhunderts bauten, hat es keine gewachsene, auf das Außen, auf Kairo hin bezogene Infrastruktur und wird von im 19. Jahrhundert seßhaft gemachten Beduinen-Clans beherrscht. Die Eliten beider Dörfer kennen sich. Man hat gemeinsame Freunde in Minya oder in Kairo. Man besucht sich von Zeit zu Zeit, angelegentlich einer Bittstellung oder eines Todesfalles etc. Anhand zweier Leitfiguren des dörflichen Lebens, mit denen ich über lange Zeit intensiven Kontakt hatte, will ich kurz die unterschiedlichen »Charaktertypen « der Transformationsidee, die in beiden Dörfern platz gegriffen hatte, versinnbildlichen: Die Transformationsidee ist mit der Durchsetzung des Projekts der Islamisierung als Fokus des sozialen und politischen Diskurses an der Wurzel der Gesellschaft verknüpft. Die Frage des sozialen Status eines Dorfbewohners hängt nun unmittelbar und unhinterfragbar von der Tatsache ab, ob er sich als guter Muslim erweist. Informelle Familientreffen sind Anlaß zur Durchsetzung eines kollektiven Gebets. Der im Koran Bestunterwiesene leitet die Gebetsgruppe an. Es gilt als fromm, das Abendgebet möglichst lange zu gestalten. Familien- und Freundestreffen gewinnen nun offen einen religiösen Charakter. Sprache, Wiederholung koranischer Redewendungen, Kleidung und äußere Haltung spiegeln das Bild einer islamischen Lebensweise. Der kollektive Besuch einer Trauerrezitation von Freundes- und Altersgruppen (shilla) als Kondolenz gilt nun als fromme Tat. Nicht das »Faktische" an einem Freundschafts- oder Verwandtschaftsverhältnis zum Verstorbenen zählt nun als Relevanzkriterium, sondern die Teilnahme an einem sakralen Ritus, der Dorföffentlichkeit konstituiert: fast täglich bieten sich Gelegenheiten, Dorftraditionen im Gewand des Islams zu repräsentieren. 


\section{Beispiel 1}

A.M. ist die Kernfigur einer Gruppe von Altersgenossen. Er ist eine tizianische Figur des ägyptischen Dorfes. Er ist etwa 55 Jahre alt, groß, fett und mit roten Wangen, roter Nase, Schweinsohren und Glatze. Eine eng geschnittene, im ganzen Dorf einzigartige galabiyya preßt seinen umfangreichen Bauch nach oben vor die Brust. Das Kleid ist weiß, obwohl es in Schnitt und Form eher an einen Mönchskittel erinnert. Auch ist die Kopfbedeckung, hoch oben über der Stirn ansetzend, eher einem Bäckerhut ähnlich als irgendeiner der sonst üblichen taqiyyas und 'immas. An kühleren Abenden legt er sich noch einen Umhang aus weißer Baumwolle um, eine 'ibaya, und wenn er aufs Feld geht, um nach dem rechten zu sehen, so hat er immer einen ganz normalen, aber ebenfalls mit weißem Tuch bespannten Knirps mit sich, den er als Sonnenschirm benutzt.

A.M. ist der größte Grundbesitzer bäuerlicher Abstammung in Abu Girg. Trotz seiner obskuren Aufmachung gab es so etwas wie ein gegenseitiges Einverständnis von unserer ersten Begegnung an. Er sprach in ganz sachlicher Weise mit mir über das Leben in Europa, in Kairo, über Wissenschaft und Universitäten und gab zu erkennen, daß er zu wissen meinte, was ich wollte. A.M. mit seinem eigentümlich unkorrekten Auftreten wählte mich zu seinem Gesprächspartner, so wie ich ihn zu meinem Informanten wählte, ohne Mißbehagen und Bitterkeit, eine gegenseitige Adoption.

$\mathrm{Zu}$ seiner Gruppe gehören ein Lehrer, ein leitender Steuerbeamter, ein Schulinspektor, ein Unternehmer und »Labour-Boss « mit wechselnder Fortune, der in den Hoch-Zeiten des Ölbooms noch bis zu 200 Arbeiter jährlich nach Jiddah in Saudi-Arabien vermittelte.

Trotz A. M.s Eigentümlichkeit ist das Zusammensein in der Gruppe durch rituelles Betragen geordnet: Kleidung, äußere Haltung und Anrede sind in abstrakter Weise auf »Islam « hin kodifiziert. Geschichten erzählen, sich gegenseitig bedienen, freundlich sein, all das gilt als islamisch tugendhaft. Ich habe Mitte der 70er Jahre im Delta viel Zeit unter solchen Gruppen verbracht. Aber nie waren sie weiß gekleidet und so steif und formal.

Die Gruppe trifft sich, als wäre alles zufällig, am Abend im Haus eines beliebigen Mitglieds. Von hier aus bereitet man dann die Besuche im Dorf vor.

Bei Kondolenzen im Todesfall steht A.M. unter den trauernden 
Verwandten und nimmt die Kondolenz der Leute entgegen, auch wenn es sich nicht um enge Verwandte handelt. Weniger prominente Verwandte helfen der Familie und gehen in den Lesepausen durch die Reihen der Sitzenden und bieten Kaffee und Zigaretten an. A.M. und seine Freunde gehen auf einzelne Leute zu und reichen ihnen ehrenhaft eine Zigarette. Sie achten sehr auf eine hierarchische Sitzordnung, offenbar aber auch, um sie zu durchbrechen. Hier gilt Herkunft und Alter, nicht religiöser Habitus als Status. Aber man mischt sich ein, bricht die Reihe.

Am späten Abend versammelt sich eine Restgruppe engerer Verwandter im Salon um den Koranleser. Das Kommen und Gehen hat aufgehört, man konzentriert sich auf den Koran. Die Schönheit des Gesangs oder des Textes wecken Ausrufe des Entzückens. Nach einem kurzen Leseabschnitt hört man immer häufiger das Allabu Akbar. A.M. hat eine unverkennbare Art, es repetitiv auszustoßen. In einer Ecke sitzt B., ein Fellache aus dem alten Dorfzentrum, mit einem Nachbarn. Völlig unbeteiligt blickt er mit etwas schamhaftem Lächeln zu mir herüber. B. weiß, daß ich mir dauernd die Frage stelle: wie muß ich hier jetzt richtig sitzen, wie muß ich aussehen? Er weiß auch, daß A.M. mich zur habituellen Äußerung einer Gefühlsstimmung, Bewunderung des Islams, fordert. Die Sitzung verwandelt sich in eine Art mystische Veranstaltung. Wie im zikr (sufitische Meditationssitzung) werden jetzt innere Gefühle zur Teilhabe an der Schönheit des Textes ekstatisch umgesetzt. Exklamationen, das Kopfwedeln des Lesers wird imitiert, stumme erlösungssuchende Blicke. Lange nach Mitternacht endet die Lesung. Die Kassette wird zurückgespult und neu aufgelegt. Aber man redet sich jetzt an, begrüßt sich, als wäre man von einer Reise zurückgekehrt. Bezeugt Ehrerbietungen.

A.M. ist andererseits ein ganz praktischer Mensch, der seine Vorteile sucht. Immer zur richtigen Zeit erscheint. Er bewundert die Große Welt der Bildung, der islamischen wie der weltlichen. Sie symbolisiert sich für ihn in den großen Landhäusern in den Palmhainen draußen vor dem Dorf, die Ministern und Gelehrten gehörten, islamische Reformer alle, und Taha Hussain, den berühmtesten der Modernisierer oft beherbergten. Er ist im Innern ein Verehrer Gamal Abdel Nassers geblieben. Aber er steht auch ganz auf der Seite der Islamisierungswelle. Er bewundert die Spiritualität der mystischen Virtuosi, aber er sucht immer Kollektiviät als Handlungsbezug. Nie hätte er vor 
der Islamisierungswelle sein Haus renoviert, jetzt mußte er das halbherzig in Gang setzen. A.M. ißt viel und oft. Aber er fastet einmal in der Woche einen ganzen Tag. A.M. weiß, wie die Regeln einzuhalten sind. Die symbolische Erneuerung unter dem Zwang der Zeit und die Berufung auf die Regel, den guten Geist als Tradition des Dorfes, helfen ihm, seinen Reichtum ganz individuell zu wahren, mit dem islamischen Radikalismus des Sohnes und seiner Migrantenfreunde und mit den ewigen Bauern wie B. fertig zu werden. Durch seines und seiner Gruppe Auftreten bei jeder öffentlichen Angelegenheit im Dorf wird der "gute « Islam, wie er ihn versteht: konventionell und regierungstreu zur Regel. Es hat den Effekt einer dauernden Erfindung des Sakralen als Dorföffentlichkeit, gegen die die Jungen, die Radikalen keine Chance haben. Idee und Interesse bleiben hier auf das freundlichste getrennt.

\section{Beispiel 2}

Eine islamische Homogenisierung der dörflichen Öffentlichkeit gibt es nicht in Bani Walims, dem zurückgebliebenen Dorf am Rand der Wüste. Fast 90 Prozent aller Migranten gingen hier in den Irak, nur ein paar gut verdienende Lehrer nach Saudi-Arabien. Die Migrationswelle hat hier nicht viel verändert. Nur daß viele alte Lehmhäuser nun in roten Backsteinziegeln wiedererbaut wurden. F.s Freunde sind Lehrer und alle in Saudi-Arabien. Draußen am Dorfrand haben sie sich weiß verputzte Häuser gebaut.

Man weiß nicht so recht, ob man F. zu den erfolgreichen oder zu den gescheiterten Existenzen zählen kann, zu den Gebildeten oder zu den Fellachen, zu den Gesicherten oder den Ungesicherten. F. ist $m u-$ stashar (Kanzler) und in einem praktischen Sinne heißt das, er ist Richter einer regionalen Berufungsinstanz am Amtsgericht in Minya, der Provinzhauptstadt. Er hat es abgelehnt zu migrieren. Er ist etwa 45 Jahre alt und fährt in der Woche drei Tage nach Minya, um sein Amt auszuüben, muß also zwei bis drei Nächte in der etwa 30 bis $40 \mathrm{~km}$ entfernten Stadt in den für solche Fälle eingerichteten Unterkünften des Amtsgerichts verbringen. F. gehört zu einer der vier führenden Großfamilien im Dorf. Zwei dieser Großfamilien sind christlich und stehen unter der Schutzherrschaft der beiden restlichen muslimischen Familien. Im Falle einer Blutrache oder eines Streits zwischen einem Muslim und einem Christen der jeweils anderen Familie treten die 
muslimischen Familienclans zusammen und beraten über Schlichtungsmaßnahmen. Keiner der Clans verfügt über nennenswerten, größeren Grundbesitz. Die Clans verfügen über Status, nicht über faktische Macht.

F. war über lange Jahre in diesen Schlichtungskämpfen zwischen den Familien sehr stark engagiert. Er hat sich in den letzten Jahren zurückgezogen, den konkreten Grund dafür nennt er mir nicht.

Ich habe F. zum ersten Mal 1977 getroffen. Damals war er ein militanter Linksnasserist, Mitte dreißig und gerade sechs Jahre verheiratet. Ich erinnere mich an seine überzeugenden Reden, daß man aus dem Widerstand des Dorfes, aus den Widerstandskräften der Fellachenkultur eine militante Bewegung gegen das Sadat-Regime entfachen müsse. F. war ganz für die Rückbesinnung auf die Werte des Dorfes gegen die Stadt, er war gegen alles Ausländische und Westliche, damals noch aus einer linken, antiimperialistischen Haltung heraus, gegen die Öffnungspolitik Sadats gerichtet und ganz gegen die schwachen, aber doch ebenso verwerflichen Anzeichen einer neuen Konsumbürgerkultur im Dorf. F. hatte damals gerade eine Stelle als Hilfsrichter in der Provinzhauptstadt Minya angetreten. Ursprünglich hatte er eine Lehrerstelle in einem Nachbardorf auf der anderen Seite des Bahr YusufKanals, näher zur Wüste hin gelegen, und er hat während seiner Lehrerzeit in Abendkursen und Spezialkursen ein volles Jura-Studium in Minya absolviert, das es ihm ermöglichte, die Richterlaufbahn einzuschlagen. In den zehn Tagen, die ich 1977 im Dorf verbrachte, saßen wir fast an jedem Abend diskutierend zusammen in irgendeiner Wohnstube der Gruppe von Lehrern und jungen Hochschulabsolventen, die sich um F. scharten. F. machte damals ganz den Eindruck eines jungen Führers einer linken Bewegung oder des »Dorfkommissars « einer sozialistischen Partei. Trotz der Freundschaft habe ich seine Frau nie kennengelernt. Sie wurde immer im Haus gehalten. Von den Freunden hörte ich, daß es eine Frau aus dem Fellachenstand sei und daß F. sie deshalb den Freunden insgesamt vorenthalte.

F. begleitete mich damals auch während des Tages viel im Dorf, beobachtete peinlich mein Umgehen mit den Bauern und war immer darauf bedacht, daß die Bauern auch die richtige, d.h. die ideologische, die nasseristische, die revolutionäre Antwort geben. Damals war er noch in westlichen Hosen, aber mit überlangem Frack oder Hemd bekleidet. Von Zeit zu Zeit legte er auch eine galabiyya an, die ganz im 
Stil der Dorf-Galabiyyen gehalten war und sich auch in der Farbe von den normalen Fellachen-Galabiyyen nicht unterschied.

F. hat mich auch diesmal freundlich aufgenommen, aber in seinem Haus hatte sich Entscheidendes geändert. Die Freunde wurden nicht mehr in seiner Studierstube mit den alten staubigen Gesetzestexten und Studierbüchern empfangen. Wie überhaupt, kaum noch ins Haus geführt, saß man jetzt in einem großen, fast das gesamte Erdgeschoß des alten, großen Lehmhauses umfassenden "Salon «, in dem überall an den Wänden kleine bunt bezogene Kanabeen standen und zwei kleine runde Tische, auf denen man Tee oder Kaffee abstellen konnte. Ein paar Stühle standen noch mitten im Raum verstreut. Wenn man den Raum betrat, war - neben dem auf einem hohen Ständer stehenden Windfang - das Auffallendste, daß an der gegenüberliegenden Wand nun das »Amtsbild « von F. hing: Das Bild vom Tage seiner Amtsernennung zum mustashar (Kanzler) am Apellationsgericht. Hier auf dem Bild trug F. einen schwarzen Anzug, ein weißes Hemd und eine silberne Krawatte, über den ganzen Körper zog sich eine in den $\mathrm{Na}$ tionalfarben gehaltene Schärpe. F. erscheint auf dem Bild in fast militärischer Strenge. Mit einem sehr starren Blick schaut er aus dem Bild heraus, oben gegen die Decke seines Salons. Auch nahm F. jetzt von den wilden Essen nach Dorfessitte mit sehr fettigen Soßen und mit fettbeklebten Fleischbrocken, die meinem Magen meist außerordentlich schlecht bekamen - Abstand, und es wurde nur noch Tee gereicht oder ab und zu eine Fruchtschale oder eine Coca Cola. Dennoch blieb F. im persönlichen Umgang formlos und direkt, erkundigte sich genau nach dem Ziel meiner nunmaligen Forschung, hielt das Thema für wichtig und war überzeugt, daß ich genau zwei Thesen hier zu vertreten hätte, denn etwas anderes habe Migration und der Wandel der letzten zehn Jahre nicht gebracht:

1. Die Remigration hat im Dorf gar nichts geändert. Die Remigranten verplempern ihr Geld mit roten Ziegel-Häusern und tragen nichts mehr produktiv zur Entwicklung des Dorfes bei.

2. Dadurch, daß die jetzt Geld haben, halten sie sich nicht mehr an die alten Sitten, grüßen sich nicht mehr, sind nicht mehr freundlich zueinander; das alte Solidaritätsgefüge sei auseinander geraten und habe sich zum Schlechten hin entwickelt. Dem könne man nur mit der Einführung des islamischen Rechts, der shari'a islamiyya, begegnen. 
F. hat ein großes Haus geerbt und etwa zwei bis drei Feddan Land (ca. 1 ha), um die er sich nicht kümmert. Er verpachtet sie, aber im Haus und im Hof laufen Ziegen herum. Seine Frau backt Brot, züchtet Hühner und Geflügel. Fast ein ganz normaler Mittelbauernhaushalt, für den er seine Kinder und seine Frau völlig einspannt. Das Haus steht im Dorfzentrum und ist völlig heruntergekommen. Nur das untere Stockwerk, in dem sich der Salon befindet, und vor allem der Teil des Salons selbst, sind einer flüchtigen Renovierung unterzogen. F. fährt einen alten Fiat, Baujahr 1956, der wegen seiner Altersschwäche nicht dazu benutzt werden kann, nach Minya zur Arbeit zu fahren, sondern nur aus dem Stall herausgefahren wird, wenn es um halboffizielle und offizielle Besuche in anderen Dörfern oder in der nähergelegenen Distriktstadt Maghara oder Bani Mazar geht. Tragisch ist, daß die Hygiene in F.s Haus sehr zu leiden scheint und seine Kinder zwei Kinder waren bereits verstorben - und seine Frau, auch wenn sie an heute leicht zu heilenden Krankheiten leiden, von irgendwelchen Kurpfuschern, die sich Ärzte nennen und gleichermaßen zunächst einmal in Saudi-Arabien viel Geld gemacht hatten, nun mit irgendwelchen Massenprodukten der Chemie vollgepumpt werden, wenn sie krank sind. Kurz bevor ich bei meinem letzten Besuch abreiste, hörte ich, daß F.s Frau außerordentlich krank sei und daß er sie ins Krankenhaus nach Minya fahren mußte. Es handelt sich dabei immer um typhusähnliche Erkrankungen, die sich aufgrund mangelnder Hygiene sehr leicht ergeben. So sehr F. als der Wissende und Progressive auftritt, so sehr erduldet er auch noch die komischsten Anweisungen eines Kurpfuscher-Arztes; so sehr F. sich als wissenschaftlicher Mensch versteht und den Fortschritt der Wissenschaft predigt, so sehr wird er andererseits zum Opfer seiner eigenen Philosophie: die Eigenkräfte des Dorfes sind keine Eigenkräfte und sind offenbar auch wenig hilfreich in konkreten Notsituationen.

F.s Endogenismus widerspricht völlig seinem eigenen Karrierebewußtsein und den Erwartungen für den sozialen Aufstieg seines Sohnes. Er äußert sich - nie Widerspruch und Abweichung duldend - zu allen Dingen der Dorf- und der Weltpolitik gleichermaßen: Islam ist die Lösung. Bezogen auf seine eigenen Lebenslagen ist das eine ideologische Verbindung von Dorfphilosophie und symbolischem Islamismus. In der Praxis, in der er bis vor kurzem noch ein ganz fundamentalistischer Säkularist war: ein neuer Lebensstil, mit dem er selbst fertig 
werden muß, andere überzeugen muß; aus der Handlungsnot oft zu einer Art intelligenten Scharlatanerie gezwungen.

F.s ältester Sohn studiert im zweiten Jahr Jurisprudenz an der Universität in Bani Suef (100 km nördlich zwischen Kairo und Minya gelegen). Er gilt als einer der besten Studenten und macht auch sonst einen sehr intelligenten Eindruck. Nach seiner politischen Orientierung an der Universität gefragt, gibt er sich als militanter Islamist zu erkennen. Es ist nicht ausfindig zu machen, wer wen zuerst bekehrt hatte: der Sohn den Vater oder der Vater den Sohn.

Ich erinnere mich an ein locker begonnenes Gespräch über Religiosität im frühen Islam oder die Religiosität im Ägypten der ersten Eroberungszeit. Kannten die Erobernden des islamischen Heeres den Koran als Text auswendig? Es war mir bekannt, daß sich viele der Heerführer und Unterheerführer der jung zum Islam übergetretenen Christen bedienten (der mawalis), um religiöse Fragen und Rechtsfragen mit den Neueroberten zu lösen, weil sie selbst die Texte nicht kannten. Diese Bemerkungen stießen jedoch auf den heftigsten Widerspruch des Jungen, der mir in Bestimmtheit eines Geschichtsprofessors zu verstehen gab, daß mir als Nicht-Muslim die Kompetenz fehle, solche Äußerungen zu tun. Der hinzukommende Vater, kurz die Diskussionslage wahrnehmend, entschied sich nicht dafür, den Gast mit ein paar Floskeln aus der drückenden Umklammerung des Jungen zu befreien. Ganz im Gegenteil, er sprang dem Sohne bei, mehr noch, er beschimpfte mich in aller Direktheit des falschen Orientalistentums und behauptete, daß der Teilnehmer am Ägyptenfeldzug auf muslimischer Seite "hafiz al-Qur'an « gewesen sei, d.h. den Koran, wie er heute niedergeschrieben sei, voll auswendig gelernt hatte. Es ist sicherlich unverzeihlich, daß ich nun selbst ernst wurde und meinen Freund der Hypokrasie und der Verdummung seines eigenen Sohnes bezichtigte. Ich bin nun selbst ganz Opfer meines Einfühlungs- und Einmischungstriebs geworden und mußte als letzte Rettung das Gespräch abrupt abbrechen, um zu bedeuten, daß ich »zu Hause« zum Abendessen erwartet werde. F. war verstimmt ob meiner dann doch so heftigen Reaktion. Vielleicht hing dies mit dem Gefühl zusammen, ich hätte ihn für einen Heuchler (munafiqun) gehalten. Unsere Freundschaft war damit sehr getrübt. Er hielt den Termin für den nächsten Abend, für den er zugesagt hatte, mich abzuholen, nicht ein. Es lag nun an mir, ihn aufzusuchen und er ließ mich lange in seinem Salon alleine sitzen 
und warten. Schließlich kam der Sohn, mit dem ich einige Höflichkeitsfloskeln austauschte. Ansonsten schwiegen wir uns gegenseitig eine Weile an, bis ich es wagte, den Sohn zu fragen, ob der Vater denn von meiner Präsenz wisse. Die Antwort war »er betet «. Mit dem Beten war sodann natürlich alles erklärt. Auch war mir jede Möglichkeit genommen, überhaupt noch zu behaupten, die lange Wartezeit sei vielleicht doch ungebührlich und ich müsse mich nun zurückziehen.

Nach einer kurzen Zeit kam F. doch und tat so, als wüßte er nicht, daß wir verabredet waren. Er überlegte kurz neu, was er mit mir machen könnte mit dem Ergebnis, daß er einen Besuch bei seinem Freund A., einem auf Urlaub von Saudi-Arabien zurückgekehrten Lehrer und Verwandten, vorschlug. Dieser Freund war zugleich ein Cousin von F. Er war als Lehrer schon vier Jahre in Saudi-Arabien gewesen und wohnte in seinem Vaterhaus, ebenfalls im Dorfzentrum, nicht weit von F.s Haus entfernt. Das Haus war selbst nur wenig renoviert, aber in einem etwas besseren Zustand als das von F. Der Kühlschrank stand im Salon und wie ich später erfuhr, hatte A. für seine zwei Söhne, die beide zur Universität gingen, wenn auch nicht zu so angesehenen $\mathrm{Fa}-$ kultäten wie der Sohn von F., ein Mehrfamilienhaus in Maghara gebaut. Weiter hatte er im Dorf zwei Feddan Land gekauft und nun selbst auch als Lehrer ein Rinder- und Viehzuchtprojekt auf Anteilbasis (schisk) mit Bauern betrieben. Außerdem habe er, der insgesamt vier Kinder hat, nämlich zwei Söhne und zwei Töchter, jetzt gerade angefangen, ein Haus hier außerhalb des Dorfes zu bauen.

Bevor wir losgingen, ließ sich F. von seinem Sohn seine Pistole bringen und er schnallte sie unter die Achsel, unter seine weiße galabiyya. Der Freund und Lehrer A. war nicht zuhause und die Nachricht war, daß A. nun zum Abendgebet in der Moschee sei. F. hatte dies kaum gehört, als er sogleich nach einem Gebetsteppich schicken ließ, den er, kaum in Empfang genommen, auf eine der hohen Holzbänke legte, die im Zimmer standen. Er stieg auf die Holzbank hinauf und betete dann auf dem Teppich mit großer Innigkeit, ausführlich, lange. Wir waren selbst nur zu zweit im Zimmer und mir blieb nichts anderes übrig, als an die Decke zu starren oder durch das schmale Fenster hinaus auf die staubige, enge Gasse zu blicken. Von dieser Zeit an war F. für mich als Informant verloren, wenn wir uns auch noch weiterhin gegenseitig besuchten und untereinander Freundlichkeitsfloskeln austauschten. 
Ausgehend von meinen Überlegungen zur Hermeneutik der Alltagsbewältigung durch symbolische Idealisierung stand die hier angegangene Erforschung der Felder sozialer Realität nicht unter der Fragestellung, »welche Idee verkörpert eine Person «, sondern »wie und in welchen Anwendungsfeldern verschlüsselt eine bestimmte Idee die körperliche Erscheinung und das Alltagshandeln eines bestimmten Individuums «. Das ist eine ganz entscheidende Umkehrung der Perspektive sozialwissenschaftlicher Kulturforschung von Bachofens »Grundgedanken« bis hin zu Webers »Idealtyp«. Handlungszwang, im Kontext dreier »Nexen « widergespiegelt, setzt die Bedingungen körperlicher Versinnbildlichung. Letztere ist nicht als ganzheitliche Bestimmung des Subjekts zu sehen, sondern als aus dem Alltag geborene Not der sozialen Präsenz.

Sie zirkuliert als Paradox hier die Abschaffung und Tabuisierung von Notwendigkeit und materieller Not, dort die Praxis ideeller Selbstrealisierung.

Was A.M. und F. verbindet, ist der Zwang zur Abschaffung materieller Zwänge und der Negation praktischen Interesses in der "Idee« der Islamisierung als symbolische Verteidigung des Dorfes. Was beide trennt, ist die Form der körperlichen Versinnbildlichung: Hier, Bani Walims, wirkt der bedrohte Gemeinschaftsnexus als Element der imaginären Bindung der »Idee« an die Praxis. Dort, Abu Girg, der akzeptierte "Geld-Nexus « als Element ihrer Separierung; Islamisierung als symbolische Überlagerung der Praxis.

Deutlich sei daran erinnert, daß das, was Bani Walims und Abu Girg zum Forschungsobjekt machte, die pragmatische Idee meiner »Adoption « in ein Klientel-Verhältnis war. Meine »Adoptiv-Väter« und »Patrone« galten als Garanten für den erfolgreichen Feldeinstieg. Man hätte erwarten können, daß sich ein solches Verhältnis in einem »unterentwickelteren« Dorf besser realisieren ließe. Paradoxerweise kam es ganz anders: F. sabotierte indirekt meine Präsenz im Dorf. Er sah mich als ganz praktischen Widerspruch zu seiner »Idee« der Islamisierung. A.M. dagegen tolerierte und förderte meine Präsenz als Element der Aufwertung seiner eigenen symbolischen Islamisierung. 



\section{Stadt und Land in Ägypten: Folgen der Modernisierung}

Der »übersozialisierte Mensch « ist zu einer stereotypen Figur im modernen sozialwissenschaftlichen Denken geworden. Er tritt heute ins soziologische Bewußtsein als nostalgisch befrachteter Mensch. Die Theorie der Gesellschaft und der gesellschaftlichen Entwicklung bedient sich metatheoretischer Episteme, die die nostalgische Annahme irgendeines Goldenen Zeitalters heroischer Tugenden, moralischer Geschlossenheit und ethischer Selbstvergewisserung wertend einbeziehen. ${ }^{1}$ Schon in Alexandre de Tocquevilles Beschreibungen Amerikas wird das wertende Staunen über den Verlust des Gemeinschaftshandelns der alten Aristokratien deutlich. Er entdeckt ein eigentümliches Paradox der amerikanischen Demokratie: hier der sozial integrierende demokratische Prozeß als Abstimmungsmechanismus und die alles umfassende Kirchenkultur, dort ein verantwortungsloser Individualismus der an Öffentlichkeit und Gemeinschaftsaufgaben NichtInteressierten.

Eine Parallele findet dieses Paradox in der amerikanischen liberalen soziologischen Theorie, wo die höhere Verstaatlichung oder auch nur Kollektivierung der Bedürfnisse des Individuums in einen grundsätzlichen Gegensatz zur Freiheit des Individuums gesetzt wird. Mehr Staat, so hören wir, schafft politische Apathie und stellt eine psychische Last für die Zivilgesellschaft dar, in der das Individuum entsprechend den Notwendigkeiten seiner persönlichen "gains and losses « $\mathrm{zu}$ handeln habe. Für die dem amerikanischen Liberalismus verbundene Soziologie hat Selbstregulation der Zivilgesellschaft Priorität vor staatlich kontrollierter gesellschaftlicher Regulierung. ${ }^{2}$

In dieser Sichtweise gilt nun die Tatsache, daß im heutigen Ägypten und anderswo in der arabischen Welt sich die gebildeten Eliten aus dem Nationalstaatsprojekt der 60er, 70er und frühen 80er Jahre zurückzuziehen scheinen, als Anlaß, das Projekt der sich selbstregulierenden bürgerlichen Gesellschaft als Ziel und neue Entwicklungsvorstellung zu propagieren.

Aber auch ein anderes Theorem ist scheinbar unter Beschuß geraten. Es ist dies das Theorem der Superiorität des kulturell Authenti- 
schen vor dem Kosmopolitanen. Äußerlich scheint dies die Aufgabe lang propagierter entwicklungspolitischer Positionen zu sein, deren Schlagworte »Anpassung «, »Autochthonisierung « und "Endogenisierung " waren und die mit einer indirekten Apologie des radikalen Islamismus das Erstarken einer modernen zivilen Ethik und einer alternativen Wirtschaftskultur visionär herbeizuzitieren suchten. Das Projekt der kulturellen Authentizität galt einem großen Teil der Entwicklungssoziologie als Verheißung, nicht immer nur, wo es von radikalen politischen Lösungen abgetrennt erschien. Es gilt nun als vorteilhaft, es dem liberalistischen Projekt kosmopolitaner Toleranz unterzuordnen (siehe Binder 1988). Entwicklungspolitisch ist damit wenig beziehungsweise nichts gesagt: Die Möglichkeit der Verbindung von Islam und liberalistischem Staat sagt nichts über den entwicklungspolitisch notwendigen Grad staatlicher Präsenz aus. Und die religiöse Überfrachtung des Projekts der Zivilgesellschaft ist eben kein Garant für die Umsetzung selbstregulierender Kräfte in der Gesellschaft. Um es einfacher auszudrücken: Die aktuellen sozial-religiösen Bewegungen und gesellschaftlichen Islamisierungstendenzen können das, was Weber den alles erschütternden Prozeß der Rationalisierung durch die protestantische Ethik genannt hat, nicht ersetzen oder nachholen. Auch sind innerhalb der arabischen Gesellschaften die institutionellen Differenzierungen nicht geleistet, die es erlauben könnten, von der Einrichtung eines bürgerlichen Nationalstaats zu reden. Notwendige Verrechtlichungsprozesse, durch die bürgerliche Sanktionsformen an der Basis der Gesellschaft einklagbar würden, sind nicht geleistet. Der islamische Radikalismus, darauf hat uns Sivan zu Recht hingewiesen, hat gerade im Alltagsleben, wo die Projektionen unterschiedlicher Lebensformen am unmittelbarsten aufeinanderstoßen, viel in Bewegung gebracht (Sivan 1985). Aber hat er zivilgesellschaftliche Lösungen zu bieten?

Wer heute Kosmopolitanismus predigen will und dabei die kosmopolitane Geschichte des Islams vergißt, wird unglaubwürdig. ${ }^{3}$ Ebenso ist es unglaubwürdig, von einer Superiorität des Projekts der Zivilgesellschaft (Binder 1988: 20) zu sprechen und als Entwicklungsvorstellung in ein Land zu projizieren, in dem der bürgerliche Nationalstaat noch in seinen Kinderschuhen steckt. Die Reorientierung der Entwicklungstheorie bedarf mehr als des politico-philosophischen 
Diskurses: sie bedarf vor allem empirisch vermittelter Einsichten in die aktuellen Wandlungsdynamiken der peripheren Gesellschaften selbst.

Die Herausforderung des Islams liegt in der geschlossenen und doch anpassungsfähigen, affirmativ menschenzentrierten Lebensform, die er vermittelt. Der Islam ist eine Sprache der Alltagsordnung, der Körperlichkeit und individuellen Selbstvergewisserung, der Spiritualität und des Gefühlslebens. Damit ist die Bedeutung des Islams als Hochkultur keineswegs gemindert. Die Verbindung der zwischen der in Koran und Sunna festgeschriebenen Glaubenslehre und der praktischen Lebenshaltung ist geschlossen, die Gottesgewißheit der Muslime ungebrochen. In seiner Menschen- und Weltbejahung zeigt sich der orthodoxe Islam als außerordentlich offen und tolerant gegenüber lokal vorgefundenen Praktiken und Vorstellungen von eroberten und bekehrten Völkern. Es ist dieser Zusammenhalt von wenigen, einfachen und einheitlich angewandten Glaubensregeln und der Vielfalt lebendiger und lokal variierender, islamisch begründeter Lebenspraktiken, die den Islam zu einer Sprache und zu einer Vision der Lebenserfüllung zugleich werden lassen. Die Fülle der Varietät in dieser Einheit ist für westliche Beobachter nicht ohne Bewunderung geblieben. Michel Foucault hat - als journalistischer Beobachter der iranischen Revolution 1978 - in dieser Einheit den »politischen Spiritualismus des Islams « und eine neue organische Sprengkraft gegenüber der brüchigen Moderne zu finden gehofft. ${ }^{4}$

Diese apologetische Beschwörung der islamischen Revolution entsprang jedoch eher den Nöten des okzidentalen Intellektualismus als der Kenntnis der islamischen Geschichte. Die Weltanpassungsforderung des Islams begründete eine tolerante Orthodoxie, der jede Fundamentalisierungstendenz und utilitaristische Verknüpfung von Diesseitsinteresse und Jenseitsschicksal fremd ist. Die historische Funktion der islamischen Orthodoxie war in der Tat die Entkoppelung des Spannungsverhältnisses zwischen religiösen Ideen und praktischen Interessen. Gerade durch diese Entkoppelung wurde es möglich, daß der Islam schon sehr früh zum Gegenstand weitreichender Manipulationen des weltlichen Interesses politischer und sozialer Gruppen wurde. Der außerweltlich orientierte, spirituelle Islam wurde zur Begründung säkularer Interessen benutzt, ohne daß es zu einer inneren Spannung zwischen Handlungspraxis und religiöser Spiritualität der Gläubigen 
kommen mußte. Nur in dieser Trennung ließ sich paradoxerweise die Einheit von Glauben und Lebenspraxis, von islamischer Gottesvorstellung und Alltagshandeln erhalten.

Die orthodoxe Toleranz des Islams beginnt in der Gegenüberstellung mit den säkularen, rational begründeten Modernitätshaltungen zu wanken: Der Islam mußte sich nun als moderner Lebensstil begründen, als kompatibel mit wissenschaftlicher Haltung zur Welt, als Sprache, die in der Lage ist, moderne, materielle Interessen mit Glaubensideen zu verbinden. Hier entstehen jene Spannungsfelder der neuen ideellen Verbindung von religiösem Spiritualismus und materiellen und politischen Interessen, die unter dem Stichwort des »politischen Spiritualismus « des Islams als soziale Felder des sozialen und politischen Widerstands und des religiösen Fundamentalismus gegen die Hegemonie der westlichen Kultur beschworen werden. Dieser Arena gilt hier mein analytisches Interesse. Es sind im heutigen Ägypten gerade diese Spannungsfelder sozialer Interaktion, die den klassischen Bruch zwischen Stadt und Land, Bauern und Staat, Metropole und Peripherie, Zivilität und Verderbtheit des Volkes tendenziell aufheben. Ich will versuchen, einzelne Typen solcher Felder herauszustellen und in ihrer Bedeutung für die Entwicklungsdynamik im ländlichen Ägypten zu würdigen.

Lassen Sie mich zuvor noch etwas über die imaginierte Geschichte der ägyptischen Dorfgemeinde berichten und auch über Modernität und Wandel der letzten dreißig Jahre. Wie Sie wissen, gilt das antike Ägypten ebenso sehr wie das moderne als ein Paradebeispiel für eine staatskontrollierte Naturalwirtschaft. Hegel, Marx, Rosa Luxemburg und vor allem Max Weber haben dieses Bild bemüht: Die zentrale Staatsmacht stärkt ihre Revenuen und die Bedeutung ihrer Verwaltungen und ihres Oikos durch die Kontrolle über die auf Selbstversorgung gestellte Naturalwirtschaft der Fellachen einerseits und die Kontrolle des Fernhandels andererseits. Damit ist die ständige Schwächung von Tendenzen der Herausbildung eines inneren Marktes und des auf Geld gestellten Warentausches strukturell angelegt. Die ökonomischen Interessen in der Gesellschaft bleiben über Jahrtausende weitgehend den von der zentralen Bürokratie gesetzten Notwendigkeiten unterworfen. 
Auf der Gegenseite des Bildes von Willkür und Allmacht der Bürokratie erwächst die Vorstellung von einer ebenso strukturell angelegten Schwächung jeder Tendenz zu einem historisch beständigen lokalen Aristokratismus und als Folge davon Unterdrückung eines jeden Individualismus. Dies auch in den nur zögernd und später als anderswo in der Region sich herausbildenden Städten: Verhinderung der Ausbildung einer städtischen Bürgerschaft mit dem Privileg individuellen Handels und städtischer - wie überhaupt - lokaler Institutionen mit administrativer Autonomie und Verantwortung.

Eine individuelle Verantwortlichkeit des Bauern gegenüber Staat und Gesellschaft wird durch die kollektive Verantwortung gegenüber den Forderungen der Staatsmacht verhindert. Die soziale Stellung des Individuums in der Dorfgemeinschaft hängt von seinem Beitrag zu den gemeinschaftlich zu entrichtenden Abgaben und Arbeitsleistungen ab. Ein privates Eigentum an Grund und Boden gibt es nicht. Wo immer sich eine solche Kategorie bildet, so nur als Appendix zur bürokratischen Macht des Staates; sie kann willkürlich suspendiert werden.

Durch Reichtum zuerst, Korruption sodann und Privilegienwirtschaft der Beamten und des Priestertums schließlich bilden sich im Zerfall der Zentralmacht Gegentendenzen der Feudalisierung, Lokalisierung und Individualisierung heraus. Sie bleiben rechtsbegrifflich jedoch an ein Lehenssystem gebunden, das auf bürokratischen Titeln basiert. Hier nun individualisiert und rationalisiert sich das System durch die Heraufkunft lokaler und individueller Verantwortlichkeiten, Überführung der Abgabe- und Arbeitsdienste an lokale Herren, Entwicklung einer selbstwirtschaftenden, mittelständischen Bauernschicht und eines ländlichen Agrarproletariats. Das Bild einer tendenziell sich aus der Allmacht des Staates entlassenden Zivilgesellschaft erscheint als ein blasser Schimmer historischer Möglichkeit und als Gegenbild zum orientalischen Despotismus.

Ich rekapituliere die abendländische Befangenheit in diesen Bildern, um Wandel neu vorstellbar werden zu lassen. Die Tragweite der aktuellen sozialen Wandlungsprozesse im ländlichen Ägypten ist am ehesten noch vor dem Hintergrund der hier eingegangenen strukturellen Determinanten zu verdeutlichen. Auch die traditionelle Modernisierungs- und Urbanisierungstheorie betrachtete den Staat und die Stadt als die eigentlichen Vehikel von Modernität und bürgerlichem Leben. 
Daß sich gewissermaßen im Milieu einer jahrtausendelang kollektiv versklavten Bauernschaft mit ihrer bodengebundenen Lehmhüttenkultur so etwas wie eine eigenständige Zivilität und Modernität herausbilden könnte, blieb außerhalb des Blickwinkels konventioneller Forschung.

Gewiß, zunächst waren es die Bürokratien, die in Ägypten wie anderswo in Afrika ein auf Ausbeutung und Kontrolle der traditionellen Naturalwirtschaft gerichtetes Kooperativen-System errichteten. Sie vollbrachten aber auch Zivilisationstaten - in Ägypten, ein wirksames Erziehungssystem, die Elektrifizierung und neuerdings Asphaltstraßenverbindungen von Dorf zu Dorf. Dann aber waren es der Transistor, der Kassettenrekorder, der Toyota, die Mikrophone und die ganze neue audiovisuelle Hochtechnologie, die eine kulturelle Revolution im Dorf zustande brachten.

Fünfzehn Jahre Arbeitsmigration im Rotationsverfahren, individualisiertes Reisen von Millionen von Bauern in die Ölstaaten am Golf haben diesen Trend verstärkt, wenn nicht in seiner Radikalität initiiert. Ein durch Migranten-Rimessen bewirkter Bauboom, der fast alle Dörfer des Deltas und viele Dörfer in Mittel- und Oberägypten zunächst in Beton- und Backsteinwüsten verwandelte, hat zum ersten Mal in der Geschichte Ägyptens dazu geführt, daß ein selbstregulierter Markt unabhängig von den Subsistenznöten der Bauern und den Notwendigkeiten der Naturalwirtschaft entstand. Der Zufluß von dauerhaften Konsumgütern in die Fellachenhaushalte bewirkte unter diesen ein neues, an Cash orientiertes Verhalten, neue Formen der Geldallokation. Die durch den Toyota als Kollektivtaxi bewirkte, geradezu revolutionäre Rastlosigkeit und Mobilität der sonst kaum über den Rand des Dorfes blickenden ländlichen Unterschichten unterstützte einen boomenden ländlichen Markt von Dorf zu Dorf, Distriktstadt zu Distriktstadt. Die Einrichtung von relativ leistungsfähigen Werkstätten und Dienstleistungsbetrieben, Läden oder »Boutiquen«, wie sie im Dorf genannt werden, hat schließlich zu einem ständigen Anwachsen der häuslichen und individuellen Ausstattungen geführt. Eine neue ländliche Mittelschicht ist entstanden. Landbesitzende Klein-, ja Kleinstbauern gehören dazu, Handwerker, Ladenbesitzer, Taxifahrer, darunter eben auch Halb- oder Analphabeten. Die sozialen Grenzlinien zwischen Beamtentum und Bauerntum, zwischen Gebildeten und Ungebildeten, zwischen Alphabetisierten und Analphabeten scheinen 
gefallen. Der Konsumismus der Medien- und Massenkultur scheint der ländlichen Gesellschaft eine neue Form des bildhaften Skripturalismus aufzuerlegen, an dem alle gleichermaßen partizipieren. Die Beton- und Backsteinhäuser werden verschönt, geweißt, mit leuchtenden Farben gefärbt. Vorgärten werden angelegt. Bäder und Salonausstattungen sorgen für die Umsetzung neuer Reinheitsvorstellungen. Die Einrichtungen bedingen ein neues Ordnungsverhalten im Haus, begleitet vom Rückzug der Frau aus der Öffentlichkeit, von Feldarbeit und Marktverkauf und von einer starken Repräsentationssucht, die für das neue Freizeitverhalten des Mannes bezeichnend ist.

Ein neuer, auf das Haus, die Ausstattung, auf Sauberkeit und Reinheit sowie auf guten Umgang gestellter Verhaltenskodex der Zivilität und des Wohlstands greift Platz, der sich in offener Feindschaft zur verwahrlosten Öffentlichkeit des Dorfes befindet: mit müllbeladenen Kanalufern, staubigen, oft mit Abfällen und Plastiktüten übersäten Gassen, Viehzügen und streunenden Hunden, Staub aufwirbelnden Fahrzeugen, Taxis und Traktoren. Der Kampf um einen Platz im Toyota oder im Bus, der Streit mit den Nachbarn um Sauberkeit und Ordnung im öffentlichen Raum vor den Häusern bleiben aber Probleme, für die der neue Verhaltenskodex keine Lösung bereithält.

Die praktisch-alltäglichen Mikrozusammenhänge der sozialen Öffentlichkeit bleiben von dieser neuen Zivilität relativ unberührt. Mit Veranden, Vorgärten und protzigen Mauern versucht sich die neue Mittelschicht im Dorf gegen Schmutz und Schande draußen in der Öffentlichkeit zu schützen.

Der lediglich auf das politische Monopol und auf Makro-Strukturleistungen bedachte Staat bietet in diesem Bürgerkrieg des Alltags keine Lösungen an. Schaffen hier der Rückgriff auf den konventionellen Ritus und seine symbolische Vertiefung und Restrukturierung neue Ordnungsmöglichkeiten und Regulierungsmechanismen?

Die überragende Bedeutung des Islams für die politische Verfassung und soziale Gestaltung Ägyptens in der Moderne ist nicht neu. Ich brauche nur an die Bedeutung der nabda al-islamiyya, der islamischen Renaissance, zu erinnern, die am Ende des 19. Jahrhunderts in Kairo ihren Ausgang nahm und den politischen Diskurs des Landes be- 
stimmte. Sie ermöglichte es den modernisierten Eliten, einen aufgeklärten, den Erfordernissen der Moderne sich anpassenden Islam und eine eingeschränkte soziale Rolle der Religion im öffentlichen Leben zu propagieren. Sie legte aber auch die diskursiven Fundamente, die es einer radikalen Minderheit von Intellektuellen aus den nichtprivilegierten Schichten erlaubten, den Islam modernistisch vereinfacht und purifiziert als Instrument politischer Emanzipation einzusetzen. Sie knüpften dabei auch an Organisationsformen des Volkssufismus an. Beide Gruppen, die Modernisierer um Ali Abderraziq, Taha Hussain und Ahmad Amin, und die Muslim-Bruderschaft und ihre Führer Hassan al-Banna und Sayyid Qutb stützten sich auf die im Austausch mit westlichen Orientalisten stehenden Denker der islamischen Renaissance. Und beide Richtungen prägten bis in die Sadat-Zeit, ja in gewisser Weise bis heute die Argumentationslinien des politischen Diskurses.

Die Islamisierungswelle erfaßte die ländliche Mittelschicht zu Beginn der 80er Jahre. Die unglaubliche Ermordung des Staatsoberhauptes durch islamische Fundamentalisten hatte weitreichende Folgen in der Gesellschaft. Zuerst änderte sich das Bild der äußeren Erscheinung. Man beobachtete zunehmende Moscheebesuche von Jugendlichen und das Auftreten von Jugendgruppen mit spezifischen religiössymbolischen, habituellen Ausdrucksformen einer islamischen Lebenspraxis. Zunehmend gehorchten auch junge Frauen dem propagierten Purifizierungsgebot und das Symbol der reinen, der muslimischen Schwester, das weiße Kopftuch (hegab), fand immer mehr Verbreitung in der Öffentlichkeit der Städte, in Universitäten, Verwaltungen und Kaufhäusern. Unter jungen Frauen in den Dörfern galt der Schleier als Gegensymbol zum traditionellen, je nach Alter und sozialem Anlaß schwarzen oder grellfarbenen Kopftuch (mandil) der Fellachenfrauen. Junge Männer in Jeans und Armeejacken erschienen mit Bartwuchs als Zeichen ihrer Verbundenheit mit der islamischen Tradition. Sie propagierten den gezielten Bruch mit säkular-konsensuellen und von der Orthodoxie als islamisch abgesegneten Regeln, indem sie gegen solche Neuerungen, bid' $a$, neue bid' $a$ einführten, diese aber gemessen an ihrer sozialen Lage mit praktischem Sinn füllen konnten: so etwa neue Formen der Heirat und der Verteilung von Frauen und neue Formen des Zusammenlebens und der Selbsthilfe. So wurde versucht, das Problem der wegen mangelnden Geldes und mangelnder Wohnung aufgescho- 
benen Heirat durch neue Hochzeitsformen ohne Güteraustausch, ohne Brautpreis, Morgengabe und Mitgift zu regeln, indem man es dem religiösen Führer der Gruppe, dem 'amir al-gama' $a$, vermittelnd überließ, eine Braut zu wählen. Diese Jugendgruppen sind radikal; Staat und Gesellschaft werden als gahiliyya, als Zeit des Heidentums, der säkulare Konsensus in der Gesellschaft als kufr, als Ketzerei, angegriffen. Die gama'at al-islamiyya, die neuen islamischen Gruppen, der einzig in der Öffentlichkeit der Gesellschaft sichtbare Körper, in dem sich das offenbar effektive und von der Regierung gefürchtete Gerippe der Untergrundgruppe al-Gehad verbirgt, der soziale Arm der Bewegung, schienen zeitweise der sozial und wirtschaftlich deprivierten, arbeitslosen, ihrem äußeren Bildungsstand nach jedoch oft hochqualifizierten Jugend in den Kairoer Vororten und innerstädtischen Massenquartieren und in den ländlichen Distriktstädten, die durch die Bewegung berühmt wurden, praktische Lösungen anzubieten.

Anfang der 80er Jahre schließlich schossen die islamischen Investitionsbanken und Kleinfirmen aus dem Boden, die hochrentable Anlagemöglichkeiten für die neue, vom Petrodollar abhängige Mittelschicht schufen. Sie boten sich aber auch den Kleinen, den Arbeitern in den Ölstaaten an, warben um deren Rimessen. Sie wollten meist jedoch mehr sein als nur Firmen und Finanzinstitute. Dieses Mehr ist es, das heute so viele Fragen offenläßt: Man stellt sich die Frage, ob sich hinter den reinen, ästhetisierten Imaginationen islamischer Spiritualität und religiösen Lebens, die die Firmenaufmachung, die äußere Erscheinung der Eigner und die Werbespots verbreiteten, nicht auch das Reinheitsgebaren von Waschanlagen von Mafia-Dollars des regionalen Drogen- und Waffenhandels verbargen. Jungen Muslimen, meist aus den unteren Mittelschichten der Massenquartiere, wurde sowohl als Angestellten als auch als Kreditnehmern ein modernes, sorgenfreies Konsumentenleben vom Heiratsarrangement bis zur vollständigen Wohnungsausstattung, von muslimischer Kleidung bis zur beruflichen Existenz angeboten. Und andere Institute entstanden, Moschee-Institute neben den bekannten in Kairo, wie dasjenige Mustafa Mahmuds im islamisch fashionablen Stadtteil Mohendessin, und solche auf dem Land, etwa im Dorf Simbo, in der Nähe von Mit Ghamr im östlichen Delta, ein riesiger Moscheekomplex in einer Mischung aus weißem Marmor und bunten Märchenfarben mit Schwimmbad und Jugendsportklub. Oder eine islamische Berufsschule in der Nähe von Sim- 
belaween. Beide wurden mit Zustimmung der Regierung und mit dem Motiv des Erlasses hoher Steuerstrafen gebaut, beides islamische Gebäudekomplexe, die gewissermaßen ins Feld draußen, in kostbares Agrarland gesetzt wurden.

Islamische soziale Dienste, Schulen und Krankenhäuser boten sich an, scheinbar leistungsfähiger und effizienter als die öffentlichen Einrichtungen. Islamische Nachbarschaftsgruppen und über den lokalen Lebenszusammenhang im Stadtviertel hinausreichende Netzwerke von geschlechts-, alters- und berufsspezifischen Gruppen wurden überall etabliert. Sie boten zunächst einmal im Privaten Lösungsmöglichkeiten für die schlimmsten Nöte des Alltags an. Über diese gegenseitige Selbsthilfe wurde zunehmend ein autonomer sozialer Raum geschaffen und als islamisch definiert und symbolisch besetzt. So entstanden in einzelnen Stadtteilen Kairos und vor allem in ländlichen Distriktstädten Oberägyptens staatsfreie Räume, »befreite Gebiete« gewissermaßen, in denen die lokale Bevölkerung dem Diktat der islamischen Gruppen ausgeliefert war. Im Mafia-Stil wurden Nichtergebene bestraft.

In einem ähnlich offenen sozialen Raum operierte und operiert heute in eingeschränkter Weise der al-Sa'd-Konzern in der Region Mansura/Simbelaween im Delta als eine Art Macht-Broker, eine der islamischen Investitionsbanken, die sich nach Offenlegung ihres Finanzgebarens jüngst dem Regierungsdiktat unterworfen hat. Die Lebensgeschichte von Ashraf Sa'd selbst legt ein schillerndes Zeugnis der Sadat- und Nach-Sadat-Ära ab: Sohn eines khuli, eines FellachenVorarbeiters und Arbeiteraufsehers eines Landgutes der Region, Handelsdiplom, etwa ein Jahr Gefängnis als Devisen- und Drogenschieber, drei Jahre Saudi-Arabien, 1982 Rückkehr aus Saudi-Arabien mit einem Kapitalstock von 36 Millionen ägyptischen Pfund. Die heutigen lokalen Verflechtungen des Sa'd-Konzerns im Gouvernement Dakakhliya und mit der Zentralregierung sind sehr eng. Offensichtlich haben dem Konzern die Kooperationen mit den Firmen Osman Ahmad Osmans geholfen, die Krise von 1988/1989 zu überdauern. Der Bruder des Gouverneurs von Mansura/Dakakhliya ist im Konzern angestellt, ebenso wie viele Ministeriale des Innenministeriums auf seiner Gehaltsliste stehen. Angestellte des Konzerns müssen wie der Eigner mit Bart, weißer galabiya und Sandalen gekleidet auftreten. Mit gezielten Werbekampagnen suggeriert der Konzern seine Beteiligungen an gro- 
ßen Entwicklungsprojekten und seinen Anteil am Wirtschaftsaufkommen der boomenden Distriktstadt Simbelaween. Die Verbindungen des Konzerns mit den Gama'at mögen nur propagandistischer Art sein. Wie der Konzern führen auch diese gezielte Aktionen und inszenierte Öffentlichkeitsspiele durch, um islamische Verhaltensnormen oder was sie dafür halten - in der Öffentlichkeit zu propagieren. Es galt, die alten Kodes zu revidieren und das staatliche Interventionsund Gewaltmonopol in der Öffentlichkeit zu brechen, aus dem sozialen Raum der Alltagsnöte der Bevölkerung heraus politischen Operationsraum zu gewinnen. Das gilt für die islamischen Konzerne ebenso wie für die islamischen Gruppen.

Man kann rückblickend sagen, daß es dem Verband von alten, aus der Verbannung in Saudi-Arabien zurückgekehrten Muslimbrüdern (das Rückgrat einer neureichen islamischen Bourgeoisie), den sogenannten fundamentalistischen gama'at al-islamiyya und den islamischen Konzernen bis Ende 1988 gelungen war, der ägyptischen Gesellschaft als ganzer den islamischen Konsensus als verbindliches Rückgrat eines jeden Diskurses und eines großen Teils der bildlichen und figürlichen Produktionen des öffentlichen Lebens aufzuoktroyieren.

Die neue ländliche Mittelschicht steht ganz im Spannungsfeld dieser Angelpunkte des Dreiecks zwischen den heute zum orthodoxen Konventionalismus neigenden Muslimbrüdern, den Gama'at und den Konzernen: Kleine und mittlere Beamte des lokalen Schuldienstes und der Staatsverwaltungen, Ärzte und Ingenieure, die zeitweise oder gänzlich vor allem in Saudi-Arabien tätig waren. Es gibt hier eine eindeutige Korrelation zwischen Bildungsgrad und Migrationsland. Diese Schicht, sich neu im Dorf etablierend, ist nicht radikal, aber sie sympathisiert mit den Forderungen der islamischen Gruppen nach stärkerer Islamisierung des Rechts und der sozialen Öffentlichkeit. In ihrer Praxis im Dorf vertritt sie das Projekt der Islamisierung des konventionellen Ritus der dörflichen Gemeinschaft; damit gilt ihr zugleich auch der islamische Konsensus als das verbindliche Rückgrat eines jeden öffentlichen Diskurses im Dorf. Seinen äußeren Ausdruck findet dies in einer nicht in der Tradition des Dorfes gewachsenen Kleidung - ein weißes Gewand, das im Schnitt der Fellachen-galabiya ähnelt, in seiner Aufmachung und mit der weißen Kopfbedeckung jedoch stärker auf die Kleidung des hajji oder vielmehr der hagg, des aus Mekka zurückgekehrten Pilgers, anspielt. Wer durch ein Staatsamt in der Distrikt- 
stadt zu moderner westlicher Kleidung gezwungen wird, zieht sich nach Rückkehr vom Dienst um. Die westlichen Anzüge oder die an Nasser und Nkrumah anknüpfenden Kleider mit den langen Hemdjacken sind aus dem öffentlichen Leben des Dorfes verschwunden; dieses zeigt sich völlig von einer tiefen, religiösen Symbolik überfrachtet.

Die Symbiose zwischen alltagspraktischer Modernität und religiöser Vertiefung der dörflichen Symbolwelt prägt dem konventionellen Ritus eine eigenartige Spannung auf. Am deutlichsten wird dies in den Rezitationsriten, 'aza, die bei Trauerfeiern vorgetragen werden. Die Trauersitzung ist ihrer Art nach kein islamischer Ritus. Die Geschichte ihrer Tradition reicht in pharaonische Zeiten zurück, zumindest in seiner Bedeutung als Übergangs- und Inkorporationsritus. Van Gennep (1960: 146ff.) zeigt, daß Riten der praktischen Trennung vom Körper des Toten einfach und weniger bedeutsam sind als Riten, die sich auf den Übergang ins Jenseits oder auf den Prozeß der Inkorporation des Verstorbenen in die Welt der Toten beziehen. Das gilt auch für das 'aza.

Das 'aza findet in Oberägypten an den ersten drei Abenden nach der Beerdigung statt, dann am 15. und schließlich am 40. Tag, dem nach pharaonischem Volksglauben - Tag des Großen Weitergehens, tala' $a$, in die Totenwelt. Es wird sodann als Erinnerungsritus am Jahrestag der Beerdigung wiederholt. Sie können sich vorstellen, daß gemessen an dieser Häufigkeit in einem größeren Dorf fast jeden Abend irgendwo ein 'aza stattfindet. Und obwohl es als Schande, 'aib, gilt, über Lautstärke und Art der Durchführung mit Nachbarn zu streiten, gibt es viele Berichte über solche Streitereien. Am Abend nach dem Begräbnis kommen ein oder zwei Koranleser (muqri oder faqib) ins Haus. Die Rezitationen können den ganzen Abend vom Maghreb-Gebet an bis zur Mitternacht andauern. Verwandte, Freunde, Nachbarn oder eben einfach nur Dorfgenossen, aber auch Leute aus Nachbardörfern, zu denen der Tote in irgendeiner Beziehung stand, kommen in unregelmäßiger Reihenfolge, werden von den Trauernden begrüßt oder von jemandem, der sie vertritt -, setzen sich eine Zeit, lauschen der Lesung und gehen dann wieder. Es werden Kaffee und Zigaretten gereicht und meist hängt die Länge der Präsenz einer Person davon ab, wie nahe sie dem Verstorbenen gestanden hat. Früher, als es noch keine Mikrophone gab, wurde der Koranleser von einem Chor, der be- 
stimmte Passagen nachzusingen hatte, begleitet. Die Sitzungen scheinen in den zwanziger Jahren sehr viel formeller gewesen zu sein als in der Nasser- und Sadat-Ära. Blackman (1927: 114) berichtet, daß damals Kaffee und Zigaretten nur in den Lesepausen zwischen den einzelnen Leseteilen, $g u z$ ', gereicht wurden und daß während der Lesung selbst niemand rauchte oder Kaffee trank. Er schreibt, daß er von der Exzellenz der Stimmen ebenso wie von der Ehrwürdigkeit der Haltung der Anwesenden beeindruckt gewesen sei. Mitte der 70er Jahre, in der frühen Post-Nasser-Zeit, als ich zum ersten Mal einer solchen Sitzung beiwohnte, aber auch noch am Anfang der 80er Jahre wurden solche Rezitationssitzungen sehr viel formloser durchgeführt. Wichtig war nicht so sehr die innere Teilnahme am Ritus, das Hören und Genießen der Koranrezitation, sondern die Tatsache der Präsenz. Man unterhielt sich oft laut genug während der Rezitation, bekam Kaffee und Zigaretten auch während derselben gereicht. Entsprechend wenig beachtete man die Qualität der Stimme und des Vortrags bei der Auswahl der Koranleser, die meist schlecht ausgebildet waren und ebenso schlecht bezahlt wurden. Man lud sie zum Essen und beschenkte sie mit Kleidern des Toten, gab ihnen Zigaretten und etwas Geld. Dies hatte sich schon zur Mitte der 80er Jahre geändert, als jede Koranrezitation formal entgolten wurde - bis zu 20,30 Pfund für die kleinen, nur lokal gebildeten Koranleser, bis zu 300 Pfund für die großen, in der ganzen Region bekannten und meist in einer Einrichtung der alAzhar-Universität ausgebildeten Koranleser.

Die neue Bedeutung des 'aza fiel zusammen mit den oben geschilderten Entwicklungen im größeren Rahmen der Gesellschaft: die Durchsetzung des Projekts der Islamisierung als Fokus des sozialen und politischen Diskurses. Die Frage des sozialen Status eines Dorfbewohners hing nun unmittelbar und unhinterfragbar von der Tatsache $a b$, ob er sich als guter Muslim erwies. Immer häufiger wurden damals informelle Familientreffen dazu benutzt, die Anwesenden zum kollektiven Gebet im Haus anzuregen. Hier ist es der im Koran Bestunterwiesene, der die Gebetsgruppe leitet. Es gilt beim Abendgebet als fromm, möglichst lange zu beten. Familien- und Freundestreffen am Abend gewinnen so einen stark religiösen Charakter; die Sprache der Wiederholung religiöser Ausrufe und Redewendungen sowie Kleidung und Habitus untermalen dies.

Der kollektive Besuch eines 'aza bildet meist den Abschluß der all- 
abendlichen Freundestreffen der shilla-Altersgruppe von Dorfnotabeln (al-kubar). Es ist diese soziale Gruppe, die sich in die neue Mittelschicht integriert. Und es sind die neu Arrivierten, die sich in diese Gruppe hofierten und habituell integrierten. Das 'aza wird so zum Ort, an dem insbesondere die Männer der neuen Mittelklasse ihre Abende verbringen, eine beständige Neu-Bestätigung ihres sozialen Status unter den Dorfgenossen suchend. Shillas der neuen Mittelklasse verbringen endlose Abende bei Trauerrezitationen. Man trifft sich nach dem Maghreb im Haus eines beliebigen Mitglieds, informell und unangemeldet, und geht dann gemeinsam zum 'aza. Dort wird das Abendgebet ('isha) als kollektives Gebet abgehalten, dem entweder der faqib oder ein Mitglied der shilla vorsteht. Je nachdem, wie die Beziehungen zum Verstorbenen und der Familie sind, bleibt die Gruppe oder bleiben einzelne Mitglieder noch nach dem Abendgebet bis in die Nacht hinein. Oder man geht weiter im Dorf zum nächsten 'aza, dessen Besuch geplant war oder sich auch nur ergab.

Es gibt reiche und arme Rezitationen, feierliche und weniger feierliche, mystisch aufgeladene und formal säkulare Rezitationen. Der soziale Erfolg hängt vom Reichtum ab. Der Reichtum drückt sich in der äußeren Gestaltung aus: eine mit Mikrophon im Salon eines neuen Backsteinhauses installierte Hifi-Anlage; mit Teppichen belegte Bänke im Flur, im Vorgarten oder auch auf der Straße vor dem Haus, alles lichtüberflutet. Reichtum drückt sich nun auch in der Wahl des Koranlesers aus. Es bedarf eines teuren faqih mit formeller Azhar-Bildung. In den frühen Abendstunden, wenn die Mehrzahl der Besucher kommt und geht, ist die ganze Veranstaltung sehr ermüdend. So kommt es, daß etwa ein Notabler mit allen äußeren religiösen Insignien gewissermaßen die Familie der Trauernden adoptiert und sich an den Kopf der Empfangs- und Begrüßungsgruppe begibt, auch wenn er nicht in unmittelbarer Linie verwandt ist. Während sich die Frauen in der Küche oder im Hinterhaus versammeln, Essen bereiten und den beständig zu servierenden Kaffee kochen, wird von engeren männlichen Verwandten auch draußen verlangt, daß sie Hilfestellung leisten, Kaffee reichen oder auch eigens mitgebrachte Zigaretten anbieten.

Am späten Abend, wenn sich die Trauergemeinde im Salon um den faqib konzentriert, wird es ruhiger. Die Anwesenden stellen sich auf die Lesung selbst ein, der Koranleser, des Auditoriums sicher, kürzt die Pausen, die bisher durch zuvor auf Kassetten aufgenommene Pas- 
sagen gefüllt wurden. Die Schönheit der Stimme, des Ausdrucks oder auch einer Aussage des Korans ruft zunehmend Ausrufe der Bewunderung und Exklamationen der Anteilnahme hervor. Das 'aza verwandelt sich nun in eine geschlossene Sitzung, die einem sufitischen $z i k r$ ähnlich ist. Die inneren Gefühle der Individuen werden in restriktiven Haltungen der Selbstbeherrschung oder des exklamierenden Ausdrucks nur angezeigt. Es gibt keine Armen und Reichen mehr im Raum. Nur die habituellen Unterschiede der Restriktion oder der Verzückung bleiben. Wenn der Lesezyklus zu Ende ist, löst sich diese Stimmung auf. Die Kassette wird zurückgespult und neu aufgelegt. Man redet jetzt wieder einander an, begrüßt sich, als wäre man von einer Reise zurückgekehrt, fragt nach dem Wohlbefinden des Anderen, bezeugt Ehrerbietungen.

Die alten säkularen Eliten haben die Initiative verloren; die nächste Generation der vierzig- und fünfzigjährigen kabir hat sich habituell, wenn nicht innerlich den Arrivierten des islamischen »Kulturbürgertums « angeglichen. Dadurch ist auch der Handlungsspielraum des Staates im Dorf eingeschränkt. Aber die vertieften Verbrüderungsrituale schütten den Graben gegenüber den Anwesenden der nichtprivilegierten säkularen Schichten, den Landlosen, Tagelöhnern und Kleinstbauern, nicht zu. Die neuen figurativen Evokationen islamischer Kultur verklären und verdrängen nur den lebenspraktischen Kulturkontext. Die islamistische Wiedererfindung des Ritus dient hier als ein Projektionsbild, als ein Mittel der Statusrepräsentation. Die praktische Kontrolle der sozialen Regulierungsmechanismen bleibt ausgeklammert. Aber auch die Repräsentationsform wirkt eher erhärtend. Während in den alten volkssufitischen Bruderschaften im mystischen Erlebnis die Unterschiede zwischen Privilegierten und Nichtprivilegierten faktisch durch den esoterischen Charakter der Sitzungen ausgeklammert waren, wie überhaupt die Bruderschaften als Instrumente der Statusversicherung ausfielen, dient hier nun die habitualisierte mystische Transformation eines Volksritus der Eroberung eines neuen Feldes der Statusversicherung. Die praktische Unmöglichkeit der Selbstversicherung und der Statusabsicherung in einer zerfallenden Öffentlichkeit zwingt in das Dilemma, in den Restbeständen dörflicher Öffentlichkeit durch symbolische und habituelle Vertiefung des Ritus das Unmögliche zu suchen: die Versöhnung mit der verlorengegangenen Kultur der Fellachen. 
Wie in der Stadt, so setzt sich auf dem Dorf ein neuer religiöser Konformismus der Mittelklasse durch, in vieler Hinsicht radikaler und unausweichlicher. Die alten säkularen Eliten können sich dem nicht entziehen und auch nicht mehr nur mit Lippenbekenntnissen folgen. Die Kulturisierung der Öffentlichkeit setzt Normen der habituellen und inneren Einstellung im Auftreten. Die Sprache der Staatsverwaltung und des Brokerspiels der Vermittlung ist hiervon nicht mehr zu lösen. Aber sie kann sich auch nicht hierin auflösen. Dies ist das Dilemma der ländlichen Entwicklung in Ägypten. Das Islamisierungsprojekt, dem die alten Staatseliten - auch wo sie sich äußerlich noch einen säkularen Habitus erhalten - unterliegen, ist persönlich, hautnah, nachbarschaftlich und alltäglich. Sie werden gefordert von den Gebildeten, den Arrivées, den aus Saudi-Arabien Zurückkehrenden. Sie beobachten und werten den Ritus, gründen islamische Jugendklubs und nehmen gezielt Konflikte mit Bauern, Christen und den säkularen Nicht-Rituellen in Kauf. Am Staat vorbei, so scheint es, hat sich ein religiös-rituelles und konsensuell formalistisches Islamisierungsprojekt durchgesetzt.

Diesem ritualistischen und durchformalisierten Islamisierungsprojekt stehen die Landarbeiter und Kleinstbauern, selbst in einer tiefen Volksreligiosität verwurzelt, auf die alles hinzudrängen scheint, gegenüber, die das "Spiel« nicht mitspielen. Sie haben ihren eigenen, aus der Öffentlichkeit mehr und mehr verbannten Ritus - wo nicht mehr in der Volkstradition, so in einer neuen populistischen Massenkultur. Die weitverzweigten Relikte der Fellachenkultur, hinreichend bis in die Verteilung von Kassetten mit religiösen Liebes- und Volksliedern ganz eigener, gewissermaßen dionysischer Art, sind in das islamistische Gesellschaftsprojekt nicht einzugliedern - ganz zu schweigen von der Fußball-, der Kaffeehaus-, der Spieler-, der Video-, ja der Drogenkultur, von einem konsumistischen Freizeitgebaren Jugendlicher und negativ privilegierten Remigranten, die es nicht schafften und die im Irak und in Jordanien mit säkularer Massenkultur in Berührung gekommen sind. Diese Gruppen unterwerfen sich dem islamischen Gesellschaftskonsensus, sind in ihren praktischen Lebensgewohnheiten aber von Tradition und Ordnungsvorstellungen dieses Konsensus weitgehend unkontrolliert. In diesen Gegensätzen werden im Ansatz soziale Konflikte deutlich. Es stoßen hier nicht so sehr politisch konfligierende Zielprojektionen als vielmehr unterschiedliche Formen der 
praktischen Lebenshaltung und der inneren Einstellung zur Welt aufeinander.

Die neue islamische Zivilität grenzt alte wie neue säkulare Lebensformen aus. Soll das Projekt der Zivilität Erfolg haben, so sind die Restformen der Fellachenkultur ebenso zu integrieren wie die neuen, im Konsumismus erwachsenden Lebensformen. Sie bedürfen der diskursiven und der figurativen Repräsentation. Das islamische Zivilisationsprojekt, so fruchtbar es in den letzten zehn Jahren gewirkt hat, kann entwicklungspolitisch nur wirken, wenn es ein Projekt unter anderen bleibt. Der Diskurs über die Formen der Verrechtlichung von Alltagspraxis und Lebenszusammenhängen, den das Islamisierungsprojekt einem weitgehend autoritären Obrigkeitsstaat aufzwingt, schafft bei kluger infrastruktureller Orientierung die Voraussetzungen für Integration und Repräsentation säkularer Projekte und zu notwendiger sozialer und struktureller Differenzierung. Wenn hier entwicklungspolitische Initiativen gefragt sind, dann sind es solche, die die variierenden Lebensformen des islamistischen Projekts mit den variierenden Formen des säkularen Projekts sozial kompatibel machen.

\section{Anmerkungen}

1 Zur Kritik der nostalgischen Soziologie vergleiche Stauth/Turner: 1988a, S. 47ff.

2 In gewisser Weise darf man Daniel Bell als den großen Exponenten dieser Tradition betrachten; vergleiche etwa Bell: 1976, 1980.

3 Man darf es als Zynismus der Geschichte bezeichnen, daß gerade die deutsche Islamwissenschaft von Theodor Nöldeke bis C.H. Becker diesen Kosmopolitanismus der islamischen Orthodoxie entdeckt und gefeiert hat. Die einseitig machttheoretische Orientalismus-These E. Saids hat dieser Dimension der deutschen Orientalistik keine Beachtung geschenkt (vgl. hierzu meine Habilitationsschrift [1987], veröffentlicht 1993 als »Islam und westlicher Rationalismus. Der Beitrag des Orientalismus zur Entstehung der Soziologie«).

4 Foucault war in den Jahren 1978 und 1979 mehrmals als Journalist für italienische und französische Zeitungen tätig. Vergleiche dazu »Der Aufstand des Iran läuft über die Bänder von Minikassetten«. Corriere de la Sera, 19.11.1978. Mir liegt der Text in einer 
Übersetzung von Robert Neumann, Frankfurt, vor. In den einflußreichen Arbeiten von G. Kepel $(1983,1987)$ und B. Étienne (1987) wirkt diese Einschätzung Foucaults epistemisch weiter. Vgl. hierzu den Beitrag "Foucaults Abenteuer im Iran« auf S. 57ff. im vorliegenden Band. 


\section{Arbeitsmigration und Restrukturierung ländlicher Gesellschaften: Fallbeispiel Ägypten}

\section{Arbeitsmigration und Globalisierung}

Seit etwa Ende der 70er Jahre hat man sich zunehmend Klarheit darüber verschafft: Arbeitsmigration stellt eine neue Dimension in der internationalen Zirkulation von Kapital und Ressourcen dar (vgl. etwa Sassen-Koob 1978: 509-545). Aus der Sicht des Entwicklungssoziologen ist der Zusammenhang von Arbeitsmigration und ländlichem Strukturwandel offensichtlich. ${ }^{1}$ Die Arbeitsmigration breitester Bevölkerungsschichten ist zu einem der dramatischsten Wandlungsfaktoren der Entwicklungsgesellschaften geworden. Weitgehend unabhängig und ungestört von nationalen Verwaltungen, Gesellschafts- und Wirtschaftspolitiken drehen sich nun die lokalen Milieus ganz im Sog der Weltwirtschaft. Eine Entwicklungsdynamik von eigenartig unkontrollierbarer Spannkraft erfaßt Zentren und Peripherien gleichermaßen und verbindet sie auf eine völlig neue Weise miteinander: Die Mischung aus Anziehungskraft und Abwehr findet ihren Ausdruck in neuen kulturellen Turbulenzen.

Die Hauptbedingung dieser neuen Art der Völkerwanderung ist, daß jeder soziale Wandel zu einem großen Grad von globalen Interaktionsfeldern bestimmt ist. In dieser Situation figurieren die traditionellen Bauerngesellschaften nicht nur als Reservate der Arbeitsrekrutierung, sondern auch als die Orte, von denen durch radikale Kontrastierung unterschiedlicher Traditionen entscheidende Kulturimpulse ausgehen. Paradoxerweise fällt die Forderung nach einer autonomisierten islamischen Kultur, der aller sozialer Wandel sich zu unterwerfen habe, mit einer ungeheuren Dynamisierung und Kontrastierung der Lebenswelten zusammen, die die Migration bewirkt.

Dabei handelt es sich heute um »freiwillige« internationale Arbeitsmigration. Waren noch für die Systeme der kolonialen Unterwerfung und der nationalstaatlichen Industrialisierungs- und Modernisierungsprogramme Zwangs- und Kontraktarbeit oder die zwanghafte Verbringung einheimischer Bevölkerungen kennzeichnend, so hat, wie etwa Castles, Sassen-Koob und Miles zeigen, erst die jüngste Konsolidierung des Weltwirtschaftssystems zu einer »Befreiung « der Rekrutierung der Arbeiter weg von der bäuerlichen Wirtschaft, weg von 
Haus und Hof, hin zu relativ frei flottierenden, grenzüberschreitenden Arbeitsströmen hin zu und zurück von den neuen Zentren kapitalistischer Akkumulation geführt (Castles 1987; Sassen-Koob 1987: 138154; Miles 1984). Das Entscheidende ist, daß man mit sonst nicht zugänglichen Verkehrsmitteln wie dem Flugzeug und dem Schiff in ein anderes Land geht und nach einer bestimmten, meist nicht allzu langen Periode, wieder ins Dorf zurückkehrt: diese Form der Migration zielt auf Lebenswandel im Dorf, zunächst nicht auf ein neues Leben anderswo.

In der neuen Migrationsliteratur wird viel über die Vorteile und Defizite dieser »Befreiung « sowohl für das Kapital und die Empfängerländer als auch für die Arbeiter und deren Herkunftsregionen gestritten. Wie dem auch immer sei: Am Beispiel Ägyptens wird deutlich, wie radikal, kontrastreich und widersprüchlich die sozialen und kulturellen Wandlungseffekte dieser Migrationsbewegung sind.

Die Migrationsströme in die ölproduzierenden Länder am Persischen Golf sind gewissermaßen zum inneren Bestandteil des Lebens in den Dörfern der Herkunftsregionen im Nahen und Mittleren Osten und in Südostasien geworden. Für das ländliche Ägypten, für die Dorfgemeinschaften des Niltals und Nildeltas, stellt dies einen Erfahrungshintergrund ganz besonderer Art dar.

Die Dörfer treten mit den Migrationsbewegungen der 80er und 90 er Jahre, vor allem nach Saudi-Arabien und in den Irak, in ein neues Stadium der Vernetzung mit internationalen Wirtschaftsdynamiken ein. In soziologischer Perspektive ist die Tatsache bedeutsam, daß lokale soziale Räume zum ersten Mal unmittelbar - d.h. ohne staatlichen Eingriff in die Rekrutierungs- und Versendungsmechanismen - in einen internationalen Handlungsrahmen gestellt werden. Soziologen haben das Modewort der »Globalisierung lokaler Gemeinschaften « geprägt. Es umschreibt in der Tat einen Kern der aktuellen Wandlungsdynamik auch noch in den abgelegensten Dörfern.

Das Globalisierungsparadigma in der Soziologie zielt perspektivisch keineswegs einfach auf Homogenisierung der Weltgesellschaft; es stellt vielmehr jene Relativierungsprozesse ins Zentrum, die durch die individuelle und kollektive Partizipation in sozialen Feldern globalisierter Interaktion bewirkt werden (Robertson 1992: 29). Man kann solche Prozesse der Relativierung auf verschiedenen Ebenen beobachten. Ich will dies an meinem Beispiel der Auswirkungen der Migration 
im ländlichen Ägypten zeigen. Dabei sind zunächst folgende Konzeptualisierungen denkbar:

1. Offensichtlich relativiert der Migrationsprozeß die Lebensgeschichte des Individuums gegenüber den zurückgelassenen kommunalen Handlungsräumen und Akteuren. Es entsteht in der neuen Erfahrung von Welt eine virtuelle Selbstreflexivität der Subjekte gegenüber den Formen des Gemeinschaftshandelns. Die Erfahrung, daß Geld ein eigenständiger, alles umfassender Regulationsfaktor sein kann, verschärft solch reflexive Distanzierungen.

2. Darüber hinaus wird die Teilnahme am Massenkonsum wichtig, durch die gewissermaßen ein neuer Lebensstil käuflich wird. Sie relativiert das materielle Notwendigkeitsdenken der dörflichen Subsistenzproduktion und die Bindung an Haus und Boden.

3. Ebenso versinnbildlicht und verschärft sich aus der Distanz heraus die in der arabischen Kulturwelt selbst schon überpointierte Trennung zum anderen Geschlecht.

4. Schließlich wird der Migrant im praktischen Leben mit den Staatsideologien säkularer oder religiöser Art der Aufnahmeländer konfrontiert. In diesen Ideologien relativiert sich das Verhältnis zum eigenen Staat, eine Art der Verbürgerlichung ohne Staat, ein verbürgerlichtes Anspruchsdenken im staatsfernen Raum tritt ein. ${ }^{2}$

Damit sind vier Kernbereiche der sozialen und kulturellen Transformation im globalisierten Interaktionsfeld zwischen Dorf und der Arbeitswelt des Empfängerlandes angesprochen.

Die Folge ist eine eigenartige, spannungsgeladene und ungleichmäßige Differenzierung der sozialen Sphären. Einerseits darf unterstellt werden, daß globalisierte Interaktion grundsätzlich einen höheren Grad an Differenzierung der Handlungsebenen impliziert, also Reflexion und Selektivität als neue Handlungsgrundlage einführt, andererseits aber fehlen die institutionellen Rückbindungen, die die Umsetzung höher differenzierter Handlungsfähigkeit stützen könnten. Sie gewinnt Kraft nur im Außenbezug. Die so in Gang gesetzten Reflexions- und Rationalisierungsprozesse laufen praktisch an den überkommenen dörflichen Institutionen und am Staat vorbei und lassen sich nicht unmittelbar in einen Prozeß institutioneller Rationalisierung transformieren. Die selektive, auf Arbeitsmigration spezialisierte Par- 
tizipation in der globalen Arena definiert das Verhältnis von Staat und lokaler Gesellschaft neu. Der autoritäre, neo-klientelistisch verfaßte Staat wird virtuell seines umfassenden Herrschaftsanspruchs und seiner totalitären Funktionsweise enthoben, in eine weitgehend passive Beobachterposition gedrängt und kann zur eigenen Funktionssicherung nur reaktiv und punktuell in die aus den neuen Bevölkerungs-, Geld- und Warenströmen entstehenden Wandlungsdynamiken eingreifen. Dies trifft auch auf die traditionellen dörflichen Landbesitzerund Führungsschichten zu: sie verlieren ihre Funktion als politische Klasse, als »Power-Brokers « und als Lenker der Zugänge zur Außenwelt. Ein flottierendes Feld neuer sozialer Elemente entsteht, das einzig auf dem Zugriff und der Dynamisierung lokal vorhandener Ressourcen basiert. ${ }^{3}$

Auf mittlerer Ebene des politischen Diskurses ist das, was uns als eine Dritte Welt-Version der »Perestroika«, als Selbstregulierung einer sich als überlegen erweisenden Zivilgesellschaft, als Liberalisierungsprozeß und notwendige Zurückdrängung des staatlichen Absolutismus beschrieben wird, ein Globalisierungseffekt und kein Entwicklungsmodell. ${ }^{4}$ Man verliert dabei leicht aus dem Auge, daß es sich auch um Souveränitätsverlust und um die Verhinderung der für die kapitalistische Entwicklung notwendigen institutionellen Rationalisierungsprozesse und des Interventionsspielraums des Staates handelt (Evans/Rueschemayer/Skocpol [Hg.] 1985). In gewisser Weise berauben globalisierte Interaktionskontexte den Staat seines traditionellen Herrschaftsraumes. Dies hat erhebliche Auswirkungen auf die Form der sozialen Differenzierungsprozesse, insbesondere in Ägypten, wo Staat und Bürokratie weiterhin bloß aus Herrschafts- und kaum aus versachlichten und verrechtlichten Verwaltungskontexten heraus operieren. Der Konflikt zwischen den in globalisierten Interaktionsfeldern Agierenden einerseits und den durch Zugang zum Staat und traditionellen Herrschaftsformen geprägten Schichten andererseits wird so strukturell vorgeprägt. Die durch Migration entwickelte Form der Globalisierung des lokalen Raums selbst weckt Reaktionen eines tendenziell sich endogenisierenden Kulturkampfes und der erneuten Abschottung vom Weltmarkt. 


\section{Staat, dörfliche Gemeinschaft, Migration}

Der israelische Orientalist und Historiker Gabriel Baer hat eine einflußreiche Darstellung der Sozialstruktur Ägyptens hinterlassen. In einer 1969 erschienenen Studie stellte er einen eigenartigen Zusammenhang zwischen der Auflösung der ägyptischen Dorfgemeinde und der zunehmenden Verstaatlichung dörflicher Funktionen her. Baer führte den Zerfall der ägyptischen Dorfgemeinde auf die Auflösung des kollektiven Eigentums an Grund und Boden und auf das Zurückdrängen der Funktionen des Dorfscheichs durch die zunehmende Verstaatlichung der Dorfämter und auf staatliche Intervention und Rationalisierung zurück (Baer 1969). Wollte man Baers These etwa auf die Nasser-Ära anwenden, so käme man stark in Bedrängnis. Hier zeigt sich, daß zunehmende Staatseingriffe nicht notwendig auf eine Auflösung der Dorfgemeinde hinauslaufen. Im Gegenteil, der Nasser-Staat hat dörfliches Gemeinschaftshandeln und kollektive Bewirtschaftungsformen wiederbelebt und zur dörflichen und agrarischen Involution beigetragen (Stauth 1983b). Verstaatlichung und Gemeinschaftshandeln stehen also nicht notwendig im Gegensatz zueinander.

Ebensowenig aber wie die zunehmende Verstaatlichung und der Funktionswandel der dörflichen Eliten an sich zur Auflösung der Dorfgemeinde führt, kann man kleinbäuerliche Arbeitsmigration schlechthin als Grundfaktor dörflichen Strukturwandels begreifen. Zeitlich begrenzte Arbeitsmigration (in Ägypten das 'umal al-tarahil-System) war zunächst als streng vom Dorf her hierarchisch gegliedertes Rotationsverfahren der bäuerlichen Fronarbeit, dann beschränkt monetarisiert als Kontraktarbeit noch in der nachkolonialen, aber auch in der kolonialen und der vorkolonialen Phase Bestandteil, wenn nicht Bedingung, dörflicher Existenz (El-Messiri 1983; Stauth 1983a: 285-313, Stauth 1983c: 341-354). Arbeitsmigration blieb hier aber eine Sache der Politischen Ökonomie des Verhältnisses zwischen Dorfgemeinde und Staat. Kennzeichnend für diese Periode ist, daß Migration Funktion der Urbanisierung und nationalstaatlicher Modernisierung bleibt (Abu-Lughod 1992: 41-56).

Wenn wir vom »freien «, länderüberschreitenden Migrationsprozeß der $80 \mathrm{er}$ und 90er Jahre als einer neuen Form der globalen Vernetzung individueller und kollektiver Handlungsebenen sprechen, so muß sich dies auf die beobachtbaren Handlungszwänge der Individuen in den 
Dorfgemeinschaften auswirken. Ich stelle hier als Folge der paradigmatischen Überlegungen zur Globalisierung diese Auswirkungen in den Zusammenhang zwischen dem Wandel des symbolisch-expressiven Verhaltens und der sozial-strukturellen Dynamik. ${ }^{5}$

Wenn wir zunächst von Wandlungszwängen im Mikrokontext des Dorfes sprechen, so stehen die Interdependenzen zwischen Marktformen und Gemeinschaftshandeln im Zentrum der Analyse. Dabei erscheint erst einmal der Kontext lokaler Handlungszusammenhänge ausschließlich als Plattform externer Intervention. In dieser Dualität des Innen und Außen gilt Geld (cash) als etwas von außen Geleitetes, von außen Eindringendes, Gemeinschaft (community) als das authentisch Einheimische. Im Handeln auf lokaler Bühne machen wir cash dafür verantwortlich, wenn community verlorengeht. Die bipolare Dynamik zwischen cash- und community-Nexus gilt lokalem Denken als Grundfaktor symbolischer Idealisierung der verlorenen Gemeinschaft. Migration gilt aus dieser Sicht der Dinge als Folge und Instrument von außen induzierter Marktzwänge. Man muß sich ihnen anpassen, verliert dabei aber den scheinbar selbst kontrollierbaren und schützenden Kontext lokaler Solidarität. Ideenwandel erscheint so als Reflex auf den Verlust »innerer « Kulturbestände. In diesem Spannungsfeld zwischen Marktanpassung und Ideenwandel ergibt sich eine völlige Reorientierung des Handlungspielraums des einzelnen, und ist dieser Subjektwandel einmal vollzogen, so ist die »freie « Rationalität der Entscheidung zwischen »Natur « und »Gemeinschaft « einerseits und »Markt« und »Gesellschaft« andererseits nicht mehr gegeben. Man lebt in einem illusionären Fetischrausch des Geldes und handelt so, als sei mit Geld alles regulierbar. Ein schicksalhaft erfahrener Rückfall in den Naturalienkontext der Subsistenzproduktion wird zum Tabu, und ereignet er sich, werden neue "Vorstellungen « und »Moralen « als scheinbar lebendige Tradition hervorgepreßt, mit denen der Rückfall selbst übertüncht und verschleiert werden soll. Die Kontextualisierung der individuellen Konfrontationen mit Markt-, Subsistenz- und Ideenformationen mündet also nicht in einen homogenen sozialen Wandlungsmechanismus des Struktur-, Ideen- und Subjektwandels, sondern sie führt zur Pluralisierung scharf getrennter und widerstreitender Imaginations- und Moralwelten (Berger/Berger/Kellner 1973) und im Dorf selbst zu institutionellen und räumlichen Relokationen und Segmentierungen derselben. 
Bezogen auf ein Feld differenziert gelagerter sozialer Realitäten wären bestimmte "Größen « zu nennen, die hypothetisch unterschiedliche Segmente sozialer Realität aktualisieren. Im Kontext des ländlichen Ägyptens wurden, ich habe das oben angedeutet, der Migrationsprozeß selbst (in seinen Wirkungen auf Individuum, Haushalt, Dorf, Außenbeziehung), Massenkonsum ${ }^{6}$ (in Relation zu Subsistenz, Ware, Arbeit, Eigentum), Geschlecht ${ }^{7}$ (in Haltung zu Segregation, Wissen, Ordnung, Reinheit) und Religion (in Bestimmung von Selbst, Glaube, Ritus, Habitus, Regel) als eng miteinander verflochtene Felder sozialen Wandels bestimmt.

\section{Migration und Globalisierung des lokalen Raums}

Die allgemeinen wirtschaftlichen Auswirkungen der Migration sind in einem sehr komplexen, vergleichenden Survey in sechs Dörfern analysiert worden. Die Daten sind veröffentlicht zugänglich (Reichert 1991: 247-274, ders. 1992: 57-100) und ich kann mich deshalb hier auf die Zusammenfassung einzelner Ergebnisse beschränken:

1. Zunächst das Ausmaß der Arbeitsmigration in den einzelnen Dörfern: Im Durchschnitt aller sechs Dörfer ergibt sich etwa ein Anteil von 27 Prozent an Haushalten, die mindestens einen Migranten als Haushaltsmitglied haben. Wenn man dieses Ergebnis mit anderen im gleichen Untersuchungszeitraum unternommenen Studien vergleicht, so kann man die Feststellung, daß etwa ein Drittel aller ländlichen Haushalte durch mindestens ein Haushaltsmitglied in den letzten zehn Jahren von der Arbeitsmigration betroffen war, als gesichert ansehen. Die Migration schließt alle dörflichen Schichten ein: die Gebildeten, Lehrer, Ingenieure, Verwalter etc., die nicht-agrarisch Arbeitenden wie etwa Handwerker, Taxifahrer etc. und die Kleinbauern-Haushalte gleichermaßen. Dabei ist ein interessantes Nebenergebnis, daß der Migrationsanteil mit der Höhe des Anteils der Kleinbauern-Haushalte im Dorf steigt. Je »fellachisierter « das Dorf, um so höher der Migrationsanteil, im Extremfall über 50 Prozent.

2. Die Zielländer sind in der Hauptsache der säkulare national-arabische Irak und das monarchische, islamische Saudi-Arabien. Der Anteil allein dieser beiden Länder beträgt 82 Prozent. Der Rest zog 
vor allem nach Jordanien und Libyen. Die Entscheidung für ein bestimmtes Land hängt nicht von der regionalen Lage der Dörfer in Ägypten ab, sondern offenbar von Zeitpunkt und Orientierung des Rekrutierungsmechanismus im Dorf. Je früher man zu migrieren begonnen hat, um so stärker ist man nach Saudi-Arabien hin orientiert, um so stärker mischen noch die traditionalen Führungsschichten als Kontrakteure etc. mit. In der Tendenz sind deshalb die abgelegeneren Fellachendörfer einerseits, aber andererseits insgesamt die Fellachenmigranten, stärker auf den Irak ausgerichtet. Es kann hier schon deutlich gesagt werden, daß die Intensität der Islamisierungstendenzen im Dorf nicht vom Anteil der Migranten im islamischen Saudi-Arabien abhängt. Eher das Gegenteil ist der Fall.

3. Betrachtet man die Art der Rimessenverwendung und die darüber im Dorf geführten Diskussionen für sich, so ergibt sich die einfache Feststellung, daß der Migrantendiskurs ein Diskurs über Haus-, Lebens- und Konsumstandards, letztendlich also über Statusverbesserung ist, nicht über Investitionen und Intensivierung der dörflichen Wirtschaft. Es geht vor allem um Grundbedingungen des Familienlebens in den Haushalten, um Hausbau, Wohnungseinrichtung, Haushaltswaren, Kosten für das Heiraten, Ausgaben für Brautpreis und Morgengabe etc. Über 70 Prozent geben ihre Rimessen für langlebige Konsumgüter aus. Etwa zwei Drittel bauten oder renovierten ein Haus oder eine Wohnung, weitere 20 Prozent kauften Bauland. Nur 30 Prozent schafften Vieh an und noch weniger, nur 12 Prozent, können sich ein neues Stück Agrarland kaufen. 7 Prozent geben an, Agrarmaschinen gekauft zu haben. Nur 2 Prozent haben versucht, sich durch ein neues Projekt selbständig zu machen.

4. Man will in Beton- und Ziegelsteinhäusern leben, nicht in Lehmhütten. Die wirtschaftlichen Folgewirkungen dieses Baubooms sind enorm und führten vor allem im Delta zu einer extremen Mobilität im ländlichen Raum. Ob sich die Kapitalisierung im Kleingewerbe des Bausektors etwa mit der Landwirtschaft der Kleinbauern zu eigenständigen Akkumulationszyklen verbinden läßt, bleibt abzuwarten und bedarf eigener Analyse.

5. Für die soziologisch wichtigen Aspekte der Auswirkung der Migration auf die Formen und den Grad der segmentären Umschichtung im Dorf etc. konnte der Survey keine Anhaltspunkte liefern. 
Hier hatte - wie ich beispielhaft zeigen will - die qualitative Analyse anzusetzen.

\section{Migration und Transformation des dörflichen Habitus}

Der Zufluß von Dauerkonsumgütern modernster Art regte auf seiten der Fellachenhaushalte zu neuen Formen der Geldallokation an: risikoreiche Kreditgeschäfte, Spekulationen und Sparguthaben über lokale Banken (vgl. etwa Rousillon 1988).

Ein neues, mobilitätsorientiertes Verhalten entstand. Mazda, Toyota und Suzuki, aber auch der garrar, der aus Rumänien billig importierte Traktor, als Transportmittel oft wichtiger denn als Landmaschine, wurden Stichworte eines völlig privatisierten Verkehrssystems. Die neue ungeheure Mobilität der ländlichen Massen löste die lokalen dörflichen Märkte aus der Bindung an die Subsistenzproduktion, vernetzte sie neu und aktualisierte die Beziehung zu den Metropolen und Sub-Metropolen.

Folgewirkung des Baubooms und der Mobilität ist auch, daß neue, relativ leistungsfähige Werkstätten und Dienstleistungsbetriebe im Dorf entstehen, Schreinereien, Ziegeleien, Reparaturwerkstätten, Hühnerfarmen und Viehzuchtprojekte, aber auch neue Läden, Boutiquen, wie sie im Dorf genannt werden.

Mit dieser Form der Mobilisierung der lokalen Ressourcen entstand aber auch eine neue ländliche Mittelschicht, für die Konsum wichtiger ist als Funktion und Professionalismus. Landbesitzende Klein-, ja Kleinstbesitzer gehören dazu, Handwerker, Ladenbesitzer, Taxifahrer, darunter auch Halb- oder Analphabeten. Die sozialen Grenzlinien zwischen Beamten und Bauern, zwischen Gebildeten und Ungebildeten, zwischen Literaten und Illiteraten scheinen gefallen. Der Konsumismus der Medien- und Massenkultur erlegt der ländlichen Gesellschaft einen neuen Code, eine neue Form des bildhaften Skripturalismus auf: die Repräsentation von Konsum.

Wer es sich leisten kann, baut sich am Dorfrand die Imitation einer Villa im saudischen oder irakischen Konsumbürgerstil. Im Dorf selbst werden die Beton- und Rotziegelhäuser verschönt, geweißt oder mit leuchtenden Farben gefärbt. Vorgärten werden angelegt, Bäder eingebaut.

Es entsteht ein neues Reinlichkeitsverhalten im Haus, das bei dieser 
Mittelschicht mit dem Rückzug der Frau aus der Öffentlichkeit von Feldarbeit und Markteinkauf oder auch -verkauf verbunden ist. $\mathrm{Zu}-$ gleich entwickeln die Männer ein neues, von starker Repräsentationssucht bestimmtes Freizeitverhalten, das auf die Herstellung einer häuslichen Öffentlichkeit, nicht aber auf die Öffentlichkeit im Dorf als Ganzem und seinen traditionell gelebten Riten gerichtet ist.

Der Kode der meist im islamischen Gewand einhergehenden häuslichen Zivilität und des Wohlstands entwickelt sich in offener Feindschaft zur verwahrlosten Öffentlichkeit des Dorfes selbst: müllbeladene Kanalufer, staubige, oft mit Abfällen und Plastiktüten übersäte Gassen, Viehzüge und streunende Hunde, staubaufwirbelnde Fahrzeuge, Taxis und Traktoren; der Kampf um einen Platz im Toyota oder im Bus, der Streit mit den Nachbarn um Sauberkeit und Ordnung im öffentlichen Raum vor den Häusern; der Kampf der Mikrophone, die für den Gebetsruf, den Straßenverkauf, für Fest und Trauer oft gleichzeitig angestellt werden.

Die praktisch-alltäglichen Mikrozusammenhänge der sozialen Öffentlichkeit bleiben vom Kode der neuen Zivilität relativ ausgenommen. Ein ägyptischer Schriftsteller, Abdou Gubair, hat vom »Bürgerkrieg des Alltags « gesprochen. Der islamisierte Repräsentationskode des Konsumbürgertums greift in diesen Bürgerkrieg tief ein.

Die Transformationsidee ist mit der Durchsetzung des Projekts der Islamisierung als Fokus des sozialen und politischen Diskurses an der Wurzel der Gesellschaft verknüpft. Die Frage des sozialen Status eines Dorfbewohners hängt nun unmittelbar und unhinterfragbar von der Tatsache ab, ob er sich als guter Muslim erweist. Informelle Familientreffen sind Anlaß zur Durchsetzung eines kollektiven Gebets. Der im Koran Bestunterwiesene leitet die Gebetsgruppe an. Es gilt als fromm, das Abendgebet möglichst lange zu gestalten. Familien- und Freundestreffen gewinnen nun offen einen religiösen Charakter. Sprache, Wiederholung koranischer Redewendungen, Kleidung und äußere Haltung spiegeln das Bild einer islamischen Lebensweise. Der kollektive Besuch einer Trauerrezitation von Freundes- und Altersgruppen (shilla) als Kondolenz gilt nun als fromme Tat. Nicht das »Faktische« an einem Freundschafts- oder Verwandtschaftsverhältnis zum Verstorbenen zählt nun als Relevanzkriterium, sondern die Teilnahme an einem sakralen Ritus, der Dorföffentlichkeit konstituiert: fast täglich bieten 
sich Gelegenheiten, Dorftraditionen im Gewand des Islams zu repräsentieren.

\section{Abu Girg und Bani Walims: zwei oberägyptische Dörfer}

Abu Girg ist eine "grosse bougarde" (Berque 1955). Es hat eine Geschichte, die bis in die Antike zurückreicht. Davon zeugen nicht nur pharaonische Sagen, sondern auch die Präsenz einer beträchtlichen christlichen Bevölkerung. Es hat auch eine moderne Geschichte. Hier im Ort finden sich die Landhäuser einer Familie, die mehrere große Islam-Gelehrte und Minister hervorgebracht hat. Der räumlichen Größe und Anzahl seiner Einwohner nach (ca. 15.000) ist es fast eine Stadt, doch blieb es äußerlich ganz von der bäuerlichen Produktionsund Lebensweise geprägt. Von den über 3.600 Haushalten wurden fast 1.500 im Kurz-Survey erfaßt. Ca. 800 (ca. 60 Prozent) der erfaßten Haushalte sind völlig durch eine agrarische Einkommensstruktur (Subsistenz, Markt, Tagelöhner) geprägt. Nur weniger als 10 Prozent der Haushalte liegen über dem Subsistenzniveau. Über 40 Prozent der Haushalte weisen in den letzten 10 Jahren einen Migranten aus, in der Mehrzahl nach Saudi-Arabien (ca. 63 Prozent) und Irak (ca. 27 Prozent). Die Mehrzahl war mehr als fünf Jahre unterwegs, ca. 30 Prozent noch zum Zeitpunkt der Untersuchung (1988). Die Mehrzahl der Migranten sind arme Fellachen, meist Analphabeten (ca. 60 Prozent), aber immerhin 20 Prozent sind als Lehrer oder in anderen professionellen Berufen ausgebildet. Nach den Intentionen gefragt, wollen 91 Prozent ihren Lebensstandard verbessern, 12 Prozent ein Haus bauen oder erneuern, 11 Prozent das Geld für die Heirat verdienen. Danach gefragt, was sie faktisch mit dem Geld machen, rangieren die Anschaffung von elektrischen Dauerkonsumgütern (84 Prozent) sowie Hausbau und -renovierung (86 Prozent) mit Abstand am höchsten. Es handelt sich dabei in der Regel um den Umbau des Hauses von sonnengebrannten Lehmziegeln auf roten Backstein. Immerhin waren 1988 noch ca. 58 Prozent der Häuser in Abu Girg mit Lehmziegeln gebaut. Der Bau-Boom und andere investive Verwendungen der Rimessen führen zu einer weiteren ökonomischen Öffnung des Dorfes: erstmals ergeben sich lokale Marktbeziehungen, die als subsistenz- und gemeinschaftsunabhängige Größen erscheinen. 
Soweit, auf ihren Kern reduziert, die Ergebnisse der quantitativen Analyse. Der »cash-Nexus « und die durch ihn vermittelten Transformationen sind angenommen, artikulieren sich aber auf der Ebene der Lokalstruktur ganz unterschiedlich. Als konfliktträchtig erweist sich der »cash-Nexus « nicht dort, wo er zur tendenziellen Auflösung des »community-Nexus « geführt hat, sondern wo cash der community wieder untergeordnet und der Rückfall in kleinbäuerliche Verhältnisse allgemein notwendig wird: in den marginalen und kleineren Dörfern.

Exemplarisch läßt sich dies in der Gegenüberstellung von Abu Girg und Bani Walims zeigen. Letzteres liegt nicht am Nil, sondern inlands wüstennah in der gleichen Region (Minya), nicht sehr weit entfernt von Abu Girg. Hier ist alles ärmer, man migriert vornehmlich (zu fast 90 Prozent) in den Irak. Hier stößt unsere Untersuchung auf Widerstand. Hier sind Konflikte unter den Clans offensichtlich.

Zunächst aber Abu Girg, wie entwickelt sich hier die neue Lebensweise?

In Abu Girg wurde das " 'umda-Amt«, das traditionelle Ehrenamt des »Bürgermeisters «, abgeschafft und die Verwaltung durch den Distrikt eingeführt: eine klare Minderung der unmittelbaren lokalen Macht der Clans und Groß-Familien, die sich jetzt der allgemeinen sozialen Entwicklung im Dorf anpassen müssen. Sie schließen sich dem neuen islamischen Konsum- und Bildungsbürgertum an. In dieser Koalition aus einer Art Kulakentum der landbesitzenden Dorfklasse und der neuen dörflichen Bildungsschichten entsteht eine dynamische Dorföffentlichkeit durch eine gewissermaßen privatisierte islamische Aneignung des dörflichen Ritus. Hauptmerkmale der Rimessenverwendung sind ein hoher Anteil an Dauerkonsumgütern, Mittel für Erziehung der Kinder, Heirat, Sparguthaben etc.

Die Kernfiguren der dörflichen politischen Öffentlichkeit sind in einer konsumbürgerlich geprägten Führungsgruppe zusammengeschlossen, die stark an den Migrationsprozeß angebunden ist, deren überragende Figur selbst nie im Ausland war. Er hatte aber zusammen mit seinem Cousin erheblichen Anteil an der Organisation des Kontraktierungsnetzwerkes nach Saudi-Arabien. Er ist etwa 55 Jahre alt (1988), groß, fett und spielt durch bewußte Umordnungen des islamischen Codes in Auftreten und Kleidung Distanz. Er ist der größte Grundbesitzer bäuerlicher Abstammung in Abu Girg. Zu seiner ständigen Begleitergruppe gehören ein Lehrer, ein leitender Steuerbeamter, 
ein Schulinspektor, ein Unternehmer - alle waren in Kuwait oder in Saudi-Arabien, auch der Cousin, der »Labour-Boss « mit wechselnder Fortune, der in den Hoch-Zeiten des Ölbooms noch bis zu 200 Arbeiter jährlich nach Jiddah in Saudi-Arabien vermittelte.

Das Zusammensein in der Gruppe ist durch rituelles Betragen geordnet: Kleidung, äußere Haltung und Anrede sind in abstrakter Weise auf »Islam« hin kodifiziert. Geschichten erzählen, sich gegenseitig bedienen, freundlich sein, all das gilt als islamisch tugendhaft. Ich habe Mitte der 70er Jahre im Delta viel Zeit unter solchen Gruppen verbracht. Aber nie waren sie weiß gekleidet und so steif und formal.

Die Gruppe trifft sich, als wäre alles zufällig, am Abend im Haus eines beliebigen Mitglieds. Von hier aus bereitet man dann die Besuche im Dorf vor. Die Gruppe besteht aus ganz praktischen Menschen. Man sucht seine Vorteile, erscheint immer zur richtigen Zeit. Islam ist hier eine Welt der Bildung, der islamischen sehr wohl, aber mit Respekt vor der weltlichen. Sie symbolisiert sich in den großen Landhäusern und Palmhainen draußen vor dem Dorf, die Ministern und Gelehrten gehörten, allesamt islamische Reformer, und die einst Taha Hussain beherbergten, den berühmtesten unter den Modernisierern. Sie sind im Innern Verehrer Gamal Abdel Nassers geblieben, stehen aber auch ganz auf der Seite der Islamisierungswelle. Die symbolische Erneuerung unter dem Zwang der Zeit und die Berufung auf die Regel, den guten Geist als Tradition des Dorfes helfen, Reichtum zu wahren. Mit dem islamischen Radikalismus der Jungen, aber auch mit der Aufmüpfigkeit der Fellachen, wird man fertig. Durch Auftreten der Gruppe bei jeder öffentlichen Angelegenheit im Dorf wird der "gute« Islam vertreten: konventionell und regierungstreu. Es hat den Effekt einer dauernden Erfindung des Sakralen als Dorföffentlichkeit, gegen die die Jungen, die Radikalen, keine Chance haben. Idee und Interesse bleiben hier auf das freundlichste getrennt.

Hier zeigt sich unter der gewandelten Form traditioneller Führung ein relativ konfliktloser Übergang. In der untersuchten Phase blieb die Islamisierung auf die rituellen Spiele dieser Schicht begrenzt. Die neue Hauskultur ermöglicht die abstrakte politische Repräsentation der »Grundidee« Islam, hier als tolerante Kultur der Gebildeten. Sie wird zugleich über verschiedene Clanmitglieder auch in verschiedenen Parteien präsent gemacht.

Abu Girg liegt nur wenige Kilometer von der Nord-Süd-Achse 
Kairo-Assuan entfernt. Es zählt einen Landstrich am Ufer des Nil zu seiner Gemarkung. Bani Walims gilt dagegen als wildes Dorf: $15 \mathrm{Ki}-$ lometer im Landesinnern westlich des Nil am Bahr Yusuf gelegen, dem parallel zum Nil verlaufenden Kanal, den die Engländer noch gegen Ende 19. Jahrhunderts bauten, hat es keine gewachsene, auf das Außen, auf Kairo hin bezogene Infrastruktur und wird von im 19. Jahrhundert seßhaft gemachten Beduinen-Clans beherrscht.

Eine islamische Homogenisierung der dörflichen Öffentlichkeit gibt es nicht in Bani Walims, dem zurückgebliebenen Dorf am Rand der Wüste. Statt dessen findet die harte politische Propagierung der Islamisierung statt. Fast 90 Prozent aller Migranten gingen hier in den Irak, nur ein paar gut verdienende Lehrer nach Saudi-Arabien. Die Migrationswelle hat hier nicht viel verändert, nur daß viele alte Lehmhäuser nun in roten Backsteinziegeln wiedererbaut wurden. Die dominante Freundesgruppe besteht aus Lehrern, und alle waren sie in Saudi-Arabien. Draußen am Dorfrand haben sie sich weiß verputzte Häuser gebaut.

Die politische Kernfigur hier in Bani Walims gehört eher zu jenen, die gegen die Arbeitsmigration sind. Es haben sich daraus nur Nichtsnutze im Dorf entwickelt, sagt er einmal. Er war nie im Ausland. Aber eine junge, aus der Migration zurückgekehrte Bildungsschicht von Lehrern stellt sich unter seine Führung. Sie waren alle in Saudi-Arabien. Ihnen gegenüber stellt er im konsumbürgerlichen Sinne eher eine gescheiterte Existenz dar. Er ist mustashar (Kanzler), oberster Richter einer regionalen Berufungsinstanz am Amtsgericht in Minya, der Provinzhauptstadt, hat beruflich also viel Erfolg gehabt. Er hat es abgelehnt zu migrieren, er ist etwa 45 Jahre alt und fährt in der Woche drei Tage nach Minya, um sein Amt auszuüben, muß also zwei bis drei Nächte in der etwa $30-40 \mathrm{~km}$ entfernten Stadt in den für solche Fälle eingerichteten Unterkünften des Amtsgerichts verbringen. Er gehört zu einer der vier führenden Großfamilien im Dorf. Zwei dieser Großfamilien sind christlich und wurden unter seinem und der jungen Garde Einfluß unter der Schutzherrschaft der beiden muslimischen Großfamilien gestellt. Im Falle einer Blutrache oder eines Streits zwischen einem Muslim und einem Christen der jeweils anderen Familie treten die muslimischen Familienclans zusammen und beraten über Schlichtungsmaßnahmen. Keiner der Clans verfügt über nennenswerten, grö- 
ßeren Grundbesitz. Die Clans zeichnen sich durch Status, nicht durch faktische Macht aus.

Die islamistische Kerngruppe der Jungen hat jedoch den Clan als Rat weitgehend abgeschafft und zu ersetzen versucht. Man sitzt zusammen und diskutiert die Dorfangelegenheiten, will Islamisierung als Reglungsinstrument der Konflikte im Dorf.

Zur Migrationsfrage nimmt der Kopf der Gruppe selbst Stellung: 1. Die Remigration hat im Dorf gar nichts geändert. Die Remigranten verplempern ihr Geld mit roten Ziegel-Häusern und tragen nichts mehr produktiv zur Entwicklung des Dorfes bei. 2. Dadurch daß sie jetzt Geld haben, halten sie sich nicht mehr an die alten Sitten, grüßen sich nicht mehr, sind nicht mehr freundlich zueinander, das alte Solidaritätsgefüge sei auseinander geraten und habe sich zum Schlechten hin entwickelt. Dem könne man nur mit der Einführung des islamischen Rechts, der shari a islamiyya, begegnen.

Der Endogenismus der Gruppe widerspricht den eigenen Erwartungen für den sozialen Aufstieg, der von der Regierung draußen abhängt. Die Lösung aller Widersprüche ist der Islam. In der Praxis muß jetzt ein neuer Lebensstil her, mit dem andere überzeugt werden können, denn sie waren bis vor kurzem noch fundamentalistisch-sozialistische Säkularisten.

Islamisierung ist offenes politisches Programm, direkt festmachbar am Versuch, die christlichen Clans in einen Klientelstatus gegenüber den muslimischen Clans innerhalb des dörflichen Schlichtungsmechanismus und Vendetta-Kriegs zu bringen.

Blickt man auf die Korrelationen der Rimessenverwendung, so findet man in Bani Walims den Kauf von Dauerkonsumgütern, Landkauf und Tierkauf, Investitionen in Agrarmaschinen, eine sehr große Neigung zu Häuserrenovation und -neubau als Hauptpunkte, jedoch kaum unternehmerische Verwendung von Rimessen und Mittel für Kindererziehung. Der Bauboom geht auf kollektive Anstrengungen zurück: die roten Ziegelsteine werden mittels pharaonischer Techniken von Selbsthilfegruppen gebrannt und zum Stückpreis verkauft, oft aber auch noch eigenhändig auf eigenständig zum Bauland erklärtem Familienacker produziert.

In Bani Walims sind bewaffnete Konflikte an der Tagesordnung. Die Auseinandersetzungen zwischen Muslimen und Christen bilden 
das Hauptproblem. Familienclan und religiöse Gemeinschaft bleiben dominante Faktoren von Rechtsschutz und sozialer Stellung.

Die Eliten beider Dörfer kennen sich, man hat gemeinsame Freunde in Minya oder in Kairo. Man besucht sich von Zeit zu Zeit angelegentlich einer Bittstellung oder eines Todesfalles etc.

Dennoch repräsentieren beide Dörfer zwei unterschiedliche Formen des Strukturwandels im Zeichen der Migration und der Islamisierung. Die beduinische, tendenziell akephale Struktur des wüstennahen Dorfes verflicht den Migrationseffekt in eine neue Form der praktischen und ideologischen Kommunalisierung im Zeichen eines politischen, militant fundamentalistischen Islams, der auf Emanzipation der kleinbäuerlichen Migranten gerichtet ist, auf eine ideelle Sakralisierung des dörflichen Alltags, zu dem er zugleich in ein unlösbares Spannungsverhältnis tritt. Der Islam erscheint hier als Lösung der Bauernexistenz unter der Bedingung der durch Migration hervorgerufenen Globalisierungseffekte. Transformation steht hier ganz im Zeichen der Spannung zwischen religiöser Ideologisierung der praktischen Bauernexistenz und ihrer lebendigen materiellen Kontinuität.

\section{Rekonzeptualisierung des Verhältnisses von Migration und Strukturwandel}

Der zu Beginn der 80er Jahre einsetzende Paradigmenwechsel in der Migrationsforschung, Migranten nicht nur als Opfer struktureller Herrschaft, sondern als bewußte Akteure und rational Handelnde zu begreifen $^{8}$, reflektiert die durch den Globalisierungseffekt hervorgerufene Transformation sozialer Gruppen im lokalen Kontext nur ungenügend.

Was unsere dörflichen Fallbeispiele zeigen ist, daß die unterschiedliche Dorfstruktur und die unterschiedliche lokale Präsenz des Staates sich nicht nur auf Wirtschaftsentwicklung und Einkommenschancen trennend auswirkt ${ }^{9}$, sondern auch auf den Transformationsprozeß selbst. Was das große, urbanisierte Dorf am Nil mit dem marginalen Bauerndorf am Wüstenrand verbindet, ist die Islamisierung als Abschaffung materieller Zwänge und als symbolische Verteidigung des Dorfes. Was beide trennt, ist die Form der Umsetzung und körperlichen Versinnbildlichung der Idee Islam: Hier, in Bani Walims, wirkt der bedrohte »Gemeinschaftsnexus « als Element der imaginären Bin- 
dung der »Idee « an die kleinbäuerliche Praxis und den aus dem Globalisierungskontext entwachsenen Zwang zur Emanzipation. Dort, in Abu Girg, wirkt der akzeptierte »Geldnexus « als Element der Distanzierung der Islamisten, die die Unwirtlichkeit des Dorfes und die Materialität kleinbäuerlicher Existenz überspielen. Ritus wird zum Ersatz staatlicher Durchregulierung.

Im ländlichen Ägypten hat die Monetarisierung der Kleinbauernhaushalte und das Entstehen eines Konsumbürgertums zu einer inneren Zerrissenheit der dörflichen Sozialstruktur und zur Delegitimation des herrschaftspolitisch und nicht verwaltungstechnisch und schon gar nicht sachentscheidenden patrimonialen Kontroll- und Abschöpfungsapparats des Staates beigetragen. Die selektive Teilnahme am modernen Massenkonsum ist für alle am Staat vorbei möglich geworden. Auf Deregulierung wird auf kürzester Distanz der sozialen Räume in ganz unterschiedlicher Weise reagiert.

Ich habe mich hier auf die Darstellung zweier Modelle beschränkt: die Verteidigung kleinbäuerlicher Existenz als militante Islamisierung, als Emanzipations- und Ordnungsprogramm im staatsfernen Dorf, dagegen die Islamisierung des dörflichen Ritus und Habitus als Regelungsersatz und Verteidigung privilegierter Statusgruppen. Wenn Sie mir dieses abschließende Postulat gestatten: die spezifische Form der Globalisierung durch Arbeitsmigration, sollte sie nicht in einer neuen Art der »Libanonisierung « enden, erfordert neue Formen staatlicher, auf Sachverwaltung basierender Regulierung lokaler Kontexte und entwicklungspolitischer Impulse $\mathrm{zu}$ entsprechender institutioneller Rationalisierung.

\section{Anmerkungen}

1 Für den Nahen Osten vgl. etwa, Birks/Sinclair 1985; CERMOC 1985; Richards / Martin (Hg.) 1983.

2 Dies ist detaillierter ausgeführt in meinem Beitrag: Stauth 1991c: 91-114.

3 Ein anschauliches Bild dieser Dynamik liefern Evers/Schiel (1988). Für den städtischen Raum Kairos vgl. Semsek/Stauth 1987.

4 Vgl. etwa Binder 1988. Siehe auch meine Kritik zu "Leonard Binder's Hermeneutic of Authenticity. A Review Article« (1993b, c). 
5 Vgl. zu den folgenden Ausführungen Stauth 1990/1991: 157-170. Siehe auch Kreutz (Hg.) 1991.

6 Vgl. hierzu Stauth 1989a: S. 223-236. Zur allgemeinen Problematik im Nahen Osten siehe Stauth/Zubaida (Hg.) 1987.

7 Vgl. Stauth 1990b: 32-50, ders. 1988. Siehe auch die umfassenden Darstellungen von Abaza 1987 und Weyland 1993.

8 Vgl. etwa Wood 1982: 298-319; Bach/Scharmi 1982: 320-341; vgl. auch Loomis 1989.

9 Dies wird noch von Peek und Standing einleuchtend herausgearbeitet: Peek/Standing (Hg.) 1982. 


\section{Teil IV}

\section{Islam und Soziologie}

"Romanticism in one form or another had always been a factor in the Orientalists' motivation: if not to pursue the bizarre or exotic, then to lose oneself in another time and civilization, out of estrangement from one's own: to find a lost, purer faith through another distant, more "spiritual", than one's own (never really known), simply to go "native" or "primitive " among strange tastes, sounds, sights, smells, and gestures, to go back to the "sources", or, if one were a missionary or, more recently, a technocratic developer, to do the reverse of all these, romantically: to alter, to prove, to pacify, reform, control the backward, underdeveloped Oriental. Massignon stood firmly against missionaries and technocrats, but was drawn to "the sources", to roots, to origins of his own and humanity's spiritual life. No doubt, he would have liked to have Goldziher's approval..."

(Herbert Mason, Foreword to the English Edition, in: Louis Massignon, The Passion of Hallaj. Mystic and Martyr of Islam, 1986)

"... sociologists are either not interested in Islam or have nothing to contribute to Islamic scholarship."

(Bryan S. Turner, Weber and Islam, 1974) 



\section{Frühe Ansätze zu einer Soziologie des Islams: Ignaz Goldziher und Max Weber}

Wer sich heute in rein religionssoziologischer Absicht mit dem Islam befaßt, wird schwerlich am Werk der beiden großen Gelehrten Ignaz Goldziher (1850-1921) und Max Weber (1864-1920) vorbeikommen. Dies ist nicht so leicht und nicht auf den ersten Blick evident.

Weber hat wenig, fast nichts über den Islam geschrieben - jedenfalls nichts, was auf eine genuine Soziologie des Islams gerichtet wäre. Goldziher hat nichts im modernen Sinne Soziologisches über den Islam geschrieben, islamwissenschaftliches Quellenstudium betrieben, sich am Detail orientiert und nicht primär an Kategorien und Klassifikationsmerkmalen der in Blüte geratenen vergleichenden Kulturwissenschaft. So jedenfalls darf man das herkömmliche Goldziher-Verständnis interpretieren, wenngleich es ihm nicht nur Detailfülle, sondern auch Überblick attestierte (Becker 1922). Die Goldziher nacheifernde Islamwissenschaft hat denn auch ihr Augenmerk kaum auf Goldzihers Werk als Ganzes gerichtet, sondern sich mehr an den Materialien selbst erfreut, die es bereitstellte (als rühmliche, aber dennoch breite Lücken lassende Ausnahmen vgl. Waardenburg 1962 und Simon 1986).

Nichts also, was diese beiden Männer, den Soziologen und den Islamwissenschaftler, verbände? Der eine, Weber, war seit 1984 - dem aufkommenden Geist der Zeit ganz entsprechend - ein eifriger Leser der Werke Nietzsches (Hennis 1987: 173); der andere, Goldziher, beklagte sich noch 1899, daß er und die jüdische Gemeinde in Budapest (er war deren Sekretär) sich habe einen Nietzsche-Vortrag anhören müssen (TB": 224).

Warum also diese Gegenüberstellung zweier sich scheinbar so ferner Geister? Schluchter (1987b: 18) deutet an, daß Weber die Arbeiten Goldzihers zur Kenntnis genommen habe, freilich ohne uns die Quelle seines Wissens zu erschließen. Vieles deutet darauf hin, daß Goldziher in der gleichen Gruppe von Wissenschaftlern zum Weltkongreß nach St. Louis fuhr wie Max Weber (vgl. Weber 1926: 292-317; Goldziher, TB, 1904). Beide standen in ihrer Jugend religiös-nationalistischen

* Ein Verzeichnis der abgekürzt zitierten Schriften befindet sich auf S. 237. 
Bewegungen nahe, der eine, Weber, einem sozial engagierten Protestantismus ebenso verbunden wie einer nach Weltmacht strebenden deutsch-nationalen Reichspolitik (De Bernart/De Marco 1987); der andere in einer jüdisch-nationalen Bewegung, die ganz gegen die Reichspolitik Österreich-Ungarns gerichtet war. Dies alles sind aus der Entwicklung und den politischen Strömungen der Zeit verständliche, eher biographische Anknüpfungspunkte. Rechtfertigen sie die Gegenüberstellung?

Die vor dem Ersten Weltkrieg in Europa weitgehend friedlich ausgetragenen Kämpfe waren Kulturkämpfe, Kämpfe um »eigene« oder »neue« oder »höhere Kulturen«. Man muß an die Wirkung von Nietzsches Kulturkritik des Abendlandes erinnern. An seinen Kampf für eine »neue« Kultur. Nietzsche hat diesen Kulturkampf zum Tanzen gebracht. Er hat diese »neuen«, die neuen »höheren« Kulturen kritisiert. Er spricht in diesem Zusammenhang von einem »Doppelgehirn«:

"Wenn nun die Wissenschaft immer weniger Freude durch sich macht und immer mehr Freude durch Verdächtigungen der tröstlichen Metaphysik, Religion und Kunst nimmt: so verarmt jene größte Quelle der Lust, welcher die Menschheit fast ihr gesamtes Menschentum verdankt. Deshalb muß eine höhere Cultur dem Menschen ein Doppelgehirn, gleichsam zwei Gehirnkammern geben, einmal um Wissenschaft, sodann um Nicht-Wissenschaft zu empfinden: nebeneinander liegend, ohne Verwirrung, trennbar, abschließbar; es ist dies eine Forderung der Gesundheit. Im einen Bereiche liegt die Kraftquelle, im anderen der Regulator: mit Illusionen, Einseitigkeiten, Leidenschaften muß geheizt werden, mit Hilfe der erkennenden Wissenschaft muß den bösartigen und gefährlichen Folgen einer Überheizung vorgebeugt werden.«

(KA 1980, 2: 209)

Diese ironische Haltung Nietzsches zur Wissenschaft wird bei Weber Programm. Aber schon lange vor der Wissenschaft war es die Religion, die selbst der »tröstlichen Metaphysik« der magischen Weltbetrachtung Abbruch tat. Schon die »höhere« Kultur der Religion konstruiert ein »Doppelgehirn«. Nicht zuletzt blickt der Mensch aus der Blickweite der Hochkultur mit einer gewissen Nostalgie auf die niedere Kultur hinab: 
»Erschütterung, Selbstmitleid im Angesicht der niederen Cultur ist das Zeichen der höheren Cultur; woraus sich ergibt, daß durch diese das Glück jedenfalls nicht gemehrt worden ist. Wer eben Glück und Behagen vom Leben ernten will, der mag nur immer der höheren Cultur aus dem Wege gehen.«

(KA 1980, 2: 228)

Max Weber spricht in diesem Zusammenhang vom asketischen Puritanismus und vom Protestantismus als den konsequentesten Formen der religiösen Zurückweisung von im magischen Weltbild verhafteten religiösen Praktiken. Nur die vom Puritanismus geschaffene Lebensmethodik brachte auch jene untröstliche Paradoxie hervor, die religiöse Vertiefung so eng an diesseitiges Interesse bindet und dabei »diese nur auf den allerersten oberflächlichen Blick seltsame, scheinbare Umkehr des >natürlichen< (RS I: 524) hervorbringt. In Webers Perspektive ist es die innerweltliche Askese des Puritanismus, die jenes einzigartige (nicht »Doppelgehirn«, sondern) »Doppelgesicht « (RS I: 540) hervorbrachte, mit dem ein immer weitergreifendes »Diesseitsinteresse « mit »Jenseitsschicksal« sich verbindet und so das Streben nach Vermehrung des alltäglichen Nutzens mit außeralltäglichem Habitus erst als moderne Kulturleistung durchsetzt (RS I: 239f.). Weber macht diesen spezifisch »okzidentalen Rationalismus « der christlichen Religion für alle Weltreligionen insofern verbindlich, als er ihn als Meßlatte kulturübergreifender moderner Religionssoziologie einführt. Das »Doppelgehirn « einer Religion, ihre eigentliche, universell zivilisatorische Bedeutung bemißt sich für Weber in dem Maß, in dem sie sich »rationalisiert «:

»Für die Stufe der Rationalisierung, welche eine Religion repräsentiert, gibt es vor allem zwei, übrigens miteinander in vielfacher innerer Beziehung stehende Maßstäbe. Einmal der Grad, in welchem sie die Magie abgestreift hat. Dann der Grad systematischer Einheitlichkeit, in welche das Verhältnis von Gott und Welt und demgemäß die eigene ethische Beziehung zur Welt von ihr gebracht worden ist.«

(RS 1: 512)

Stehen nicht Goldzihers Arbeiten über den frühen Islam ganz im Zeichen dieses Blickwinkels? Und wenn ja, zu welchem Ergebnis kommt 
er? Und wie unterscheidet sich bei gleicher Perspektive Webers Islambild von Goldzihers Einsichten?

Die Fragen über die Trennungslinien und die verbindenden Elemente zwischen den »höheren « Kulturen der Welt und zwischen Islam und Christentum insbesondere waren Fragen der Zeit, die beide Autoren bewegten. Die Art und Weise, wie sie sie zu beantworten suchten, sind für die Geburtsstunde kulturübergreifender sozialwissenschaftlicher Forschung ausschlaggebend gewesen und bis heute bestimmend.

Die deutsche Islamwissenschaft hat - von wenigen Ausnahmen abgesehen - auf ihre Geschichte und ihre Grundlagen selten zurückgeblickt (vgl. etwa Paret 1968; Fändrich 1976; van Ess 1980; Schulze 1982; Heine 1985). Es ist deshalb verständlich, daß das ins Monumentale gewachsene Lebenswerk Ignaz Goldzihers weiterhin einer kritischen Würdigung entbehrt. Das Negativbild, das in der amerikanischen und angelsächsischen Literatur über Goldziher verbreitet wird, zeigt uns einen in seiner Karriere benachteiligten, ressentimentgeladenen ungarischen Juden, dem es letztlich am tieferen Verständnis für die islamische Kultur mangelt (vgl. Said 1978: 209; Hourani 1980: 50-51; Fluehr-Lobban 1978; App. 1). Dieses Bild tut jedoch sowohl dem Werk als auch dem in seinem Tagebuch und in seinem Schriftverkehr zutage getretenen Charakter dieses besessenen, in die islamische Kultur verliebten und in vielem auch verspielten Wissenschaftler unrecht (vgl. Goldziher TB, Goldziher B). Goldzihers weitab vom akademischen Apparat betriebene Wissenschaft vom Islam schöpfte - hierin Weber vergleichbar - voll aus dem Ideenreichtum der Gründer- und Umbruchzeit und des sich akademisch durchsetzenden kritischen Historismus.

Für die hier zur Diskussion stehende moderne soziologische Betrachtung von Goldzihers Islamwissenschaft und Webers universalhistorischer Kultursoziologie mag es gerechtfertigt sein, auf einige wenige, vielleicht die theoretischsten Schriften Goldzihers, besonders aus der Zeit des reiferen Wissenschaftlers, zurückzugreifen. In den zwischen 1888 und 1890 erschienenen »Muhammedanischen Studien « beschäftigt sich der Autor in kritischer Gegenüberstellung unterschiedlicher Materialien der Hadith-Literatur mit den sozialen Folgen der 
Ausformulierung und Durchsetzung der islamischen Glaubenslehre. Exemplarische Bedeutung hat die Studie über »Muruwwa« und »Din«, mit der die Gegensätze zwischen heidnisch-arabischen Stammestugenden und der neuen Religion ansatzweise offengelegt werden. Die beduinische Mannestugend war Grundlage der sozialen Regulation innerhalb und zwischen den arabischen Stämmen. Hauptpfeiler der sozialen Ordnung in der weitgehend akephalen, staatenlosen Stammesgesellschaft war die Blutrache. Dagegen lehrte der Islam eine über die Blutsverwandtschaft hinausreichende Form der sozialen Zuordnung des Individuums. Die Grenzlinien zwischen Freund und Feind wurden neu gezogen und damit auch die alten, an die Stammestugenden gebundenen Sinnzusammenhänge neu definiert. Die universelle Solidarität der neuen Religion mußte, wenn schon Blutrache und Stammesfehden nicht zu beseitigen waren, ein neues allumfassendes Zeichen der Brüderlichkelt unter den Gläubigen setzen. Der Rache- und Vergeltungsgedanke bleibt weiterhin wichtig, ja regulativ, neben ihn tritt jedoch das Postulat, ihn unter Glaubensbrüdern durch Vergebung und Liebe zu überwinden. Die Erlösungshaltungen und Heilserwartungen, die die neue Religion weckte, waren darüber hinaus mit Reinheitsgeboten und asketischen Begrenzungen der Lebenslust verbunden, denen die Araber sich widersetzten. So wurde eben versucht, Regelungen wie etwa das Fastengebot im Monat Ramadan oder die körperlich anstrengenden Gebetsübungen und das rigide Verbot des Weingenusses zu umgehen oder offen als Glaubensregel minderer Bedeutung zu bestreiten. Goldziher beschreibt hier sehr farbig die verschiedenen Reaktionen und Argumente der Parteien, die in diesen frühen Disputen über die praktischen Folgen der sich ausformulierenden islamischen Sozialethik auftreten. Seine Beobachtungen sind darüber hinaus jedoch ganz von jenen, den Zeitgeist beherrschenden, in der gerade heraufkommenden Ethnologie und Soziologie wichtig werdenden Widersprüchen zwischen Gemeinschaft und Gesellschaft, Heidentum und Religion, Zivilisation und Wildheit, undeterminierter Universalität und Nationalstaatsbildung geleitet.

In dem 1904 vor dem Congress of Arts and Sience in St. Louis gehaltenen Vortrag - Weber war auf diesem Kongreß anwesend, und man darf die Vorstellung, daß Weber hier als stiller Zuhörer Goldzihers aufgetreten sein mag, nur als eine phantasievolle Bereicherung annehmen - wird Goldziher allgemeiner und stellt Querverbindungen 
zur Methode und zu den Ergebnissen von Nachbardisziplinen wie der Geschichte und der vergleichenden Religionswissenschaft her. »Die Fortschritte der Islam-Wissenschaft in den letzten drei Jahrzehnten « lautete das Thema (vgl. GS IV: 443-469), und Goldziher bezeichnet hier die Anwendung der Methode historischer Kritik als einen wichtigen Schritt vorwärts in der Islamwissenschaft, insbesondere daß die islamischen Texte nun gleichen methodischen Betrachtungen unterzogen werden, wie sie etwa in der Bibelwissenschaft entwickelt wurden. Er begrüßt die neue Einsicht, »daß die traditionellen Zeugnisse der Entstehung und Entwicklung des Islams derselben historisch-kritischen Betrachtungsmethode unterliegen, die uns die moderne Wissenschaft gelehrt hat, z. B. auf die literarischen Zeugnisse des Urchristentums oder auf die ältesten Produkte des rabbinischen Judentums anzuwenden « (GS IV: 444). Die Forderung nach Generalisierung und Systematisierung der Methode greift auf die sich von der vergleichenden Religionswissenschaft her durchsetzende Einsicht zurück, daß die Weltreligionen generalisierbare Verhaltenstypen hervorbringen. Goldziher setzt hier auf die Verwendung von Ergebnissen der vergleichenden Religionswissenschaft, »die für das Verständnis der Entstehung und des Wachstums der religiösen Vorstellungen der Menschheit allgemeingültige völkerpsychologische Gesichtspunkte aufgezeigt hat, die wir uns zum Verständnis der komplizierten Erscheinungen des historischen Islams zunutze gemacht haben " (ibid.). Goldziher hebt in geradezu soziologischer Weitsicht hervor, wie sehr einerseits die Durchforschung der vorislamischen Religion - »die Gefühlswelt und die Institutionen der vorislamischen Araber « (GS IV: 447) - gelungen sei und betont andererseits - in kritischer Anspielung auf die Ironie der modernen Wissenschaft -, daß die kritische Philologie zuerst in der Dogmenbildung des Islams zur Blüte geraten sei: »das älteste Beispiel für solche kritische Tätigkeit in der ganzen Weltliteratur « (GS IV: 450). Die Ironie liegt nun darin, daß auch mit der kritischen Philologie noch »jede Lehr- und Schulmeinung ... sich eine Autorität geschmiedet (hat), die bis in die Zeit des Propheten zurückreicht«(GS IV: 451). Goldziher beschwört das Fatum einer spezialisierten, wissenschaftlich hochgezüchteten Dogmenbildung, nämlich daß sie gegenüber der Glaubenspraxis willkürlich und folgenlos bleibt. Der aus den islamischen Quellen der Tradition entwickelte Rechtskodex stellt sich ihm als »ein Code Napoléon des Islams« (GS IV: 455) dar, der lebensprak- 
tisch wenig wirksam war. Hätte Max Weber - was durchaus möglich war - im Auditorium gesessen, so müßte er gerade bei diesen Ausführungen Goldzihers hellhörig geworden sein: Goldziher weist auf jenes Paradoxon zwischen Wahrheitsanspruch und systematischer Dogmenbildung in Religion und Wissenschaft hin, das für Webers Spätwerk gerade in der Zeit nach 1904 so große Bedeutung gewinnt: Es ist dies das Paradoxon, daß die in Religion, Recht und Wissenschaft sich durchsetzenden und auf Wahrheitsanspruch gegründeten Rationalisierungen von einem Fachspezialistentum verwaltet werden, das diesen Wahrheitsanspruch gegenüber einer ritualistisch regulierten Praxis aufzugeben bereit ist. Dies hat Weber am eindringlichsten in seinem 1919 gehaltenen Vortrag »Wissenschaft als Beruf « dargelegt (WL: 582-613). Das Spannungsverhältnis dieses Paradoxons, folgt man Goldziher und Weber, war der Gelehrtenwelt der islamischen Orthodoxie deshalb fremd, weil sie die zwischen Glaubensformeln und Lebenspraxis auftretenden Widersprüche und Spannungen anstatt auszutragen zu glätten suchte. Die Ausformulierung der islamischen Glaubensdoktrin blieb Schriftwissen, das sich der moralischen Anfechtungen der lokalen Volkstraditionen zu erwehren wußte.

Eine über die Detailfragen seiner Einzeluntersuchungen hinausreichende Darstellung der islamischen Religion liefert Goldziher in seinem 1913 in Uppsala gehaltenen Vortrag »Katholische Tendenz und Partikularismus im Islam« (GS V: 285-312). Goldziher konstatiert hier »den vollständigen Mangel eines dogmatischen Triebes «, der für die Gestaltung des Verhältnisses von Islam und Gesellschaft von ausschlaggebender Bedeutung sei. Das Streben zur Einheitlichkeit habe im Islam nicht dazu geführt, »die Tolerierung »berechtigter Eigentümlichkeiten « auszusetzen (GS V: 285). Dies hat zu der Uneinheitlichkeit der religiösen Vorstellungen, der Ausbildung des Ritus und der Begründung der ersten Lehrmeinungen geführt. Auf im wesentlichen bereits von Wellhausen, Caetani und Lammens entwickelte Thesen zurückgreifend werden vornehmlich politisch-ökonomische Antriebe zur Ausbreitung des islamischen Reiches und zur Entwicklung seiner Eroberungsdynamik geltend gemacht. In seiner Frühphase war der Islam für Goldziher, »eher eine Kriegsparole als eine Doktrin « (GS V: 286). Recht und Gesetz entwickeln sich aus provinziellen Kontexten heraus. Und wo generelle Festsetzungen getroffen werden und eine schulmäßige Behandlung der Lehrmeinungen zu ersten Verallgemeine- 
rungen führen, werden örtliche Unterschiede und widersprüchliche Traditionen toleriert. Goldziher weist auf seinen in den »Muhammedanischen Studien « erschienenen Aufsatz über die Entwicklungen des Hadith hin: Das islamische Traditionswesen - die Grundlagen des islamischen Rechts setzend - entstand aus dem lokalen Kontext verschiedener Gelehrtenschulen, die über Generationen hinweg in den Zentren der frühislamischen Gelehrsamkeit (etwa Kula, Basra, Medina) sich entwickelten. Diese Schulen passen ihre Ideen den Läufen der Welt an: »Ein hervorragender Zug der islamischen Theologie ist die Anerkennung des historisch gewordenen, des fait accompli, wodurch infolge fortgesetzter langer Übung und allgemeiner Verbreitung mit der Zeit oft sogar auch Islamwidriges zum religiösen Brauch, zur Sunna, zur verpflichtenden Tradition umgestempelt wird« (GS V: 290). Mittels der »adat-Rechte" wurde zugleich auch »ein Dualismus der Rechtsprechung « akzeptiert: die gleichzeitige Anerkennung weltlicher Gerichtsinstanzen auf der einen und religiöser auf der anderen Seite (GS V: 294).

Weber spricht in seiner Rechtssoziologie von einem »Dualismus weltlicher und geistlicher Rechtspflege « überall in den großen islamischen Reichen (W. u. G.: 476) und von einer

»mangelnden formalen Rationalität des Rechtsdenkens vor allem auch die Unmöglichkeit einer systematischen Rechtsschöpfung zum Zweck der inneren und äußeren Vereinheitlichung des Rechts.«

(W. u. G.: 475)

Die Toleranz, ja die geradezu theoretische Begründung der Anerkennung des Dissenses in der islamischen Theologie und Rechtsprechung, dieser »Mangel eines dogmatischen Triebes, hat zu Verhältnissen geführt,

»wo die Uniformierung nicht Resultat theoretischer Erwägungen, sondern zumeist das äußerer Gewalt und weltlichen Zwanges war, für den dann die Theologen - nach dem oben erwähnten Gesetz vom fait accompli - hinterher ihre Theorie zu zimmern pflegten, gleichsam gute Miene zum bösen Spiel machend.«

(GS V: 303$)$. 
»Da der Islam die Lehre vom Konsensus (igma') als Prüfstein der religiösen Korrektheit « (GS V: 310) ursprünglich auf die große Kollektivität der Bekenner bezog, wurde dieses Prinzip zum Grundpfeiler der Orthodoxie und der Loyalität erhoben und auf die erreichbare Konstatierung der Übereinstimmung der großen Lehrautoritäten der Vergangenheit beschränkt. Das Prinzip des igma' hat in der islamischen Geschichte eine eher schillernde Existenz geführt; es ist dennoch bis heute zu einem Grundpfeiler des Diskurses zwischen Religionsgelehrten, Rechtsgelehrten und Muslimen geworden. Außerordentlich weitblickend fügt Goldziher hinzu:

»In seiner gegenwärtig und schon seit langer Zeit gültigen Definition wird sein Wesen nicht in die aktuellen Lebensverhältnisse der islamischen Weit, sondern vielmehr in eine abgestorbene Vergangenheit verlegt. Die lebensfähige Reform des Islams hängt in theologischem Sinne nicht zum geringsten von einer Neugestaltung dieses Begriffes ab.«

(GS V: 312)

Man darf, blickt man aus der Perspektive Webers auf das Goldzihersche Werk, die Ausführungen zum islamischen Asketismus nicht vergessen.

Für Mohammed und seine ältesten Schüler war das Christentum vor allem mit der Vorstellung eines moralischen Asketentums verbunden, das sich von der irdischen Welt abhob, ganz auf das himmlische Königreich ausgerichtet war und daher wenig mit dem kriegerischen Geist und den Kampfinstinkten der Araber zu verbinden war, die diese in der Jugend des Islams besaßen (GS II: 314). Zu allen Zeiten habe der islamische Geist auf vollständige Hingabe zu Gott bestanden. Sie bedeutete Heiligung des Lebens. Nicht im Verzicht auf irdische Güter, sondern in allen weltlichen Handlungen und Bewegungen müsse sie sich manifestieren. Nur die Beachtung der göttlichen Gesetze vervollkommne den Menschen. Islam bedeutet so zwar die Zurückweisung aller jener Güter, die Gott uns vorenthält, aber auch zugleich das vollständige und bejahende Vergnügen jener Güter, die Gott uns gewährt (ibid.):

»S'il est vrai que le portrait qu'une communauté réligieuse trace de son fondateur est caractéristique de ses tendances et de sa conception du monde, on ne 
saurait méconnaitre l'importance du trait qui se retrouve en général dans toutes les descriptions du Prophète: >Il ne s'abstenait pas des liens que Dieu a permis; il aimait le miel et les douceurs

(Ibid.)

Andererseits stellt die islamische Mystik eine Wiederbelebung asketischer Tendenzen dar. Die bereits von Alfred von Kremer (1868) im ersten Buch seiner »Herrschenden Ideen des Islams « getroffene Feststellung eines christlich-asketischen Einflusses in der frühen Phase der islamischen Mystik, die eben noch ganz unter dem Einfluß des christlichen Mönchs- und Einsiedlerlebens steht, belegt Goldziher in seinem 1898 erschienen Aufsatz "De l'ascétisme aux premiers temps de l'islam « (GS IV: 159-169) mit einer Reihe von Beispielen einzelner asketischer Übungen. Dieses Bild der Bedeutung des Asketentums in der Frühphase des islamischen Sufismus ergänzt Goldziher in seinen "Vorlesungen über den Islam (Heidelberg 1910) durch Hinweise etwa auf Anlehnung der ältesten Sufisten an das Neue Testament, aber auch auf Formen der praktischen Lebensführung und der Liturgie. In dieser Anfangsstufe des Sufismus scheinen eine Überhöhung des Gottvertrauens (tawakkul) und die ärmliche äußere Erscheinung wie das Tragen eines groben Wollkleides einem religiösen Quietismus das Wort geredet zu haben, der den Sufismus von jeder auf die Veränderung der Lebenspraxis gerichteten Ausdeutung der Glaubensdogmatik abhielt. Die Bejahung des Vergnügens am Leben führt zur frühen $\mathrm{Zu}-$ rückweisung des Asketismus und des Mönchstums im alten Islam. Goldziher sieht in der klaren Aussage »a rahbaniyya fil-islam « eine unmittelbare Reaktion auf die Eremitenbewegung im orientalischen Christentum. Die Opposition zum orientalisch-christlichen Asketismus der Eremitenbewegung läßt sich auch in der Haltung des Islams zur Sexualität nachweisen. Dabei ist die Zurückweisung des Zölibats nur ein Aspekt unter vielen. Die besondere Bedeutung der Heirat und die besondere schutzbedürftige Stellung der Frau in der Familie, aber auch im sozialen Leben als Ganzem, sind weitere bedeutende Elemente dieser antiasketischen islamischen Haltung. Dabei ist die traditionelle islamische Glaubensdoktrin, daß derjenige, der in der Verteidigung seiner Güter getötet wird, zugleich auch als Märtyrer (shahid) anzusehen sei, ein weiteres Beispiel für die religiöse Bejahung der Lebenspra- 
xis des Islams. Goldziher bringt dies generalisierend zum Ausdruck, wenn er sagt:

»Toutes ces doctrines s'inspirent d'un esprit foncièrement réaliste, appropriaux besoins du monde et aux conditions de la vie sociale, libre de toute disposition monacale ou de toute tendance ascétique.«

(GS II: 318)

Mit seinem Artikel über den christlichen Einfluß im religiösen Denken des Islams macht Goldziher erneut deutlich, wie sehr die subtilsten Auseinandersetzungen in der Entwicklung der religiösen Glaubenslehren der Weltreligionen Christentum, Judentum und Islam für die Positionsbestimmung des Übergangs zur Moderne, des Übergangs zum okzidentalen Rationalismus von Bedeutung sind. Goldziher geht es darum aufzuzeigen, wie groß die Toleranz der islamischen Glaubenslehre gegenüber den vielfältigen Erscheinungsformen des praktischen Alltagslebens der Gläubigen gewesen ist. Daß diese Toleranz in einem modernistischen, christlich-abendländisch geprägten Interpretationsschema vor allem als ein unterentwickelter Barbarismus erscheinen mag, kann man Goldziher selbst nicht anhängen. Er war sensibel genug, in all seinen universalistischen Auslegungen der islamischen Religion bereits im Ansatz solchen modernistisch einseitigen Interpretationssträngen entgegenzuwirken.

Ignaz Goldziher ist eine Persönlichkeit, die außerordentlich ungeeignet ist, in den Geruch des praktischen Komplizentums mit Kolonialismus und Imperialismus gesetzt zu werden. Auch solche an den Haaren herbeigezogenen und aus dem Kontext herausgerissenen Feststellungen, Goldziher habe zwar einer gewissen Sympathie für die islamische Religion nicht entbehrt, jedoch zusammen mit anderen Orientalisten den Koran lediglich als ein Buch Mohammeds aufgefaßt und andere »statements that are distinctly offensive to Muslims « gemacht, entbehren sowohl jeglichen Feingefühls für die historischen Rahmenbedingungen der erwachenden Islamwissenschaft als auch für die zivilisatorische Ausgangslage, die der Zeitgeist des ausgehenden 19. Jahrhunderts in der Begründung der modernen Kultur als derjenigen des abendländischen Nationalismus hat (Fluehr-Lobban 1987, App. 1). Man darf deshalb auch solch generalisierende Behauptungen zurückweisen, wie sie etwa Edward Said anbringt. 
»Yet Ignaz Goldziher's appreciation of Islam's tolerance towards other religions was undercut by his dislike of Mohammed's anthropomorphismus and Islam's to exterior theology and jurisprudence.«

(Said 1978: 209)

Das zentrale Thema der Goldziherschen Studien über den Islam liegt dort, wo dieser selbst einen völligen Bruch mit der mythologischen Vergangenheit eingeht. Es geht Goldziher darum herauszuarbeiten, wie der Islam einem Prozeß der fortschreitenden Formulierung seines Glaubens- und Rechtssystems durch ein sich höher entwickelndes religiöses Bewußtsein unterliegt. Dies ist ein zentraler thematischer Schwerpunkt der Weberschen Religionssoziologie. Es ist der Prozeß der graduellen Ausformung, der auch das Thema von Goldzihers Studien ausmacht. Es geht ihm dabei um die fortdauernde Spannung zwischen heidnischer Umgebung und Sophistikation der religiösen Lehre, denen der Islam unterlag. Goldzihers Verständnis der weiteren dogmatischen und religiösen Rechtsentwicklung ist von der Einsicht geprägt, daß diese religiösen Lehren historischen Gesetzen und Entwicklungen unterliegen und durch die innere Logik historischen Bewußtseins sich wandeln. Man darf heute mit Recht sagen, daß gerade die inneren Spannungen, die Goldziher im Zusammenhang der religiösen und der historischen Entwicklung aufspürte, zu einer bis heute unerreichten orientalistischen Wissenschaft führten, daß sie ein Wissen über den Islam produzierten, das von muslimischen wie von christlichen Gelehrten gleichermaßen Anerkennung verdient.

\section{III}

Webers universalgeschichtlicher Vergleich der Weltreligionen steht ganz unter dem in der Vorbemerkung zur »Protestantischen Ethik « (RS I: 1-16) formulierten Postulat, nach dem die Einzigartigkeit, die ausgezeichnete Stellung der Moderne, die ja selbst erst universell gültige Maßstäbe gesetzt hat, in ihren historischen Voraussetzungen zu untersuchen ist. Folglich ist auch das Problem der Differenz zwischen östlichen und westlichen Kulturen lediglich unter dem Gesichtspunkt »des welterschütternden Prozesses der Rationalisierung zu untersuchen « (Robertson 1982: 8). Damit ist den orientalischen Religionen nicht grundsätzlich jede Tendenz zur Rationalisierung abgesprochen. 
Doch nur der asketische Protestantismus hat die praktische Rationalisierung aller Lebensbereiche in einer Weise vollzogen, die von universeller Gültigkeit zeugt. Wie die Islamwissenschaft Ignaz Goldzihers setzt auch die Webersche Religionssoziologie zwei Maßstäbe, mit denen unterschiedliche Stufen der lebenspraktischen Systematisierungen, die Religionen hervorrufen, vergleichbar werden: 1. der Grad der Überwindung der Magie, 2. der Grad der Systematisierung und Vereinheitlichung des Verhältnisses zwischen Gott und Mensch und der dadurch bewirkten moralischen Einstellung zur Welt. Die zuerst von den Religionen bewirkte "Entzauberung der Welt « gipfelt im Protestantismus in der konsequenten Verteufelung alles Magischen, während die Religion als letztlich wertvoll nur noch das praktisch-rationale Handeln anerkennt, »das sich in Gottes Gebot, aus der gottgeheiligten Gesinnung heraus « (RS I: 513) rechtfertigt. Mit der »Entzauberung der Welt « muß ein neues Verhältnis zu den praktischen Dingen geboren werden, ein "Weltbild «, in dem die psychologischen und pragmatischen Zusammenhänge zur Bedeutung gelangen und damit zugleich auch die auf die menschliche Antriebsstruktur als Ganzes wirkenden Anreize für praktisches Handeln (Schluchter 1976: 261).

Im »Weltbild « der puritanistischen Ethik sieht Weber ein pathetisches Spannungsverhältnis entstehen, stärker ausgeprägt als bei allen anderen Religionen, ein Bild der Welt, in dem die rational ethischen Forderungen in ihrem Spannungsverhältnis zu den Irrationalitäten der praktischen Welt sich zu bewähren haben (RS I: 513). Am Beispiel des Konfuzianismus macht Weber deutlich, daß der in dieser Religion geprägte Intellektualismus sowohl auf ein Minimum der religiösen Entwertung als auch auf jede praktische Ablehnung der Welt verzichtete. Während die ethischen Konzeptionen des Puritanismus und Protestantismus die religiöse und ethische Entwertung dieser Welt betrieben, haben sie doch andererseits in der radikalen Konzentration auf

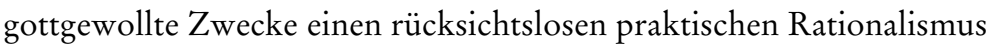
hervorgebracht. Dieser ist nach Weber auch Grundlage für eine methodische Konzeption, etwa der Betriebsführung. Er pflegt den Abscheu gegen illegale politische, koloniale und auf Menschengunst beruhende Monopolisierungen; ja im Gegensatz dazu bringt er eine nüchterne, strenge Legalität und eine gebändigte rationale Energie des Alltagslebens hervor. Mit der religiösen Entwertung der Welt entstanden im christlichen Weltbild ethische Konzeptionen, die jenen Geist des Be- 
rufsmenschentums begründeten, der auf eine praktische Bejahung der Welt im Sinne einer religiös systematisierten und rationalisierten, auf Zweckmäßigkeit und religiös begründeter Arbeitswilligkeit beruhenden Weltbeherrschung zielte. Dagegen wendet Weber den Begriff der »Weltverneinung «, begründet in verschiedenen Stufen und Richtungen religiöser Weltablehnung, als den eigentlichen »Nihilismus « allein auf die »indische Religiösität« an. Da Weber im wesentlichen nach den »innerlich konsequentesten Formen eines aus festgegebenen Voraussetzungen ableitbaren praktischen Verhaltens « (RS I: 337) sucht, wurde auch die Haltung der religiösen Weltablehnung nur unter diesem Gesichtspunkt behandelt. Die Weltflucht begründet sich als gottgewolltes Handeln, als ein Handeln, das sich des Heilsbesitzes bewußt ist und auf die Verwirklichung desselben drängt. Dem steht der kontemplative Heilsbesitz der Mystik gegenüber, der nicht eigentliches Handeln begründen will, sondern nur irrationalen und außerweltlichen Heilserfahrungswert. Damit treten innerweltliche Askese, die sich durch Handeln bewährt, und mystische Askese, nämlich Heilssuche, die sich in Schweigen hüllt, damit Gott sprechen kann, in einen idealtypischen Gegensatz zueinander.

Völlig atypisch und in den hier aufgezeichneten Widerspruch der Idealtypen nicht einzufügen ist der Islam, der in seiner Frühform die Askese direkt verwirft und auch in der Ausprägung der »DerwischReligiosität ganz anderen (mystisch-ekstatischen) Quellen entstammt als der Beziehung zum überweltlichen Schöpfergott « (RS 1:538). Diese mystisch-ekstatischen Quellen der islamischen Mystik stehen jedoch, wie Weber betont, der okzidentalen Askese auch ihrem inneren Wesen nach völlig fern. Damit gerinnt der Islam und die von ihm hervorgebrachte religiöse Ethik insgesamt zu einem sich insofern verflüchtigenden »Weltbild « als dieses für die universalgeschichtliche Perspektive Webers idealtypisch belanglos bleibt. Es entsteht das Bild, daß die ekstatisch-mystischen Quellen auch in der Zeit des späten Islams einer rationalen Systematisierung der Lebensführung entgegenstanden. Sofern Lebensreglementierung auftritt, so bleibt diese - in der Weberschen Perspektive - von der islamischen Glaubensmethodik und der durch sie vermittelten Heilserwartung insofern getrennt als mit ihnen das Streben nach praktischen »Heilsgütern « nicht geweckt werden kann.

Weber streitet der religiösen Idee des neuen Islams die Kraft der le- 
benspraktisch wirksam werdenden Innerlichkeit ab. Der Islam tritt aus der Dialektik des puritanischen Doppelgesichts heraus, das da heißt: »Weltablehnung einerseits, Weltbeherrschung kraft der dadurch erlangten magischen Kräfte andererseits « (RS 1: 540).

Es ist hier eben auch vor allem die sufistische Gottesliebe, in der jene »spezifisch anti-rationale innere Haltung ... einer Religion des schrankenlosen Gottvertrauens, welche zuweilen bis zu akosmistischer Indifferenz gegen verstandesmäßig praktische Erwägungen « führt, wirksam wird (W. u. G.: 343, 345).

Rationalismus bedarf nicht nur der Innerlichkeit, sondern auch der Diesseitigkeit. Aber »religiöse Ethik greift ... in die Sphäre der sozialen Ordnung sehr verschieden tief ein « (W. u. G.: 349), und wenn die Doppelgesichtigkeit dieser magischen und schicksalhaften Verbindung zwischen Innen- und Außenherrschaft nicht gegeben ist, fehlen die habituellen, die persönlichen, die inneren Voraussetzungen zu gesellschaftlicher Rationalisierung. Vornehmlich unter diesem Gesichtspunkt bleiben die hervorragendsten Vertreter der Prädestinationslehre, Calvin und Mohammed, der Puritanismus und der Islam, unmittelbar vergleichbar. Unter diesem Gesichtspunkt der Außenweltbeherrschung sind plötzlich die islamische Kriegerethik und der ethische Rigorismus sowie die rationale Lebensmethodik der Puritanisten vergleichbar: "Disziplin und Glaubenskriege waren die Quelle der Unüberwindlichkeit der islamischen, ebenso wie der Cromwellschen Kavallerie, innerweltliche Askese und disziplinierte Heilssuche im gottgewollten Beruf die Quelle der Erwerbswirtschaft bei den Puritanern" (W. u. G.: 346f.). Die islamische »Prädestinationslehre« kannte eben, wie Weber sich ausdrückt, jenes doppelte Dekret nicht, das das Außen mit dem Innen verbindet. Sie kannte nicht »die Prädestination zur Hölle«, ebensowenig, wie sie »die Determination des religiösen Jenseitsschicksals des Einzelnen« voll entwickelte. Dann bleiben ihr »die rationalen Elemente des > Weltregiments « weitgehend fremd « (W. u. G.: 347).

»Daher entfaltete die Prädestination im Islam ihre Macht stets erneut in den Glaubenskämpfen, wie noch in denen des Mahdi, büßte sie dagegen mit jeder ,Verbürgerlichung des Islams ein, weil sie keine inneralltägliche Lebensmethodik stiftete wie im Puritanismus, wo die Prädestination gerade das Jenseitsschicksal betraf und also die scertitudo salutis gerade an der inneralltäglichen 
Tugendbewährung hin, daher allein mit der Verbürgerlichung der Religiosität Calvins ihre Bedeutung gegenüber dessen eigenen ursprünglichen Anschauungen stieg.«

(W. u. G.: 347)

Während die puritanische Innerlichkeit auf das »Jenseitsschicksal« gerichtet bleibt, deutet Weber an, wie etwa in der Omaijaden-Zeit der islamische Prädestinationsglaube einer »Wendung zur Determination konkreter Weltvorgänge « unterliegt und damit den »ethisch-rationalen Charakter « einer Prädestinationslehre tendenziell verliert (ibid.). Das dabei bereits von Goldziher oft hervorgehobene politische Opportunitätsdenken Mohammeds spielt auch bei Weber eine zentrale Rolle. Man fühlt sich an Verteufelungen des frühen Romantikers Schlegel erinnert, wenn dem Islam generell die innere Erlösungskraft abgesprochen wird:

»Der Begriff der >Erlösung< im ethischen Sinn des Wortes ist ihm direkt fremd. Sein Gott ist ein unbegrenzt machtvoller, aber auch ein gnädiger Herr, und seinen Geboten zu entsprechen, geht durchaus nicht über Menschenkraft. Die Beseitigung der Privatfehde im Interesse der Stoßkraft nach außen, der Regulierung des legitimen Geschlechtsverkehrs im streng patriarchalischen Sinn und die Verpönung aller illegitimen Formen (infolge des Fortbestandes des Konkubinats mit Sklavinnen und der Leichtigkeit der Scheidung faktisch eine ausgeprägte sexuelle Privilegierung der Begüterten), die Verpönung des >Wuchers sowie die Abgaben für den Krieg und die Unterstützung Verarmter waren Maßregeln wesentlich politischen Charakters.«

(W. u. G.: 375)

Es ist eben vor allem die Vorstellung der Sündenlosigkeit dieser Religion und ihres Propheten, die das Islambild Webers bestimmt:

»Die Selbstverständlichkeit der Sklaverei und der Hörigkeit, die Polygamie und die Art der Frauenverachtung und -domestikation, der vorwiegend ritualistische Charakter religiöser Pflichten, verbunden mit großer Einfachheit der hierher gehörenden Ansprüche und noch größerer Bescheidenheit in den ethischen Anforderungen sind ebensoviele Merkmale spezifisch ständischen feudalen Geistes. «

(W. u. G.: 375) 
Und so wie das »Eindringen des Heiligenkults und schließlich der Magie« von eigentlicher Lebensmethodik abführt (W. u. G.: 376), so nutzt Weber an anderer Stelle zugleich auch die islamwissenschaftlichen Diskussionen Alois Sprengers und Ignaz Goldzihers etwa über die Verpönung schriftlicher Tradition und die möglicherweise damit verbundene Willkürlichkeit und mangelnde Einheitlichkeit der Überlieferung (Goldziher, Muh. Stud. III; Sprenger 1856-57) zu dem Hinweis, daß dem Islam weitgehend der »Anstaltscharakter der religiösen Gemeinschaft« fehle (W. u. G.: 459f.). Hier wird also angedeutet - und wie später in den Studien zur Rechts-, Wirtschafts- und Stadtentwicklung im Islam stärker ausgearbeitet -, daß nicht nur innere Bedingungen der Glaubenslehre, sondern auch äußere Faktoren der glaubensgemeinschaftlichen und sozialen Organisation Grundelemente der rationalistischen Entwicklung sein können. Dabei geht Weber dann allerdings die Doppelperspektive verloren, die er für seine verstehende Soziologie, insbesondere in der Protestantischen Ethik, entwickelt hatte: Für den Islam treten die äußeren Bedingungen stärker in den Vordergrund (Turner 1974). Unsere Überlegungen beschränken sich auf Webers soziologische Interpretationen der "Erlösungsethik « des Islams. Hier zeichnet das Webersche Islambild Konturen eines islamischen Monotheismus, der sich nicht in eine diesseits gerichtete asketische Religion transformierte. Die ihn tragende Schicht der Kriegerkaste konnte nur eine äußerliche, unmittelbare Form der Weltbeherrschung entwickeln. Die religiöse Botschaft des Islams glich sich zunehmend einer Reihe von Werten an, die lediglich auf die weltlichen Bedürfnisse dieser Kriegerschicht ausgerichtet war. Das Erlösungsmoment des Islams war in die weltliche Frage nach der Eroberung von Land und Territorium umgesetzt worden. Und in der Phase der Verteidigung des Eroberten entwickelte sich der Islam zu einer Religion der universellen Vereinigung, zu einer Religion der Behaglichkeit und des Sich-Einrichtens in der Welt, zu einer Religion des Bewahrens, nicht zu einer Religion des Bedrohens bestehender Institutionen, des Übergangs, des Wandels.

Die rigide und unbestechliche Form des mechanischen Monotheismus wurde schließlich vom Sufismus aufgeweicht und den emotionalen und orgiastischen Bedürfnissen des Volkes angepaßt. Während die Kriegerkaste den Islam zu einer Ausformung ihrer kriegerischen Ethik benutzte, wurde der Islam unter dem Einfluß des Sufismus für die 
Massen des Volkes zu einer Religion der mystischen Flucht. Gerade darin sah Weber den Beweis, daß der Islam keine Ethik entwickelt habe, die sich mit dem Aufkommen des rationalen Kapitalismus als kompatibel erwies.

Darüber hinaus hat der Islam keine unabhängige Priesterschaft hervorgebracht. Es fehlt ihm die Institution der Kirche, es fehlt ihm der Anstaltscharakter, den eine Religion braucht, um in einem organisatorischen Sinne Grundlagen gesellschaftlicher Rationalisierung zu schaffen. Goldziher hat darauf hingewiesen, daß das gute Glück den Egoismus der arabischen Krieger beflügelt habe, daß es ihr Selbstvertrauen bestärkt habe und daß es schließlich wenig darauf angelegt war, sie zu tiefen religiösen Gefühlen zu bewegen (MS I: 13).

Damit ist in wenigen Worten angezeigt, was man als eine Form kultureller Resistenz der beduinischen Araber gegen die zivilisatorischen Anstrengungen, aber auch Kolonialisierungen der neuen Religion bezeichnen kann. Goldziher war sich bewußt, daß es Mohammed gelang, den beduinischen Lebensstil innerhalb der islamischen Religion zu reinigen und zu heiligen und damit als affirmatives Kulturmuster innerhalb der islamischen Zivilisation fortzuführen. Mohammed befolgte das Prinzip des »la din illa bi muruwwa " (keine Religion ohne beduinische Tugend). Diese ungebremste kulturaffirmative Kontinuität des arabischen Heidentums innerhalb der Religion des Islams ist das eigentliche Anathema zu einer modernen Zivilisationstheorie und daher in der Konstruktionsphase des okzidentalen Rationalismus und der modernen Kultur das grundlegende und unterscheidende Klassifikationsmerkmal, mit dem am Beispiel der islamischen Geschichte operiert wird. Abgekürzt lautet es wie folgt: Der Islam war von einer beduinischen Stammeskultur und ihren Traditionen beherrscht. In der Aufnahme dieser Traditionen blieb er barbarisch, wild und heidnisch. Der Islam reintegrierte Kulturtraditionen der Antike, des Judentums und des Christentums, und nur insofern ihm diese Reintegration gelang, entwickelte er sich $\mathrm{zu}$ einer eigenständigen zivilisatorischen Macht. Aber diese Form der Klassifikation bedeutete natürlich in ihrer komplementären Umwendung: Der Islam bestätigte die Identität und Authentizität der arabischen Stammeskultur und damit das Arabertum und auch die Kriegerethiken des Beduinentums, die den eigentlichen Enthusiasmus begründeten, mit dem das neue religiöse Denken durch die mit dem Schwert erzwungenen Eroberungen in die mediterranen 
Hochkulturen hineingetragen wurde. Und erst durch die Wiedererrichtung zivilisatorischer Mächte, gewissermaßen als Fremdkörper im neuen enthusiastisch-islamischen Arabertum, durch Übernahme und Routinisierung von Strukturen und Formen der Herrschaft altorientalischer Kulturen entstehen auch die Elemente der späteren Dekadenz des islamischen Reiches. In der Strukturierung des Verhältnisses von um Schlegels Wort aufzugreifen - »natürlicher Religion« der Araber und altorientalischem Despotismus liegt für die deutsche Kulturgeschichte der Schlüssel zum Niedergang der islamischen Zivilisation. Es war gerade C.H. Becker, der spätere preußische Kulturminister, der Islampolitiker (Schulze 1982; Heine 1984; vgl. auch van Ess 1980: 2734 und 471), der diese beiden Perspektiven kombinierte und sozusagen $\mathrm{zu}$ einem vollständigen Bild vereinigte und unter der Vorstellung einer »islamischen Weltanschauung" propagierte (Becker 1924: 40-53). Weber hat dies aufgegriffen und als Kulturbild übernommen.

\section{IV}

Goldziher und Weber pochen auf die Besonderheit und Einzigartigkeit der in der islamischen Glaubenslehre angelegten und sich religiös begründenden Haltung zur Welt. Beide, der Orientalist und der Soziologe, bestätigen den im Prinzip offenen Charakter dieser Glaubenslehre: Ergebnis des historischen Wachstums und der Auseinandersetzung mit vorgefundenen philosophischen und religiösen Weltbildern. Beide erkennen auch das Paradox der islamischen Religionsgeschichte, nämlich daß als Gegenpol dieser Offenheit eine orthodoxe Gelehrtenschicht skripturalistisch, textifiziert und ritualistisch einen Kanon verwaltet, der als weitgehend ideelles System mit der Lebens- und Religionspraxis lokaler Gemeinschaften nichts zu tun hatte, ja harmonisierend und tolerierend über diese gestülpt wurde (vgl. Simon 1986: 153). Beide waren in ihren Betrachtungen des Islams von der Frage geleitet, welche spezifischen inneren und äußeren Konturen der Rationalisierung durch die islamische Form der religiösen »Entzauberung « der Welt hervorgebracht wurden.

Der eine, Goldziher, obwohl ganz in den Zeichen der Zeit denkend, orientiert sein Interesse am Detail der Quelle, am Kulturunterschied des in der Quelle zutage tretenden Phänomens. Ihm, dem Orientalisten, gerinnt in der versöhnenden Betrachtung des Toleranz- und 
Wertgebarens der orthodoxen Gelehrtenexistenz der Islam - fast möchte man sagen - zu einer alternativen Lebensform der Moderne. Der andere, Weber, die Grenzen des philosophischen und religionswissenschaftlichen Fachverstands überschreitend, scheint - aus unterschiedlichen fachlichen Wissensbeständen schöpfend - thematisch eingefangen von den weltanschaulichen Anforderungen seiner Zeit und bleibt sich des Widerstreits der Kulturen in der Moderne bewußt. Dem Kultursoziologen Weber - Wertfreiheit postulierend und selbst um den Erhalt letzter Werte ringend (vgl. Stauth 1990b) - bleibt der innere Kampf der islamischen Orthodoxie um den Erhalt der religiösen Weltsicht und die Lösungen, die sie findet, fremd. Er sieht die inneren Voraussetzungen für eine rationalistische Bürokratie im Islam nicht gegeben. Wie sehr er auch im »stählernen Gehäuse« des okzidentalen Rationalismus den Sinn für die letzten Werte bedroht sieht, kann er doch der islamischen Lösung der außerweltlichen Wertbestimmung der Lebenspraxis keinen Gefallen abringen. Für Weber ist der Islam Antithese zur modernen Lebensweise.

Die Weber-Forschung zum Islam hat sich, ausgehend von Rodinsons Zurückweisung der Protestantismusthese (1968), zu stark auf die Bestätigung oder Entkräftung einzelner Konturen des Weberschen Islambildes beschränkt (vgl. Turner 1974, 1978; Schluchter 1987b). In Tibis Ansätzen zu einer aktuellen Soziologie des Islams setzt sich das Webersche Koordinatensystem implizit fort. Der Islam erscheint als eine in der Moderne revitalisierte "vorindustrielle Kultur, die im Kontext der innergesellschaftlichen und der globalen Spannungen durch Rückständigkeit und Unterentwicklung neue gesellschaftliche Funktionen übernimmt. Im Fundamentalismus drängen sich diese Funktionen jedoch als eine fatale »Politisierung des Sakralen « (Tibi 1985: 157ff.) auf: Der Islam verschärft die in der Gesellschaft angelegte mangelnde funktionale Differenzierung (Tibi 1981, 1985). Tibi plädiert für » Änderungen an dem islamischen kulturellen System « (Tibi 1985: 242).

Mit der Verdammung des Weberschen »Eurozentrismus « gerieten auch die deutschen Islamwissenschaftler, auf die sich Weber stützte, ins Feuer der Kritik. Die Aktualität Goldzihers liegt m.E. darin, daß ihm dieser Vorwurf des Eurozentrismus guten Gewissens nicht gemacht werden kann. Goldziher, im Gegensatz zu Becker und Weber, hielt seine Studien aus dem Streit heraus, den die Islampolitik etwa seit 
der Debatte zwischen Afghani und Renan über die Kulturwerte der Moderne vom Zaun zu brechen begann. Das Bild von der intellektuellen Kraft und der universalistischen Toleranz, das Goldziher vom frühen Islam und der sich formierenden Orthodoxie zu zeichnen in der Lage war, geriet erst in der Weberschen Umdeutung zum Anathema der Moderne und in der islampolitischen Beschwörung frühfundamentalistischer Tendenzen im Islam neuerdings in den Hintergrund religionssoziologischer Betrachtung (vgl. z.B. Freund 1987 und Peters 1987). Goldziher war der einzige der klassischen Islamwissenschaftler, dem bewußt blieb, daß die islamische Kultur nicht unter dem Gesichtspunkt der Departmentalisiening von Glaubensdoktrin, Theologie, Recht und profanen Wissenschaften zu stellen ist. Ihm war gerade die ungeheure Integrationskraft ein Rätsel, die der Islam gegenüber allen Phänomenen des praktischen und geistigen Lebens auszuüben in der Lage war. Mit solchen Affirmationen des Ichs in der Welt, mit der kulturellen Verschonung alles Ungebändigten, »Niederen «, die der Islam scheinbar problemlos leistete, konnte andererseits der modern, der soziologisch denkende Weber, dem gerade das Spannungsverhältnis zwischen Individuum und Gesellschaft ein unlösbares schien, wenig anfangen.

\section{Abgekürzt zitierte Schriften}

Nachfolgend sind die Abkürzungen erläutert, mit denen die Schriften Goldzihers, Nietzsches und Webers zitiert worden sind. Die ausführlichen Angaben befinden sich im Gesamtliteraturverzeichnis.

Goldziher:

$\begin{array}{ll}\text { B } & \text { Goldziher (1985) } \\ \text { GS } & \text { Goldziher (1967-74) } \\ \text { MS } & \text { Goldziher (1967-1971) } \\ \text { Muh. Stud. } & \text { Goldziher (1888-1890) } \\ \text { TB } & \text { Goldziher (1978) }\end{array}$


Nietzsche:

KA Nietzsche (1980)

Weber:

RS Weber (1947)

W. u. G. Weber (1980)

WL Weber (1968) 


\section{Anmerkungen zur Soziologie des Islams}

Die fachsoziologische Analyse des Islams setzt mit dem Werk Max Webers ein, mit der Religions- und Rechtssoziologie (Weber 1980: 446ff., 474ff.). Weber identifizierte zwei grundsätzliche Unterschiede gegenüber dem Christentum: erstens den Mangel an einer Ethik der innerweltlichen Askese und zweitens die religiöse Stützung patrimonialer Pfründen-Verhältnisse, die die Entstehung des Privateigentums und eines bürgerlichen Rechtsstaats verhindern. In beiden Bedingungen sieht Weber auch den Grund der Abwesenheit kapitalistischer Wachstumsbedingungen.

Was man herkömmlicherweise »Soziologie des Islams « genannt hat, sind Studien und theoretische Beiträge, die sich auf die Bestätigung oder die Zurückweisung dieser beiden Thesen Max Webers beschränken und damit im Dualismus und Komparativismus des Modernisierungsdenkens verhaftet bleiben (Rodinson 1971; Zubaida 1972; Turner 1974; Schluchter 1987). ${ }^{1}$

In Frankreich und in der angelsächsischen Welt sind jedoch - oft parallel hierzu - schon früh auch Studien entstanden, die davon ausgehen, daß der Islam selbst eine besondere Gesellschaftslehre beinhalte (Roberts 1990; Charnay 1977). ${ }^{2}$ Auch konnte gezeigt werden, daß die sozialen Gebote des Koran und der kanonischen Texte in den zeitlichen und räumlichen Dimensionen der Ausbreitung des Islams zu einer Vielfalt sozialer und politischer Praxis geführt haben (Geertz 1971).

Ein weiteres Gebiet stellt die soziologische Beschäftigung mit islamischen Sektenbewegungen dar $^{3}$ und später - und im Zusammenhang damit - die Analyse der islamischen politischen Bewegungen der 1970er und 1980er Jahre. Es lassen sich hier zwei Hauptrichtungen bestimmen: erstens die Bedeutung des islamischen Idioms als emanzipative, kulturelle Selbstbestimmung gegen Fremdherrschaft, westlichen Kolonialismus und den Einfluß der Moderne (z.B. Enayat 1982). Zweitens die retrospektive Wiederentdeckung der islamischen Symbolwelten (z.B. Gilsenan 1982) durch einzelne soziale Gruppen ('Ulama, Händler, Zünfte etc.), die sich zu jenen Prozessen der Säkularisierung und Modernisierung, die den post-kolonialen Prozeß der 
Nationwerdung begleiten, in einen Gegensatz gesetzt sehen (z. B. Eikkelman 1976).

Diese unterschiedlichen Ansätze soziologischer Betrachtung des Islams übersetzten nur die Varianten des Bildes der traditionalen islamischen Kultur in den wissenschaftlichen Diskurs der Moderne. ${ }^{4}$ Ich lege an diesen Stelle Wert darauf, dieser Feststellung die Beobachtung hinzuzufügen, daß der wissenschaftliche Objektivismus, der sich an der Vielfalt dessen reibt, was er als Wesen und Struktur des Islams zu bestimmen versucht, mit den Bewegungen der Politisierung des Islams und dem Entstehen eines modernistischen islamischen Selbstbegriffs zeitlich zusammenfällt (vgl. Stauth 1996: 17-42). Doch ist der intrinsische Zusammenhang zwischen wissenschaftlicher Bestimmung von Wesen und Struktur des Islams und dem modernen Kampf um kulturelle Anerkennung des Islams noch kaum Gegenstand wissenschaftlicher Forschung. ${ }^{5}$

Robert Bellah, der Doyen der amerikanischen Religionssoziologie, beschreibt das Wiedererstarken der »traditionalen Religionen « als Problem des modernen Wandels sozialer Ordnung. Er stellt noch 1978 fest: »Aus der Sicht der traditionalen Religionen kultiviert die moderne Ideologie mit ihrer Suche nach materieller Erlösung nur Motive wie Geiz, Neid und Herrschsucht, die am stärksten die Möglichkeit geistiger Erfüllung verhindern« (Bellah 1978: 148).

Die herkömmliche Religionssoziologie bleibt im dichotomischen Evolutionismus der Modernisierungstheorien befangen. Macht man sich, wie es Colonna (1995) tut, die Religionssoziologie selbst zum Gegenstand, so zeigt sich aber ein gänzlich neues Bild, das nicht mehr durch den Gegensatz von Vormoderne und Moderne, sondern durch variierende Stufen der Inklusion des Islams als nicht-westliche Kultur in den Diskurs der Moderne gekennzeichnet ist. ${ }^{6}$ Die Konflikte und Widersprüche sind damit jedoch weder auf lebenspraktischer Ebene, noch in Hinsicht auf die soziologische Theorie einfacher geworden. Die Frage, die sich für die heutige Soziologie des Islams am dringendsten stellt, lautet: Was passiert mit der »traditionalen Religion« gerade auch in nicht-westlichen Gesellschaften, wenn sie zur modernen Religion geworden ist. Was wird aus traditionaler Religion, wenn sie moderne Ideologie ersetzt, ja wenn sie in der gesellschaftlichen Funktion moderner Ideologie wirkt? Lassen Sie mich an diese Frage in der gebotenen Kürze ein paar vorläufige Überlegungen anschließen. 
"Soziologie« heißt die Lehre von der Gesellschaft oder vom Gesellschaftlichen. Sie erwuchs aus der Erkenntnis, daß unterschiedliche Ideen, Gottes- oder Naturvorstellungen sich auf die Formen des $\mathrm{Zu}$ sammenlebens der Menschen untereinander auswirken.

Sie entstand als eine Modewissenschaft in Frankreich, wo sie das geistige Leben seit der zweiten Hälfte des 19. Jahrhunderts beherrschte und im Grunde bis heute noch stark beherrscht. In Frankreich gab es dementsprechend auch seit 1885 an der École des Hautes Études einen Lehrstuhl für Islamwissenschaften und seit 1902 am Collège de France ein Ordinariat für islamische Soziologie (vgl. Fück 1955: 269). In Deutschland bemühte sich Martin Hartmann mit durchaus skurrilen Vorstellungen über das Soziologische und im Grunde nur mit terminologischen Entlehnungen, die Sache der Soziologie in die Islamwissenschaft einzuführen. Vergeblich, wie wir wissen. Und doch wäre es verfrüht $\mathrm{zu}$ sagen, die »Islamwissenschaft « des 19. und beginnenden 20. Jahrhunderts habe mit Soziologie nichts zu tun, habe nichts zu tun mit dem Einbau vormoderner Religion in den kulturübergreifenden Diskurs der Moderne. Es sind vielmehr durchaus Bereiche zu identifizieren, die ein enges Berührungsfeld zwischen Islamwissenschaft und Soziologie umschreiben. Sie stehen heute wie damals im Zeichen der modernen »Rückkehr zur Religion« und der Wiederentdeckung des Orients als des Kulturraums der Geburt der Weltreligionen.

Die »großen « Islamwissenschaftler machten sich noch insgeheim über die "Soziologie« eines Martin Hartmann lustig. Nöldeke, Snouck Hurgronje, C.H. Becker belächelten seinen »proletarischen « Geist und den gewiß von Simmel übernommenen Begriff der »Gesellung «, in den sich Hartmann verliebt hatte. Stellvertretend für die vielen Auslassungen über Hartmann hier nur ein Zitat aus einem Brief von Nöldeke an Goldziher vom 7.2.1915:

»Die Thesen Caetanis und Lammens werden durch zügellose Adepten ins ungeheuerliche übertrieben. Es kommt so weit, daß für die Entstehung des Islams Muhammed als ganz zufällige Nebenfigur und als hauptsächlichster Entstehungsgrund die Getreidepreise in Mekka betrachtet werden. Martin Hartmann 
ist im Stande, auch diese Behauptung stilistisch auszuformen. Nahe ist er dran.«

Die deutschsprachigen, in Deutschland geschulten und dem Rationalismus und Humanismus der deutschen Aufklärung verpflichteten Begründer der Islamwissenschaft hatten sich längst darüber verständigt, $\mathrm{da} ß$ und wie Islamwissenschaft soziologisch zu sein hätte. Sie beneideten zwar Lammens und Caetani, denen es gelungen war, mit einer materialistischen Soziologie auch für Historiker neues Licht in die islamische Frühgeschichte zu bringen. Nöldeke, Goldziher, Wellhausen und Becker entwickelten dagegen ein inneres, begreifendes, kulturübergreifend ausfühlendes, auf die Psychologie des Propheten gerichtetes Verständnis der sozialen Konstruktionen des Islams. ${ }^{7}$ Sie blieben dabei äußerlich »im Fach «, dem kritischen Rationalismus und der vorherrschenden "politischen Philologie ${ }^{8}$ verpflichtet. Erst nach der Niederlage von 1918 legte Becker ein offenes Bekenntnis zur Soziologie ab. Im Grunde muß man ihm, dem Islamwissenschaftler, der dann als Bildungsreformer einer sozialdemokratischen Regierung einen sprichwörtlich Humboldtschen Humanismus pflegte, für die Institutionalisierung des Faches Soziologie an den deutschen Universitäten dankbar sein. ${ }^{9}$

Lange bevor Becker seinen berühmten Aufsatz »Der Islam als Problem " $(1910)^{10}$ veröffentlichte, erschien in der Vosschen Zeitung ein Beitrag von Lou Andreas-Salomé (die damals in religionswissenschaftlichen Dingen journalistisch dilettierte, die Wunderfrau oder das weibliche enfant terrible des deutschen Geisteslebens der Jahrhundertwende) unter dem Titel: »Das Problem des Islams « (1894a, 1894b). Man muß sicherlich den Bogen der Vernetzungen nicht zu weit spannen. Tatsache ist aber, daß im Jahre 1894 Lou Andreas-Salomés Nietzsche-Buch erscheint $(1894 \mathrm{c})^{11}$, daß Max Weber in diesem Jahr mit der Nietzsche-Lektüre beginnt ${ }^{12}$ und daß dies zum Kontext dieses Islam-Artikels gehört. Lou Andreas-Salomé entwickelt hier - in völlig un-, ja gegenrassistischer Absicht - aus den Schriften Dozys, Goldzihers, Robertson Smiths, Snouck Hurgronjes und Wellhausens heraus Nietzsches Gegensatz zwischen der Herrenmoral der ursprünglichen Menschen des »freien Wüstenlebens « und des alten Arabertums und der neuen Sklavenmoral der »religiösen Kultur« des Islams. ${ }^{13}$ Sie fin- 
det diesen Gegensatz in Goldziher's Ausarbeitungen des »Widerspruch(s) zwischen Muruwwa und Din, zwischen Altarabertum und islamistischer Kultur « bestätigt und sieht im sozialen Moment der Entwicklung der arabischen Religion zum Monotheismus keineswegs eine »so hohe Errungenschaft ihrer Kultur « und nicht »den Gipfelpunkt ihres religiösen Lebens « (Andreas-Salomé 1894a, 1894b).

Das Entscheidende an diesem Versuch ist, daß er - lange vor Weber und Freud - auf die psychische Wirkung des Monotheismus abgestellt ist, hier im Gegensatz zu Freud und Weber auf eindeutig negative Weise: Es wird - wie zuvor schon in der deutschen Romantik beim frühen Schlegel etwa - der außerweltliche Individualismus der »natürlichen Religion « - wenn man so will - freiheits- und kulturschöpferisch besetzt. Dagegen werden die moralischen »Gesetze« und Sublimierungsleistungen, die der Monotheismus auch im Islam hervorbringt, als Einschnürungen der schöpferischen Entfaltungsmöglichkeiten der menschlichen Kultur bewertet.

Andreas-Salomé argumentiert weder antisemitisch noch proarabisch. Sie bleibt auch nicht dem Pro-Ariertum der philologisch beherrschten deutschen Geisteswissenschaften des 19. Jahrhunderts verhaftet. ${ }^{14}$ Vielmehr handelt es sich um eine kultur- und modernitätskritische Position gegen den Zivilisierungseffekt des Monotheismus in den Weltreligionen. Weber und Jaspers machen dann umgekehrt die Grade des Übergangs von außerweltlichem Individualismus zu innerweltlichen Orientierungen für die ersten modernistischen Revolutionen der Achsenzeit verantwortlich (Weber 1947: 237ff.; Jaspers 1949). Freud (1939) verbindet den Monotheismus des späten Judentums mit mentalen Sublimierungsleistungen, die dem modernen Zivilisationsprozeß vorgelagert sind.

Der Andreas-Salomésche (1894a, 1894b) ist meines Wissens der erste kulturtheoretische Versuch, die Wirkungen des Monotheismus und der Ausgestaltung der Religionsvorstellungen auf den verwandten Volkscharakter von Arabern und Juden - die ursprüngliche Gottesverehrung bei den Juden, die höchste Entwicklung zum reinen Monotheismus - vor dem Hintergrund der Ergebnisse der »neuen « Islamwissenschaft zu reflektieren. Es mag erlaubt sein zu fragen, inwieweit diese Konzeptualisierungen von Altarabertum und Islam - eine Konzeptualisierung, die ja die Herrenmoral auf eine weltoffene, ursprüngliche, naturverbundene Säkularität, den Monotheismus aber als eine 
Art der moralischen Versklavung des freien Menschen begreift - über das in der Islamwissenschaft damals übliche Maß hinaus nun später in den 1930er und 1940er Jahren trotz des dort vorherrschenden reinen, d.h. politischen Philologieverständnisses, zu jenen Kulten des alten Arabertums und der orientalischen »Führergestalten « führte (Schaeder 1934: 118ff., 1944; Hanisch 1995: 348ff.), der in der deutschen Mainstream-Orientalistik noch lange über den Nationalsozialismus hinaus vorherrschte. Es ist auch anzumerken, daß Freud (1939 [1934-38]) sicher auch als Reaktion auf die Thesen seiner Schülerin - die Kulturleistungen des Monotheismus affirmiert. Entscheidend aber ist hier, daß es 1894 einer fachfremden Intellektuellen erstmals gelang, der Islamwissenschaft, die Hemmnisse philologischer Bindungen transzendierend, einen soziologischen Kern abzuringen. ${ }^{15}$

Soziologie des Islams beginnt hier mit einer - zugegebenermaßen sehr weit gefaßten - Offenlegung und Neubestimmung der soziologischen Episteme der Islamwissenschaft. Islamwissenschaft wird damit selbst Kern und Gegenstand der Soziologie des Islams.

\section{III}

Meines Wissens stammt der erste deutsche islamwissenschaftliche Fachtext, der sich zur soziologischen Betrachtungsweise expressis verbis bekennt, aus dem Jahre 1935. Es handelt sich um einen Aufsatz von Joseph Schacht, der damals in der Zeitschrift »Der Islam« unter dem Titel »Zur soziologischen Betrachtung des Islamischen Rechts« erschien. ${ }^{16}$ Ehrlicherweise muß man zugeben, daß es hier mit der Soziologie eher schlecht bestellt ist, denn Schacht unterzieht Max Webers (im wesentlichen von Goldziher, Snouck Hurgronje und Becker beeinflußte) Thesen zur islamischen Rechtssoziologie ${ }^{17}$ nur der textlich kritischen Prüfung. Er kommt zu zwei wesentlichen Schlußfolgerungen: Erstens soll Webers soziologische Betrachtungsweise dazu dienen, »eine bisher fehlende Charakterisierung « der »inneren Struktur « des islamischen Rechts nachzuholen. Zweitens soll die "Anwendbarkeit der soziologischen Fragestellung auf die islamische Rechtsgeschichte (Schacht 1935: 207) nachgewiesen werden.

Allerdings nicht ohne eine entscheidende soziologische Neubestimmung zu treffen: Gegen Webers Annahme eines auch für das islamische Recht geltenden materiellen Rationalismus insistiert Schacht 
prinzipiell auf »der religiösen Fundierung des islamischen Gesetzes«, die mit dem patrimonialen Charakter der Herrschaft nicht - wie Weber behauptet - in Zusammenhang stehe (Schacht 1935: 208). Dies hat Auswirkungen sowohl auf die innere Differenzierung der Rechtsgebiete als auch auf den Formcharakter des objektiven Rechts und schließlich grundlegend auf die Art der Rationalisierung des Rechts: Es »ist die entscheidende Tatsache in der Geschichte der Shari'a nicht die, daß die >Lösung der heiligen Gebote vom weltlichen Recht< ausblieb (das ist allerdings auch der Fall gewesen)« - wie Weber meint -

»sondern umgekehrt daß die religiöse Pflichtenlehre das vorhandene und einer selbständigen Weiterentwicklung fähige >weltliche Recht< durchdrang. Das Ergebnis war das gleiche: es entstand ein spezifisch unformales Recht.«

(Schacht 1935: 225)

Es darf in diesem Zusammenhang nicht vergessen werden, daß zuvor bereits Martin Plessner (o.J., ca. 1931) in seinem 1929 in Frankfurt gehaltenen Habilitationsvortrag den islamischen Wissenschafts- mit dem islamischen Rechtsbegriff gleichgesetzt hat und so anknüpfend an ähnliche Ideen Goldzihers und Snouck Hurgronjes (vgl. Goldziher 1889: 352-370, 354) eine auch in der späteren Islamwissenschaft vor allem von Gotthelf Bergsträßer (1924: 76-81), dem Lehrer Schachts, und bis auf heute gängige Vorstellung theoretisch $\mathrm{zu}$ fundieren versuchte, nämlich, um es einmal mit den Worten von Otto Spies auszudrücken, daß der Islam »ohne Berücksichtigung des Rechts nicht gebührend verstanden und in seinem Wesen nicht richtig erfaßt werden kann" (Spies 1965-1965: 80). Interessant ist hierbei durchaus, daß Spies es in bezug auf einen Teil des Schachtschen Werkes zur Einführung in das islamische Recht von 1964 im Jahre 1965 durchaus für angemessen hält, von »eine(r) soziologische(n) Betrachtung und Analyse des islamischen Rechts zu sprechen, die in der Erfassung des Wesens und der Struktur einmalig und einzigartig sind «(Spies 1965-1967: 80). Die Frage, die sich mir stellt, ist die folgende: Sind die heutigen Bemühungen islamischer Theoretiker, sind die aktuellen orthodoxistischen Wiedererweckungen und modernen Rechtsverbindlich-Machungen des islamischen Rechts ohne die »soziologischen « Anstrengungen eines Gotthelf Bergsträßer, eines Martin Plessner und eines Josef Schacht überhaupt denkbar? Ich überlasse es anderen, den mühsamen 
Weg der Geburt der Schachtschen Thesen in der deutschen Orientalistik der Vor- und Nachkriegszeit des Ersten Weltkriegs und den mühsamen Weg ihrer Internationalisierung als Folge der Vorbereitung und Durchführung des Zweiten Weltkriegs zu untersuchen. Aber die Frage muß - gemessen an den überwältigenden, nicht immer negativen Reaktionen, wie das Beispiel Fazlur Rachmans zeigt - erlaubt sein: Wie hat der islamwissenschaftliche Begriff von der - aber durchaus nicht für die Form des praktischen Rechts unwirksamen - Praxisferne des heiligen Rechts im Islam sich auf die heutige muslimische Rechtstheorie ausgewirkt? Die Aktualität dieser Frage, die sich heute an den Affären »Rushdy «, »Nasr Hamid « und »Mykonos « kaum dringender stellen könnte, birgt auch die Erkenntnis in sich, daß eine Soziologie, die den Islam im Weberschen Sinne nur als innerlich kohärente Form religiöser Weltanschauung untersucht, nicht mehr haltbar ist.

\section{IV}

Wie nun läßt sich die kritische Position gegenüber der im Weberschen Essentialisierungsgedränge verhafteten Soziologie konkretisieren? Wie läßt sich, wenn der »originäre «, der »ursprüngliche « Islam oder gar das "Wesen « islamischer Strukturen nicht mehr Gegenstand der Soziologie sein können, ein richtungweisendes Programm soziologischer Analyse noch bezeichnen?

Bei der Konstruktion moderner Kulturidentität geht es um die Wirkungsgeschichte gerade jener als »originär « und »authochton « bezeichneten Ideen und Wesensmerkmale. Man muß dem hinzufügen: Die Bestimmung der »Geburt« und des »Ursprungs « Europas ist spätestens seit dem pro-arisch und anti-semitisch ausgeformten Diskurs über Mythologie und Wissenschaft in den Kulturphilosophien des 19. Jahrhunderts in ein gegenseitiges Wechselspiel kulturübergreifender Interaktionen zwischen Europa und dem Islam - das Judentum ist hier nicht unser Gegenstand, man muß es aber mitdenken - eingebunden. ${ }^{18}$ Ich halte deshalb das weit gespannte Feld dessen, was man heute Orientalismus und Re-Orientalisierung nennt - also den aus der Sicht der »authochtonen « Orientalen revidierten, selbstentwickelten Orientalismus als Instrument der modernen Selbstfindung - für ein ganz zentrales Feld soziologischer Kulturforschung.

Neben der Kulturschöpfungsfunktion religiöser Ideen und ihrer 
wechselhaften Rekonstruktionen ist ihre Ordnungsfunktion von soziologischer Brisanz. Die an Indien und Europa gewonnenen Unterscheidungsmodelle zwischen Holismus und Individualismus des französischen Anthropologen Louis Dumont (1986) - auf das Verhältnis Europa und Islam bezogen - können durchaus zur Klärung herangezogen werden: Dumont unterscheidet zwischen einem holistischen Prinzip des Sozialen und der Hierarchisierung einerseits und einem individualistischen, ökonomistischen, egalitären Prinzip sozialer Organisation andererseits. Nimmt man den (islamischen) Holismus und den (westlichen) Individualismus einfach nur als "partiale Repräsentationen der Welt « (Todorov 1993: 398), wie jüngst Tzevetan Todorov vorgeschlagen hat, dann könnte man beide als komplementäre, den gegenseitigen Horizont der Ordnungsvorstellungen ergänzende Prinzipien verstehen.

Die moderne Islamwissenschaft beginnt mit der Kritik der seit der Frühromantik pro-arisch und anti-semitisch ausgelegten Mythos-Wissenschaft durch Ignaz Goldziher. Während der junge Goldziher den Orthodoxen seiner jüdischen Gemeinde in seiner Heimatstadt die Notwendigkeit einer Verwissenschaftlichung ihrer Relgionspraxis als Form der wirklichen, bürgerlichen Emanzipation und Integration predigt, tritt er gegen die von Schlegel und Renan beherrschten Lehrmeinungen an, Juden und Arabern sei - weil ohne jede ursprüngliche Mythologie - der Zugang zu den höheren Weihen der Wissenschaft und Literatur verwehrt. ${ }^{19}$ In Goldzihers semitischer Inklusion des Arabertums zeigt sich eine neue Form des komplementären Kulturaustauschs.

Ich frage mich, ob hier nicht die Analysen einer soziologischen Kulturwissenschaft anzusetzen hätten, nämlich an der Kritik und Parodie der Kultur des forschenden Subjekts selbst, womit diese erst einmal zur Disposition zu stellen wäre.

Aber noch bevor man von Komplementarität spricht, muß man erkennen, daß globales universalistisches Ordnungsdenken erst zur Ausarbeitung partikularistischer Systeme führt und etwa die Entdeckung des Islams als "mode of governance in einem modernen Sinne erst Bestandteil dieses globalisierten Universalismus ist. Es handelt sich bei 
der Konstruktion solcher Prinzipien und den Versuchen, ihre Partikularität zu überwinden, nicht einfach um einen philosophischen Voluntarismus, mit dem man die gegenseitigen Exklusionen, hier der Aufklärung, dort des individuellen Humanismus, überwinden könnte - wie Todorov und viele andere in der Debatte unterstellen. Es handelt sich also vielmehr um partikularisierende Effekte der Globalisierung, die so lange nicht gewissermaßen lenkbar und philosophisch bestimmbar sind, solange die politischen Realitäten - der faktische Partikularismus politischer Systeme - weit hinter dem Grad der kulturellen, ökonomischen und kommunikativen Globalisierung zurückbleiben. Religion hat somit eine Stützungsfunktion für partikularistische Ordnungen. Die Politisierung des Islams ist in ihren unterschiedlichsten Schattierungen eine Form der strategischen Inklusion lokaler in globalisierte Systeme. Die Funktionen des Islams sind unter diesem Aspekt und unter dem Gesichtspunkt der Vielfalt und hierarchischen Lagerung lokaler partikularistischer Ordnungen erst noch zu untersuchen.

Wenn es nun die "Großen Narrative« der Vernunft, des Fortschritts, der Säkularisierung und Modernisierung nicht mehr gibt und man im post-modernen und post-kolonialen Diskurs zunehmend darum bemüht ist, Aufklärung nicht an die Stelle der Religion zu setzen, sondern zu betonen, daß es auch unter der Ägide der Menschenrechte eine Kontinuität der Hierarchie der Werte geben muß, daß Freiheitsund Autonomieforderungen nicht das Prinzip menschlicher Solidarität bedrohen müssen und daß die Notwendigkeit der Forderung nach mehr öffentlicher Moral nicht notwendig in die Zeit der religiösen Intoleranz und Inquisition führen darf (Todorov 1993: 399), dann bedarf es in der Tat einer Kulturwissenschaft, die hybride Duplizität der Kultur des forschenden Subjekts - nicht nur diejenige des erforschten anderen - im Forschungsprozeß zur Disposition stellt.

\section{Anmerkungen}

1 Unfähig, Webers soziologische Betrachtung als Zusammenfassung des islamwissenschaftlichen Forschungsstandes seiner Zeit und als diskursive »Stellungnahme« zu begreifen, ergeht sich die angelsächsische Kritik des Weberschen »Orientalismus « immer noch in unschuldigen Feststellungen ihrer »non-correctness«; s. etwa Nader Naderi 1990. 
2 Dagegen stehen natürlich auch die vielen Untersuchungen und "Stellungnahmen«, die den Islam aus der Analyse der arabischen Gesellschaften ausgeklammert haben. Jaques Berque hielt es gar für unmöglich, den Islam überhaupt in einer solchen Analyse zu verankern; vgl. hierzu Fanny Colonna 1995: 234.

3 Eine Zusammenfassung hierzu liefert Shmuel N. Eisenstadt 1998.

4 Dies ist kürzlich in einem sehr interessanten Aufsatz über die französische Religionssoziologie gezeigt worden; s. Fanny Colonna 1995: 225-44.

5 Von einem sehr konkreten philosophischen Bewußtsein dieses Problems sind die Arbeiten von Muhammed Arkoun gekennzeichnet; vgl. neuerdings Arkoun 1996: 28-66.

6 Daß der Volksislam nun, nachdem die europäische Geschichtsschreibung das »andere "Christentum als Volksreligion des Ancien Régime entdeckt hat, als eine Alternative "which could have happened, but did not happen « erkennbar wird, birgt in der Tat einigen forschungsstrategischen Sprengstoff in sich; vgl. Colonna 1995: 239.

7 Neue Einblicke über die unterliegenden Ideen und Wertungen vermittelt der nun vorliegende Schriftverkehr Nöldeke-Goldziher, Snouck Hurgronje-Nöldeke, Snouck Hurgronje-Goldziher etc.; vgl. Robert Simon 1986; van Konigsveld 1985, 1987.

8 Einen interessanten Einblick in die geistige Lage im Zentrum der philologischen Altertumswissenschaften liefert Luciano Canfora 1995.

9 Das ambivalente Verhältnis Beckers zur Soziologie wäre noch in einer eigens anzusetzenden Studie zu untersuchen. Die von Fück und van Ess behauptete Soziologie-Feindlichkeit bleibt zu oberflächlich philologisch. Sicher ist, daß das Jahr 1906/07 (aus der Sicht der Veröffentlichungen) für Becker wie für Weber (damals beide in Heidelberg, der eine Schüler, der andere Freund von Jellinek, dem Staatsrechtler) den Übergang von materialen rechtlichen zu religiösen Fragestellungen bezeichnet. Stellvertretend für die vielen Hinweise auf Beckers Engagement in Sachen »Fachsoziologie « in Reden und Reformschriften nach 1919 möge man Marianne Webers Ausführungen über den Versuch Beckers heranziehen, Weber 1919 mit einem höchst lukrativen Angebot nach Bonn zu 
locken. Weber geht statt dessen aus höchst privaten Gründen nach München. Vgl. Marianne Weber 1988: 645.

10 Vgl. hierzu spezifisch Mark Batunsky 1981: 287-310; s. auch Baber Johannson, der anerkennt, daß Becker immerhin eine Dimension eröffnet, den Islam als kulturelles und soziales System zu analysieren (Johannson 1990: 89).

11 Man kann den Einfluß dieses Buches auf die Nietzsche-Rezeption bis hin zu Foucault nicht hoch genug einschätzen. Und doch wird dieses Buch nur selten zitiert!

12 Vgl. etwa Wilhelm Hennis 1987: 171. Dort wird der Zeitpunkt weiter gefaßt auf die Jahre zwischen 1892 und 1895.

13 Weber entwickelt dagegen einen sehr materiellen Begriff des Islams als »Herrenreligion « fern jeder romantischen Idealisierung des Altarabertums. Vgl. Max Weber, 1980: 375; vgl. auch auf S. 519 die Zusammenfassung der Studie Wellhausens.

14 Vgl. hierzu Dietmar Rotermund 1986, hier insbes. Kap. 2, „Friedrich Schlegel and the Wisdom of India«, S. 22ff.

15 Inwieweit dieser soziologische Zugriff nun selbst wieder die Ideenwelt eines August Fischer und einiger seiner für die Kontinuität der Islamwissenschaft über die Zeiten des Nationalsozialismus hinaus einstehender Kollegen beflügelte, die ja - mit Zustimmung ihrer auf nationale Emanzipation hoffenden arabischen Kollegen - im Islam weitgehend nur ein sprachliches Phänomen des Altarabertums sehen wollten, bleibt weiterer Forschung überlassen.

16 Joseph Schacht 1935, aber auch schon 1933. Vgl. hierzu R. Brunschvig 1970.

17 Vor allem die Paragraphen 3 bis 5 der Rechtssoziologie, vgl. Max Weber 1980: 441-482, insbes. S. 474ff.

18 Man wird hier in der Tat reichlich bedient, wenn man ausgehend von Goldzihers »Mythos bei den Hebräern« sich die Schriften Renans einerseits und Steinthals andererseits einmal vornimmt: Ignaz Goldziher 1876, insbes. S. 4ff., S. 44-60, S. 61-80. Es sind die »Aufgeklärten«, die Universalisten Steinthal und Waitz, bei denen Goldziher in die Schule gegangen ist. Durch sie erst wird für den jungen Goldziher Renans verhängnisvoller Relativismus kritisierbar. Über die Brisanz der Mythosforschung für die "politische 
Philologie« des 20. Jahrhunderts vgl. Carlo Ginzburg 1985: 695715.

19 Goldzihers Wintervorlesungen 1887-88 vor der Pester jüdischen Gemeinde » $\mathrm{Zu}$ Entwicklung und Wesen des Judenthums « erschienen auf Ungarisch (Magyar-Zsidó Szemle, Vol. 5, 1888). Vergl. hierzu Robert Simon 1987: 144f. Zur komplementären Reversion des Pro-Ariertums Renans in Goldzihers Kritik, gewissermaßen als semitische Emanzipationschance der Araber, vgl. die brillanten Ausführungen Massignons in Revue de l'histoire des religions, 86 (1922): 71. 



\section{Der »entgrenzte« Islam als soziologischer Forschungsgegenstand}

\section{Islam und lokale Ordnung}

Die folgenden Ausführungen nehmen die Frage nach der Bedeutung des zeitgenössischen Islams für die sozialen Ordnungen in lokalen Kontexten auf. Modellhaft reflektieren sie Forschungserfahrungen in Ägypten in kleinbäuerlich-dörflichen Kontexten im östlichen Nildelta (Simbelaween) und in stammesgemeinschaftlichen Kontexten seßhafter Beduinen im Nord-Sinai. ${ }^{1}$

Es handelt sich dabei um den Versuch, vergleichende Untersuchungen zu strukturieren, die sich in ihrem Umfang auf drei Untersuchungsbereiche - gewissermaßen auch als Parameter zu verstehen beschränken. Ich will sie Eingangs kurz benennen: Erstens erschließt sich die Entgrenzungsproblematik lokaler islamischer Kontexte aus dem Zusammenhang, daß das Spannungsfeld miteinander konkurrierender lokaler Ordnungsvisionen sich in unterschiedlichen Formen der Textpräsenz, der modernistischen wie der traditionalistischen, der fundamentalistischen wie der ritualistischen niederschlägt. Zweitens bezeichnen die Formen der strukturellen Verflechtung im ZentrumPeripherie-Gefälle ein Feld der konkurrierenden Netzwerkentfaltung. Drittens stellen die Wechselspiele der Annahme, Zurückweisung oder Umformulierung von Fremdbeschreibungen und Formen ihrer Verkörperung bei der symbolischen Besetzung öffentlicher Räume ein weiteres Spannungsfeld der Konstitution lokaler sozialer Ordnung dar.

Die Problematik der religiösen Entgrenzung ist für die moderne Religionssoziologie von überragender Bedeutung. Ich will sie, auch weil sie übergreifend für die hier genannten Bereiche gilt, aufgreifen und am Beispiel der lokalen Textpräsenz, der Netzwerkanalyse, der Wirkungsweise gegenseitiger symbolischer Hegemonialisierung erläutern: Es geht hier vor allem um » Text « und soziale Textpräsenz, strukturelle Verflechtungen, und um symbolische Gegenseitigkeit, perzeptionelle Nähe sowie Verkörperungen von Ideen als Dimensionen der Entgrenzung. Bezogen auf Text kann man sie sich beispielhaft noch am deutlichsten im Extremfall des Verlusts von Exklusivität im $\mathrm{Zu}-$ gang zum Text vorstellen. 


\section{Entgrenzung als Problem}

In bezug auf die sich intensivierende kulturübergreifende Dimension gesellschaftlicher Praxis kann man »Kulturkontakt« als einen aktuellen theoretischen Schlüsselbegriff unserer Zeit begreifen. Kulturkontakt ist auch eine Form der Entgrenzung, ist in mehrerer Hinsicht Grenzüberschreitung. Die Grenzüberschreitung wäre hier in dem Sinne vorzustellen, daß zum Beispiel eine Person, soziale Beziehungen überhaupt oder eine Idee sich nicht mehr innerhalb der einmal gesetzten Grenzen bewegen. Seit dem 19. Jahrhundert werden diese vor allem unter nationalstaatlichen Bedingungen verstanden, so daß hier das Bild der Entgrenzung zunächst einmal als Topographie der Außenbeziehungen entsteht.

Will man den Begriff der Entgrenzung auf den Islam als einer religiösen Idee anwenden so ergeben sich eine Reihe von Problemen.

1. Der Islam ist eine Weltreligion. Der universalistische Anspruch, der damit verbunden wird, ist »grenzüberschreitend «. Zunächst einmal reicht er rein topographisch über die Grenzen der Nation hinaus.

2. Er versteht sich als die Religion aller Religionen und ist dadurch mittelbar auch grenzüberschreitend in einem religiösen Sinne. Er grenzt andere Weltreligionen nicht aus, sondern verleibt sie sich gewissermaßen erst einmal im eignen System ein.

3. "Grenzüberschreitung « als Entgrenzung bezieht sich jedoch auf den sozialen Prozeß der Wert-Umwertung im Zeichen abstrakter Prinzipien wie Liebe, Gleichheit, Solidarität, Freiheit etc.

Gegenüber der Stammessolidarität der alten Araber bedeutete die Lehre des Propheten bereits eine solche »Entgrenzung «: die Umma des Propheten galt plötzlich als der »höhere« Solidarverband, obwohl ihr keine Verwandtschaftsprinzipien mehr zugrunde gelegt werden sollten.

Man könnte es fast als ein Charakteristikum der Entfaltung der islamischen Zivilisation begreifen, daß diese Entgrenzung eigentlich immer wieder im Widerspruch zu den vorherrschenden Solidarund Traditionsgebundenheiten bewußt entfaltet wurde. Auch hier eine Entgrenzung ohne Ausgrenzung.

Entgrenzung heißt also schon in diesem frühen Kontext so etwas wie Transgression der Ordnungspraxis, eine Werte-Umwertung, 
einen neuen Lebensstil, eine Öffnung des sozialen und geographischen Horizonts.

4. Das verstärkt sich völlig mit der Einführung des Regiments des Nationalstaats in muslimischen Ländern, wenn auch zunächst nur schrittweise. Es setzt eine politische Rationalisierung der Religion ein, zunächst staatlich verwaltet, dann in Konkurrenz zu den staatlichen Institutionen, weltlichen Parteien etc.

Diese zweite Stufe - wo Religion zur Funktion des modernen Nationalstaats wird - ist es, die man heute als die eigentliche Stufe des »entgrenzten « Islams bezeichnen könnte, wo alle islamischen Prinzipien und Werte unter modernistischen Prämissen des Individualismus, des Egalitarismus und der kulturellen Anerkennung, der Menschenrechte, der Demokratie, modernen Charismalösungen etc. neu formuliert werden.

Aus der Globalisierungstheorie eines Roland Robertson (1992) ist dabei zu lernen, daß die im 19. Jahrhundert voranschreitende Universalisierung der Grundbegriffe der westlichen Aufklärung zugleich auch die Folie für höchst partikularistische Ausarbeitungen in den lokalen Kulturen lieferte. So sind etwa der westliche, der nationalstaatliche Demokratiebegriff, der bürgerlich-wissenschaftliche Begriff von Religion, von Zivilisations- und Modulierungsprozessen unter konfigurativen Bedingungen des Zusammenspiels von modernem Staat und Gesellschaft, auch in jene antiwestlichen Rekonstruktionen von postkolonialer Kultur eingegangen, die heute den Hybridisierungsprozeß zunächst vor allem in der nichtwestlichen Welt gestalten, von dort aber auch wieder prägend auf die westliche Welt zurückwirken. Die Werte der kulturellen Anerkennung und Emanzipation sind dabei auf die äußere Form von Werkzeugen reduziert, mit denen heute überall auf der Welt Ordnungsprinzipien und Visionen lokaler Kulturen wieder neu in Begriffe wie Nation, Gesellschaft, Zivilisation, Demokratie gepreßt und entsprechend verändert werden.

Wenn man von "Weltgesellschaft « spricht, kann man sich solche Prozesse der Universalisierung und Partikularisierung von Kulturbegriffen in dieser doppelt gelagerten Dimension vorstellen: einerseits die technische Reduktion westlicher Kulturbegriffe und ihr Export in die nichtwestliche Welt und andererseits das außerordentliche Spannungsverhältnis zwischen postkolonialer Selbstbe- 
stimmung und lokaler Kulturgeschichte, das durch Reduktion und Export westlicher Kultur hervorgerufen wird. Der von außen bestimmte Selbstbegriff der »eigenen« Kultur löst eine kulturelle Motorik aus, deren explosiver Charakter schwer zu verstehen ist. Denn die Prinzipien und Visionen der lokalen Kulturgeschichte bleiben gewissermaßen nur das Material, an dem die neuen, die »fremden «, emanzipatorischen Werkzeuge arbeiten, ohne die Ideen dieser Geschichte je auslöschen oder aus dem sozialen Gedächtnis verbannen zu können.

In bezug auf den Islam und die Ausbreitung der Moderne im 19. Jahrhundert ist diesbezüglich von der Entstehung eines »islamischen Substrats « gesprochen worden (Nagel 1996: 92ff.). In Anlehnung an Hourani, den jüngst verstorbenen libanesischen Historiker, weist der deutsche Islamwissenschaftler Nagel auf die Tatsache hin, daß das moderne islamische Denken auf die Herausforderung Europas vornehmlich mit »Aufnahme, Umdeutung und Abwehr « reagierte. Man erkennt hier, daß es nicht mehr um ungebrochene islamische Kontinuitäten geht, auch nicht um die bloße Durchsetzung des modernen Europas. Es ist die technische Wirkung von Kultur, etwa über die Verallgemeinerung der Gleicheitsidee, die den Drang zur kulturellen Anerkennung hervorruft und eine neue, explosive Kulturentwicklung in Gang setzt. Sie führt zur zwanghaften, kontinuierlichen Ausarbeitung alternativer Varianten, höchst partikularistischer, modern-strategischer (und zugleich modernitätskritischer) Adaptionen des Islams quasi als moderne Selbstbestimmungen aus dem Repertoire der Geschichte. Die »Perversionen«, die die technische Umsetzung solcher Islam-Konzepte hervorrief und weiterhin unerschütterlich hervorruft, reichen tief in den Konstitutionsprozeß einer lokalen Gesellschaft hinein.

5. Wenn hier also vom »entgrenzten Islam«als einem sozialanthropologischen Forschungsgegenstand gesprochen wird, dann geht es darum, wie in muslimischen Gesellschaften, wie in lokalen islamischen Gemeinschaften dieser Umformulierungs- und damit auch Entgrenzungsprozeß stattfindet, gewissermaßen auf der Graswurzelebene gesellschaftlicher Interaktion.

Von hier ausgehend ist hier eine religionsethnologische Perspektive 
zunächst über die Frage nach dem Zusammenhang von Text und sozialer Praxis weiter zu verfolgen.

\section{Ordnungsvisionen: Islam als Text, Islam als Praxis}

Die frühen Islamwissenschaftler, so vor allem Ignaz Goldziher, Christian Snouck Hurgronje und Carl-Heinrich Becker, fragten bereits danach, welche Idee der sozialen Ordnung sich über die islamische Glaubenslehre vermittelt. Sie stießen auf drei Komplexe, die später in den Stellungnahmen der Religions- und Herrschaftssoziologie Max Webers ausformuliert wurden: Erstens die frühislamische Kriegerethik: die beuterische Willensunmittelbarkeit des islamischen Kriegers wird bestärkt, der Krieger selbst mittels des Dogmas der Prädestination in einen Zustand der Heilsgewißheit (jihad, mujahid) versetzt. Zweitens stellt die als Offenbarungswissen niedergelegte Pflichtenlehre, das islamische Recht (shari'a), den dogmatischen Rahmen für die Heilsgewißheit eines auf der Pfründe basierenden, mit dem »Wissens «-Monopol ('ilm) ausgestatteten Standes orthodoxer Glaubensgelehrter ('ulama) dar. Drittens gewinnt die Heilsagnostik des islamischen Sufismus in den Händler- und Handwerkerzünften der Städte eine soziale Basis und verbindet sich überall mit lokalen Volkstraditionen von Bauern- und Nomadenvölkern.

Diese im Drang zu postkolonialer Emanzipation seit Beginn der 1960er Jahre als westlicher »Orientalismus « verschrieene islamkundliche Dogmentheorie blieb unter muslimischen Intellektuellen und Theologen nicht ohne Reaktionen. Ohne diese hier im einzelnen nachzuzeichnen, kann man als Ergebnis dieser Reaktionen von einer gewissen Vielschichtigkeit dogmentheoretischer Überlegungen und Orientierungen ausgehen, die sich auch aus dem Wechselspiel zwischen »orientalistischer « und »authentisch islamischer « Interpretation ergeben. Einerseits setzen die Bindungen an die verschiedenen Handlungsbezüge des lokalen Milieus ein Ordnungsdenken voraus, das sich von abstrakten Orientierungen gestört fühlen muß, andererseits ereignet sich lokale Tradition selbst als Vision und kann in den großen dogmatischen Kategorien der Heilssuche mitgedacht werden. Auch die lokale Tradition kann so als Heilsvision geboren werden, als Lösung praktischer oder erfahrener Ordnungsprobleme, als Loslösung und Entma- 
terialisieung gelebter Zusammenhänge, als transzendentale Transgression, also selbst als Form der Entgrenzung. Hier setzt der Mechanismus der Dezentrierung lokaler Kultur aus dem Gesamtzusammenhang gesellschaftlicher Konstitution ein.

Eine Soziologie der Entgrenzung - und man kann dies als die Kernproblematik eines solchen Untersuchungsansatzes bezeichnen müßte also untersuchen, wie sich unterschiedliche Aneignungen der »Idee « Islam in lokale Ordnungsvorstellungen transformieren oder wie sich lokale Ordnungsvisionen in verschiedene Ideen von Islam überführen.

Eine besondere Bedeutung gewinnt unter vergleichenden Aspekten zwischen »Fellachen « und »Beduinen « zum Beispiel der Zusammenhang von Kontinuitäten materieller Kultur und spiritueller Tradition: Sufismus wird paradoxerweise in unterschiedlich ausgerichteten materiellen Kulturen für die Rekonstruktion moderner Ordnungsmuster wichtig. Jüngst hat Nadia Abu-Zahra (1997) gegen die herrschende Lehrmeinung der unaufhebbaren Trennung von Schrift- und Volkskultur gezeigt, wie sehr die islamische Volkskultur gewissermaßen in um den Ritus sich gruppierende funktionale Differenzierung unverbrüchlich in die Traditionen der Schriftkultur eingebunden ist. Das gilt auch für das Verhältnis von militanten Gruppen zu orthodoxen Gelehrten, von sogenannten islamischen Reformisten zu Modernisten.

Am Beispiel der Post-Gellner-Diskussion verdeutlicht Abu-Zahra, wie sehr die Sozialanthropologie zunächst an der Vorstellung von der Abgrenzung der islamischen Volkskulturen arbeitete und damit selbst den Prozeß ihrer »Entgrenzung « interpretativ vorbereitete.

Gellners These ist, daß der »Islam eine konstante Größe außerhalb jeder Gemeinschaft « ist. Hauptcharakteristikum ist die »Homogenität des Textes «. Letzterer steht die ungeheure Diversität der muslimischen Gesellschaft gegenüber: Islam der Beduinenstämme, der städtischen Armen, der Stadt-Bourgeoisien (Gellner 1981: 49-50, 99). Gellner behauptet eben den absoluten Bruch zwischen »little « und »big tradition «, zwischen Skripturalismus und Volkstradition.

Hier sind Anthropologen wie Antoun (1989) anzuführen, die in der Nachfolge von Gellner nur noch zwischen Handeln und Glauben unterscheiden. Islam sei eine Vielfalt von rituellen Handlungsmustern, die nur eine Form der Durchgängigkeit kennen, die Homogenität des Glaubens, die shabada. Ähnlich verfolgen Tapper and Tapper (1987) 
im Ritual und Geschlechterbeziehungen die Linie der Trennung von Text und Praxis, indem sie die Kombination von Orthodoxie und oft nicht- oder vorislamischer Volkskultur für durchgängig halten. Dagegen versuchen muslimische Anthropologen wie etwa Talal Asad und eben Nadia Abu-Zahra, auf das Primat der islamischen Lehre abzustellen. Sie fragen »wie sind die vertexteten Vorschriften des Islams (Skripturen) unterschiedlich in muslimischen Gesellschaften entwikkelt und integriert «?

Es ergeben sich hier sehr interessante Fragen nach dem Zusammenhang von Text und Praxis. Wie werden islamische Texte angewandt? Welche lokalen Institutionen werden um den Text herum entwickelt? Was ist die Rolle von Texten im Volksritus? Wenn also hier islamische Texte zum Teil des muslimischen Lebens gemacht werden, des gesellschaftlichen wie des häuslichen, so geht es um eine neue Anthropologie des Textes. Aber es geht auch um den »Text « als Ordnungsvision schlechthin, um die Vielfalt der sozialen Anwendungen und um die unterschiedlichen Formen der Präsenz des Textes.

Zur Verdeutlichung ist hier beispielhaft nachzutragen, daß es dabei selbstverständlich nicht nur um die Formen des Kennens und Lesens der kanonischen Texte, des Qur'an und des Hadith, geht (wichtig ist hierbei, wie Abu-Zahra [1998] zeigt, deren Präsenz bei Übergangsriten, insbesondere bei Fruchtbarkeits- und Todesriten), sondern auch um die neue Rolle von Verschriftlichungen der Tradition, etwa des 'urfi-Rechts im Falle der Beduinen oder um Popularisierungstexte sowohl der Orthodoxie als auch fundamentalistischer Ideologien.

\section{Der Zentrum Peripherie-Nexus}

Für die Matrix der Vergleichsanalyse, mit der die verschiedenen Umsetzungen des »entgrenzten Islams « zu erfassen sind, ist das ZentrumPeripherie-Modell wichtig. In der konventionellen Weltsystem-Analyse eines Immanuel Wallerstein (1974) standen noch die Wandlungsdynamiken struktureller Verflechtungen lokaler Mikro-Systeme (Haushalte, Latifundien etc.) mit dem Makro-System des kapitalistischen Weltmarkts im Vordergrund. Zunehmend wurde das Modell auch auf kulturelle Dynamiken bezogen, etwa auf die Verflechtungen und Spannungen zwischen hetherodoxen Ideen und Bewegungen einerseits und einem orthodoxen Zentrum andererseits. Dabei wurde für 
die Gegenwart die Dynamik der »Dezentrierung des Zentrums« und die kontinuierliche Konfrontation zwischen Zentrum und Peripherie mit dem Begriff des möglichen Sieges der Peripherie über das Zentrum (Eisenstadt 1993: 19) als ein wesentlicher Faktor bezeichnet. Die kulturellen Zentren gerieten so in einen neuen relativierten Betrachtungszusammenhang (Eisenstadt 1998; Robertson 1992). Damit gehen Dekonstruktionen einher, die nicht nur die Bedeutung traditionaler Kulturzentren, sondern auch die ideologischen Grundlagen des säkularen Nationalstaates zunehmend infragestellen (Chatterjee 1993).

Unter diesen Voraussetzungen können in lokalen Kontexten neue Hegemonien entstehen, etwa heterodoxe oder fundamentalistische Orientierungen als legitimes lokales Protestpotential mit äußerlich antimodernem und antiwestlichem Charakter durchzusetzen (Eisenstadt 1998). Seit Anfang der 1980er Jahre stehen deshalb symbolische Besetzungen des öffentlichen Raums und der neue Zusammenhang von Religion und Öffentlichkeit im Zentrum des soziologisch/sozialanthropologischen Forschungsinteresses (Gilsenan 1982; Eickleman 1984; Eade 1993). Im Hinblick auf den Islam fand in diesem Zusammenhang ein Perspektivenwandel von paradigmatischer Bedeutung statt: weg von einer Vorstellung vom »offiziellen Islam « der als Gegensatz zum »Volksislam « gedacht wurde (Waardenburg 1978), hin zur »islamischen Öffentlichkeit« (Schulze 1998; Salvatore 1998).

Einmal in den hegemonialen Zusammenhang solcher Transformationen gestellt, werden Dorf- und Stammesgemeinschaften potentiell zu Arenen der Repräsentation quasi souveräner Ersatz-Staaten. Die lokalen Elaborationen von »Religion« manifestieren sich in einem globalen Rahmen rapiden sozialen Wandels, den wir heute als Bedingungen der Globalisierung bezeichnen (z. B. Beyer 1994; Turner 1994; Harvey 1989; Jameson 1985; 1991; Stauth/Turner 1988b; Holton/ Turner 1989; für den Islam spezifisch Ahmed 1992; Gellner 1992). Man muß deshalb mit Zubaida (1998) davon ausgehen, daß der moderne "politische Islam « alle lokalen Traditionen, seien sie lebenspraktisch oder dogmatisch relevant, in neue, postkoloniale politische Visionen der sozialen Emanzipation und kulturellen Anerkennung übersetzt.

Die lokalen Akteure und Träger des Kulturkontakts stammen ihrem sozialen Status nach meist aus ideologisch und ethisch engagier- 
ten Mittelschicht-Gruppen (Ibrahim 1988). Dazu gehören neu urbanisierte Volksschichten und aus bäuerlich-städtischen Kontexten stammende nouveau riche mit neuen, islamisch sich auszeichnenden Konsumgewohnheiten; dazu gehören in (beduinischen) Stammesgemeinschaften auch Clans mit komplexen grenzüberschreitenden und interregionalen Verbindungen; dazu gehören auch die »Aussteiger «, die im multikulturellen Kontext der Großstädte nach einem neuen Leben suchen, schließlich auch Migranten, die sich über unterschiedlich gelagerte Netzwerke an die lokale Gemeinschaft, Bruderschaft und Familie zurückbinden und mit neuen »Ideen « auf sie einwirken. Aber auch der umgekehrte Weg ist präsent: die städtischen Emigranten, die als "power-brokers « instrumentalisiert die Verbindung zum Zentrum ermöglichen oder durch neue »sponsored organizations « aufrechterhalten. In vergleichender Hinsicht kann man bei der Analyse des Verhältnisses von Mittelschichtbildung und Islamisierung auch auf die Ergebnisse der in Südostasien in Gang gekommenen Diskussion über die sogenannten »neuen Mittelklassen « zurückgreifen (z. B. Kahn et al. 1992; Robinson/Goodman 1996). Die Anwendung des Zentrum-Peripherie-Modells auf den Islam ist zwar in der Literatur gut eingeführt, forschungsstrategisch jedoch sehr problematisch und gerade von muslimischer Seite immer wieder hinterfragt worden (Asad 1986). Die konventionelle Tendenz in Literatur und Forschung betont eine Verbindung oder eine komparative Perspektive zwischen islamischen Peripherien und Zentren (Gellner 1981; Gilsenan 1982; Fischer/Abedi 1990; Abaza 1994a; Mehmet 1990). Neuerdings wird gar von "Zwei Islams" (von der Mehden 1994) gesprochen. Es ist einerseits von einem Tiefenmodell des islamischen Zentrum-Peripherie-Verhältnisses auszugehen, andererseits, wie in der islamkundlichen Zivilisationstheorie etwa eines von Grunebaum (1955), sind die gegenseitigen Präsenzen und Übergänge von peripherem und Zentrumsislam durchaus fließend. Der intensivierte Kulturaustausch schafft aber dennoch Trennungen, die hier nur mit dem - zugegebenermaßen vagen - Begriff der gegenseitigen symbolischen Hegemonisierung umschrieben werden können. Darüber hinaus gibt es übergreifende strategische Ketten des Islamisierungsdiskurses, die überall gleichzeitig in den lokalen islamischen Gemeinschaften wirken. Wie sehr auch in ritueller, spiritueller und intellektueller Sicht von einer hoch diversifizierten »is- 
lamischen Peripherie " gesprochen werden kann, so sehr gleichen sich möglicherweise die materialen Strukturen und »Ideen« im Zeichen globaler Kommunikation.

\section{Das Problem der »Querlagerung« der Entgrenzung}

$\mathrm{Da}$ sich politische Ordungsvorstellungen allein aus vorgegebenen Bedingungen der natürlichen Umwelt und aus tradierten Formen des $\mathrm{Zu}$ sammenlebens ergeben, ist das Kredo herkömmlicher politischer Theorie. Es setzt sich dagegen zunehmend die Vorstellung durch, daß trotz oder gerade wegen des weiterhin vorherrschenden Bedürfnisses nach dem »Sinn für das Ganze« die Konstruktionen menschlicher und gesellschaftlicher Ordnung auch aus den »Querlagerungen« des Diskurses zu erklären sind, die sich aus den im Streben nach symbolischen Hegemonien liegenden Gegenseitigkeiten und Wechselspielen bilden. Die auf das Gegeneinander, auf »Differenz « angelegten Kräfte bringen durchaus andere, mit dem Gemeinschaftssinn konkurrierende Ordnungsmodelle hervor. Todorovs Untersuchungen über die Präsenz des Fremden in der Entwicklung des modernen französischen Denkens werden neuerdings in ihrer Bedeutung für die Emanzipation nicht-europäischer Kulturen erkannt. Todorov - wie die in den Cultural Studies verankerte zeitgenössische »Kulturgeschichte« überhaupt - erkennt in der Idee des sich historisch vergewissernden modernen "Selbst « und in seinem Streben nach der »Kontrolle über die Kommunikation « eine entscheidende Funktion im Prozeß kultureller Erneuerung. Wer kulturelle Mißverständnisse im Aufeinanderprallen einander fremder Kulturen zu kontrollieren in der Lage ist, darf sich seiner strategischen Position im Prozeß des »empire-building " gewiß sein (Osterhammel 1997: 152f.). Seit Edward Said gehört solche Erkenntnis auch zum Bestand nicht-westlicher, und besonders der islamischen Kultur (Stauth 1993b, c).

»Fremdheit«muß jedoch nicht nur als Form der Selbstzentrierung begriffen, sie kann auch als Kommunikationsoffenheit gedacht werden. Todorov (1993: 392) beendet die erwähnte Studie mit einer Reflexion über Louis Dumonts Indien: Moderne und Vormoderne werden als eine zivilisationsinteraktive Geichzeitigkeit gedacht. Zwei grundlegend antagonistische Ordnungsvorstellungen, Moderne und Vormoderne, Gemeinschaft und Gesellschaft, ländliche und städtische, Zen- 
trums- und Peripherie-Lebensordnungen befinden sich in vergleichender Interaktion. Im praktischen Gesellschaftsprozeß stehen sie in einem ständigen Zusammenspiel. Der Ordnungskonflikt zwischen holistischen und individualistischen Gesellschaftsvorstellungen kennzeichnet diese Gleichzeitigkeit. Es wird dabei eine völlig unterschiedliche Konstitution des kollektiven Bewußtseins in nicht-europäischen vormodernen Gemeinschaften vorausgesetzt. Gemeinschaften, in denen das Ganze in einer dominanten Stellung gegenüber dem Einzelnen verweilt, bestehen fort, während in den modernen Gesellschaften und dem modernen Gemeinschaftsdenken, in dem sie wurzeln, das Individuum mehr gilt als das soziale Ganze, zu dem es gehört. So können Egalitarismus, Demokratismus und das Freiheitsgebot für alle ebenso wie Werthierarchie, Solidarität, öffentlicher Ritualismus und Konventionalismus sich überlagernde, gewissermaßen miteinander wetteifernde Integrationsformen der Gesellschaft darstellen.

Als »moderne « Ordnungsideen knüpfen beide Orientierungen an die Komplementärregelungen der praktischen Lokalgemeinschaften unterschiedlich stark an. Die Idee des Islams, wie sie für Muslime im Kontext rapiden und radikalen Wandels und im Spannungsfeld lokaler und lokal übergreifender Ordnungen bedeutsam wird, erscheint dem syrischen Islamwissenschaftler Aziz al-Azmeh (1996) als »Islamisierung des Islam «, als innere Transformation des Islams in eine moderne religiöse Ideologie. So klar und eindimensional sich »Entgrenzung « hier als Projekt der Islamisierung - im kritischen wie im affirmativen Sinne - auf der Ebene des modernistischen Intellektuellen-Diskurses ausmachen läßt, so widerborstig und komplex zeigt sich das Problem auf der praktisch gesellschaftlichen Ebene.

Ausgangslage ist die - in der klassischen wie der aktuellen islamwissenschaftlichen Literatur weitverzweigt erörterte - Spannung zwischen allgemein wirksamen ordnungspolitischen Ideen des Islams und den im Volksislam verhafteten Lokaltraditionen. Aber, wie oben bereits angedeutet, gibt es über die Lagerungen dieses Problems höchst gegensätzliche Deutungen und schon aus dem Begriffsapparat der klassischen Islamkunde ergibt sich durchgängig die Vorstellung vom lebenspraktischen, relativ unverbindlichen islamischen Skripturalismus.

Strukturell sind auch der innere Wandel und die Intensivierung der inneren Organisationsformen traditionaler muslimischer Vereinigungen wirksam. Dies hat die Diskussion über den Begriff des »Neo-Su- 
fismus « sehr deutlich gezeigt (Levtzion 1997, 1996; O'Fahey/Radtke 1993; Rahman 1966a), aus der man - mit der gebotenen Vorsicht durchaus eine These hinsichtlich der Wirkungen der Nationalstaatspräsenz auf sufistische Organisationen ableiten könnte.

Man kann die »Querlagerungen« also als ein Zusammenspiel spezifischer kultureller, ethnischer und staatlicher Hintergründe und Strukturen denken, die die modernen Aneignungen der »Idee« des Islams unterschiedlich bestimmen. Im Vergleich wäre sodann auch noch eine weitere Bandbreite zu beobachten, daß sich nämlich auch die verschiedenen neuen Typen von mittelschichtorientierten ideologischen und ethischen Engagements in verschiedenen sozialen Kontexten aufzeigen lassen. In einer vergleichenden Analyse sind die Umsetzungen und neuen ideologischen Konzepte der »Idee « des Islams auf der Graswurzelebene der Alltagsinteraktionen und der kulturellen Repräsentationen des Sozialen zu benennen. Von hier ausgehend lassen sich "quergelagerte«, universell wirksam werdende, ordnungsrelavante Wandlungsdynamiken bestimmen. Sie stehen im globalen Kontext sozialen Wandels, tragen zu einer Vielfalt lokaler Konzeptualisierungen von Ordnung bei und beeinflussen an der Basis des gesellschaftlichen Prozesses die Alltagspraxis der sozialen Akteure und ihre Institutionen gleichermaßen:

Es handelt sich hier zunächst um den Widerspruch zwischen Ethik und Ästhetik, der sich durch die Medienkultur ergibt. Sie betreibt tendenziell die Ablösung der geschriebenen durch die bildliche Sprache und etabliert sich als Hauptquelle der Information. Zu verzeichnen ist dabei ebenso eine starke Tendenz der Charakterisierung durch immer höhere symbolische und imaginative Aspekte der institutionellen Rekonstruktion, die den konventionellen funktionalen und rationalen Aspekten lediglich eine sekundäre Bedeutung zuweisen (vgl. etwa Luhmann 1992; Knorr-Cetina 1994). Massentourismus und Konsumgesellschaft haben dazu beigetragen, daß es zu einer Zunahme aller Formen interkultureller Interaktion kommt, speziell jener, die Exotismus und die Imagination des kulturell Anderen als Lebensstilfrage in den Vordergrund der Alltagspraxis stellen (z.B. Featherstone 1987).

Die Globalisierung der Finanzmärkte scheint zumindest virtuell die Existenz unbegrenzter Ressourcen an Kredit und Finanzen zu symbolisieren. »Cash « wird dabei zu einem neuen Faktor der sozialen Regu- 
lation in allen, auch den lokalen, von den Produktionsformen her noch völlig entkapitalisiert erscheinenden Sozialkontexten gemacht.

Schließlich stehen konventionelle Perzeptionen von Zeit und Raum durch die Globalisierung der Medien und Kommunikationssysteme unter Druck. Denn potentiell ist nun jedes lokale Ereignis bereits zum Zeitpunkt seines Geschehens ein hier und jetzt in der Welt passierendes, die »Menschheit als Ganzes« (Robertson 1992) betreffendes Ereignis.

Im Kontrast zur vorherrschenden Perspektive der konventionellen Soziologie, in der Wissenschaft, Technologie und Bürokratisierung als Hauptquellen von Wandel konstatiert werden (z. B. Berger et al. 1973), sind die oben erwähnten Faktoren als eine neue Befindlichkeit des Subjekts zu verstehen, als Determinanten eines Wandels, der die »Revolution der Dörfer «, die Befreiung lokaler Bindungen in einem zuvor nie gekannten Ausmaß vorantrieb. Diese Form der »Entgrenzung « betrifft besonders die 1980er und 1990er Jahre. Sie zeigt an, wie der »Islam « in den verschiedenen lokalen Kontexten gefordert war, Ideen und Visionen eines wahren religiösen Lebens als kohärente Gegenideologie zum existierenden Pluralismus materieller Kultur zu entwikkeln.

An diesen Problemlagen knüpft man heute in den sogenannten Kulturstudien wieder an, wenn man - wie zum Beispiel in der »Subaltern Studies«-Gruppe - über kulturelle Hybridisierung spricht. Aber einen empirisch ausgelegten Beitrag zur Soziologie jener Konstitutionsbedingungen, die kulturelle Vielschichtigkeit, Ambiguität und »doublemindedness « vermitteln, gibt es unter ordnungstheoretischen Gesichtspunkten nicht. Das hier gestellte Problem zielt also auf ein Vergleichsinstrumentarium heteroplexer Konstitutionsbedingungen von Gesellschaft in lokalen Kontexten ab.

\section{Ideologische und lebenspraktische Differenzierung}

Die Formenvielfalt aus Textpräsenz, Prozessen der Dezentrierung und den durch die Wechselspiele des Kulturkontakts sich abzeichnenden Formen der Hybridisierung, die auch die selbstaffirmierten Formen der Kulturbeharrung einschließen, ist die zentrale Dimension, die das Entgrenzungspotential lokaler Kontexte erschließt. Der Diskurs über 
die Zukunft islamischer Gemeinschaften und ihre Verankerung in der modernen Kultur ist auf der Ebene theoretischer Auseinandersetzung in vollem Gange. Oft tritt hier die tatsächliche Vielfalt der Pfade der Islamisierung hinter der Vorstellung einer blockbildenden Vereinheitlichung des modernen Islamdiskurses zurück (Huntington 1993). Die vorliegende Skizze für einen Forschungsansatz setzt dagegen an Fragen der faktischen Differenzierung der islamischen Ideen und Projekte an: Die Umsetzungen islamischer Begriffe und Ideen im Gestaltungsprozeß lokaler Institutionen, die Emergenz einer weitverzweigten, lokalen, neuen islamischen Mittelschicht und deren Rolle bei der Einbindung lokaler Netzwerke in die internationale Szene, die Wirkungsweise des globalen Diskurses über kulturelle Differenz - all dies sind Faktoren, die auf die strategische Bedeutung lokaler Gemeinschaften in der Bestimmung der modernen Rolle »des Islams « hinweisen. Der Vergleich von Unterschieden und Ähnlichkeiten der vielschichtig gelagerten Ordnungsbeziehungen zwischen »Zentrum « und »Peripherie «, die Ambivalenz der Problemlagen in den materiell und ideell unterschiedlich gebundenen Gruppen und Gemeinschaften, die aus solchen Spannungen sich entwickelnde Zukunft des Islams, stellt die Besonderheit dieses Ansatzes dar.

\section{Anmerkung}

$1 \mathrm{Zu}$ den vorliegenden Ausführungen habe ich von Herrn Professor Bierschenk, Mainz, wichtige Anregungen erhalten. Für die Einladung, den hier vorgestellten Forschungsansatz umzusetzen und für Untersuchungen in Ostafrika zu erweitern, bin ich Herrn Bierschenk, dem Sonderforschungsbereich Kulturelle und Sprachliche Kontakte und der Universität Mainz zu großem Dank verpflichtet. 


\section{Literatur}

\section{Gesamtliteratur}

Abaza, Mona (1987): The Changing Image of Women in Rural Egypt, Cairo Papers in Social Science 10, Monograph 3, Cairo: American University in Cairo Press.

Abaza, Mona (1991): »The Discourse on Islamic Fundamentalism in the Middle East and Southeast Asia: A Critical Perspective«. Sojourn. Social Issues in Southeast Asia 6/2, S. 203-239.

Abaza, Mona (1994a): »Islam in Southeast Asia: Varying Impact and Images of the Middle East«. In: Hussin Mutalib/Taj-ul Islam Hashmi (Hg.), Islam, Muslims and the Modern State, London: Macmillan, S. 139-151.

Abaza, Mona (1994b): »Perceptions of Middle Eastern Islam in Southeast Asia and Islamic Revivalism«. Orient 35/1, S. 107-124.

Abaza, Mona (1998): Re-Thinking the Social Knowledge of Islam Critical Explorations in the >Islamization of Knowledge $<$ - Debate Between Malaysia and Egypt. Manuskript, FU Berlin.

Abdel-Malek, Anwar (1963): »L'Orientalisme en crise «. Diagnose 44, S. 109-142.

Abu-Lughod, Janet L. (1992): »Die Auswirkungen internationaler Migration auf das Wachstum Kairos und auf die Urbanisierung der ländlichen Gebiete Ägyptens«. Jahrbuch für Vergleichende Sozialforschung 1990, Berlin, S. 41-56.

Abu-Zahra, Nadia (1997): The Pure and Powerful, Reading: Ithaca.

Adorno, Theodor W. (1966): Negative Dialektik, Frankfurt/M.: Suhrkamp.

Al-Attas, Syed Muhammad al-Naguib (1978): Islam and Secularism. Muslim Youth Movement (ABIM), Kuala Lumpur: A.I. Jalan Pantai Baru.

Al-Attas, Syed Muhammed al-Naquib (1985): Islam, Secularism and the Philosophy of the Future, London, New York/NY: Mansell.

Al-'Azm, Sadiq Jalal (1981): »Orientalism and Orientalism in Reverse $\ll$. Khamsin 8, S. 5-26.

Albrow, Martin (1990): »Introduction«. In: Martin Albrow / Elisabeth King (1990). 
Albrow, Martin/King, Elisabeth (Hg.) (1990): Globalization, Knowledge and Society, London: Sage.

Amin, Samir (1989): Eurocentrism. Translated by Russell Moore, New York/NY: Monthly Review Press.

Andreas-Salomé, Lou (1894a): »Das Problem des Islams«. Teil I. Vossische Zeitung, Nr. 338, Sonntagsbeilage Nr. 29.

Andreas-Salomé, Lou (1894b): »Das Problem des Islams«. Teil II. Vossische Zeitung, Nr. 350, Sonntagsbeilage Nr. 30.

Andreas-Salomé, Lou (1894c): Friedrich Nietzsche in seinen Werken, Wien: Carl Konegen.

Antoun, Richard (1989): Muslim Preacher in the Muslim World: A Comparative Case Study in Comparative Perspectives, Princeton/ NJ: Princeton University Press.

Arbeitsgruppe Bielefelder Entwicklungssoziologen (Hg.) (1981): Subsistenzproduktion und Akkumulation, Saarbrücken, Fort Lauderdale: Breitenbach.

Archer, Margret S. (1991): »Sociology for One World: Unity and Diversity«. International Sociology 6, S. 131-147.

Arkoun, Muhammed (1996): »Der Euro-Mediterrane Raum als Schicksalsgemeinschaft «. KulturAustausch 3, S. 78-80.

Arkoun, Muhammed (1996): »Transgresser, Deplacer, Depasser«. Arabica XLIII, S. 28-66.

Arnason, Johann P. (1989): »Weltauslegung und Verständigung«. In: Axel Honneth/Th. McCarthey/Claus Offe/A. Wellmer (Hg.), Zwischenbetrachtungen im Prozeß der Aufklärung. Jürgen Habermas zum 60. Geburtstag, Frankfurt/M.: Suhrkamp, S. 66-88.

Asad, Tulal (1982): »A Comment on the Idea of Non-Western Anthropology «. In: Hussein Fahim (Hg.), Indigenous Anthropology in Non-Western Countries, Durham/NC: Carolina Academia Press, S. 284-287.

Ayrout, S.J. Henry (1943): Fellahs, Cairo: Horus.

Bach, Robert L. / Schraml, Lisa A. (1982): »Migration Crisis and Theoretical Conflict«. International Migration Review XVI, S. 320-341.

Baer, Gabriel (1969): Studies in the Social History of Modern Egypt, Chicago/IL: University of Chicago Press.

Batunsky, Mark (1981): »Carl Heinrich Becker: From old to Modern Islamology«. IJMES 13, S. 287-310. 
Baudrillard, Jean (1982): Der symbolische Tausch und der Tod, München: Matthes und Seitz.

Baudrillard, Jean (1983): Laßt Euch nicht verführen, Berlin: Merve.

Becker, Carl-Heinrich (1910): »Der Islam als Problem«. Der Islam I, S. 15-24.

Becker, Carl-Heinrich (1922): »Ignaz Goldziher«. Der Islam XII, S. 214-215.

Bell, Daniel (1976): The Cultural Contradictions of Capitalism, New York/NY: Basic Books.

Bell, Daniel (1980): Sociological Journeys. Essays 1960-1980, London: Heinemann.

Bellah, Robert (1978): »Faith Communities Challenge - and are Challenged by - The Changing World Order«. In: Gremillion et al. S. 148-170.

Benedict, Peter/Tümertekin, E./Mausur, F. (Hg.) (1975): Turkey: Geographic and Social Perspectives, Leiden: E.J. Brill.

Bennabi, Malik (1980): »The Chaos of the Western World «. Islamic Studies XIX/3, S. 183-194.

Bennabi, Malik (1991a): The Qur'anic Phenomenon. An attempt at a Theory of Understanding the Holy Qur'an, übersetzt von Abu Bilal Kirkari, Kuala Lumpur: Islamic Book Trust.

Bennabi, Malik (1991b): "Sociology< and sSocial Values of the Qur'an«. In: Malik Bennabi, The Qur'anic Phenomenon. An Attempt of a Theory of Understanding of the Holy Qur'an, übersetzt von Abu Bilal Kirkari, American Trust Publ., repr. Kuala Lumpur: Islamic Book Trust.

Berger, Hartwig (1975): »In Verteidigung des Pueblo«. Prokla 25, S. 39-104.

Berger, Peter L./Berger, Brigitte/Kellner, Hannsfried (1973): The Homeless Mind: Modernization and Consciousness, Harmondsworth, Middlesex: Penguin.

Berger, Peter L./Luckmann, Thomas (1980): Die gesellschaftliche Konstruktion der Wirklichkeit, Frankfurt/M.: Fischer.

Bergsträßer, Gotthelf (1924): »Anfänge und Charakter des islamischen Rechts«. Der Islam XIV, S. 76-81.

Berque, Jacques (1955): »Dans le delta du Nil: le village et l'histoire«. Studia Islamica 4, S. 91-109. 
Beyer, Peter (1994): Religion and Globalisation, London: Sage.

Binder, Leonhard (1988): Islamic Liberalism. A Critique of Development Ideologies, Chicago/IL: University of Chicago Press.

Birks, J. S. / Sinclair, C. A. (1980): International Migration and Development in the Arab Region, Genf: ILO.

Blackman, Winnifred (1927): The Fellahin in Upper Egypt, London.

Boon, James A. (1982): Other Tribes, Other Scribes, Symbolic Anthropology in the comparative Study of Cultures, Histories, Religions, and Texts, Cambridge: Cambridge University Press.

Bourdieu, Pierre (1974): »Der Habitus als Vermittlung zwischen Struktur und Praxis«. In: ders., Zur Soziologie der symbolischen Formen, Frankfurt/M.: Suhrkamp, S. 125-158.

Bourdieu, Pierre (1979): Entwurf einer Theorie der Praxis, Frankfurt/M.: Suhrkamp.

Bourdieu, Pierre (1979): »Struktur, Habitus, Praxis«. In: ders., Entwurf einer Theorie der Praxis, Frankfurt/M.: Suhrkamp, S. 139202.

Braudel, Fernand / Duby, George / Aymard, Maurice (1990): Die Welt des Mittelmeeres. Zur Geschichte und Geographie kultureller Lebensformen, Frankfurt/M.: Fischer.

Brière, Claire/Blanchet, Paul (1979a): Iran, la Révolution au nom de Dieu, Paris: Seuil.

Brière, Claire/Blanchet, Paul, (1979b): »L'esprit d'un monde sans esprit« (Der Geist einer geistlosen Zeit). Interview mit Claire Brière und Pierre Blanchet. In: Claire Brière/ Pierre Blanchet 1979a: 227-241. Ins Englische übersetzt von A. Sheridan et al., in Michel Foucault (1988a): 211-224.

Brunschvig, R. (1970): »Bibliographie der Arbeiten Schachts«. Studia Islamica 31, S. XI-XVI.

Buber, Martin (1932): Königtum Gottes, Heidelberg: Lambert Schneider.

Canfora, Luciano (1995): Politische Philologie, Altertumswissenschaften und moderne Staatsideologien, Stuttgart: Klett-Cotta.

Casanova, Jose (1994): Public Religions in the Modern World, Chicago/IL, London: The University of Chicago Press.

Castles, S. (1987): Migratory Process, Ethnic Relations and Labour Market Segmentation. Occasional Paper No. 6, Centre of Multicultural Studies, University of Wollongong, New South Wales. 
CERMOC (1985): Migrations et changements sociaux dans l'orient Arabe, Beirut.

Charnay, Jean Paul (1977): Sociologie religieuse de l'Islam, Paris: Sindbad.

Chatterjee, Partha (1993): The Nation and its Fragments, Colonial and Postcolonial Histories, Princeton/ NJ: Princeton University Press.

Colonna, Fanny (1995): »Islam in the French sociology of religion«. Economy and Society 24 / 2, S. 225-244.

Corbin, Henri (1958): L'imagination créatrice dans le soufisme d'Ibn 'Arabi, Paris: Ernest Flammarion.

Corbin, Henri (1977): Spiritual Body and Celestial Earth. From Mazdean Iran to Shi' ite Iran. Translated by N. Pearson, Bollingen Series XCI, 2, Princeton/NJ: Princeton University Press.

Cragg, Kenneth (1985): The Pen and the Faith. Eight Modern Muslim Writers and the Qur'an, London: Allen \& Unwin.

Dar, B.A. (1972): »Iqbal and Bergson«. In: M. Saeed Sheikh (Hg.), Studies in Iqbal's Thought and Art, Lahore: Bazm-i Iqbal.

De Bernart, Maura/De Marco, Pietro (1987): »Question sociale, modernisation, éthique religieuse: le jeune Weber entre le Christianisme et la Machtpolitik «. Social Compass XXXIV, S. 243-264.

Dreyfus, Hubert L./Rabinow, Paul (1982): Michel Foucault. Beyond Structuralism and Hermeneutics. With an Afterword by Michel Foucault, Brighton: Harvester Press.

Dumont, Louis (1967): Homo Hierarchicus, Paris: Gallimard.

Dumont, Louis (1986a): Essays on Individualism. Modern Ideology in Anthropological Perspective, Chicago/IL, London: The University of Chicago Press.

Dumont, Louis (1986b): »On Value, Modern and Nonmodern«. In: ders., Essays on Individualism. Modern Ideology in Anthropological Perspective, Chicago/IL, London: The University of Chicago Press, S. 234-268.

Dweyer, D. (1978): Images and Self-Images: Male and Female in Morocco, New York/NY: Columbia University Press.

Eade, John (1993): »The Political Articulation of Community and the Islamisation of Space in London «. In: R. Barot (Hg.), Religion and Ethnicity: Minorities and Social Change in the Metropolis, Kampen: Kok Pharos Publishing House. 
Eder, Klaus (1992): »Contradictions and Social Evolution: A Theory of the Social Evolution of Modernity«. In: Hans Haferkamp/Neil J. Smelser (Hg.), Social Change and Modernity, Berkeley/CA, Los Angeles /CA, Oxford: University of California Press, S. 320-349.

Eickelman, Dale F. (1981): The Middle East. An Anthropological Approach, Hempstead.

Eickelman, Dale F. (1976): Moroccan Islam: Tradition and Society in a Pilgrimage Center, Austin/TX, London: University of Texas Press.

Eisenstadt, Shmuel N. (1979): Tradition, Wandel und Modernität, Frankfurt/M.: Suhrkamp.

Eisenstadt, Shmuel N. (1982): »The Axial Age: The Emergence of Transcendental Visions and Rise of Clerics «. Journal of Sociology 23/2, S. 294-314.

Eisenstadt, Shmuel N. (Hg.) (1987): Kulturen der Achsenzeit - Ihre Ursprünge und ihre Vielfalt. 2 Bde. Übersetzt von R. Achlama und G. Schalit, Frankfurt / M.: Suhrkamp.

Eisenstadt, Shmuel N. (1993): »Civilisational frameworks, historical experiences and cultural programmes of modernity - the structuring of protest in modern societies «. In: Lars Gule/Oddovar Storebo (Hg.), Development and Modernity. Perspectives on Western Theories of Modernization, Bergen: Ariadne, S. 11-36.

Eisenstadt, Shmuel N. (1998): Die Antinomien der Moderne. Die jakobinischen Grundlagen der Moderne und des Fundamentalismus. Heterodoxien, Utopismus und Jakobinismus in der Konstitution fundamentalistischer Bewegungen. Übersetzt und mit einem Nachwort von Georg Stauth, Frankfurt/M.: Suhrkamp; zuerst englisch 1994.

El-Messeri, Sawsan (1983): »Tarahil Laborers in Egypt«. In: Allan Richards / P. L. Martin (Hg.), Migration, Mechanization and Agricultural Labor Markets in Egypt, Boulder/CO.

Elster, Jon (1989): The Cement of Society. A Study of Social Order, Cambridge, New York / NY: Cambridge University Press.

Enayat, Hamid (1982): Modern Islamic Political Thought, London: MacMillan International College Editions.

Eposito, John L. (1987): Islam and Politics, Syracuse/NY: Syracuse University Press (1. Auflage 1984).

Eribon, Didier (1989): Michel Foucault, Paris: Flammarion. 
Étienne, Bruno (1987): L'Islamisme radical, Paris: Hachette.

Evans, Peter/Rueschemeyer, Dietrich/Skocpol, Theda (Hg.) (1985):

Bringing the State Back in, Cambridge: Cambridge University Press.

Evers, Hans-Dieter/Schiel, Tilmann (1988): Strategische Gruppen, Berlin: Reimer.

Fähndrich, H. (1976): »Invariable Factors Underlying the Historical Perspective in Theodor Nöldeke’s >Orientatische Skizzen (1892)««. In: Akten des VII. Kongresses für Arabistik und Islamwissenschaft, Göttingen, 15.-22. August 1974, hg. von Albert Dietrich, Göttingen: Vandenhoeck \& Ruprecht, S. 146-154.

Faruqi, Ismail R. (1980): »The View of Society and History«. In: Ismail R. Faruqi, Islam and Culture, Kuala Lumpur: ABIM, S. 32-37.

Fathy, Gourna Hassan (1969): A Tale of Two Villages, Cairo: Ministry of Culture.

Featherstone, Mike (1987): »Consumer Culture, Symbolic Power and Universalism«. In: Georg Stauth/Sami Zubaida (Hg.) (1987), S. 17-47.

Featherstone, Mike (1990): »Global Culture: An Introduction«. Theory, Culture and Society 7/2-3, S. 1-14.

Featherstone, Mike (1991): Consumer Culture and Postmodernism, London: Sage.

Fischer, Michael M.J./ Abedi, Mehdi (1990): Debating Muslims. Cultural Dialogues in Postmodernity and Tradition, Madison/WI: The University of Wisconsin Press.

Fluehr-Lobban, Carolyn (1987): Islamic Law an Society in the Sudan, London: Frank Cass.

Foucault, Michel (1977): Discipline and Punishment. The Birth of the Prison. Translated by A.M. Sheridan-Smith, London: Allen Lane. Deutsche Übersetzung: Überwachen und Strafen. Die Geburt des Gefängnisses, Frankfurt/M.: Suhrkamp, 1977. Zitiert wird nach der englischen Ausgabe.

Foucault, Michel (1978): Dispositive der Macht. Über Sexualität, Wissen und Wahrheit, Berlin: Merve.

Foucault, Michel (1980): Power/Knowledge: Selected Interviews and other Writings 1972-1977. Translated and edited by Colin Gordon, Brighton: Harvester Press. 
Foucault, Michel (1984): »On the Genealogy of Ethics«. Interview by Hubert L. Dreyfus and Paul Rabinow, Regents University of California. University Publishing 13, S. 5-6.

Foucault, Michel (1988a): Politics, Philosophy, Culture. Interviews and Other Writings: 1977-1984. Translated by A. Sheridan et al., edited and introduced by L.D. Kritzmann, New York/NY, London: Routledge.

Foucault, Michel (1988b): »Technologies of the Self«. In: Luther H. Martin/Huck Gutman/Patrick H. Hutton (Hg.), Technologies of the Self. A Seminar with Michel Foucault, Amherst: The University of Massachusetts Press, S. 16-49 (Deutsche Fassung, Frankfurt/M.: Fischer 1994).

Freud, Sigmund (1939): Der Mann Moses und die Monotheistische Religion: Drei Abhandlungen, Amsterdam: Allert de Lange.

Freund, Wolfgang S. (1987): »Jüdischer und islamischer Fundamentalismus: Entsprechungen, politische Konsequenzen «. Der Orient 28 / 2, S. 216-228.

Fück, Johann (1955): Die Arabischen Studien in Europa, Leipzig: Harrassowitz.

Geertz, Clifford (1971): Islam Observed; Religious Development in Morocco and Indonesia, Chicago/IL: The University of Chicago Press.

Geertz, Clifford (1973): »Deep Play Notes on the Balinese Cockfight $\ll$. In: ders., The Interpretation of Cultures, Selected Essays, New York/NY: Basic Books.

Geertz, Clifford (1986): »Diapositives anthropologiques«. Communications 44, S. 71-90.

Gehlen, Arnold (1969): Moral und Hypermoral, Wiesbaden: Athenäum.

Gellner, Ernest (1968): »A Pendulum Swing Theory of Islam«. Annales Marocaines de Sociologie, S. 4-14.

Gellner, Ernest (1981): Muslim Society, Cambridge: Cambridge University Press.

Gellner, Ernest (1992): Postmodernism, Reason and Religion, London, New York/NY: Routledge.

Gibb, Hamilton A.R. (1975): Modern Trends in Islam (zuerst 1947), New York/NY: Octagon Press. 
Gilsenan, Michel (1982): Recognizing Islam. An Anthropologist's Introduction, London, Canberra: Croom Helm.

Ginzburg, Carlo (1979): Der Käse und die Würmer. Die Welt eines Müllers um 1600, Frankfurt/M.: Syndikat.

Ginzburg, Carlo (1985): »Mythologie germanique et nazisme. Sur un livre ancien de Gorges Dumézil «. Annales 40/4, S. 695-715.

Goldberg, Ellis (1991): »Smashing Idols and the State: The Protestant Ethic and Egyptian Sunni Radicalism «. Comparative Studies in Society and History 33/1, S. 3-35.

Goldziher, Ignaz (1876): Der Mythos bei den Hebräern und seine geschichtliche Entwicklung, Leipzig: Brockhaus.

Goldziher, Ignaz (1888): »Zu Entwicklung und Wesen des Judenthums «. Magyar-Zsidó Szemle 5.

Goldziher, Ignaz (1888-1890): Muhammedanische Studien, 2 Bde., Halle.

Goldziher, Ignaz (1889): »Muhammedanisches Recht in Theorie und Wirklichkeit«. Zeitschrift für vergleichende Rechtswissenschaft VIII, S. 352-370.

Goldziher, Ignaz (1967-1971): Muslim Studies, 2 Bde., hg. von S.M. Stern, London: George Allen \& Unwin.

Goldziher, Ignaz (1967-1974): Gesammelte Schriften, Bd. I-VI, hg. von J. Desomogyi, Hildesheim.

Goldziher, Ignaz (1978): Tagebuch, hg. von Alexander Scheiber, Leiden: E.J. Brill.

Goldziher, Ignaz/Hurgronje, Snouck (1985): Scholarship and Friendship in Early Islamwissenschaft, Letters publishad by P. Sj. Konigsveld, 2 Bde., Leiden: E.J. Brill.

Gordon, Colin (1980): »Afterword «. In: Foucault (1980): S. 229-259.

Gorz, André (1980): Abschied vom Proletariat, Frankfurt/M.: Europäische Verlagsanstalt.

Gramsci, Antonio (1967): Philosophie der Praxis, Frankfurt/M.: Fischer.

Habermas, Jürgen (1976): Zur Rekonstruktion des historischen Materialismus, Frankfurt/M.: Suhrkamp.

Habermas, Jürgen (1981a): Theorie des kommunikativen Handelns, 2 Bde., Frankfurt/M.: Suhrkamp.

Habermas, Jürgen (1981b): Die Moderne - ein unvollendetes Projekt. 
In: ders., Kleine politische Schriften I-IV, Frankfurt/M.: Suhrkamp, S. 444-464.

Habermas, Jürgen (1983a): Moralbewußtsein und kommunikatives Handeln, Frankfurt/M.: Suhrkamp.

Habermas, Jürgen (1983b): »Modernity - An Incomplete Project». In: Hal Foster (Hg.), Postmodern Culture, London, Sidney: Pluto Press, S. 3-15.

Habermas, Jürgen (1983/1984): Theory of Communicative Action, 2 Bde., übersetzt von Thomas McCarthey, Boston/MA: Beacon Press.

Habermas, Jürgen (1985): Der philosophische Diskurs der Moderne: zwölf Vorlesungen, Frankfurt/M.: Suhrkamp.

Habermas, Jürgen (Hg.) (1979): Stichworte zur geistigen Situation der Zeit, Frankfurt/M.: Suhrkamp.

Hacking, Ian (1986): »Self-Improvement«. In: David Couzens Hoy (Hg.) (1986): S. 235-240.

Haferkamp, Hans (1989): »Differentiation and Culture: Sociological Optimism under Scrutinity «. In: Hans Haferkamp, Social Structure and Culture, Berlin, New York/ NY: de Gruyter, S. 101-146.

Hanisch, Ludmilla (1995): »Semitistik, Arabistik und Islamwissenschaft im NS «. Das Argument 209, S. 348-352.

Harvey, David (1989): The Condition of Postmodernity, Oxford: Basil Blackwell.

Heine, Peter (1984): »C. Snouck Hurgronje versus C.H. Becker. Ein Beitrag zur Geschichte der angewandten Orientalistik«. Die Welt des Islam XXIII-XXIV. S. 378-387.

Heller, Agnes (1984/ 85): »The Discourse Ethics of Habermas: Critique and Apparaisal«. Thesis Eleven 10/11, S. 5-17.

Hennis, Wilhelm (1987): Max Webers Fragestellung, Tübingen: J. C.B. Mohr (Paul Siebeck).

Hobart, Mark (1986a): »Introduction: Context, Meaning and Power «. In: Mark Hobart/Robert H. Taylor (Hg.), Context, Meaning and Power in Southeast Asia, Southeast Asia Programm, Cornell University, Ithaca, New York/ NY, S. 7-19.

Hobart, Mark (1986b): »Thinker, Thespian, Soldier, Slave?«. In: Mark Hobart/Robert H. Taylor (Hg.), Context, Meaning and Power in Southeast Asia, Southeast Asia Programm, Cornell University, Ithaca, New York/NY, S. 130-156. 
Holton, Robert J./Turner, Bryan S. (1989): »Modernism, PostModernism, and Worldreligions: Some issues in Max Weber's Sociology of Religion«. In: Robert J. Holton/Bryan S. Turner (Hg.), Max Weber on Economy and Society, London, New York/NY: Routledge, S. 68-102.

Hopkins, Nicolas S. (1987): Agrarian Transformation in Egypt, Boulder/CO, London: Westview.

Hourani, Albert Habib (1980): Europe and the Middle East, St. Anthony's, London: Macmillan.

Hoy, David Couzens (Hg.) (1986): Foucault: A Critical Reader, Oxford: Basil Blackwell.

Ibrahim, Anwar (1996): The Asian Renaissance, Singapore, Kuala Lumpur: Times Books International.

Ibrahim, Saad Eddin (1988): »Domestic Developments in Egypt«. In: W.B. Quandt (Hg.), The Middle East. Ten Years After Camp David, Washington/DC: The Brookings Institute, S. 19-62.

Iqbal, Sir Mohammad (1954): The Reconstruction of Religious Thought in Islam, Lahore: Shaikh Muhammad Ashraf, repr.

Izutsu, Toshihiko (1966): God and Man in the Koran: Semantics of the Koranic Weltanschauung, Tokio: Keio Universität.

Jameson, Fredric (1985): »Postmodernism and Consumersociety«. In: Hal Foster (Hg.), Postmodern Culture, London: Pluto Press, S. 111-125.

Jameson, Fredric (1991): »Postmodernism« or The Logic of Late Capitalism, London: Verso.

Jaspers, Karl (1949): Vom Ursprung und Ziel der Geschichte, München: Piper.

Johannson, Baber (1990): »Politics and Scholarship: The Development of Islamic Studies in the Federal Republic of Germany«. In: Tarek Ismael (Hg.), Middle East Studies. International Perspectives on the State of the Art, New York/NY, Westport/CT, London: Praeger, S. 89.

Kahn, Joel S./Loh Kok Wah (Hg.) (1992): Fragmented Vision: Culture and Politics in Contemporary Malaysia. Sidney, Honolulu/ HI: Allen \& Unwin, University of Hawaii Press.

Kepel, Gilles (1983): Le prophète et le pharao. Les mouvements Islamistes dans l'Égypte contemporaine, Paris: Éditions du Seuil.

Kepel, Gilles (1987): Les banlieues de l'Islam, Paris: Éditions du Seuil. 
Knorr-Cetina, Karin (1994): »Primitive Classification and Postmodernity: Towards a Sociological Notion of Fiction «. Theory, Culture and Society 11, S. 1-22.

Kreutz, Henrik (Hg.) (1991): Pragmatische Analyse von Texten, Bildern und Ereignissen: Qualitative Methoden, Oral History und Feldexperimente, Forschungsberichte zur Soziologie und Sozialanthropologie, Bd. 3, Opladen: Leske + Budrich.

Lapidus, Ira (1985): »Islam and Modernity «. In: Shmuel N. Eisenstadt (Hg.), Patterns of Modernity, Vol. 2, London: Frances Pinter, S. 89-115.

Laroui, Abdallah (1977): L’idéologie arabe contemporaine, Paris: Maspero, 2. Aufl.

Lefèbvre, Henri (1977): Kritik des Alltagslebens, Kronberg/Ts.: Athenäum.

Lepenies, Wolf (1981): Melancholie und Gesellschaft (2. Aufl.), Frankfurt/M.: Suhrkamp. Zuerst 1969.

Levtzion, Nehemia (1996): »The Public Sphere in Muslim Societies. The Dynamics of Sufi Brotherhoods «. Paper presented to the Conference on Collective Identities, Public Sphere and Political Order, Uppsala, June 1996.

Levtzion, Nehemia (1997): »Eighteenth Century Sufi Brotherhoods: Structural, Organizational and Ritual Changes«. In: P. Riddle/A. Street (Hg.), Essays on Scripture, Thought and Society. A Festschrift in Honour of Anthony H. Johns, Leiden: E.J. Brill.

Lewis, Bernard (1997): »Demokratie und Religion im Nahen Osten «. Vortrag auf dem Kongreß >Demokratische Politik: Die Agenda der Zukunft $<$, Institut für die Wissenschaften vom Menschen, gekürzte Fassung übersetzt von Bodo Schulze, Frankfurter Rundschau 278, 29. Nov, S. ZB2.

Loomis, T. (1989): World Economy and Migrant Labour: A Regional Systems Approach, International Federation of Social Science Organizations, Wellington.

Luckmann, Thomas (1996): Die Unsichtbare Religion, 3. Aufl., Frankfurt/M.: Suhrkamp.

Luhmann, Niklas (1971): »Die Weltgesellschaft«. Archiv für Rechtsund Staatsphilosophie I, S. 1-35.

Luhmann, Niklas (1973): Vertrauen. Ein Mechanismus der Reduktion sozialer Komplexität, Stuttgart: Friedrich Enke. 
Luhmann, Niklas (1982): Funktion der Religion, Frankfurt/M.: Suhrkamp.

Luhmann, Niklas (1984): Soziale Systeme, Grundriß einer allgemeinen Theorie, Frankfurt/M.: Suhrkamp.

Luhmann, Niklas (1992): Inklusion und Exklusion. Manuskript, Universität Bielefeld, Bielefeld. Mittlerweile veröffentlicht als Soziologische Aufklärung, Bd. 6.

Luhmann, Niklas (1994): »Inklusion und Exklusion«. In: ders., Soziologische Aufklärung, Bd. 6, Opladen: Leske + Budrich.

Lyotard, Jean Francois (1979): La Condition Postmoderne. Rapport sur le Savoir, Paris: Les Éd. de Minuit.

Maffesoli, Michel (1985): La connaissance ordinaire. Précis de sociologie compréhensive, Paris: Méridiens Klincksieck.

Marcuse, Herbert (1967): Der eindimensionale Mensch, Neuwied: Luchterhand.

Mason, Herbert (1986): »Foreword to the English Edition«. In: Louis Massignon, The Passion of Hallaj. Mystic and Martyr of Islam, Boston, S. XXIII.

Mehmet, Ozay (1990): Islamic Identity and Development. Studies of the Islamic Periphery, London, New York/NY: Routledge.

Meillassoux, Claude (1976): Die wilden Früchte der Frau, Frankfurt/M.: Syndikat.

Meyers, Albert (1983): »Household, Labor Relations and Reproductive Strategies: Among Small Cane-Farmers in Jamaica«. Review VII, S. 255-283.

Miles, Robert (1984): Capitalism and Unfree Labour: Anomaly or Necessity? London: Tavistock.

Mitchell, Timothy (1990): »The Invention and Reinvention of the Egyptian Peasant«. International Journal of Middle East Studies 22, S. $129-150$.

Moore, Barrington (1982): Ungerechtigkeit - Die sozialen Ursachen von Unterordnung und Widerstand, Frankfurt/M.: Suhrkamp.

Mottahedeh, Roy P. (1993): »Toward an Islamic Theology of Toleration«. In: Tore Lindholm/Karin Vogt (Hg.), Islamic Law Reform and Human Rights. Challenges and Rejoinders, Copenhagen, Lund, Oslo Abo/Turku: Nordic Human Rights Publications, S. 25-36. 
Naderi, Nader (1990): »Max Weber and the Study of the Middle East: A Critical Analysis«. Berkeley Journal of Sociology XXXV, S. 7187.

Nagel, Tilman (1996): »Autochthone Wurzeln des islamischen Modernismus. Bemerkungen zum Werk des Damaszeners Ibn 'Abdin (1784-1836)«. Zeitschrift der Deutschen Morgenländischen Gesellschaft (ZDMG) 146/1, S. 92-111.

Nietzsche, Friedrich (1966): Gesammelte Werke, hg. von Kurt Schlechta, München: Musarion.

Nietzsche, Friedrich (1980): Kritische Ausgabe sämtlicher Werke und unveröffentlichter Texte F. Nietzsches nach den Originaldrucken und Originalmanuskripten auf der Grundlage der »Kritischen Gesamtausgabe «, hg. von Giorglo Colli und Mazzino Montinari, hier zitiert nach der »Kritischen Studienausgabe«, München: Deutscher Taschenbuchverlag.

O’Fahey, R.S./Radtke, B. (1993): »Neo-Sufism reconsidered «. Der Islam 70/1, S. 52-87.

O'Farrell, Clare (1989): Foucault. Historian or Philosopher? London: Macmillan.

Offe, Claus (1979): »Unregierbarkeit. Zur Renaissance konservativer Krisentheorien «. In: Jürgen Habermas (Hg.), Stichworte zur geistigen Situation der Zeit, Frankfurt/ M.: Suhrkamp, S. 294-318.

Osterhammel, Jürgen (1997): »Wissen als Macht: Deutungen interkulturellen Nichtverstehens by Tzevetan Todorov und Edward Said«. In: Eva-Maria Auch/Stig Förster (Hg.), Barbaren und Weiße Teufel. Kulturkonflikte und Imperialismus in Asien vom 18. bis zum 20. Jahrhundert.

Paret, Rudi (1969): The Study of Arabic and Islam at German Universities. German Orientalists since Theodor Nöldeke, Wiesbaden: Harrassowitz.

Parsons, Talcott (1971): The System of Modern Societies, Englewood Cliffs / NJ: Prentice Hall.

Parsons, Talcott (1975): Gesellschaften. Evolutionäre und komparative Perspektiven, Frankfurt/M.: Suhrkamp.

Parsons, Talcott (1991): »A Tentative Outline of American Values«. In: Roland Robertson/Bryan S. Turner (Hg.), Talcott Parsons. Theorist of Modernity, London, Newbury Park, New Delhi: Sage, S. 37-65. 
Pasolini, Pier Paolo (1978): Freibeuterschriften. Die Zerstörung der Kultur des Einzelnen durch die Industriegesellschaft, Berlin: Wagenbach.

Peek, Peter/Standing, G. (Hg.) (1982): State Policies and Migration, Studies in Latin America and the Carribian, London, Canberra: Croom Helm.

Peters, Rudolph (1987): »Islamischer Fundamentalismus: Glaube, Handeln, Führung«. In: Wolfgang Schluchter (Hg.) (1987), S. 217241.

Plessner, Martin o.J. (ca. 1931): Die Geschichte der Wissenschaften im Islam, Tübingen: J.C. B. Mohr (Paul Siebeck), Sammlung Philosophie und Geschichte, Nr. 31.

Puls, Detlev (1979): »Ein im ganzen gutartiger Streit. Bemerkungen zu Alltagserfahrung und Protestverhalten der oberschlesischen Bergarbeiter «. In: ders. / Thompson, Edward P. (Hg.) (1979), S. 298-341.

Puls, Detlev/Thompson, Edward P. (Hg.) (1979): Wahrnehmungsformen und Protestverhalten. Studien zur Lage der Unterschichten im 18. und 19. Jahrhundert, Frankfurt/M.: Suhrkamp.

Rahman, Fazlur (1957): Prophecy in Islam. Philosophy and Orthodoxy, London: Allen and Unwin.

Rahman, Fazlur (1964): »Dream, Imagination and 'Alam al-Mithal'«. Islamic Studies III/2, S. 167-180.

Rahman, Fazlur (1966a): Islam, London: Weidenfeld und Nicolson.

Rahman, Fazlur (1966b): »The Status of the Individual in Islam«. Islamic Studies V/ 4, S. 319-330.

Rahman, Fazlur (1966c): »Rezension von Toshihiko Izutzu (1966)«. Islamic Studies V / 2, S. 221-224.

Rahman, Fazlur (1967a): "Some Reflections on the Reconstruction of the Muslim Society in Pakistan «. Islamic Studies VI / 2, S. 103-120.

Rahman, Fazlur (1967b): »The Qur'anic Concept of God, the Universe and Man«. Islamic Studies VI/1, S. 1-19.

Rahman, Fazlur (1970): «Islamic Modernism: Its scope, method and alternatives». International Journal of Middle East Studies 1/4, S. 317-333.

Rahman, Fazlur (1972): »Iqbal and Modern Muslim Thought«. In: M. Saeed Sheikh (Hg.), Studies in Iqbal's Thought and Art, Lahore: Bazm-i Iqbal, S. 38-51. 
Rahman, Fazlur (1980a): »Islam: Legacy and Contemporary Challenge«. Islamic Studies XIX/4, S. 234-246.

Rahman, Fazlur (1980c): »The True Meaning of Scripture: An Empirical Historian's Non-reductionist Interpretation of the Qur'an«. International Journal of Middle East Studies 2, S. 487-505.

Rahman, Fazlur (1982): Islam and Modernity: Transformation of an Intellectual Tradition, Chicago/IL: University of Chicago Press.

Rashid, Asma (1988): »Malik Bennabi: His Life, Times and Thought«. In: Malik Bennabi, Islam in History and Society, übersetzt von Asma Rashid, Islamabad: Islamisches Forschungsinstitut.

Reichert, Christoph (1991): »Migrations de mains d'oeuvre et diversification institutionelle dans deux villages égyptiennes - Quelques resultats préliminaires«. In: Gilbert Bauge/Friedemann Büttner (Hg.), Les Migrations dans le Monde Arabe, Paris, S. 247-274.

Reichert, Christoph (1992): »Auswirkungen der Arbeitsmigration im ländlichen Ägypten - eine Rückkehreruntersuchung in sechs Dörfern $(1987 / 1988) \ll$. Jahrbuch für Vergleichende Sozialforschung 1990, Berlin, S. 57-100.

Richards, Allan/Martin, P. L. (Hg.) (1983): Migration, Mechanization and Agricultural Labour Markets in Egypt, Boulder/CO: Westview.

Riesebrodt, Martin (1990): Fundamentalismus als patriarchalische Protestbewegung, Tübingen: J.C.B. Mohr (Paul Siebeck).

Roberts, Robert (1990): The Social Laws of the Qoran, (zuerst 1925), London: Curzon Press.

Robertson, Roland (1982): »Societies, Individuals and Sociology: Intra-Civilisational Themes«. Theory, Culture and Society 1/2, S. 617.

Robertson, Roland (1992): Globalization: Social Theory and Global Culture, London, Newbury Park/CA, New Dehli: Sage.

Robinson, Richard/Goodman, David S.G. (Hg.) (1996): The New Rich in Asia. Mobile Phones, McDonalds and Middle Class Revolution, London, New York / NY: Routledge.

Rodinson, Maxime (1971): Islam und Kapitalismus, Frankfurt/M.: Suhrkamp.

Rondeau, R. et al. (1984): »Le canard et le regard ou la vie d'un philosophe«. Libération 30.6.-1.7.1984: S. 19. 
Rotermund, Dietmar (1986): The German Intellectual Quest for India, New Delhi: Manohar.

Roussillon, Alain (1987): Les Islamistes radicaux, Kairo: C.D.E.J.

Roussillon, Alain (1988): Sociétés de placement de fonds et >ouverture économique<, Dossiers du CEDEJ, Kairo.

Said, Edward W. (1978): Orientalism, London: Vintage (dt. Frankfurt/ M. 1981).

Salvatore, Armando (1997): Religious Discourse, Reading: Ithaca Press.

Salvatore, Armando (1998): Staging Virtue: The Disembodiment of Self-Correctness and the Making of Islam as a Public Norm. In: Georg Stauth (Hg.), Islam - Motor or Challenge of Modernity. Yearbook of the Sociology of Islam, Vol. 1, Hamburg, Piscataway / NJ: Lit, Transactions, S. 87-120.

Sardar, Ziaudin (Hg.) (1989): An Early Crescent. The Future of Knowledge and the Environment in Islam, London, New York/ NY: Mansell.

Sassen-Koob, Saskia (1978): »The International Circulation of Resources and Development: The Case of Migrant Labour «. Development and Change 4, S. 509-545.

Sassen-Koob, Saskia (1987): „Growth and Informalization at the Core: A Preliminary Report on New York City«. In: M. Smith/J. Feagin (Hg.), The Capitalist City: Global Restructuring and Community Politics, New York/ NY, S. 138-154.

Schacht, Joseph (1933): »Zur soziologischen Betrachtungs-Weise des islamischen Gesetzes «. Oostersch Genoots in Nederland 7de Cong., S. 18-20.

Schacht, Joseph (1935): »Zur soziologischen Betrachtung des islamischen Rechts«. Der Islam XXII, S. 207-238.

Schacht, Joseph (1963): Sociological Aspects of Islamic Law, Berkeley / CA: Berkeley University Press.

Schaeder, Hans Heinrich (1934): »Firdosi und die Deutschen«. Zeitschrift der Morgenländischen Gesellschaft (ZDMG) 88, S. 118.

Schaeder, Hans Heinrich (Hg.) (1944): Arabische Führergestalten, Heidelberg.

Schluchter, Wolfgang (1976): »Die Paradoxie der Rationalisierung. Zum Verhältnis von >Ethik $<$ und $>$ Welt $<$ bei Max Weber «. Zeitschrift für Soziologie 5/3, S. 256-284. 
Schluchter, Wolfgang (Hg.) (1987a): Max Webers Sicht des Islams Interpretation und Kritik, Frankfurt/M.: Suhrkamp.

Schluchter, Wolfgang (1987b): »Einleitung : Zwischen Welteroberung und Weltanpassung. Überlegungen zu Max Webers Sicht des frühen Islam«. In: Wolfgang Schluchter (Hg.), Max Webers Sicht des Islam, Frankfurt/M.: Suhrkamp, S. 11-124.

Schmidt-Glintzer, Helwig (1988): »Intellektueller Imperialismus? Außereuropäische Religionen und Gesellschaften im Werk Max Webers«. In: Ch. Gneuss/Jürgen Kocka (Hg.), Max Weber. Ein Symposion, München, S. 64-87.

Schmitt, Carl (1922): Politische Theologie: Vier Kapitel der Lehre von der Souveränität. München: Duncker \& Humblodt.

Schöfthaler, Traugott (1983): »Kultur in der Zwickmühle. Zur Aktualität des Streits zwischen kulturrelativistischer und universalistischer Sozialwissenschaft «. Das Argument 139, S. 333-347.

Schulze, Reinhard (1982): »Die Politisierung des Islam im 19. Jahrhundert«. Die Welt des Islam XXII, S. 103-116.

Schulze, Reinhard (1989): Islamischer Internationalismus im 20. Jahrhundert: Untersuchungen zur Islamischen Weltliga, Leiden: E.J. Brill.

Schulze, Reinhard (1998): »The Ethization of Islamic Cultures in the Late Twentieth Century or From Political Islam to Post-Islamism«. In: Georg Stauth (Hg.), Islam - Motor or Challenge of Modernity. Yearbook of the Sociology of Islam, Vol. 1, Hamburg, Piscataway/ NJ: Lit, Transactions, S. 187-198.

Scott, James (1977): »Patronage or Exploitation«. In: Ernest Gellner/John Waterbury (Hg.), Patrons and Clients, London: Duckworth, S. 21-40.

Shari'ati, Ali (1979): On the Sociology of Islam, Berkeley/CA: Mizan Press.

Shari'ati, Ali (1980a): »Mysticism, Equality, and Freedom«. In: ders., Marxism and other Western Fallacies. An Islamic Critique, übersetzt von R. Campbell, Berkeley/CA: Mizan Press.

Shari'ati, Ali (1980b): »Modern Calamities«. In: ders., Marxism and other Western Fallacies. An Islamic Critique, übersetzt von R. Campbell, Berkeley/CA: Mizan Press.

Shari'ati, Ali (1991): Return to the Self, übersetzt von Mehdi Abedi, Houston/TX: Institut für Forschung und Islamische Studien. 
Siddiqi, Mazheruddin (1970): »Intellectual Bases of Muslim Modernism - I«. Islamic Studies IX/2, S. 149-171.

Sider, G. (1971): »Christmas Mumming and the New Year in Outport Newfoundland «. Past and Present 71, S. 102-125.

Simon, Robert (1986): Iganz Goldziher. His Life and Scholarship as Reflected in his Work and Correspondence, Budapest, Leiden: Library of the Hungarian Academy of Sciences, E.J. Brill.

Sivan, Emmanuel (1985): Radical Islam, Medieval Theology and Modern Politics, New Haven: Yale University Press.

Smart, Barry (1994): »Sociology, Globalization and Postmodernity«. International Sociology 9/2, S. 149-159.

Smith, J./Wallerstein, Immanuel/Evers, Hans-Dieter (Hg.) (1984): Households and the World-Economy, Beverly Hills / CA: Sage.

Spies, Otto (1965-1967): Besprechung von »Josef Schacht: An Introduction to Islamic Law «. Die Welt des Islams 10, S. 80.

Sprondel, Walter (1986): »Max Weber's Protestant Ethic, The Universality of Social Science and the Uniqueness of the East «. In: D. Kantowsky (Hg.), Recent Research on Max Weber's Studies of Hinduism, Schriftenreihe Internationales Asienforum, Bd. 4, München, Köln, London: Weltforum, S. 59-72.

Stedmann-Jones, Gareth (1979): »Kultur und Politik der Arbeiterklasse in London 1870-1900«. In: Detlev Puls/Edward P. Thompson (Hg.) (1979), S. 317-368.

Tapper, Nancy/Tapper, Richard (1987): »The Birth of the Prophet: Gender and Ritual in Turkish Islam«. Man XXII, S. 69-92.

Taylor, Charles (1986): »Foucault on Freedom and Truth «. In: David Couzens Hoy (Hg.) (1986): S. 69-102.

Taylor, Charles (1992): The Ethics of Authenticity, Cambridge/MA, London: Harvard University Press. (Deutsche Übersetzung: Frankfurt/M.: Fischer, 1993).

Teik, Khoo Boo (1995): Paradoxes of Mahatirism. An Intellectual Biography of Mahatir Mohamad, Kuala Lumpur: Oxford University Press.

Telos (1987): Carl Schmitt - Special Issue 72.

Thompson, Edward P. (1980): Plebeische Kultur und moralische Ökonomie, Frankfurt/M., Berlin, Wien: Ullstein. 
Tibi, Bassam (1981): Die Krise des modernen Islam. Eine vorindustrielle Kultur im wissenschaftlich-technischen Zeitalter, München: Beck.

Tibi, Bassam (1985): Der Islam und das Problem der kulturellen Bewältigung sozialen Wandels, Frankfurt/M.: Suhrkamp.

Tiryakian, E.A. (1992): »Dialectics of Modernity: Reenchantment and Dedifferentiation as Counterprocesses«. In: Hans Haferkamp / Neil J. Smelser (Hg.), Social Change and Modernity, Berkeley/CA, Los Angeles / CA, Oxford: University of California Press, S. 78-98.

Tiryakian, E.A. (1994): »The New Worlds and Sociology. An Overview «. International Sociology 9/2, S. 131-148.

Tod der Moderne. Eine Diskussion (1983), Tübingen.

Todorov, Tzvetan (1993): On Human Diversity. Nationalism, Racism, and Exotism in French Thought, transl. by Cathrine Porter, Cambridge / MA, London: Harvard University Press.

Troeltsch, Ernst (1911): Die Bedeutung der Geschichtlichkeit Jesu für den Glauben, Tübingen: J.C.B. Mohr (Paul Siebeck).

Turner, Bryan S. (1974): Weber and Islam: a Critical Study, London: Routledge \& Kegan Paul.

Turner, Bryan S. (1978): Marx and the End of Orientalism, London: George Allen \& Unwin.

Turner, Bryan S. (1987): »A Note on Nostalgia«. Theory, Culture and Society 4, S. 147-156.

Turner, Bryan S. (1994): Orientalism, Postmodernism and Globalism, London, New York/ NY: Routledge.

Ulshöfer, Petra (1983): »Household and Enterprise: Towards a New Model of the Plantation Evidence from the Guatemalean Plantation System«. Review VII, S. 181-219.

van Ess, Josef (1980): »The Emergence of >Kulturgeschichte in Islamic Studies«. In: Malcolm H. Kerr (Hg.), Islamic Studies: A Tradition and its Problems, Seventh Giroglo Levi Della Vida Biennial Conference, Malibu/CA: Udena, S. 27-51.

van Gennep, Arnold (1960): The Rites of Passage, London: Routledge \& Kegan Paul.

van Konigsveld, P.S. (Hg.) (1985): Orientalism and Islam. The letters of C. Snouck Hurgronje to Th. Nöldeke from the Tübingen University Library, Leiden: Dokumentatiebureau Islam-Christendom, Faculteit de Godgeleerdheid. 
van Konigsveld, P.S. (Hg.) (1987): Snouk Hurgronje/Minor German Correspondences of C. Snouck Hurgronje: from libraries in France, Germany, Sweden and the Netherlands, Leiden: Dokumentatiebureau Islam-Christendom, Faculteit de Godgeleerdheid.

Vidich, Arthur Joseph/Bensman, Joseph (1968): Small Town in Mass Society. Class Power and Religion in a Rural Community, rev. ed., Princeton/NJ: Princeton University Press.

von der Mehden, Fred Robert (1994): Two Worlds of Islam, Interaction between Southeast Asia and the Middle East, Gainesville/FL: University Press of Florida.

Waardenburg, Jacques (1962): L'islam dans le miroir de l'Occident, Paris, La Haye: Mouton.

Wahid, Abdurrahman (1996): »Foreword «. In: G. Barton/G. Fealy (Hg.), Traditional Islam and Modernity in Indonesia, Clayton, Vic.: Monash Asia Institute, S. XIII-XVII.

Wallerstein, Immanuel (1974): The Modern World System, Vol. 1: Capitalist Agriculture and the Origins of the European World Economy in the Sixteenth Century. New York/NY, San Francisco, London: Academic Press.

Walzer, Michael (1986): »The Politics of Michel Foucault«. In: David Couzens Hoy (Hg.) (1986), S. 51-68.

Weber, Marianne (1926): Max Weber, ein Lebensbild. Tübingen: J.C.B. Mohr (Paul Siebeck).

Weber, Marianne (1988): Max Weber. A Biography. Übersetzt von Harry Zohn, mit einer Einleitung von Günther Roth, New Brunswick: Transactions.

Weber, Max (1947): Gesammelte Aufsätze zur Religionssoziologie, I, Vierte, photomechanisch gedruckte Auflage, Tübingen: J.C.B. Mohr (Paul Siebeck).

Weber, Max (1968): Gesammelte Aufsätze zur Wissenschaftslehre, 3. erw. und verb. Aufl., hg. von Johannes Winckelmann, Tübingen: J.C.B. Mohr (Paul Siebeck).

Weber, Max (1980): Wirtschaft und Gesellschaft. Grundrisse der verstehenden Soziologie, 5. rev. Aufl., hg. von Johannes Winckelmann, Tübingen: J.C.B. Mohr (Paul Siebeck).

Weiss, Peter (1978): Die Ästhetik des Widerstandes, Frankfurt/M.: Suhrkamp. 
Weyland, Petra (1993): Inside the Third World Village, London: Routledge.

Wood, Ch.H. (1982): »Equilibrium and Historical-Structural Perspectives on Migration «. International Migration Review XVI, S. 298319.

Zubaida, Sami (1972): »Economic and Political Activism in Islam«. Economy and Society 1, S. 308-338.

Zubaida, Sami (1998): »Trajectories of Political Islam«. In: Georg Stauth (Hg.), Yearbook of the Sociology of Islam 1, Islam - Motor or Challenge of Modernity, Hamburg: Lit, S. 81-86.

\section{Zitierte und nicht zitierte Arbeiten Georg Stauths im breiten thematischen Bezug}

1983a: Die Fellachen im Nildelta. Zur Struktur des Konflikts zwischen Subsistenz- und Warenproduktion im ländlichen Ägypten, Wiesbaden: Steiner.

1983b: »Capitalist Farming and Small Peasant Housholds in Egypt«.

Research Foundation of State University of New York Review VII, S. 285-313.

1983c: »Kapitalistische Agrarsysteme und Kleinbauernhaushalte. Der

Integrationskonflikt in der ländlichen Gesellschaft Ägyptens«. In: Hans-Dieter Evers/Dieter Senghaas/Huberta Wienholtz (Hg.), Auf dem Weg zu einer neuen Weltwirtschaftsordnung? BadenBaden: Nomos, S. 341-363.

1986: Remigration and Social Change, Working Paper No. 84, Forschungsschwerpunkt Entwicklungssoziologie, Fakultät für Soziologie, Universität Bielefeld.

1987a: »Local Communities and Mass Culture«. In: ders./Sami Zubaida (Hg.), Mass Culture, Popular Culture and Social Life in the Middle East, Frankfurt/M., Boulder/CO, S. 64-84.

1987b: »Remigration and Social Change - Prospects for the Migrant

Worker Sending Countries of the Middle East «. The Pakistan Development Review XXVI/4, S. 735-744.

1988: "How to Control Women? - Socio-Economic Processes and

Shifts of Power between Sexes in Rural Egypt. The Explanation of a Case«. In: Ahmad Mahrad (Hg.), Hannoversche Studien über den 
Mittleren Osten 5 (Hannover Studies on the Middle East 5), S. 51-72.

1989a: »Massenkultur, Gemeinschaft und Entwicklung«. In: Georg

Elwert / Peter Waldmann (Hg.), Ethnizität im Wandel, Saarbrücken,

Fort Lauderdale: Breitenbach, S. 223-236.

1989b: »Civilizing the Soul: German Orientalists«. In: Ewald Wagner /

Klaus Röhrborn (Hg.), Kashkul. Festschrift zum 25. Jahrestag der Wiederbegründung des Instituts für Orientalistik an der JustusLiebig-Universität Gießen, Wiesbaden, S. 157-169.

1990a: "Stadt und Land in Ägypten - Folgen der Modernisierung«. Jahrbuch für Vergleichende Sozialforschung, Berlin, S. 313-332 (in diesem Band, S. 179-196).

1990b: "Women, Properties and Migrants. Access to Land and Local Conflicts in Rural Egypt«. Zeitschrift der Deutschen Morgenländischen Gesellschaft (ZDMG) 140/1, S. 32-50.

1990/1991: »Materielle Not, kulturelle Globalisierung und sozialer Konflikt. Reflexionen zur Hermeneutik symbolischer Idealisierung «. Angewandte Sozialforschung 16, S. 157-170 (in diesem Band S. 155-178).

1991a: »Revolution in Spiritless Times. An Essay on Michel Foucault's

Enquiries into the Iranian Revolution «. International Sociology

6/3, S. 259-280 (in diesem Band in deutscher Übersetzung S. 57-81). 1991b: »Kulturkritik und affirmative Kulturanalyse. Nietzsche, Weber und die Wissenschaft von der menschlichen Kultur«. In: Gerhard Wagner/Heinz Zipprian (Hg.), Max Webers Wissenschaftslehre, Frankfurt/M.: Suhrkamp.

1991c: »Remigration: Households, Consumer Styles, and Cultural

Transformation. An Approach to the Study of Rural Change in Egypt«. In: Actes du IIème Seminaire Universitaire Tuniso-Allemande, Tunis 26-29 Oct. 1989, Tunis: Cahiers du CERES, Serie Sociologie 18, S. 91-114.

1993a: Islam und westlicher Rationalismus. Der Beitrag des Orientalismus zur Enstehung der Soziologie, Frankfurt/M., New York/NY: Campus.

1993b: »Leonard Binder's Hermeneutics of Authenticity«. Arabica XL, S. 62-83. 
1993c: »Leonard Binder's Hermeneutic of Authenticity. A Review Article«. Review of Middle East Studies 6, S. 85-105.

1993d: »Nietzsche, Weber and the affirmative sociology of culture«. Archives Européennes de Sociolgie XXXIII, S. 219-247.

1993e: »Islam and Emerging Non-Western Concepts of Modernity«.

In: Lars Gule / Oddvar Storeboe (Hg.), Development and Moderni-

ty. Perspectives on Western Theories of Modernization, Bergen: Ariadne, S. 254-272.

1996: »Islam als Selbstbegriff nichtwestlicher Modernität«. In: Helmut

Buchholt/Erhard U. Heidt/Georg Stauth (Hg.), Modernität zwischen Differenzierung und Globalisierung, Münster: Lit, S. 17-42 (in diesem Band S. 103-130).

\section{Mit anderen Autoren}

Abaza, Mona/Stauth, Georg (1988): „Occidental Reason, Orientalism, Islamic Fundamentalism: A Critique «. International Sociology 3/4, S. 343-364; Wiederabdruck in: Martin Albrow/Elisabeth King (Hg.) (1990), S. 209-230.

Schiel, Tilmann/Stauth, Georg (1981): »Subsistenzproduktion und Unterentwicklung «. Peripherie 5-6, S. 122-144.

Semsek, Hans-Günter/Stauth, Georg (1987): Lebenspraxis, Alltagserfahrung und soziale Konflikte. Kairoer Slums der achtziger Jahre, Stuttgart: Franz Steiner (in diesem Band als »Kultur und Lebenswelt. Der kulturelle Konflikt in peripheren Gesellschaften«, S. 3556).

Semsek, Hans-Günter/Stauth, Georg (1988): „Contemporary Processes within System, Cultures and Life Worlds: Some Reflections on Colonization and Resistance in Everyday Life«. Theory, Culture and Society 5/4, S. 695-714.

Stauth, Georg/Turner, Bryan S. (1988a): Nietzsche's Dance. Resentment, Reciprocity and Resistence in Social Life, Oxford, New York/NY: Basil Blackwell.

Stauth, Georg/Turner, Bryan S. (1988b): »Nostalgia, Postmodernism and the Critique of Mass Culture«. Theory, Culture and Society 5/2-3, S. 509-526.

Stauth, Georg/Zubaida, Sami (Hg.) (1987): Mass Culture, Popular Culture and Social Life in the Middle East, Frankfurt/M., Boulder/ CO: Westview. 


\section{Quellenverzeichnis}

»Moderne Essentialisierungen des Islams«. Aus: Georg Stauth, Islam und westlicher Rationalismus. Der Beitrag des Orientalismus zur Entstehung der Soziologie. Frankfurt/Main: Campus 1993.

»Kultur und Lebenswelt. Der kulturelle Konflikt in peripheren Gesellschaften«. Aus: Hans-Günther Semsek/Georg Stauth, Lebenspraxis, Alltagserfahrung und soziale Konflikte. Stuttgart: Steiner 1987. Auf Englisch erschienen in Theory, Culture and Society 5 (4), 1988.

»Foucaults Abenteuer im Iran«. Deutsche Erstveröffentlichung. Auf Englisch erschienen in International Sociology 6 (3), 1991.

»Globalisierung, Modernität, nicht-westliche Zivilisation «. Aus: Josef Langer/Wolfgang Pöllauer (Hg.), Kleine Staaten in großer Gesellschaft. Eisenstadt (Ö): Verlag für Soziologie und Humanethologie 1995.

»Islam als Selbstbegriff nicht-westlicher Modernität «. Aus: Helmut Buchholt et al. (Hg.), Modernität zwischen Differenzierung und Globalisierung. Münster: Lit 1996. Zuerst auf Englisch erschienen in: Lars Gule/Oddovar Storeboe (Hg.), Development and Modernity - Perspectives on Western Theories of Modernisation. Bergen: Ariadne 1993.

»Religiöser Fundamentalismus zwischen Orient und Okzident: Religiöse Identitätspolitik und ihr Verhältnis zur Demokratie«. Aus: Dietmar Loch/Wilhelm Heitmeyer (Hg.), Schattenseiten der Globalisierung. Rechtsradikalismus, Rechtspopulismus und separatistischer Regionalismus in westlichen Demokratien. Frankfurt/Main: Suhrkamp 2000.

»Materielle Not, kulturelle Globalisierung und sozialer Konflikt. Reflexionen zur Hermeneutik symbolischer Idealisierung «. Angewandte Sozialforschung 16 (1/2), 1990/1991. 
»Arbeitsmigration und Restrukturierung ländlicher Gesellschaften: Fallbeispiel Ägypten «. Aus: Erdmann Gromsen / Andreas Thimm, Migration in der Dritten Welt, Interdisziplinärer Arbeitskreis Dritte Welt, Bd. 7, Universität Mainz 1993.

»Stadt und Land in Ägypten - Folgen der Modernisierung «. Jabrbuch für Vergleichende Sozialforschung 1990.

»Frühe Ansätze zu einer Soziologie des Islams: Ignaz Goldziher (1850-1921) und Max Weber (1864-1920)«. Österreichische Zeitschrift für Soziologie 15 (2), 1990.

»Anmerkungen zur Soziologie des Islams«. Der Orient 38 (2), 1997.

$»$ Der entgrenzte Islam als soziologischer Forschungsgegenstand «. Erstveröffentlichung. 


\section{Die Titel dieser Reihe:}

Bisher erschienen

KARIN WERnER

Between Westernization

and the Veil

Contemporary Lifestyles

of Women in Cairo

1997, 302 Seiten, 58 DM

ISBN 3-933127-01-7

Ruth Klein-Hessling

SIGRID NÖKEL

KARIN Werner (Hg.)

Der neue Islam der Frauen

Weibliche Lebenspraxis

in der globalisierten Moderne

Fallstudien aus Afrika, Asien und Europa

Oktober 1999, 316 Seiten, 48 DM

ISBN 3-933127-42-4

Neuerscheinungen

Herbst 2000

MARgaret RAUSCH

Bodies, Boundaries and Spirit Possession

Moroccan Women and the

Revision of Tradition

Oktober 2000, 275 Seiten, 55 DM

ISBN 3-933127-46-7
Cynthia Nelson

Shahnaz Rouse (Hg.)

Situating Globalization

Views from Egypt

Oktober 2000, 356 Seiten, 58 DM

ISBN 3-933127-61-o

Georg Stauth

Islamische Kultur

und moderne Gesellschaft

Gesammelte Aufsätze

zur Soziologie des Islams

Oktober 2000, 292 Seiten, 58 DM

ISBN 3-933127-47-5

Neuerscheinungen

Frühjahr 2001

Anja Peleikis

\section{Lebanese in Motion}

The Construction of a

'Gendered' Global Village

April 2001, ca. 250 Seiten, ca. 55 DM ISBN 3-933127-45-9 